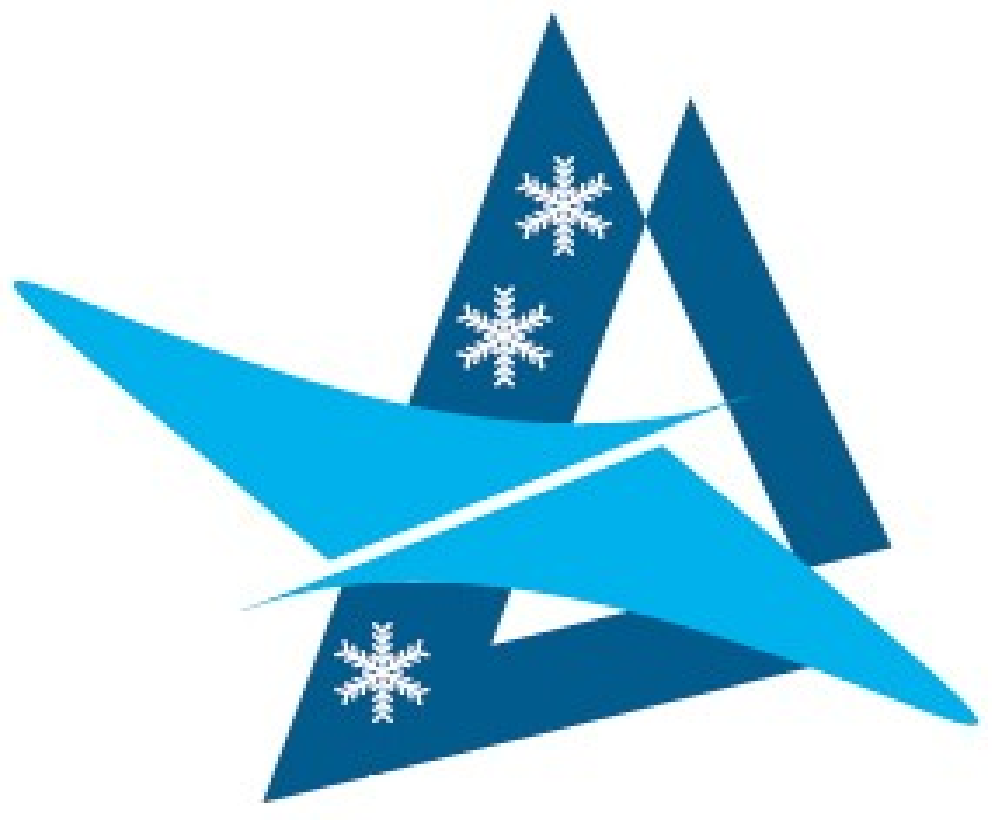

RPAS4SNOW

\title{
Investigating the Potential of Low-Cost Remotely Piloted Aerial Systems for Monitoring the Alpine Snow Cover
}

Date: 11.07.2016

Project duration: 16 months (Nov2014 - Mar2016)

Principal investigator: DI Dr Peter Mayer (BFW)

Project manager: Marc S. Adams (BFW)
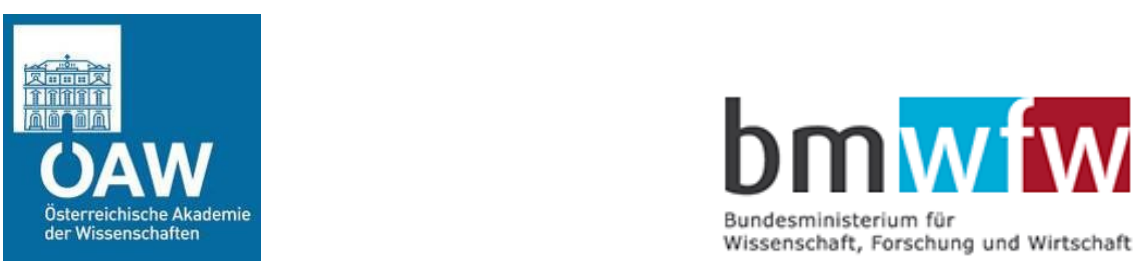

INTERNATIONALE FORSCHUNGSPROGRAMME

ISBN-Online: 978-3-7001-8011-1

DOI: 10.1553/ESS-01

RPAS4SNOW was a pilot project funded within the Austrian Academy of Sciences (ÖAW) Research programme Earth System Sciences (ESS) - International Geoscience Programme (IGCP) / Federal Ministry of Science, Research and Economy (BMWFW) 


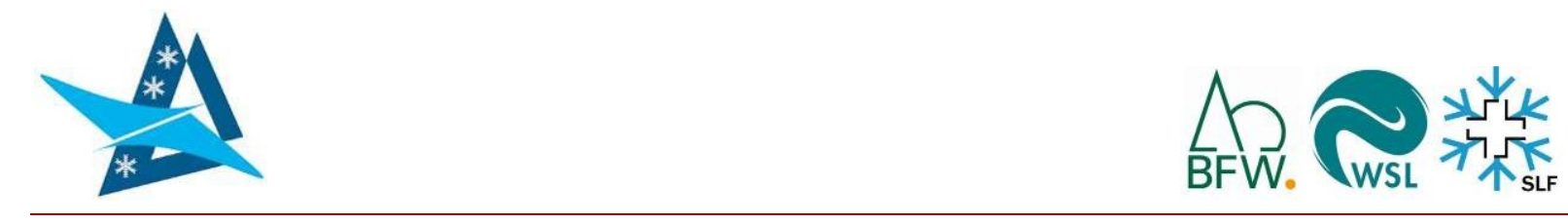

\section{Suggested citation:}

Adams, M.S., Bühler, Y., Boesch, R., Fromm, R., Stoffel, A. \& Ginzler, C. (2016): Investigating the Potential of Low-Cost Remotely Piloted Aerial Systems for Monitoring the Alpine Snow Cover (RPAS4SNOW). Final Project Report, ÖAW - Austrian Academy of Sciences, Innsbruck (Austria), pp.

82. 


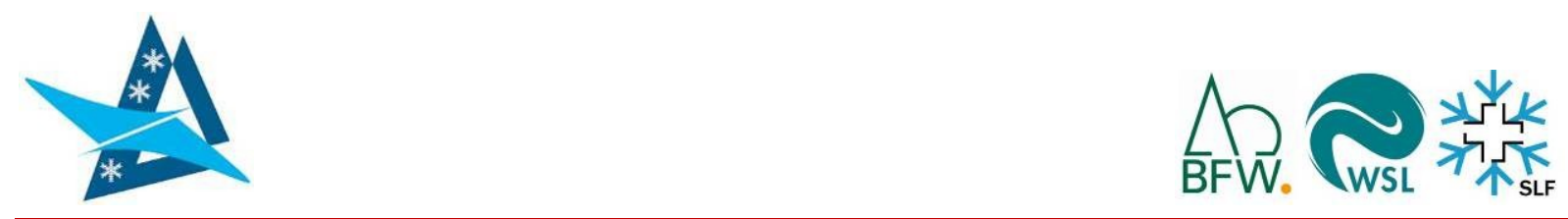

\section{RPAS4SNOW-Team}

\section{Project Partners}

\section{BFW (lead)}

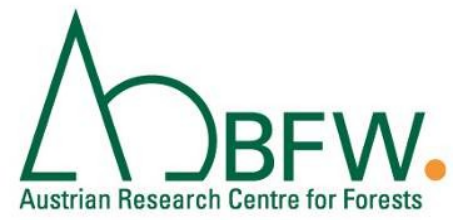

Federal Research and Training Centre for Forests, Natural Hazards and Landscape (BFW) | Department of Natural Hazards

Hofburg | Rennweg 1 | 6020 Innsbruck | Austria

Phone: +43 (0)512573933 5100

E-Mail: [given name.surname]@bfw.gv.at

http://bfw.ac.at

WSL

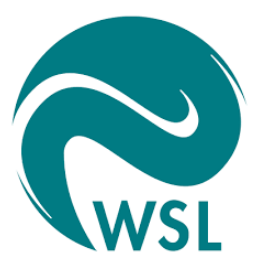

Swiss Federal Institute for Forest, Snow and Landscape Research WSL

Zürcherstrasse 111 | 8903 Birmensdorf | Switzerland

Phone: +41 (0)44739 2111

E-Mail: [given name.surname]@wsl.ch

www.wsl.ch

SLF

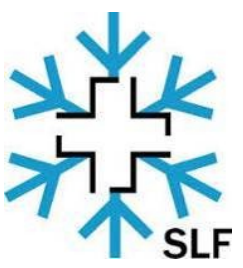

WSL Institute for Snow and Avalanche Research SLF

Flüelastrasse 11 | 7260 Davos Dorf | Switzerland

Phone: +41 (0)814170 111

E-Mail: [surname]@slf.ch

www.slf.ch 


\section{Contributors to RPAS4SNOW}

\section{BFW}

Marc S. Adams (overall project management \& coordination; supporting data acquisition in Austrian study site; data analysis with photogrammetry software; reporting and disseminating methods and results)

Reinhard Fromm (data analyses; scripting photogrammetry software; reporting and disseminating methods and results)

Armin Graf (constructing and maintaining RPAS; leading data acquisition at Austrian study site, piloting RPAS)

\section{SLF}

Yves Bühler (project management \& coordination for Swiss project partners; leading data acquisition in Swiss study sites Tschuggen, Brämabühl and Wildi; piloting RPAS; data analysis with photogrammetry software; reporting and disseminating methods and results)

Andreas Stoffel (supporting data acquisition in Swiss study sites Tschuggen, Brämabühl and Wildi; piloting RPAS, supporting data analysis with GIS software)

\section{WSL}

Ruedi Boesch (data analysis with photogrammetry software; reporting and disseminating methods and results)

Christian Ginzler (data preparation with photogrammetry software; reporting and disseminating methods and results) 


\section{Scientific Output}

Adams, M.S., Boesch, R., Bühler, Y., Ginzler, C. \& Fromm, R. (2016): On the potential of multitemporal and multisensoral UAS-based snow depth mapping in high-alpine terrain - a comparison with terrestrial laser scanning and traditional photogrammetry (in preparation).

Adams, M.S., Bühler, Y., Fromm, R., Boesch, R., Ginzler, C. (2016): Mapping snow depth in alpine terrain with remotely piloted aerial systems and structure-from-motion photogrammetry - first results from a pilot study. Geophysical Research Abstracts, 18 (EGU2016-8886), EGU General Assembly 2016 17-22 Apr. 2016, Vienna.

Adams, M.S., Fromm, R., Bühler, Y., Boesch, R. \& Ginzler, C. (2016): Avalanche and snow depth mapping from unmanned aerial systems - a verification with terrestrial laser scanning and in-situ data. International Snow Science Workshop, 3.-7.10.2016, Colorado, USA (accepted).

Adams, M.S., Lechner, V., Bühler, Y. \& Boesch, R. (2016): Do illumination conditions influence accuracy and precision of photogrammetrically derived snow depth maps? 23rd Cartographic School - Applications of UAVs in Geosciences, 8-10.6.2016, Świeradów -Zdrój, Poland.

Boesch, R., Bühler, Y., Ginzler, C. \& Marty, M. (2016): Comparison of digital surface models for snow depth mapping with drone and aerial cameras. ISPRS Archives (accepted).

Boesch, R., Bühler, Y., Ginzler, C., Adams, M.S. \& Fromm, R. \& Graf. A. (2015): Optimizing channel weights for digital surface models with snow coverage. ISPRS Archives, XL-3/W3.

Bühler, Y., Adams, M.S., Boesch, R. \& Stoffel, A. (2016): Mapping snow depth in alpine terrain with unmanned aerial systems (UAS): potential and limitations. The Cryosphere, 10, 1075-1088.

Bühler, Y., Boesch, R., Stoffel, A. \& Adams, M.S. (2015): Geodatenerfassung im hochalpinen Gelände mittels Drohnen. Geomatik Schweiz (09/2015).

Bühler, Y., Stoffel, A., Adams, M.S., Boesch, R. \& Ginzler, C. (2016): UAS photogrammetry on homogenous snow cover. Dreiländertagung der DGPF, der OVG und der SGPF, Bern, Schweiz Publikationen der DGPF, 25. 


\section{Table of Contents}

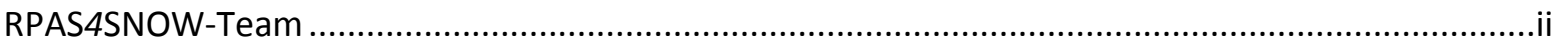

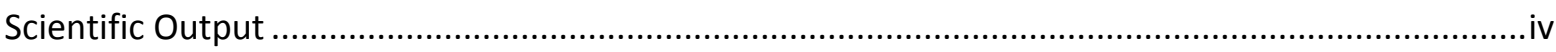

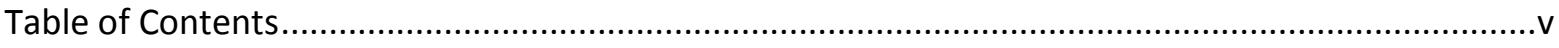

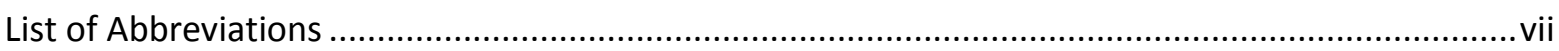

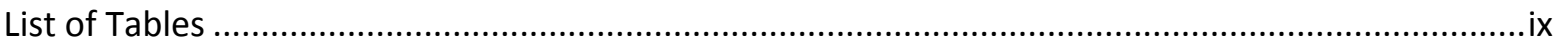

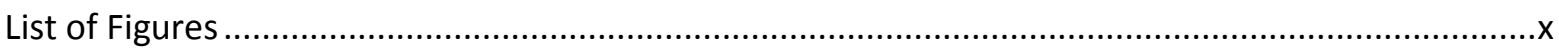

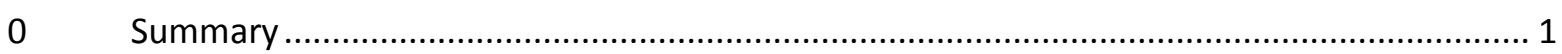

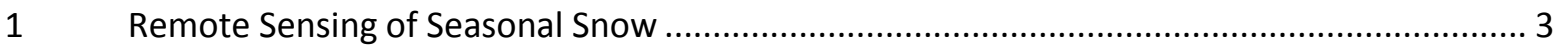

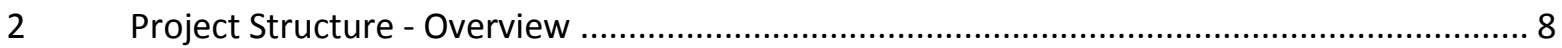

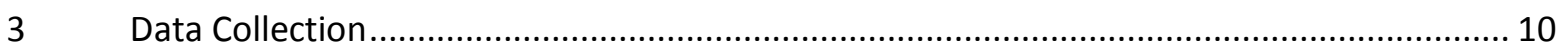

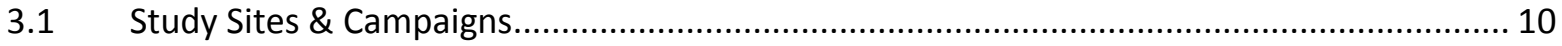

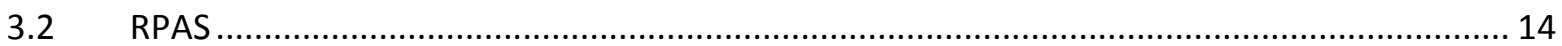

3.3 TLS

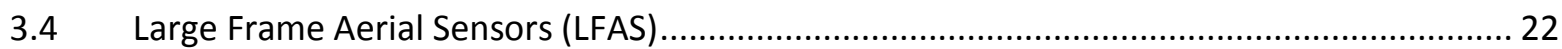

3.5 Manual probing / in-situ measurements ........................................................................ 22

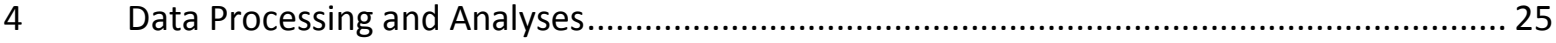

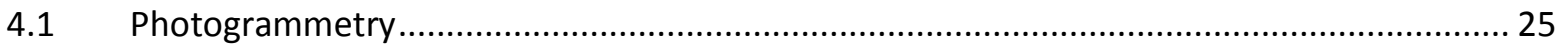

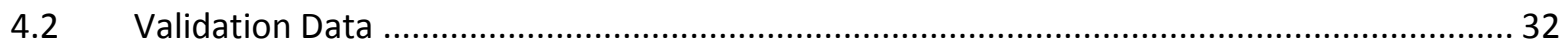

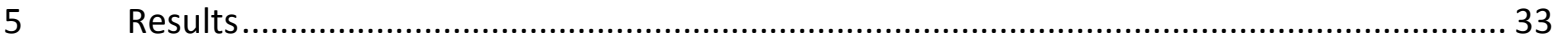

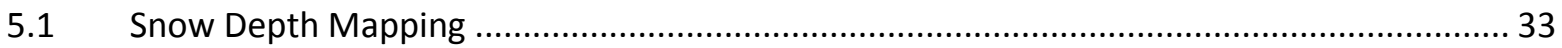

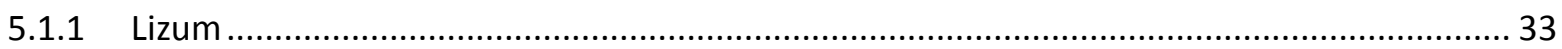

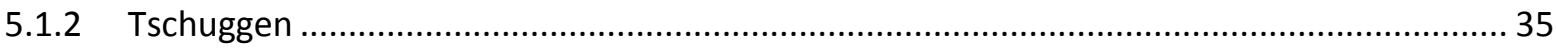

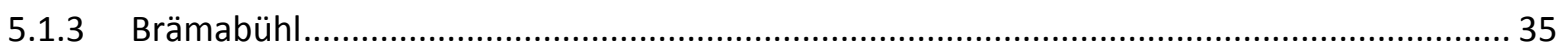

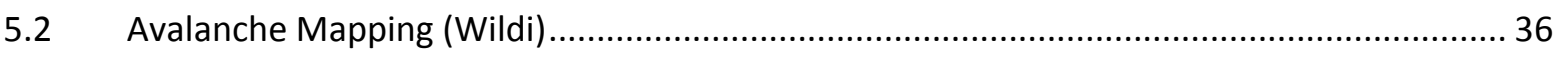

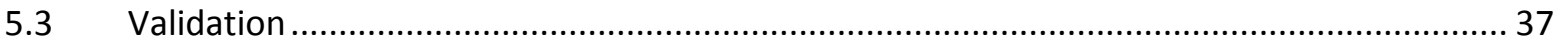

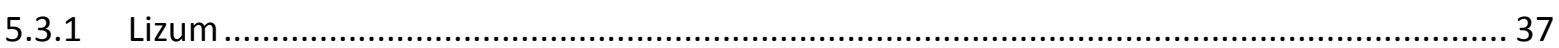

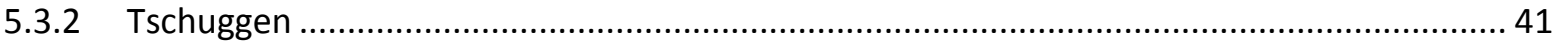

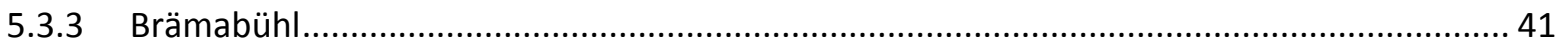

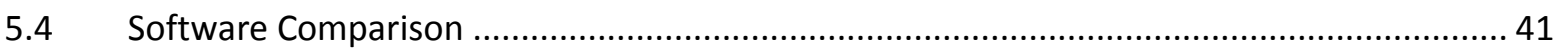

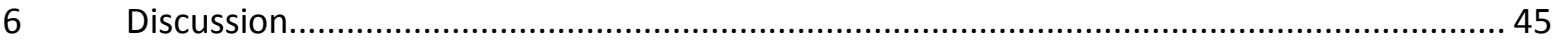




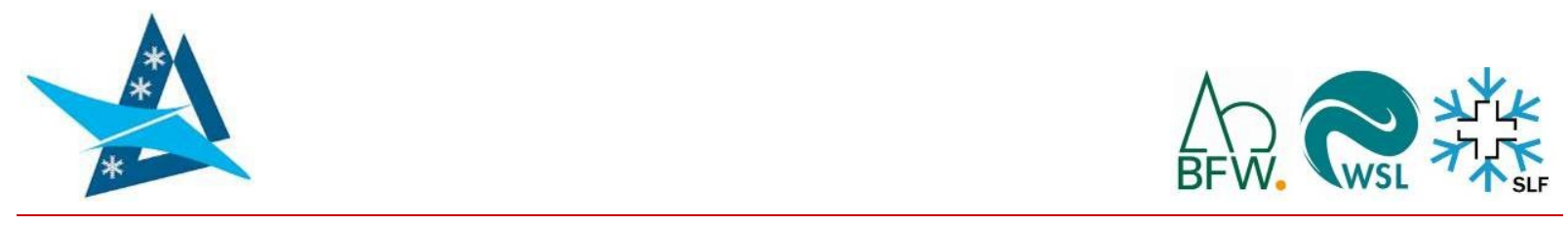

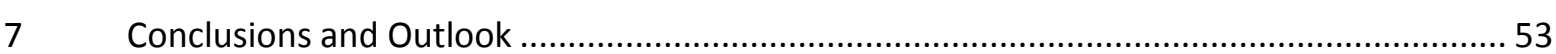

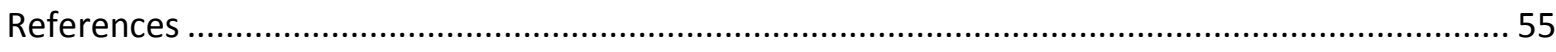

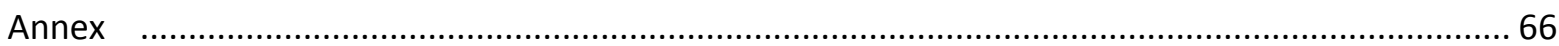

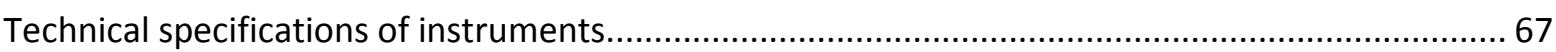




\section{List of Abbreviations}

AATSR - Advanced Along-Track Scanning Radiometer

ADS - Airborne Digital Sensor

ALS - Airborne Laser Scanning

$\mathrm{AOI}$ - Area of Interest

API - Application Programming Interface

AscTec - Ascending Technologies

AVHRR - Advanced Very High Resolution Radiometer

AWS - Automated Weather Station

BFW - Bundesforschungszentrum für Wald (Austrian Research Centre for Forests)

DPC - Dense Point Cloud

DSM - Digital Surface Model

DTM - Digital Terrain Model

EPSG - European Petroleum Survey Group Geodesy

ESS - Earth System Sciences

GCP - Ground Control Point

GIS - Geographic Information Systems

GNSS - Global Navigation Satellite System

GOES - Geostationary Operational Environmental Satellite

GPS - Global Positioning System

GSD - Ground Sampling Distance

HS - Snow Depth

ICAO - International Civil Aviation Organization

ICESat - Ice, Cloud and Land Elevation Satellite

IEEE - Institute of Electrical and Electronics Engineers

IGCP - International Geoscience Programme

IMU - Inertial Measurement Unit

IQR - Interquartile Range

KOMPSAT - Korea Multi-Purpose Satellite

Landsat MSS / TM / ETM+ - Landsat Multispectral Scanner System / Thematic Mapper / Enhanced Thematic Mapper

LASE - Low Altitude, Short Endurance 
LFAS - Large Frame Aerial Sensor

LiDAR - Light Detection and Ranging

LIS - Laserdata Information System

LLC - Limited Liability Company

LPM - Laser Profile Measuring System

MERIS - MEdium Resolution Imaging Spectrometer

MODIS - Moderate Resolution Imaging Spectroradiometer

NIR - Near-infrared (part of the electromagnetic spectrum)

NOAA - National Oceanic and Atmospheric Administration

ÖAW - Österreichische Akademie der Wissenschaften (Austrian Academy of Sciences)

OP - Orthophoto

PSP - PhotoScan Pro

QGIS - Quantum-GIS

QI - Quality Index

RMSE - Root Mean Square Error

RPAS - Remotely Piloted Aerial / Aircraft Systems

RTK - Real-Time Kinematic

SAGA - System for Automated Geoscientific Analyses

SLF - WSL Institute for Snow and Avalanche Research

SMMR - Scanning Multichannel Microwave Radiometer

SPOT - Satellite Pour l'Observation de la Terre

SSM/I - Special Sensor Microwave/Image

TGRS - Transactions on Geoscience and Remote Sensing

TIRIS - Tiroler Rauminformationssystem

TLS - Terrestrial Laser Scanning

TR - Terrestrial Radar

UAS - Unmanned Aerial System

UAV - Unmanned Aerial Vehicle

UAV-g - International Conference on Unmanned Aerial Vehicles in Geomatics

VIS - Visible (part of the electromagnetic spectrum)

WSL - Swiss Federal Institute for Forest, Snow and Landscape Research 


\section{List of Tables}

Table 1: Details on the TLS-scans of the valley floor used for validation in RPAS4SNOW

Table 2: Example of meteorological data recorded by the Lizum AWS (11 February 2015).

Table 3: Dense cloud sizes for PSP with VIS data.

Table 4: Absolute HS values measured by AWS and RPAS

Table 5: Comparison of HS changes, relative to 13 February 2015, as measured by AWS and RPAS (average over whole $\mathrm{AOI}$ ) on three campaign dates

Table 6: RMSE of TLS-validation of RPAS-DSMs.

Table 7: RMSE of RPAS-HS maps' in-situ-validation ( $n=150$ on 11 and 13 February; $n=37$ on 13 March).

Table 8: Details on all RPAS-flights performed at the Austrian study site; RPAS - MM (fixed-wing); ML (helicopter); Camera: N5 (Sony NEX 5A/R); A7 (Sony Alpha 7R). 66

Table 9: Technical specifications of RPAS (top - Multiplex Mentor Elapor; middle - AscTec Falcon 8; bottom - Mikado Logo 600SE). 67

Table 10: Technical specifications of RPAS sensors (source: Sony, 2016). 68

Table 11: Technical specifications of LPM-321 (left) and LPM 98-2k (right). 69 


\section{List of Figures}

Figure 1: Overview of the RPAS4SNOW project structure.

Figure 2: Overview of the study site Lizum and location of the AOIs for TLS \& RPAS (source OP - TIRIS 2016); location of study site in Central Europe (inset); location of the automatic weather station (white asterisk).

Figure 3: Terrestrial photo of the Austrian study site.

Figure 4: Overview of RPAS, TLS and in-situ data collection campaigns at the Austrian study site (each dot represents one campaign day).

Figure 5: Wildi avalanche near Davos; a) close-up of the deposition area; b) overview of the avalanche, showing release area, avalanche track and deposition area (Pixmap (C) 2015 swisstopo 5 704000 000).

Figure 6: Different types of LASE RPAS platforms used in RPAS4SNOW, top - Multiplex Mentor fixedwing; middle - AscTec Falcon 8 multicopter; bottom - Mikado Logo 600 SE helicopter. 15

Figure 7: Spectral response of camera with NIR-filter (left) and VIS-filter (right).

Figure 8: Reflectance of different surface types related to snow cover. The bandwidths of Landsat (TM), MODIS (M) and AVHRR are also integrated (Zeng et al., 1984, modified) (modified after Dietz et al., 2012).

Figure 9: Ground Control Points used at the Austrian study site (left - classical photogrammetric plate; right - target sprayed onto snow surface with template).

Figure 10: GNSS-measurements at the Austrian study site on 13 Feb 2015.

Figure 11: GCPs used for georeferencing at the Austrian study site (Tie Point - TP1-8); distribution within the RPAS-AOI (left); detail of TP1 \& TP7 location (right) - both against the snow-free RPAS OP.

Figure 12: Riegl LPM-321 (left) and LPM 98-2k (right) in operation for snow depth monitoring at the Austrian study site on 11 Feb 2015 and 13 Feb 2015, respectively.

Figure 13: Greyscale intensity plots of the TLS-measurements used for validation - the darker the grey, the lower the amount of energy received at the TLS instrument (blue pixels = NoData); top to bottom - 11 February 2015, 14 February 2015, 3 March 2015 \& 11 March 2015.

Figure 14: Reflective target showing up in TLS intensity plot as white spots (red circles) (left); installing a TLS-target at the Austria study site (right).

Figure 15: In-situ snow depth measurements at the Austrian study site on 11 Feb 2015.

Figure 16: Position of manual snow depth validation measurements (red dots) at study sites Lizum on 11 March 2015 (left) and Tschuggen on 24 April 2015 (right); in the background the respective UASOP.

Figure 17: Example for a simple script in PSP (Agisoft LLC, 2016). 26

Figure 18: Example of a histogram for the QI of images collected on 13 Feb 2015 (flight 1). 
Figure 19: Study site Lizum, with GCP-locations (magenta circles) and evaluation-spots (yellow circles); overview (left) and detail (right).

Figure 20: Point density within evaluation spot no. 5 (PSP, left; Match-T, right).

Figure 21: Main outputs from RPAS-data processing, exemplified with results from 10 April 2015, VISflight 1 - OP (top left); shaded DSM (top right); HS map (bottom left), calculated with snow-free DSM (hillshade, bottom right).

Figure 22: Relative HS changes between 13 February 2015 (flight 3) and i) 3 March 2015 (flight 2) (left); ii) 13 March 2015 (flight 1) (centre); iii) 10 April 2015 (flight 3) (right).

Figure 23: Results from NIR830 data collection (OP, left; HS map, right). 35

Figure 24: OP of the release zone (left) and calculated snow depth (HS) values (right). 36

Figure 25: OP of the deposition zone (left) and calculated snow depth (HS) values (right). The HS profile illustrates the scattering of the deposition into different flow arms with very variable deposition depth.

Figure 26: Four examples of TLS-validation results - each point represents a TLS-measurement, colour-coded by degree of positive (reds) and negative (blues) deviation of the RPAS from the TLS DSM [m]; 3 March 2015, flight 2 (top left); 13 March 2015, flight 1 (top right); 11 February 2015, flight 1 (bottom left); 11 February 2015, flight 2 (bottom right). 38

Figure 27: Results of the TLS-validation; on the $y$-axis the deviation of RPAS-DSM from TLS-DSM [m] is marked; flight ID (MM_DD_flightnumber) is plotted on $\mathrm{x}$-axis - each boxplot corresponds to one UASflight; whiskers in boxplot correspond to one standard deviation, outliers not included; the boxplots are based on 50,000 randomly selected samples from the TLS-point clouds. 39

Figure 28: Results from the in-situ validation of RPAS-HS maps in February 2015; on the y-axis the deviation of RPAS-HS values from in-situ-HS values [m] is marked; flight ID (MM_DD_flightnumber) is plotted on x-axis - each boxplot corresponds to one UAS-flight; whiskers in boxplot correspond to one standard deviation, outliers not included.

Figure 29: Variation of all evaluated spot heights

Figure 30: Point density within the evaluation spots $1-14$

Figure 31: Variation of single evaluated spot heights......

Figure 32: Visual inspection of shaded DSM.

Figure 33: Comparison of different RPAS-platforms with regard to their suitability for application in wintry high-alpine terrain in RPAS4SNOW; each category was rated from 1 (very poor) to 5 (very good).

Figure 34: VIS data recorded with RPAS, while AOI was in direct sunlight (top row) and shadowed (bottom row) on 13 February 2015 (flight 1 \& 5, respectively); OP (left), shaded DSM (centre) and HS maps (right). 
Figure 35: NIR data recorded with RPAS, while AOI was in direct sunlight (top row, NIR830) and mostly shadowed (bottom row, NIR700) on 13 February 2015 (flight 3 \& 4, respectively); OP (left), shaded DSM (centre) and HS maps (right).

Figure 36: Exposure Triangle, showing the dependency of shutter speed, aperture and ISO (after O'Connor et al., 2016).

Figure 37: OP \& HS of two NIR830 flights (top: 13 February 2015, flight 3; bottom: 11 February 2015, flight 1).

Figure 38: Area with medium-rise vegetation in summer (OP - top left; aerial photograph - top right) and winter (OP - bottom left; HS map - bottom right).

Figure 39: Example for the relationship between ski tracks (OP, left) and quality of HS maps (right; violet $=$ negative, implausible $\mathrm{HS}$ values) ....

Figure 40: Results from 11 February 2015, flight 1, NIR830-filter; HS map, OP, shaded DSM (left to right) 70

Figure 41: Results from 11 February 2015, flight 2, VIS; HS map, OP, shaded DSM (left to right) ....... 70 Figure 42: Results from 11 February 2015, flight 3, VIS; HS map, OP, shaded DSM (left to right) ....... 71 Figure 43: Results from 13 February 2015, flight 1, VIS; HS map, OP, shaded DSM (left to right) ....... 71 Figure 44: Results from 13 February 2015, flight 3, NIR830-filter; HS map, OP, shaded DSM (left to right)

Figure 45: Results from 13 February 2015, flight 4, NIR700-filter; HS map, OP, shaded DSM (left to right)

Figure 46: Results from 13 February 2015, flight 5, VIS; HS map, OP, shaded DSM (left to right) ....... 73

Figure 47: Results from 3 March 2015, flight 1, VIS; HS map, OP, shaded DSM (left to right) 73

Figure 48: Results from 3 March 2015, flight 2, NIR830-filter; HS map, OP, shaded DSM (left to right) 74

Figure 49: Results from 13 March 2015, flight 1, VIS; HS map, OP, shaded DSM (left to right) 74

Figure 50: Results from 13 March 2015, flight 2, VIS; HS map, OP, shaded DSM (left to right) 75

Figure 51: Results from 13 March 2015, flight 3, NIR830-filter; HS map, OP, shaded DSM (left to right)

Figure 52: Results from 4 April 2015, flight 1, VIS; HS map, OP, shaded DSM (left to right) 76 Figure 53: Results from 4 April 2015, flight 1, NIR830-filter; HS map, OP, shaded DSM (left to right) 76 Figure 54: Results from 4 April 2015, flight 3, VIS; HS map, OP, shaded DSM (left to right) 77 Figure 55: Results from 4 April 2015, flight 4, NIR830-filter; HS map, OP, shaded DSM (left to right) 77 Figure 56: Results from 21 August 2015 (snow-free data acquisition), flight 3, VIS; OP, shaded DSM (left to right) 
Figure 57: Each point represents a TLS-measurement, colour-coded by degree of positive (reds) and negative (blues) deviation of the RPAS from the TLS DSM [m]; 11 February 2015, flight 3 (top left); 13 February 2015, flight 1 (top right); 14 February 2015, flight 3 (bottom left); 14 February 2015, flight 4 (bottom right). 79

Figure 58: Each point represents a TLS-measurement, colour-coded by degree of positive (reds) and negative (blues) deviation of the RPAS from the TLS DSM [m]; 14 February 2015, flight 5 (top left); 3 March 2015, flight 1 (top right); 13 March 2015, flight 2 (bottom left); 13 March 2015, flight 3 (bottom right). 80

Figure 59: Results from the in-situ validation of RPAS-HS maps in March 2015; on the y-axis the deviation of RPAS-HS values from in-situ-HS values [m] is marked; flight ID (MM_DD_flightnumber) is plotted on x-axis - each boxplot corresponds to one UAS-flight; whiskers in boxplot correspond to one standard deviation, outliers not included. 81 


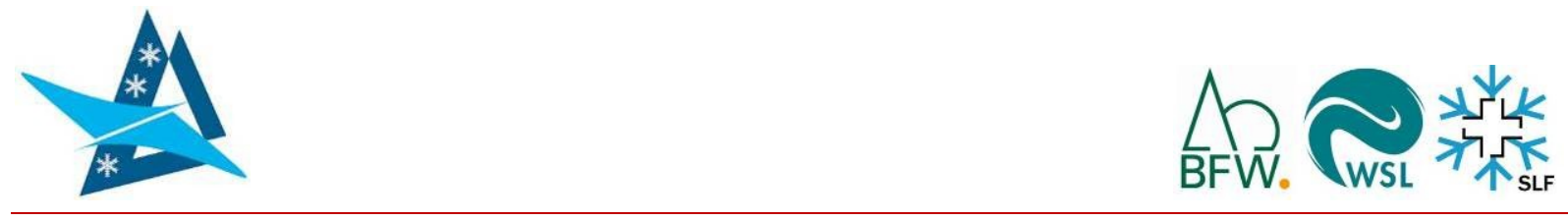

\section{Summary}

The spatial and temporal distribution of seasonal snow plays a major role in a number of interacting and interdependent economic, social and environmental components of the Earth System. With regard to the Alpine Space these include, but are not limited to: the hydrological cycle (e.g. water supply, generation of electrical power), natural hazard risk assessment and mitigation (e.g. documenting and studying trigger processes and dynamics of (extreme) avalanches, decision support in natural hazard management), flora and fauna, as well as tourism. Accurate spatially and temporally explicit snow depth distribution data forms the basis of many practical and scientific applications in the Alpine Space. Current methods for estimating the highly heterogeneous snow depth distribution in mountainous areas are however mostly only valid on a regional scale (i.e. derived from punctual interpolation of weather station data), or require a trade-off between the data's availability, cost, spatial and temporal resolution (i.e. derived from classical space- or airborne platforms). Recent technological advances have given rise to the development of Remotely Piloted Aerial Systems (RPAS), which are able to bridge the gap between full-scale, manned aerial, and terrestrial observations in the field. Their primary advantages include the possibility for flexible, costeffective, on-demand mapping missions with multiple sensors at an unprecedented level of detail (ground resolution of few centimetres to millimetres). The last decade has seen a rapid increase in the development and variety of scientific research and commercial applications of RPAS. However, there is a general lack of studies investigating the application of RPAS to snow depth mapping in alpine environments, particularly with regard to its technical feasibility, accuracy / precision, as well as the merits, drawbacks and potential of employing different sensors and platforms.

The pilot project RPAS4SNOW - Investigating the Potential of Low-Cost Remotely Piloted Aerial Systems for Monitoring the Alpine Snow Cover, evaluated the use of low-cost RPAS for cryosphere remote sensing, with particular reference to their potential for acquiring snow depth maps with high spatial and temporal resolution in high-alpine terrain. The project was carried out by an interdisciplinary team of researchers from Austria and Switzerland.

The project encompassed: i) employing different low-cost RPAS platforms and sensors during several field campaigns in four study sites to collect aerial images in (high-)alpine terrain in Switzerland and Austria; particular attention was given to critically evaluating their operational merits and drawbacks for snow and avalanche monitoring in (high-)alpine terrain, against the backdrop of the current stateof-the-art in the literature; ii) calculating multitemporal, very high-resolution Digital Surface Models (DSM) and Orthophotos (OP) from the RPAS imagery, using various state-of-the-art photogrammetry software packages; by calculating snow-free with snow-covered DSM, snow height maps were generated; we compared the different software with regard to its applicability and capabilities for processing RPAS imagery; iii) validating the RPAS results against data collected using a variety of wellestablished remote sensing (i.e. terrestrial laser scanning (TLS), large frame aerial sensors (LFAS)), and in-situ measurement techniques, which were employed at the same time as the RPAS-flights in combined, large-scale field campaigns in Austria and Switzerland; comparing the performance of results from matched imagery, recorded at different wavelengths (i.e. visible and near-infrared part of the electromagnetic spectrum); quantifying the impact of vegetation on the accuracy of snow 


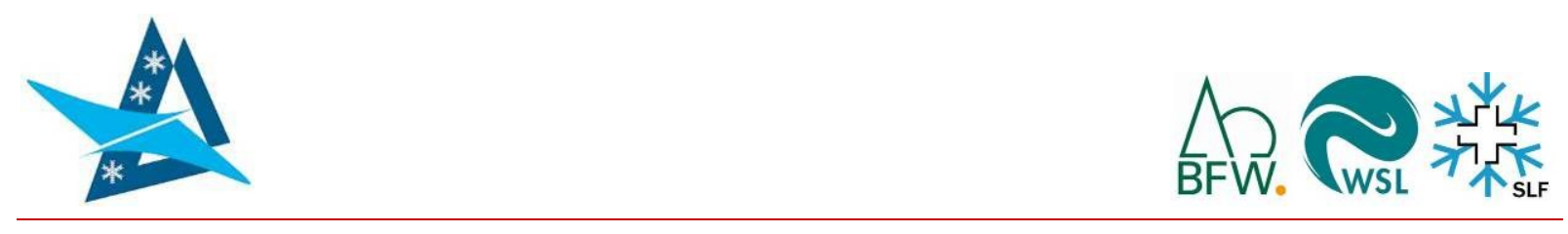

depth maps; iii) disseminating, communicating and discussing the project results in the form of scientific and non-scientific publications.

Generally, choice of the correct RPAS platform / sensor depends on the application (i.e. requirements for data - spectral / spatial resolution), size and accessibility or target area, technical specifications of the platform, and piloting skills. Results from RPAS4SNOW show, that the accuracy of the RPAS (validated against in-situ snow depth measurements, TLS and LFAS data) is in the range of 0.07 $0.3 \mathrm{~m}$, depending on the type of RPAS platform and sensor used. The precision (i.e. repeatability) of the RPAS data lies at $0.045-0.21 \mathrm{~m}$. These values are in the same range as results reported in recent studies, where snow depth was mapped from manned aircraft or RPAS. It was shown in this study, that the use of NIR-sensors for RPAS-based snow depth mapping improves the accuracy of the results considerably, thus confirming findings from previous studies with manned aircraft data. The presence of vegetation underneath the snow cover substantially influences the accuracy of the RPASbased snow depth maps.

RPAS4SNOW strongly tied in with current and recently finalised research projects at the participating research facilities. It stimulated and strengthened the bilateral activities between the Austrian and Swiss project partners and could pave the way for a potential large-scale follow-up project. 


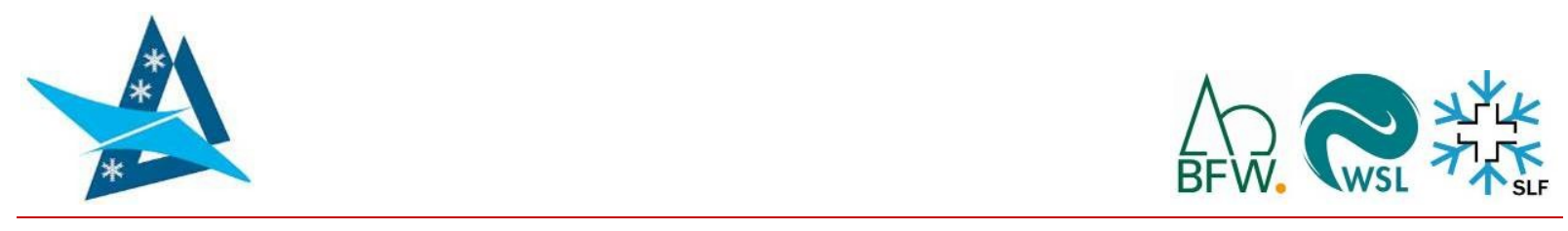

\section{Remote Sensing of Seasonal Snow}

\section{Introduction}

The spatiotemporal distribution of seasonal snow plays a major role in a number of interacting and interdependent economic, social and environmental components of the Earth System, especially in the mountainous environments (Beniston, 1997; Dietz et al., 2012). This holds true in particular for i) the hydrological cycle, especially with regard to water supply for runoff and ground water recharge (Jain et al., 2008; Hay et al., 2006; Akyürek \& Sorman, 2002; Xiao et al., 2002), as well as the generation of electrical power (Jonas et al., 2009; Marty, 2008; Vikhamar \& Solberg, 2003); ii) natural hazard risk assessment, mitigation and decision support (Eckert et al., 2012; Cappabianca et al., 2008), avalanche research and practice in general and documenting and studying trigger processes and dynamics of (extreme) avalanches in particular (Bavay et al., 2009; Schaffhauser et al., 2008; Luzi et al., 2009; Schweizer \& Kronholm 2007), as well as flood prediction and mitigation (Schöber et al., 2014; Sui \& Koehler, 2001; Singh et al., 1997) iii) the growth and habitat pattern of alpine flora and fauna (Bilodeau et al., 2013; Peng et al., 2010; Wipf et al., 2009). Furthermore, knowledge on the distribution of snow is of great concern to the tourism industry, as it is often focused on snowdependent activities and is therefore particularly reliant on the availability of snow (Trawöger, 2014; Falk, 2013, 2010; Rixen et al., 2011; Varley \& Medway, 2011). Therefore, accurate spatially and temporally explicit snow depth distribution data forms the basis of many practical and scientific applications in alpine terrain.

However, the properties of mountain snowpacks (e.g. depth, density, temperature) are highly heterogeneous (Grünewald et al., 2010; Moreno Banos et al., 2009; Schweizer et al., 2008; Elder et al., 1995). This is mainly due to the influence of the complex alpine terrain on meteorological variables, such as precipitation and surface energy fluxes on the one hand and the redistribution of the original snowfall by wind transport, sloughing or avalanche activity on the other (Cline et al., 1998; Elder et al., 1991). Current estimates of snow depths (HS) are typically derived from the interpolation of punctual measurements from either manual in-situ data collection or automatic weather stations and are combined with medium resolution satellite-based snow depth maps (Foppa et al., 2007). (HS is defined here as the vertical distance from the base to the surface of the snow pack (Fierz et al., 2009).) However, these methods are hindered by i) the fact, that gathering in-situ data of the snowpack may be labour-intensive, potentially hazardous or even impossible and ii) the lack of knowledge regarding the representativeness of snow depth measurements by automatic weather stations. The combination of these factors renders traditional snow depth approximations suitable mostly only for regional-scale applications, because they are not able to capture the present spatial variability, especially over small areas (Ginzler et al., 2013). A further issue in this context is the need for accurate and readily available information on the spatial extent and volume of released, entrained and deposited debris of avalanche events. This data serves as a vital basis of avalanche forecasting, warning and hazard mapping/mitigation measure planning (e.g. Bair, 2013; Chrustek et al., 2013; Bartelt et al., 2012; Buser et al., 1985; LaChapelle, 1980). This holds true not only for extreme avalanche periods (e.g. winter 1998/99), but also the regular documentation of smaller, 


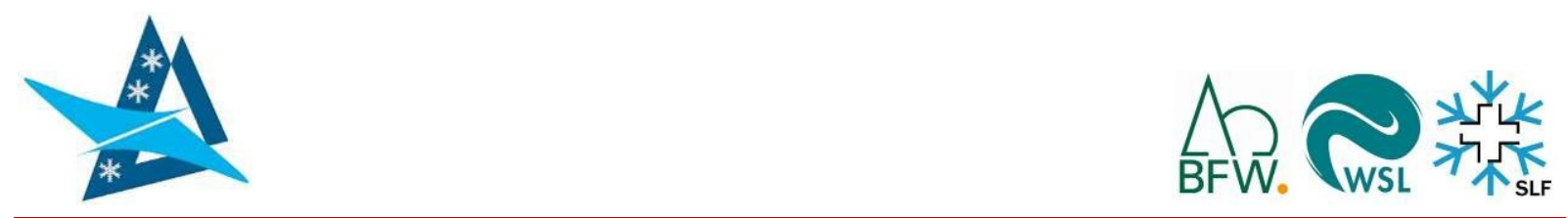

non-destructive avalanches. As this documentation has proven particularly difficult in the past, it should be addressed by current research. First attempts have been performed by Bühler et al. (2009) and Lato et al. (2012) with optical sensors and by Malnes et al. (2013) using Synthetic Aperture Radar.

\section{Traditional Approaches}

Remote sensing offers a versatile and powerful alternative to in-situ data collection, as it allows systematically gathering data on the physical properties of snow over large areas from a position, which is not endangered by avalanches (Nolin, 2010). Most techniques do not measure snow depth directly, but involve gathering surface height data at different points in time, e.g. in snow-free and in snow-covered conditions, and subtracting them. A wide range of remote sensing technologies relevant to cryosphere research have been developed (Kääb et al., 2005; Rees, 2006). They can be classified according where they are mounted: i) spaceborne, ii) airborne and iii) terrestrial:

- Cryosphere remote sensing from spaceborne platforms has been performed for decades (Dietz et al., 2012) and a wide range of sensors are currently available (Malnes et al., 2015). Optical sensors operating in the visible and infra-red bands include: i) low-resolution sensors (e.g. NOAA/AVHRR, GOES or Envisat AATSR), which reach a very high temporal resolution of up to $3 \mathrm{~h}$, at the cost of spatial resolution (typically $1000 \mathrm{~m}$ ); ii) medium-resolution sensors (e.g. Terra \& Aqua MODIS, Landsat MSS or Envisat MERIS) with data acquisition every 23 days at 80-300 m spatial resolution; iii) high-resolution sensors (e.g. SPOT 1-5, Landsat 4-5 / TM, Landsat 7 / ETM+, Sentinel 2) with a spatial resolution of $\geq 10 \mathrm{~m}$ and revisiting times reaching 2-3 days with the progression of the sentinel missions (Drusch et al., 2012); iv) very high-resolution products (e.g. Pléiades, SPOT 6-7, IKONOS, WorldView, KOMPSAT, QuickBird - partially available in stereo-view), which can generate products at decimetre-resolution, some on a daily basis. Marti et al. (2016) recently demonstrated the potential of stereo-view very-high resolution imagery to produce HS maps for a small alpine catchment. However, while some of the above-mentioned products are available free of charge (e.g. Sentinel), especially the very-high-resolution data is very cost-intensive (Whitehead et al., 2013). Alternatively, microwave sensors are available: Passive microwave sensors (e.g. Scanning Multichannel Microwave Radiometer (SMMR), Special Sensor Microwave/Image (SSM/I)) are mainly used for global monitoring due to their very low resolution, while active microwave sensors may reach spatial resolutions of up to $3 \mathrm{~m}$ (e.g. TerraSAR-X). However, the cost, temporal resolution and processing complexity of the latter data source present a significant drawback (Dietz et al., 2012). Light Detection and Ranging (LiDAR) utilises the same basic principles as the microwave radar and is viewed as the direct extension of these techniques. The main difference, however, is that it operates at much shorter wavelengths and is thus capable of delivering data with a more precise resolution and higher accuracy (Jelalian, 1992). Potential space-borne LiDAR sensors for snow depth estimation are available (ICESat), but have to date not been deemed appropriate for this application (Enßle et al., 2015). 


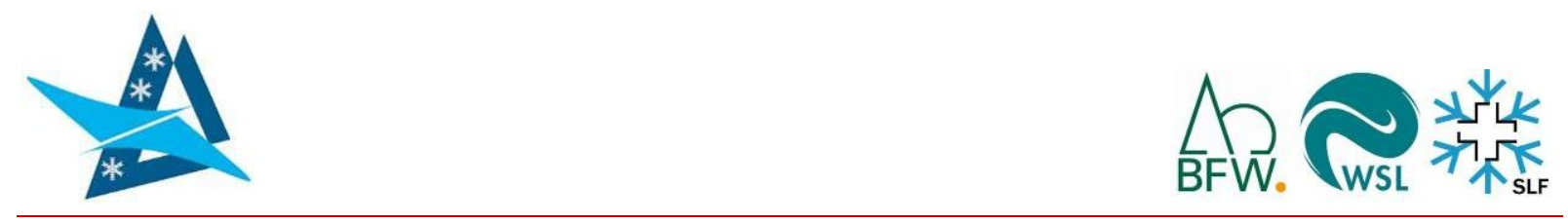

- Airborne sensors have the advantage of being closer to the observed objects than satellite sensors, resulting in the data being less affected by atmospheric influences (e.g. distortion, cloud coverage). Airborne Laser Scanning (ALS) has been applied to a wide range of snow topics (e.g. Grünewald et al., 2010). ALS is a well-established method to generate snow depth maps (e.g. Deems et al., 2013; Deems and Painter, 2006) with vertical accuracies of few decimetres to centimetres (Deems et al., 2013; Bollmann et al., 2011; Grünewald et al., 2010) over large areas. However, as Bühler et al. (2015a) point out, ALS data acquisition is general very costly. Digital photogrammetry, the generation of OPs and DSMs from high spatial resolution aerial imagery by automated point matching, is a valuable alternative. First investigations, demonstrating the potential of this method, reach back almost 50 years (e.g. Smith et al., 1967; Cline, 1993, 1994). However, the reported efficiency and the achieved accuracies of $>1 \mathrm{~m}$ at the time, were not feasible to most applications. With the advent of digital photogrammetry, this changed fundamentally (Bühler et al., 2012; Hobi \& Ginzler, 2012; Eckardt et al., 2004). Recent investigations report accuracies in the range of centimetres to decimetres, which allow a detailed analysis of the spatial variability of the mountain snow cover over large areas (hundreds of square kilometres), without the need for ground control (Nolan et al., 2015; Bühler et al., 2015a; Lee et al., 2008), but still require a fully equipped manned aircraft and corresponding maintenance logistics.

- Terrestrial techniques for determining HS, include Terrestrial Laser Scanning (TLS) and Terrestrial Radar (TR). TLS is a ground-based, automatic procedure, allowing dense sampling of a surface or object by converting distance and angle measurements to 3D coordinates (e.g. Molina et al., 2013; Prokop, 2008; Pfeifer \& Briese, 2007). The snow depth is not measured directly, but calculated by comparison of the current surface measurements with previously recorded snow-free terrain heights (Nolin, 2010). Since the advent of the use of TLS in snow science in 1999 (Moser et al., 2001), both the technical development of the hardware and software, as well as the amount of research and applications, have seen a staggering increase (Wiatr et al., 2013). On the upside, TLS may operate with high temporal and spatial resolution at vertical accuracies in the range of $0.1 \mathrm{~m}$ (Deems et al., 2013; Melvold \& Skaugen, 2013); on the downside however, TLS may only record data within the line of sight, with resolution, accuracy and coverage depending on the distance to the object and the illumination angle (i.e. laser footprint size), while being highly susceptible to poor weather conditions (i.e. fog, rain, snow or high winds) (Molina et al., 2013; Sailer et al., 2008). One of the most recently published applications, investigates the use of TLS to assist avalanche control and forecasting (Deems et al., 2015). While many applications of TR are described in the current literature, these are mainly aimed at determining qualitative snow cover properties (snow water equivalent, grain sizes or snow layering), rather than snow depth on a regional scale (e.g. Sundström et al., 2012; Previatia et al., 2011; Mitterer et al., 2011; Heilig et al., 2008). 


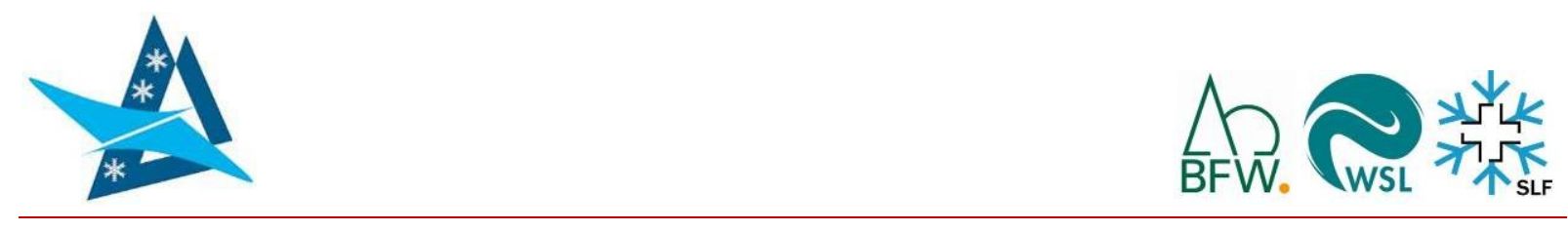

Despite the large range of available platforms and sensors, the choice of the ideal dataset for snow depth monitoring often requires a trade-off between the data's temporal and spatial resolution, as well as its availability and cost. While for instance optical satellite data typically offers a sufficient spatial coverage, it can be compromised by unfavourable meteorological conditions (e.g. cloud coverage, haze) (Whitehead et al., 2013).

\section{Remotely Piloted Aerial Systems}

Advances in recent years in the fields of aircraft construction (light weight construction \& engine development), navigation (GNSS - Global Navigation Satellite System \& IMU - Inertial Measurement Unit) as well as mechatronics in general (mechanics, electrical engineering \& informatics) and digital photogrammetric software design in particular, have given rise to the development of Remotely Piloted Aerial Systems (RPAS) (Briese et al., 2013). The term RPAS is used here according to the recommendation by the International Civil Aviation Organization (ICAO, 2014); other denominations include Unmanned Aerial Vehicle (UAV), Unmanned Aerial System (UAS) or drones. RPAS is the collective designation for i) a purpose-built, radio-controlled aircraft, ii) sensor payloads and iii) a ground control station operated by a human pilot (Van Blyenburgh, 2012; Vallet et al., 2012; Hardin \& Jensen, 2011). According to the classification suggested by Watts et al. (2012), the type of aircraft may range from Micro or Nano Air Vehicles with a typical flight time of 5-30 minutes, operating at very low altitudes $(<330 \mathrm{~m})$, to High Altitude, Long Endurance platforms, operating at altitudes of $20,000 \mathrm{~m}$ and more and with flight times of $>30 \mathrm{~h}$, used for both civil and military missions. In this context, the term RPAS refers to the scientific use of different types of Low Altitude, Short Endurance (LASE) aircraft with a typical weight of 2-5 kg, flight times of 10-30 minutes and a wing span of $<3 \mathrm{~m}$, optimised for easy field deployment / recovery and transport. The three main platforms available within this definition of RPAS include fixed-wing aircraft, helicopters and multicopters. All three RPAS-types were either operationally used or tested in the scope of RPAS4SNOW (Chapter 3.2).

Due to their specific features, RPAS are able to bridge the gap between full-scale, manned aerial, and terrestrial, field-based observations (Briese et al., 2013; Rosnell \& Honkavaara, 2012). The primary advantages of the LASE RPAS include the possibility for flexible, cost-effective, on-demand mapping missions with multiple sensors at an unprecedented level of detail (ground resolution of few centimetres to millimetres, depending on the type of sensor and the respective flight height) (Lucieer et al., 2014). Due to the fact, that RPAS are operated at lower altitudes, they are also less influenced by medium / high level clouds or haze. Due to their small size however, they can only be operated under favourable weather conditions (e.g. low wind speed, good visibility). From a scientific point-ofview, RPAS offer the advantage of allowing a flexible matching of the required spatial resolution and sensor type to the specific application, i.e. research question at hand. Additionally, the currently available software packages have significantly reduced the requirements for the recorded data, making high-performance algorithms for 3D processing (e.g. structure from motion computer vision techniques (Turner et al., 2012)) more readily available to RPAS-users (Lucieer et al., 2014; Hugenholtz et al., 2013, 2012; D’Oleire-Oltmanns et al., 2012; Eisenbeiss \& Sauerbier, 2011; Bláha, 2011; Haala, 2011). 


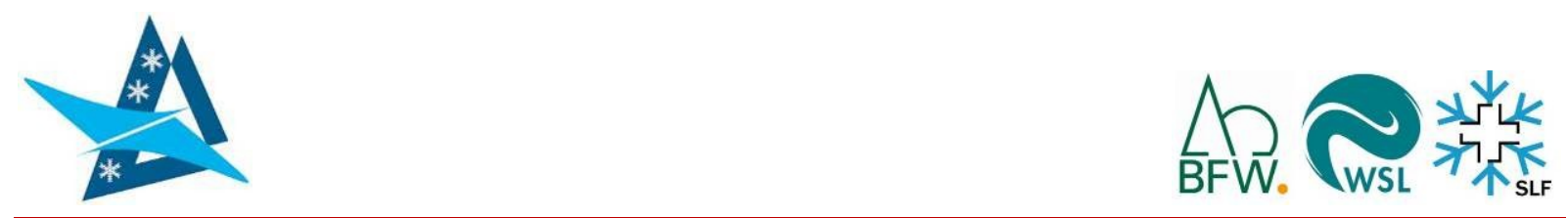

The growing popularity of RPAS is reflected in recent special issues on RPAS for remote sensing applications (IEEE TGRS: March 2009; GIScience and Remote sensing: March 2011; Geocarto International: March 2011; Remote Sensing: June 2012) in addition to dedicated conferences, such as UAV-g (Lucieer et al., 2014).

Although the concept of unmanned aerial platforms is not a recent technological advancement - the first attempts predating human-piloted flights - the last decade has seen a rapid increase in the development and variety of civil applications of RPAS in scientific research and commercial applications - a detailed summary is supplied by UVS-INFO (2016). Applications dealing with mapping and monitoring studies in mountainous regions, include: Fernández et al. (2015) - extensive overview of recent surveys of landslides; Ryan et al. (2015) and Whitehead et al. (2013) - RPAS applications on glaciers; Danzi et al. (2013) - rockfall, Dall'Asta et al. (2015) - rock glaciers and Tampubolon and Reinhardt (2015) - volcano mapping. Enßle et al. (2015) successfully tested RPAS-data acquisition in elevations up to $4,200 \mathrm{~m}$ a.s.l., proving that RPAS are capable of operating even at very high altitudes. However, to this date, the number of studies dealing with RPAS-based photogrammetry to map snow cover and avalanche are very limited: First results have recently been published by De Michele et al. (2016), Eckerstorfer et al. (2016), Harder et al. (2016) and Vander Jagt et al. (2015) within the duration of RPAS4SNOW. In all three publications the authors conclude, that UAS-based snow depth mapping holds great potential, but that further studies are required especially with regard to multi-temporal mapping, implementing sensors capable of measuring at e.g. near-infrared, or mapping different snow cover conditions or topographic areas. Additionally, Basnet et al. (2016), Prokop et al. (2015) and Thibert et al. (2015) reported on using ground-based photogrammetry for HS and avalanche detection. Further scientific applications of RPAS include: soil erosion (e.g. D'Oleire-Oltmanns et al., 2012), debris flow monitoring (e.g. Adams et al., 2016; Sortier et al., 2013), archaeology (e.g. Verhoeven, 2011), vegetation monitoring (e.g. Lucieer et al., 2014), geomorphology (e.g. Hugenholz et al., 2013) and hydrology (e.g. Molina et al., 2013). 


\section{Project Structure - Overview}

The main aims of RPAS4SNOW, including the specific research questions that were addressed by the project, were:

- Establishing a current state-of-the-art of RPAS snow remote sensing from the relevant literature as a basis for the presented investigations.

- Performing several RPAS flights in study sites in Austria and Switzerland with different RPAS platforms and sensors, testing different data collection routines (flight paths, flight heights, overlap), sensor settings (aperture, exposure) and (low-pass) filters. In the course of these campaigns, an appropriate number of ground control points are distributed in the target areas and their position determined with terrestrial GNSS-instruments, for accurate georeferencing of the RPAS-data.

- Calculating multitemporal, very high-resolution RPAS-generated DSMs and OPs with various state-of-the-art photogrammetry software packages using novel processing algorithms (i.e. structure from motion). Comparing such software with regard to their suitability for RPASdata processing.

- Validating the RPAS-results against data collected using a variety of well-established remote sensing and in-situ measurement techniques (terrestrial laser scanning, manual snow depth measurements and large-frame aerial cameras).

- Evaluating the merits and drawbacks of deploying low-cost RPAS platforms and sensors for snow depth mapping in mountainous regions; disseminating, communicating and discussing the project results in the form of (popular) scientific publications in journals and at conferences.

The project was split into three main sections: data collection, data processing / analyses and results \& reporting. Figure 1 gives on overview of processing steps within each section. The following Chapter 3 provides an overview of the instruments and methods used for RPAS and ancillary data collection; Chapter 4 presents the analysis and processing routines employed, as well as providing details on the comparison of the photogrammetry software; in Chapter 5 the results are highlighted, and discussed in Chapter 6. The Annex includes a list of publications resulting from the project, as well as the technical specifications of the employed instruments. 

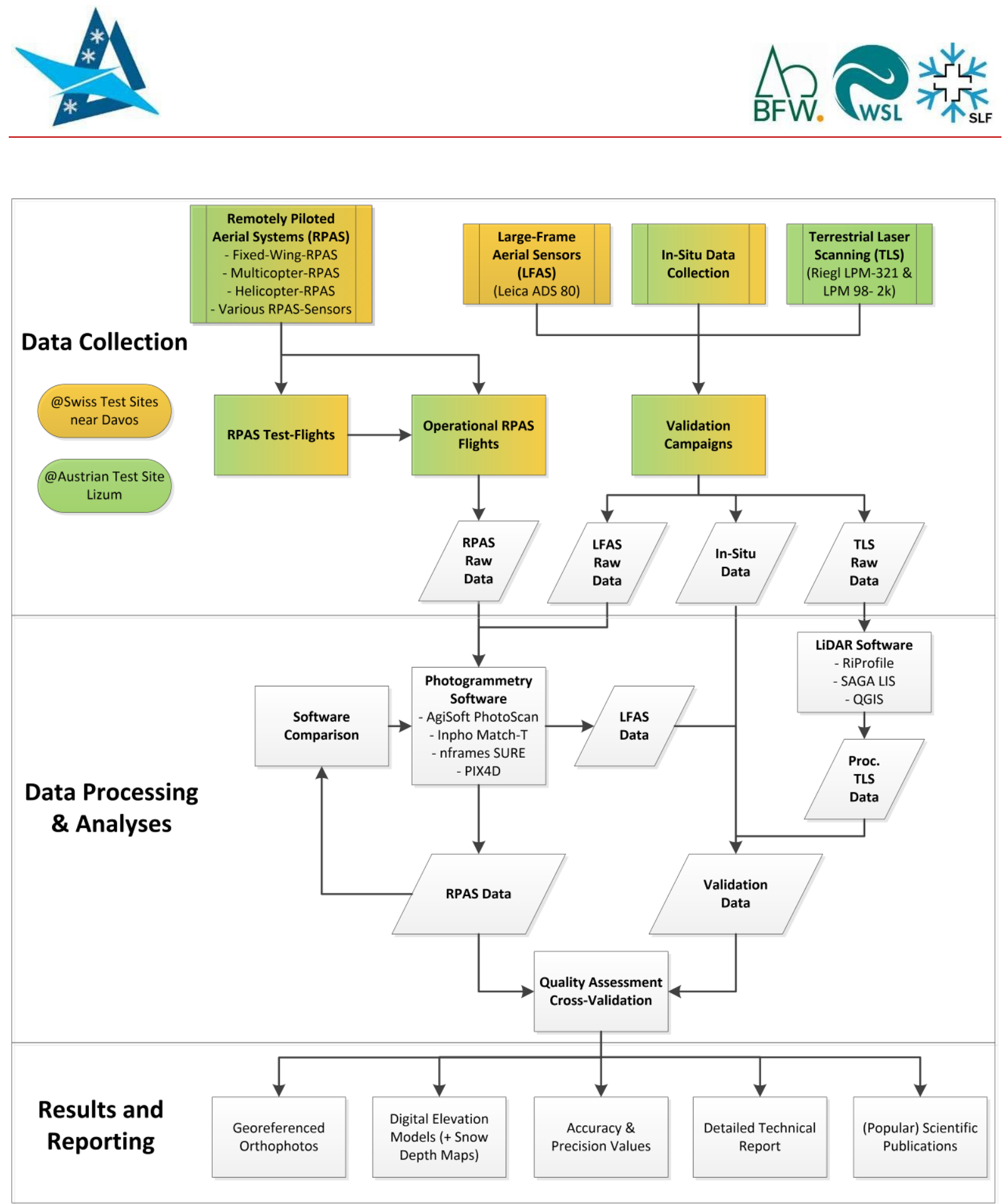

Figure 1: Overview of the RPAS4SNOW project structure. 


\section{Data Collection}

\subsection{Study Sites \& Campaigns}

During the project, the RPAS4SNOW-team conducted 20 measurement campaigns and 56 RPASflights at four study sites in Austria and Switzerland: 10 campaigns (34 flights) at Lizum (Austria), 4 campaigns (14 flights) in Tschuggen, 2 campaigns ( 3 flights) at Brämabühl and 4 campaigns ( 5 flights) at Wildi (all Switzerland). All sites represent different types of typical alpine terrain (valley bottom, slope, exposed ridge) and are characterised by very good access and a well-established infrastructure. Furthermore, data and experience from several previous projects were available for these sites.

\section{Lizum (Austria)}

The study site Lizum lies approximately $20 \mathrm{~km}$ south-east of Innsbruck, Tyrol (Austria). It is situated at the top of the Watten valley (Tuxer Alps), where the valley floor reaches an altitude of approximately $2,020 \mathrm{~m}$ a.s.l. and is surrounded by peaks, the highest reaching $2,886 \mathrm{~m}$ a.s.l. This study site was chosen mainly because of its good accessibility by road and well-established infrastructure. Figure 2 provides an overview of the study site and its location, as well as the areas of interest (AOI), where RPAS (11.8 ha) and TLS (8.6 ha) data were collected. The land cover in the study site is mainly characterised by alpine grass and shrub vegetation as well as some large boulders in the western and central part. Additionally, some gravel roads, which are partially cleared in winter, run along the northern and eastern section of the site. Figure 3 gives an impression of the site in winter, recorded from the eastern border of the study site looking westward.

An automated weather station (AWS), run by the BFW, is located in close proximity to the RPAStarget area (Figure 2). 

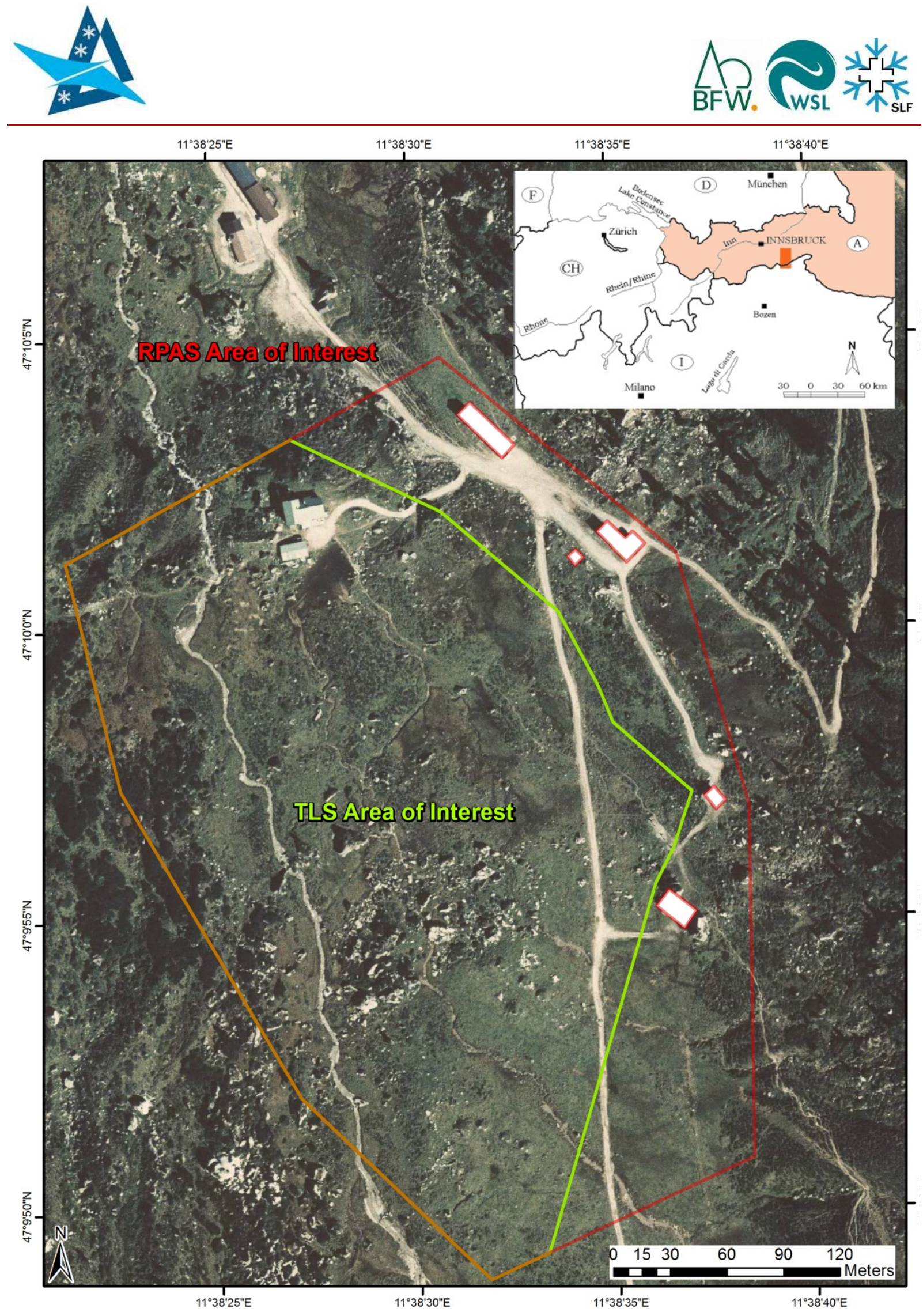

Figure 2: Overview of the study site Lizum and location of the AOIs for TLS \& RPAS (source OP - TIRIS 2016); location of study site in Central Europe (inset); location of the automatic weather station (white asterisk). 

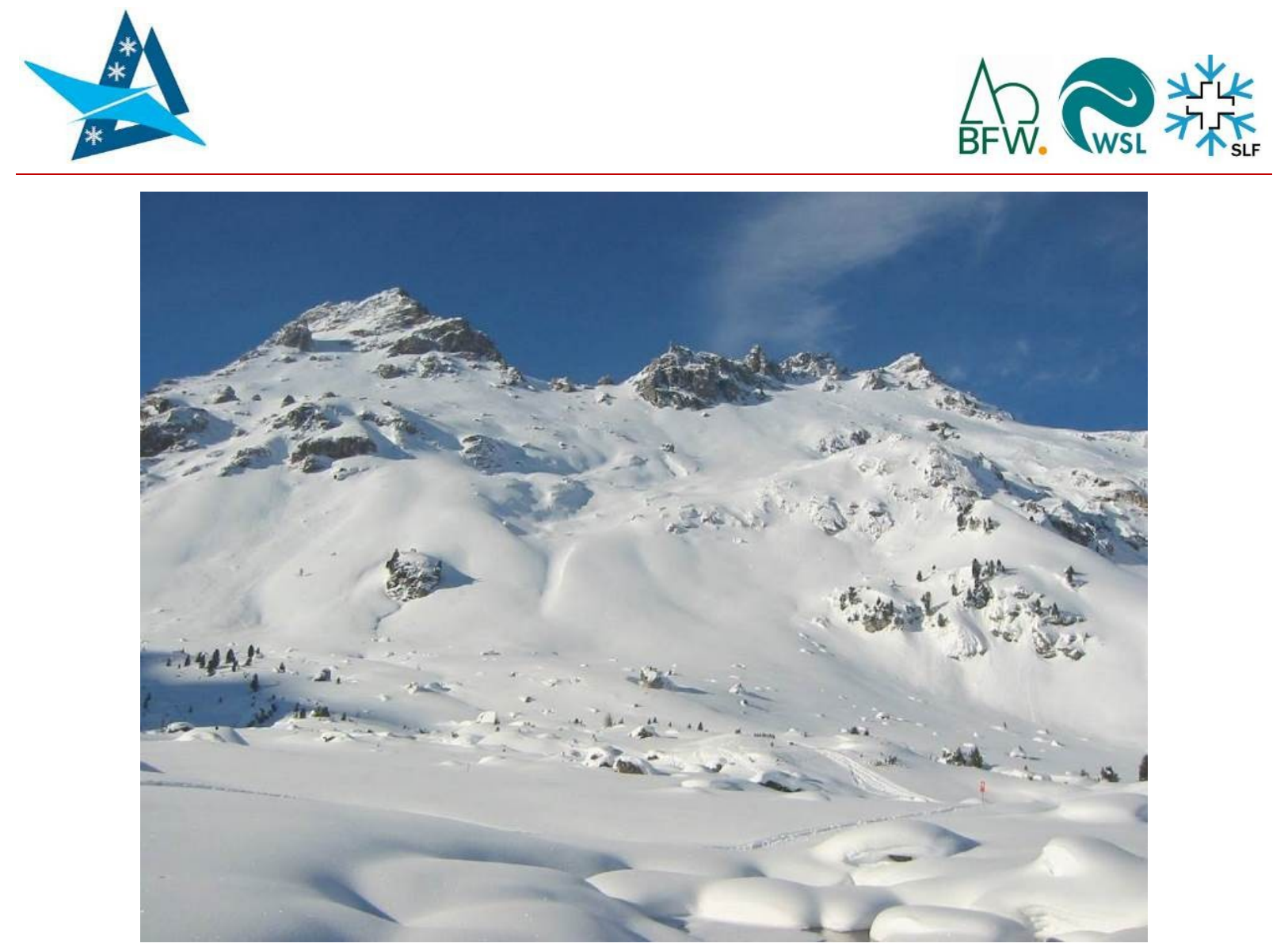

Figure 3: Terrestrial photo of the Austrian study site.

Figure 4 gives an overview of the data collection at the Lizum study site. Three RPAS- and one TLScampaign were launched at the end of 2014 and the beginning of 2015, respectively (two during snow-free and two during snow-covered conditions), to test and calibrate the equipment. The main data collection started on 11 Feb 2015, where RPAS, TLS and in-situ data were retrieved (orange, yellow and green dots, respectively). The final snow-free RPAS-flights, used to calculate the snow depths, were performed on 21 Aug 2015. In total 34 RPAS-flights were performed, of which 16 were used for further analyses. Details of all flights (i.e. flight, sensor and image properties as well as Ground Control Point (GCP) info are provided in the Annex (Table 8).

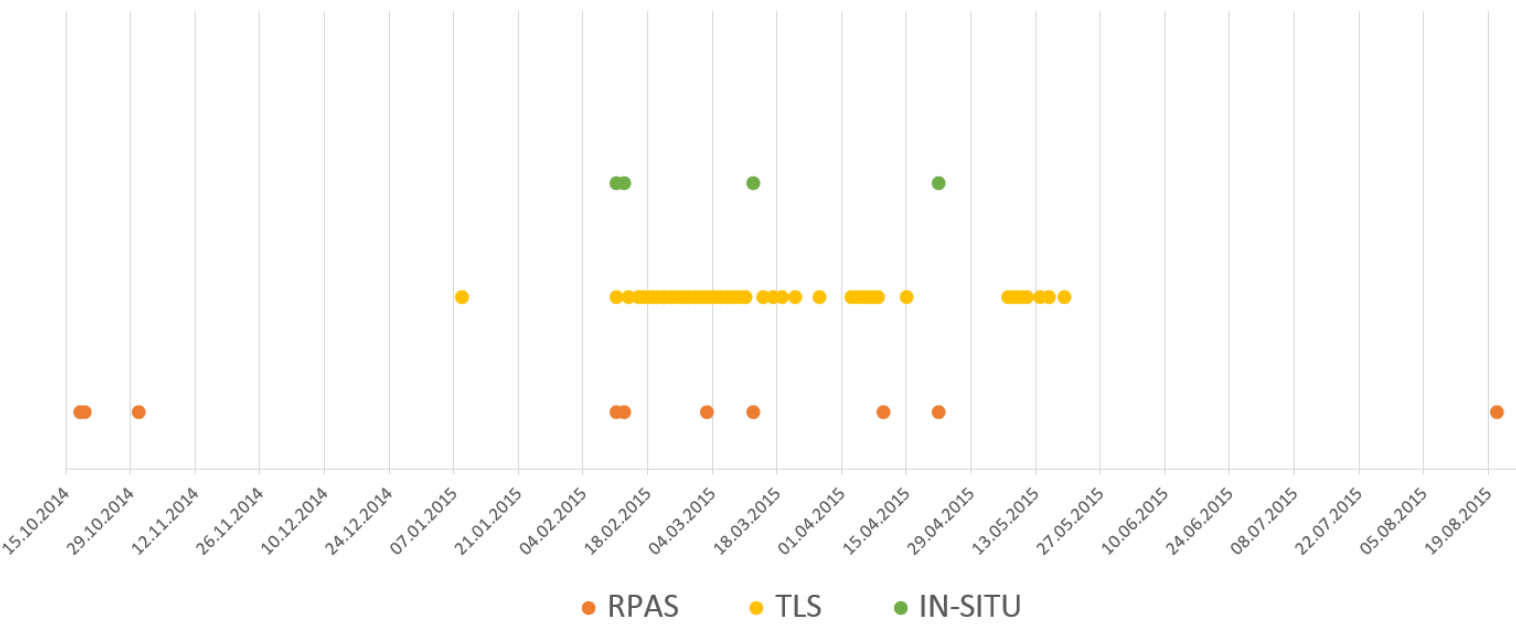

Figure 4: Overview of RPAS, TLS and in-situ data collection campaigns at the Austrian study site (each dot represents one campaign day). 


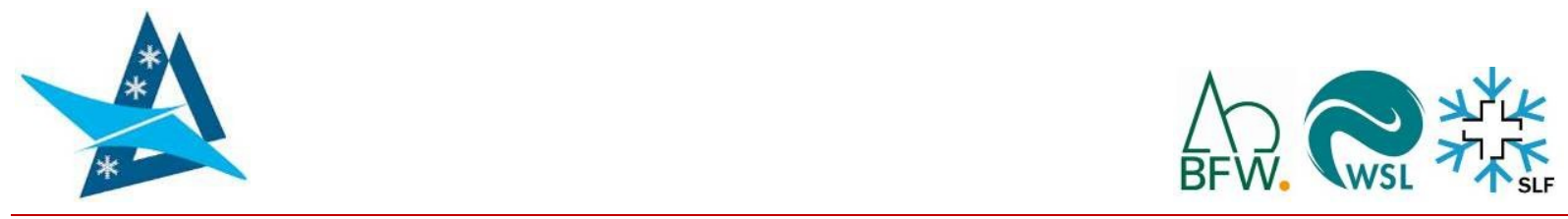

Tschuggen (Switzerland)

(the reader is kindly referred to Bühler, et al. 2016 for details)

\section{Brämabühl (Switzerland)}

(the reader is kindly referred to Bühler, et al. 2016 for details)

\section{Wildi (Switzerland)}

The Wildi-Avalanche occurs nearly every year at the entrance of the Dischma valley $\left(46^{\circ} 47^{\prime} N, 9^{\circ} 51^{\prime}\right.$

E) (Figure 5a). The release zone is located close to the ski run of the Brämabühl at approximately $2,300 \mathrm{~m}$ a.s.l. (Figure $5 \mathrm{~b}$ ). The slope is exposed to the northeast and divided into several gullies by forested ridges. In the gullies the avalanches regularly destroy the forest, thus only small trees are located here. The deposition area is located at approximately 1,600 $\mathrm{m}$ a.s.l., about $300 \mathrm{~m}$ uphill from the main road through the Dischma valley (at 1,580 $\mathrm{m}$ a.s.l.). Large avalanche events in the Wildi catchment may therefore reach the road. During Easter 2015 it snowed more than $1 \mathrm{~m}$ within three days, which was the highest amount of new snow within such a short time during the winter 2014/15. On 4 April2015 a dry snow avalanche released in the Wildi catchment. A snowboarder was posted as missing two days later. The police could localise his cell phone with an accuracy of about $100 \mathrm{~m}$ within a $4 \mathrm{~m}$ deep side arm of the avalanche that flowed to the north into the forest. By this time, the deposition was frozen hard and probing was not possible. The victim was recovered only ten days after the accident, when probing was possible due to higher temperatures (Techel et al., 2015). The exact course of events of this accident is unknown.

The Wildi avalanche release and deposition zone were mapped on 7 April 2015, two days after the avalanche occurred, using a Falcon 8 Octocopter (Ascending Technologies). The UAS acquired 99 images of the release zone and 76 images of the deposition zone (size: $0.4 \mathrm{~km}^{2}$ and $0.15 \mathrm{~km}^{2}$, respectively). It flew at an average elevation of $190 \mathrm{~m}$ (release zone) and $130 \mathrm{~m}$ (deposition zone) above ground level, with an image overlap of approximately $70 \%$ in $x$-and $y$-direction. To cover the whole area, we needed two starting locations for the release, as well as one for the deposition zone. This was necessary in order to comply with legal regulations for UAS, stating that they may only be operated within visual line of sight. The snow free images of the deposition and release zone were collected on 8 August 2015 and 21 September 2015, respectively. 

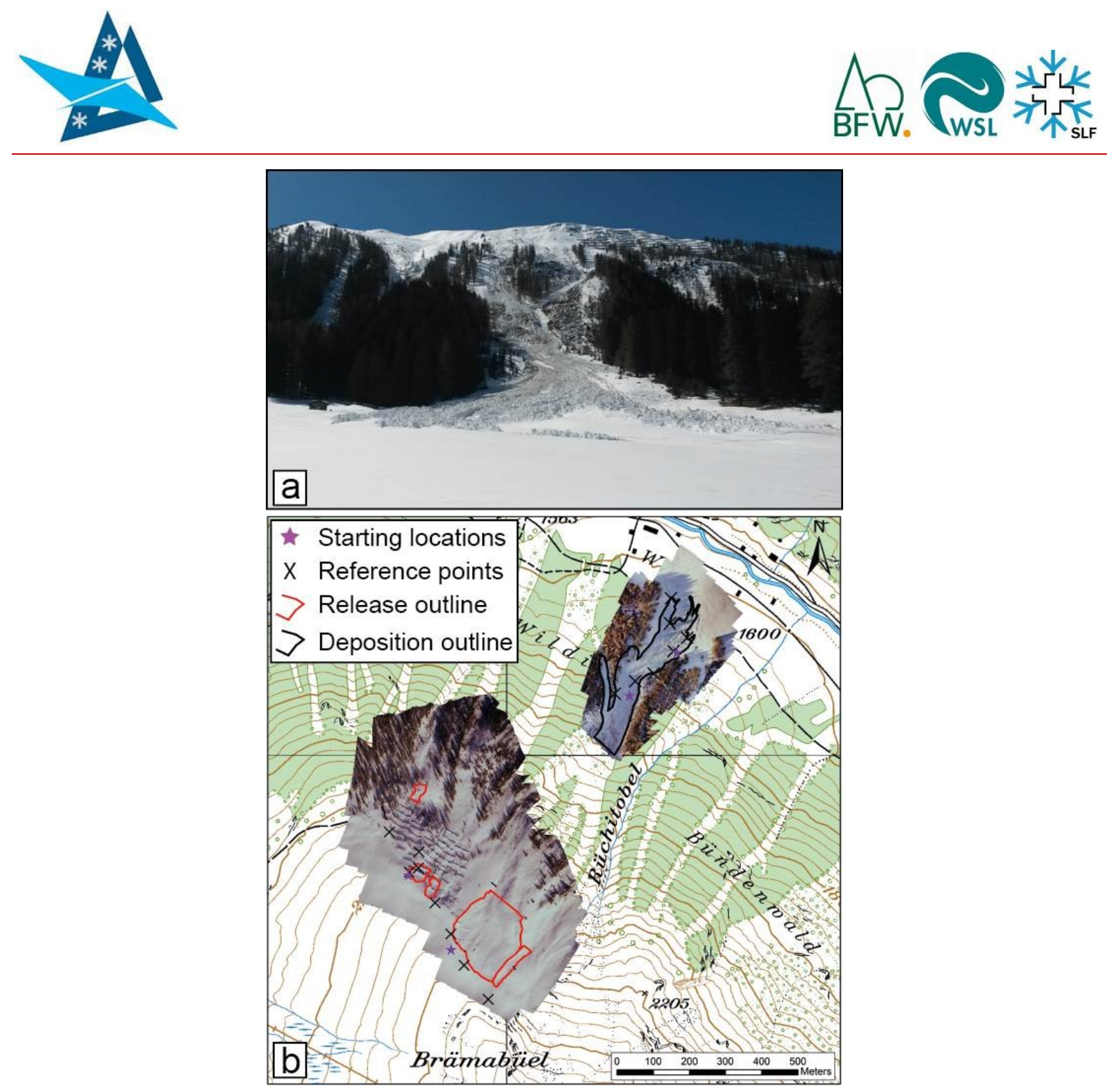

Figure 5: Wildi avalanche near Davos; a) close-up of the deposition area; b) overview of the avalanche, showing release area, avalanche track and deposition area (Pixmap @ 2015 swisstopo 5704000000 ).

\subsection{RPAS}

\section{Platforms}

The RPAS4SNOW-team had three different types of low-cost LASE RPAS platforms at their disposal for the project: i) a fixed-wing RPAS with an wing span $1.6 \mathrm{~m}$ and an average flight time of 30 minutes (Multiplex Mentor Elapor); ii) an AscTec Falcon 8 octocopter with 12-22 minutes flight time; iii) a helicopter RPAS with a blade length of $680 \mathrm{~mm}$ and an average flight time of 10 minutes (model: Mikado Logo $600 \mathrm{SE}$ ). The first two RPASs were already acquired prior to RPAS4SNOW, while the latter was bought and tested during the project runtime. The main advantages helicopters have over multicopters, are their resistance to strong / gusty winds, longer flight times through higher efficiency and the possibility for controlled landing even after total machine failure. This makes the helicopter (theoretically) substantially more suitable to high-alpine flight campaigns. All systems use electric, brushless motors, which are powered by lithium-polymer batteries. Technical specifications of all RPASs are included in the Annex (Table 9). 

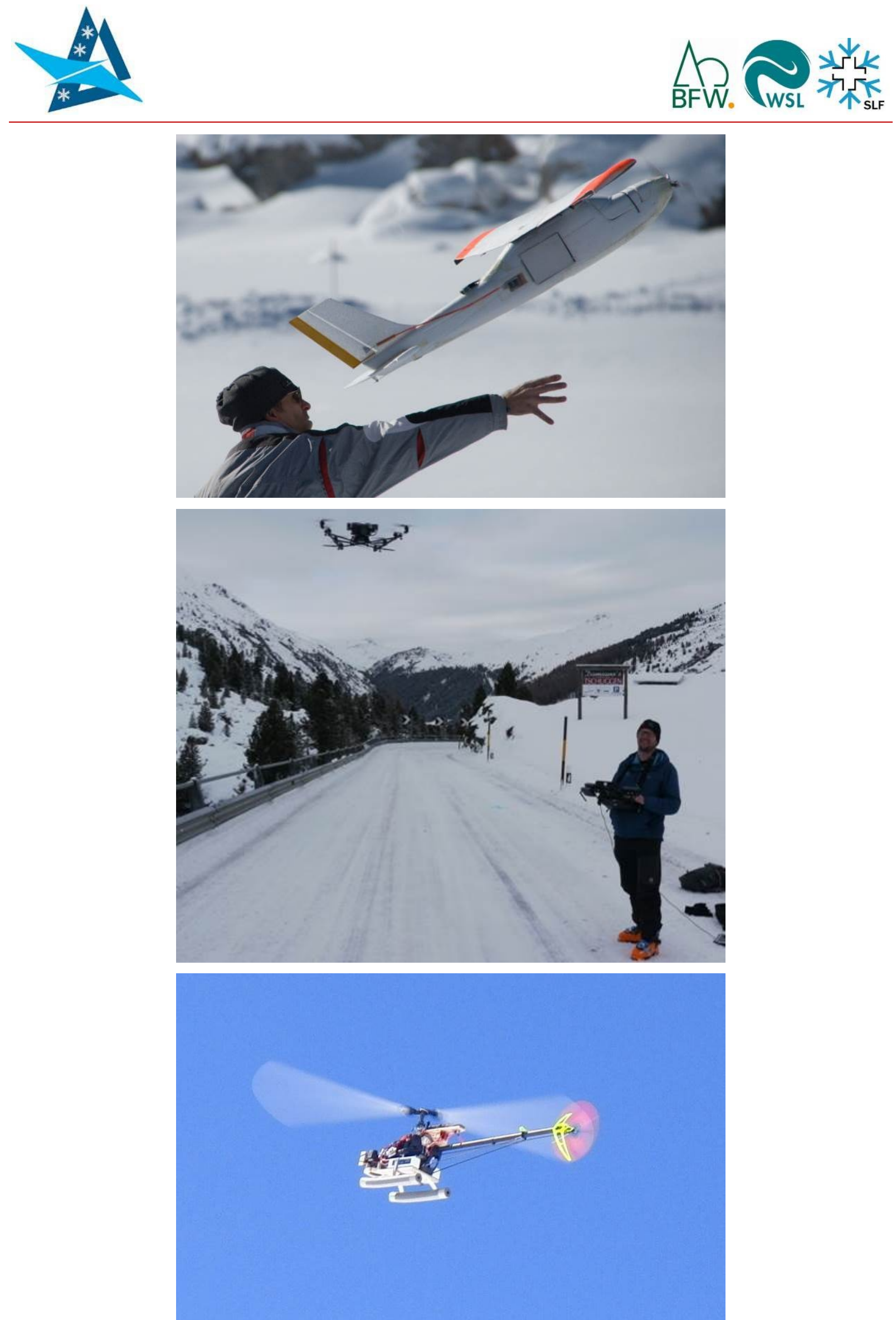

Figure 6: Different types of LASE RPAS platforms used in RPAS4SNOW, top - Multiplex Mentor fixed-wing; middle - AscTec Falcon 8 multicopter; bottom - Mikado Logo 600 SE helicopter. 


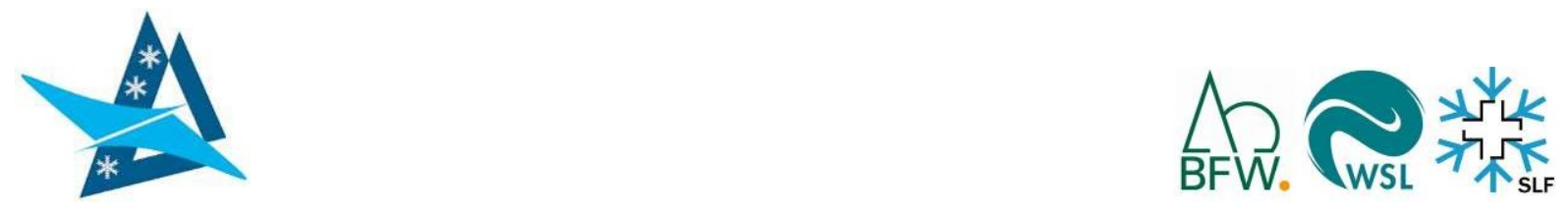

RPAS data acquisition was supported or entirely incurred by autopilot systems. These systems can be divided into two main components: hardware and software. The RPAS are equipped with an IMU, composed of an acceleration sensor, an absolute position transducer and a magnetometer, as well as a GNSS (Aber et al., 2010; Böhm et al., 2010), to determine the absolute (X, Y \& Z) and relative (roll, pitch \& yaw) position of the RPAS in space. Controlling and timing of the RPAS hardware was performed by the autopilot software, which also allowed the pre-flight mission planning. In the course of mission planning the flight path, flight height and flight speed were defined, as well as the camera trigger points. The flight data from all instruments was stored on-board the RPAS and synchronised with the recorded images after completion of the mission (geotagging), e.g. to facilitate the image-processing. All flights were conducted by experienced pilots, who were able to intervene at any time and manually pilot the RPAS. Previous flights by the BFW had proven the difficulties of automatic flight in alpine terrain, sometimes making an entirely manually conducted flight necessary (Sortier et al., 2013; Sortier et al., 2012). Both custom-built BFW-RPAS were operated with the 3DR ArduPilotMega, including an on-board GNSS/IMU and the associated software. The Falcon 8 was operated with the software provided by the manufacturer.

Due to the strongly increased utilisation of RPAS, national and transnational jurisdictions have been put into place, regulating their use (Watts et al., 2012). In the European Union the European Commission and the European Aviation Safety Agency are responsible for RPAS over a gross weight of $150 \mathrm{~kg}$. RPAS falling below this threshold are regulated on a national level. In Austria, an amendment of the aviation law (Luftfahrtgesetz) regulates the use of RPAS (Austro Control, 2013). Briese et al. (2013) provide a detailed description of the legislative situation in Austria. In Switzerland RPAS legislation is provided by the Federal Office of Civil Aviation. Legislative regulations from both countries were adhered to during RPAS4SNOW.

\section{Sensors}

The RPAS were fitted with different cameras: Sony NEX5(R) (fixed-wing), Sony NEX7 (multicopter) and Sony Alpha7R (helicopter). The choice of these sensors was based on their suitability for integration into RPAS (e.g. volume, interface, remote shutter release), sensor resolution and availability of prime lenses, essential to stable photogrammetric analysis. The following prime lenses were employed: $16,20,35,50 \& 55 \mathrm{~mm}$. Sensors in all three cameras where modified (i.e. the builtin long-pass filter removed), increasing the effective sensitivity of the standard sensors to the nearinfrared (NIR) part of the spectrum $(<1,200 \mathrm{~nm})$. Using changeable long- and shortpass filters, NIRimages ( $\lambda>770 \mathrm{~nm}$ and $\lambda>830 \mathrm{~nm}$ (Figure 7 , left)) as well as images in the visible light spectrum (VIS) (Figure 7, right), could be acquired. The achieved better response for wavelengths above $700 \mathrm{~nm}$ should be a significant advantage when measuring snow surface reflectance, mainly for transformed snow like firn, aged snow and ice (Figure 8). However, these images are not calibrated and therefore only give a rough impression of the reflectivity of the snow and vegetation in these wavelengths, as opposed to a fully-calibrated multispectral camera (Rabatel et al., 2014; Lebourgeois et al., 2008). It has been shown in the relevant literature, that NIR-sensitivity does however have advantages for snow (Bühler et al., 2015b) and vegetation (Tucker, 1979) analysis, as well as in diffuse light conditions (Bühler et al., 2016a). In RPAS4SNOW, we tested this for RPAS-data and 


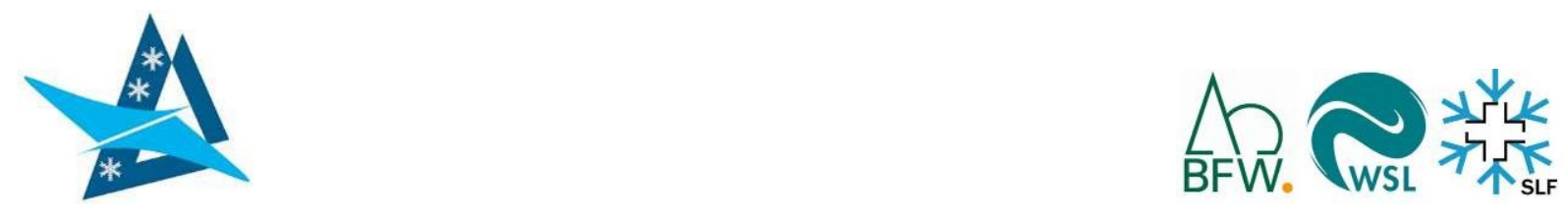

evaluated the impact on the quality of the results. The technical specifications of all cameras are listed in the Annex (Table 10).
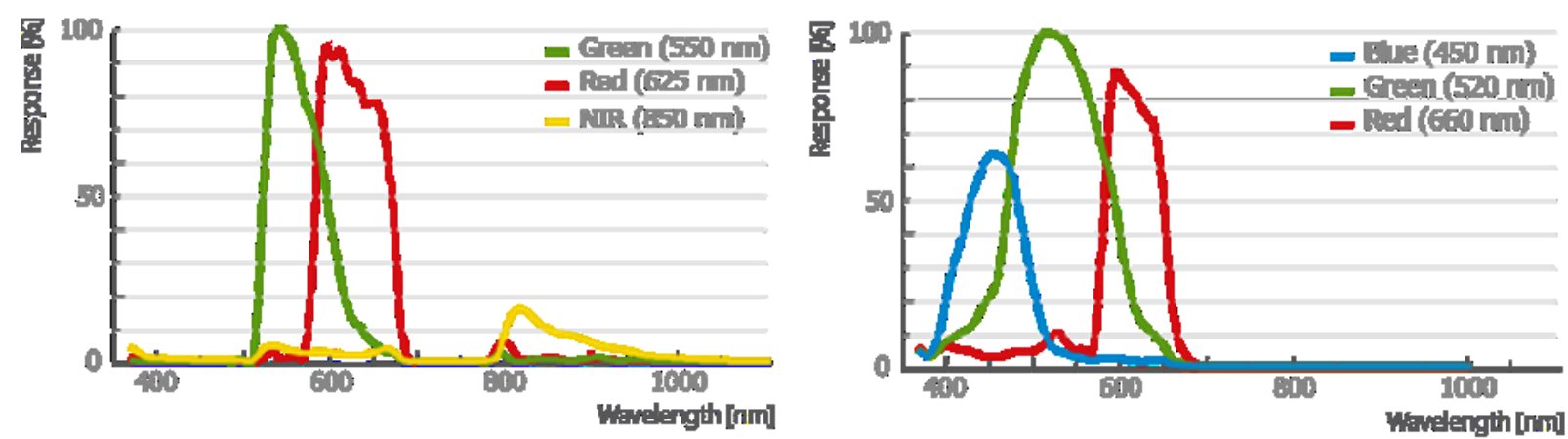

Figure 7: Spectral response of camera with NIR-filter (left) and VIS-filter (right).

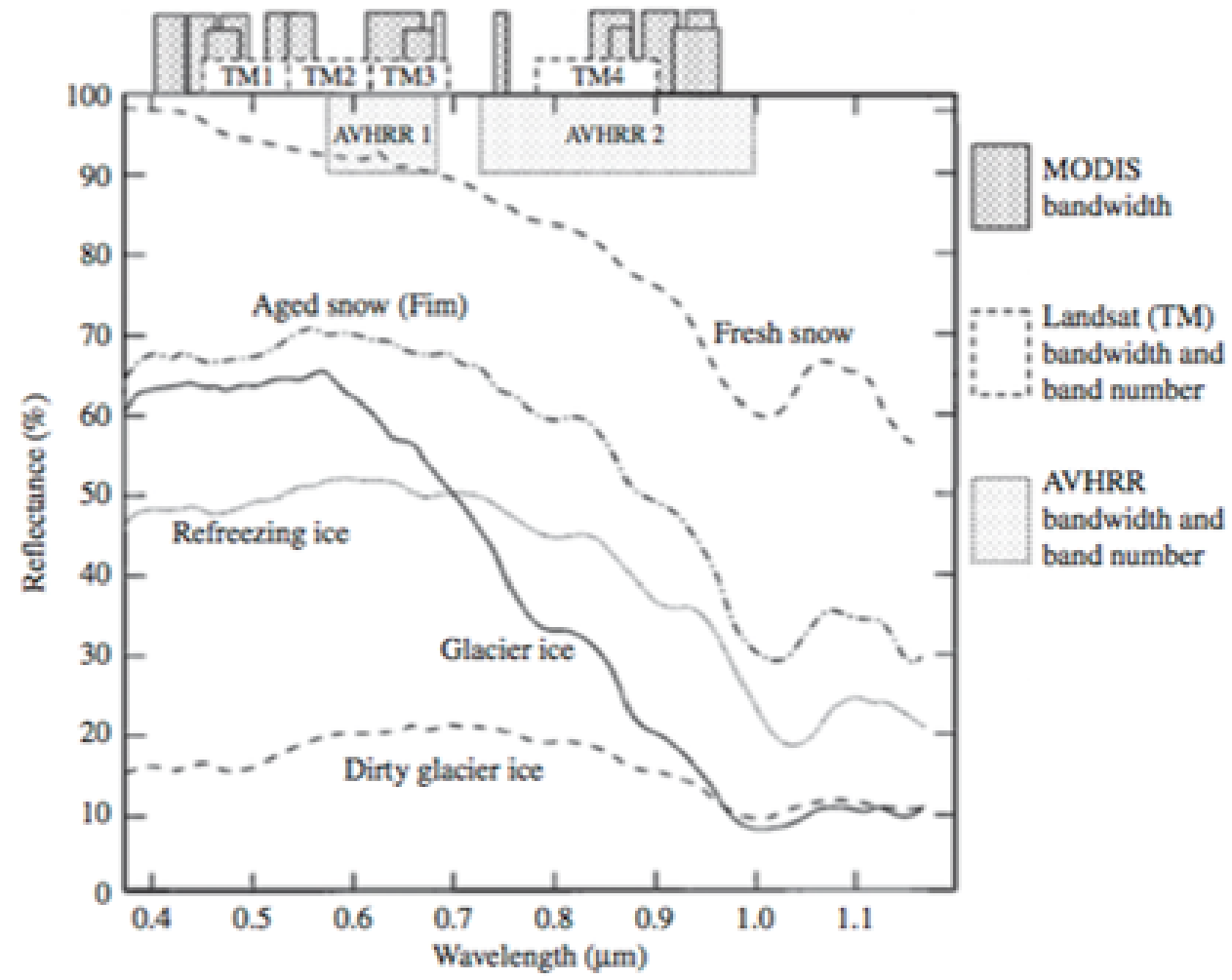

Figure 8: Reflectance of different surface types related to snow cover. The bandwidths of Landsat (TM), MODIS (M) and AVHRR are also integrated (Zeng et al., 1984, modified) (modified after Dietz et al., 2012 ).

\section{Terrestrial GNSS}

As the RPAS were not equipped with a high-quality (i.e. survey-grade) GNSS receivers to determine their location in space, or an adequately accurate IMU, indirect georeferencing with ground control had to be used (e.g. Nolan et al. 2015; Harwin et al. 2015). Prior to all RPAS-flights, GCPs consisting of $0.4 \times 0.4 \mathrm{~m}$ black and white checkered wooden boards or targets sprayed on the now surface (Figure 9), were distributed at predefined, undisturbed locations within the AOI (Figure 10). 


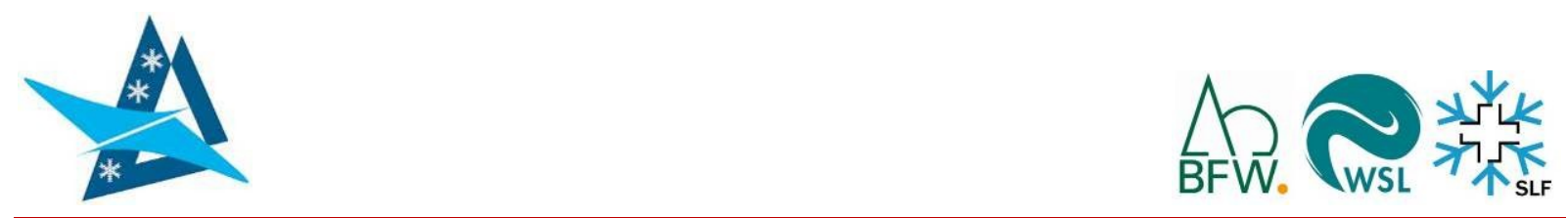

The location of the GCPs was recorded using different terrestrial GNSS instruments (Trimble GeoExplorer XT \& XH), equipped with external antennas (Figure 10). Real-time correction was used in the field and differential correction from the scripps orbit and permanent array centres in the vicinity of the study sites applied in the office via the Trimble software Pathfinder Office (Trimble, 2015). The final $x-, y-\&$ z-coordinates of each GCP were averaged from $>200$ points we recorded at each GCP location. Path Finder Office software estimates the horizontal and vertical precision for each GCP within one standard deviation $(\sigma)$ of the single measurements (Trimble, 2015). At the Austrian study site, we examined the accuracy of the Trimble-GNSS on 10 April 2015, by performing both GNSS and total station (Trimble M3) measurements of the GCPs with a prism. Due to its high accuracy $(2 \mathrm{~mm}+$ $2 \mathrm{ppm}$ distance dependent error), this state-of-the-art total station could be used to validate the GNSS-accuracy. The deviation between the results from both instruments was calculated and the root mean square error (RMSE) computed. Despite the very promising results from this comparison ( $0.06 \mathrm{~m}, 0.12 \mathrm{~m}$ and $0.22 \mathrm{~m}$ RMSE in $\mathrm{x}-, \mathrm{y}$ - and z-direction, respectively), the overall uncertainty using the GCP data from the GNSS proved too high and resulted in implausible HS maps. Alternatively, the heights of the GCPs used for referencing the snow-free RPAS-DSM, were extracted from the available ALS data (TIRIS, 2016). Natural GCPs were selected, which were snow-free during all winter flights (roof gables, flat stones, etc. - Figure 11) and their heights derived from the high-resolution snowfree RPAS-DSM. Thus, the snow-covered data could be referenced using a stable set of GCPs, ensuring minimal systematic error introduced by the GCP-procedure.
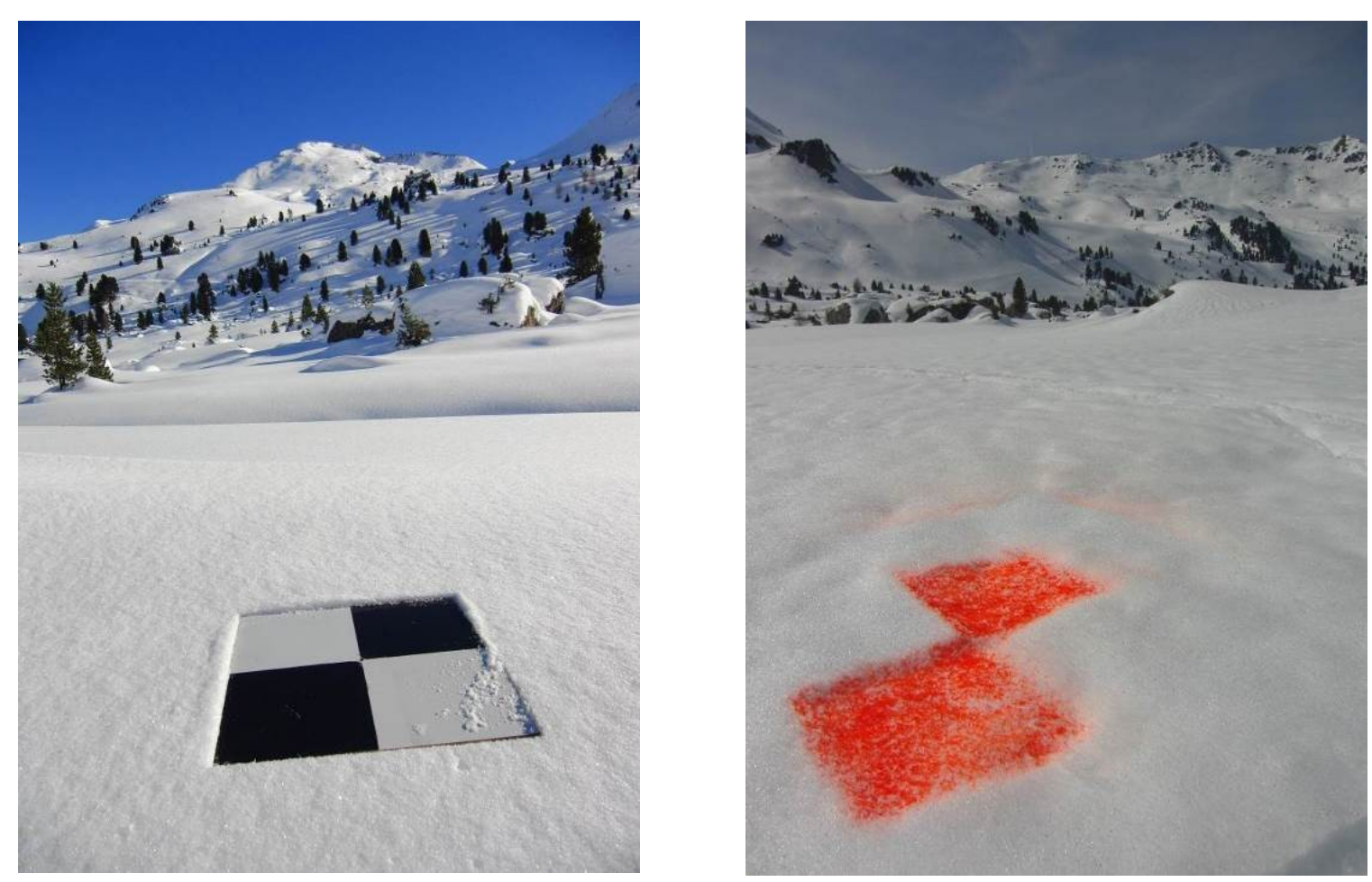

Figure 9: Ground Control Points used at the Austrian study site (left - classical photogrammetric plate; right target sprayed onto snow surface with template). 

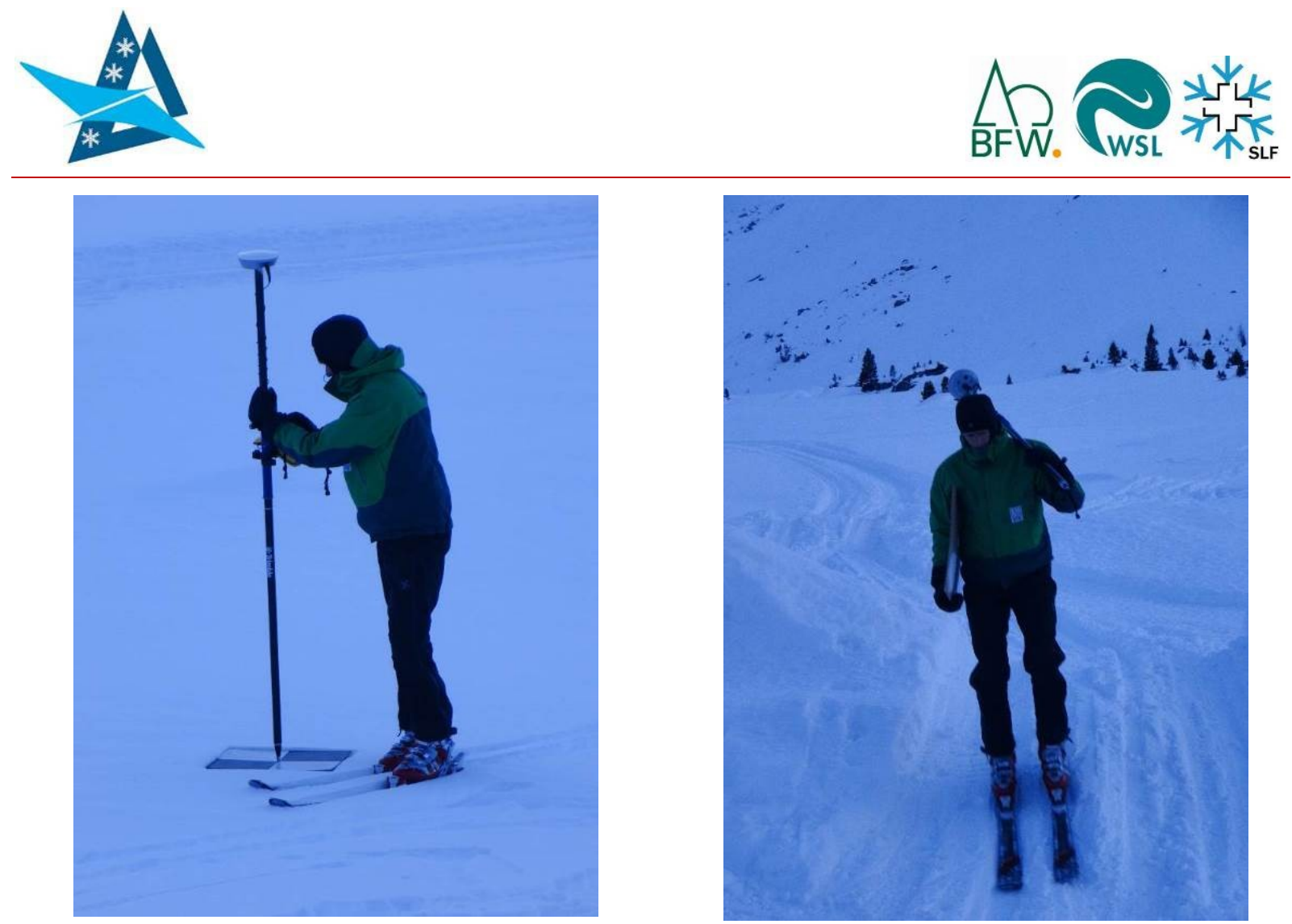

Figure 10: GNSS-measurements at the Austrian study site on 13 Feb 2015.
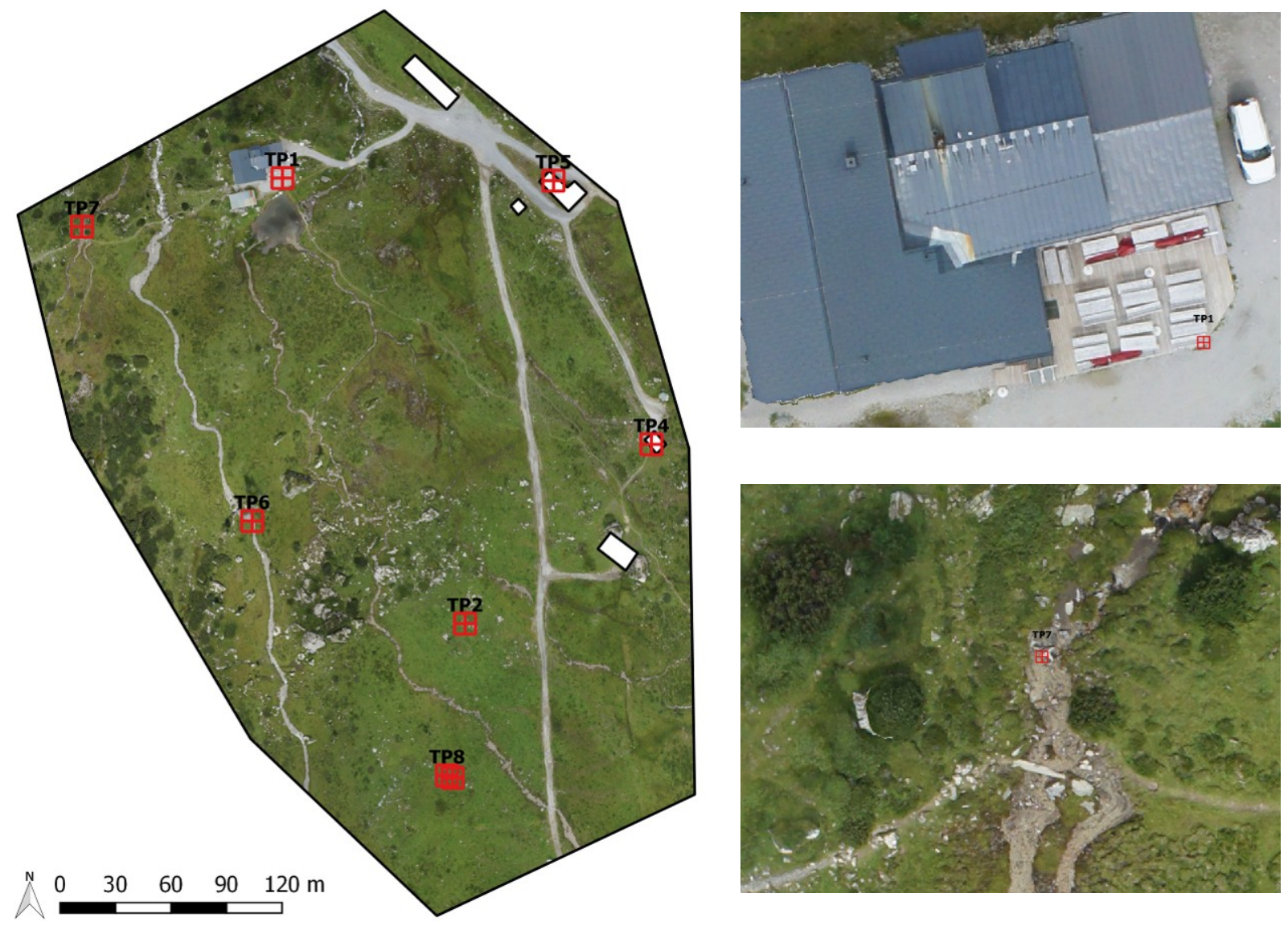

Figure 11: GCPs used for georeferencing at the Austrian study site (Tie Point - TP1-8); distribution within the RPAS-AOI (left); detail of TP1 \& TP7 location (right) - both against the snow-free RPAS OP. 


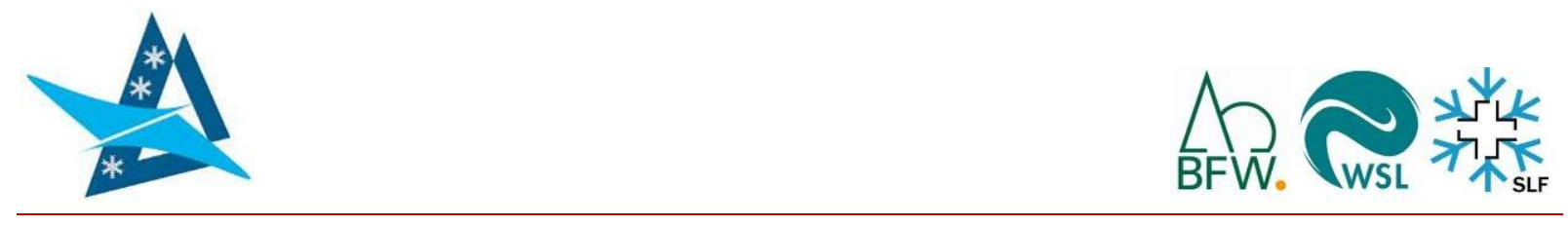

\subsection{TLS}

In the course of RPAS4SNOW, the BFW employed two long-range TLS instruments to collect validation data: the Riegl LPM-321 \& LPM 98-2k. Figure 12 shows the scanners in operation during two measurement campaigns. The scanners' technical specifications are included in the Annex (Table 11). The more recent TLS-instrument (LPM-231), is capable of delivering point measurements in a distance of up to $6 \mathrm{~km}$, reaching a sampling rate of up to 1,000 points per second at a typical accuracy of $\pm 0.025 \mathrm{~m}(1 \sigma)$, plus a distance dependant error of $\leq 20 \mathrm{ppm}$, implying that in a range of $1,000 \mathrm{~m}, 95.4 \%$ of the data can be recorded with an accuracy of $\pm 0.07 \mathrm{~m}$ (Prokop et al., 2013; Grünewald et al., 2010; Riegl, 2008). The scanner was controlled using the software RiPROFILE, provided by the manufacturer and operated at a wavelength of $905 \mathrm{~nm}$. This scanner was used for an initial scan of the study site on 9 Jan and 11 Feb 2015. As the LPM-321 was not available for the whole winter, we subsequently installed the LPM 98-2k at the test site in a fixed, weatherproof transparent glass fibre enclosure. The LPM 98-2k measures at a lower scan rate, range and accuracy than the LPM-321 ( $\leq 4 \mathrm{~Hz}$, range $<2,500 \mathrm{~m}$; accuracy $\pm 0.05 \mathrm{~m}(1 \sigma)$, plus a distance dependant error of $\leq 20 \mathrm{ppm}$ (Adams, 2008; Prokop, 2008; Sailer et al., 2008)). However, it could be set up to automatically acquire scans from the study site at given intervals with a software developed at the BFW, while a remote connection allowed changing the properties of these scans from the office. This enabled the authors to reduce the manpower required for the fieldwork and to generate a large pool of TLS-data for validation (Figure 4). The LPM 98-2k acquired 32 scans between 13 Feb and 21 May 2015. For a detailed description of the BFW's automated TLS setup, the reader is referred to Adams et al. $(2015,2013)$ and Gigele et al. (2013).
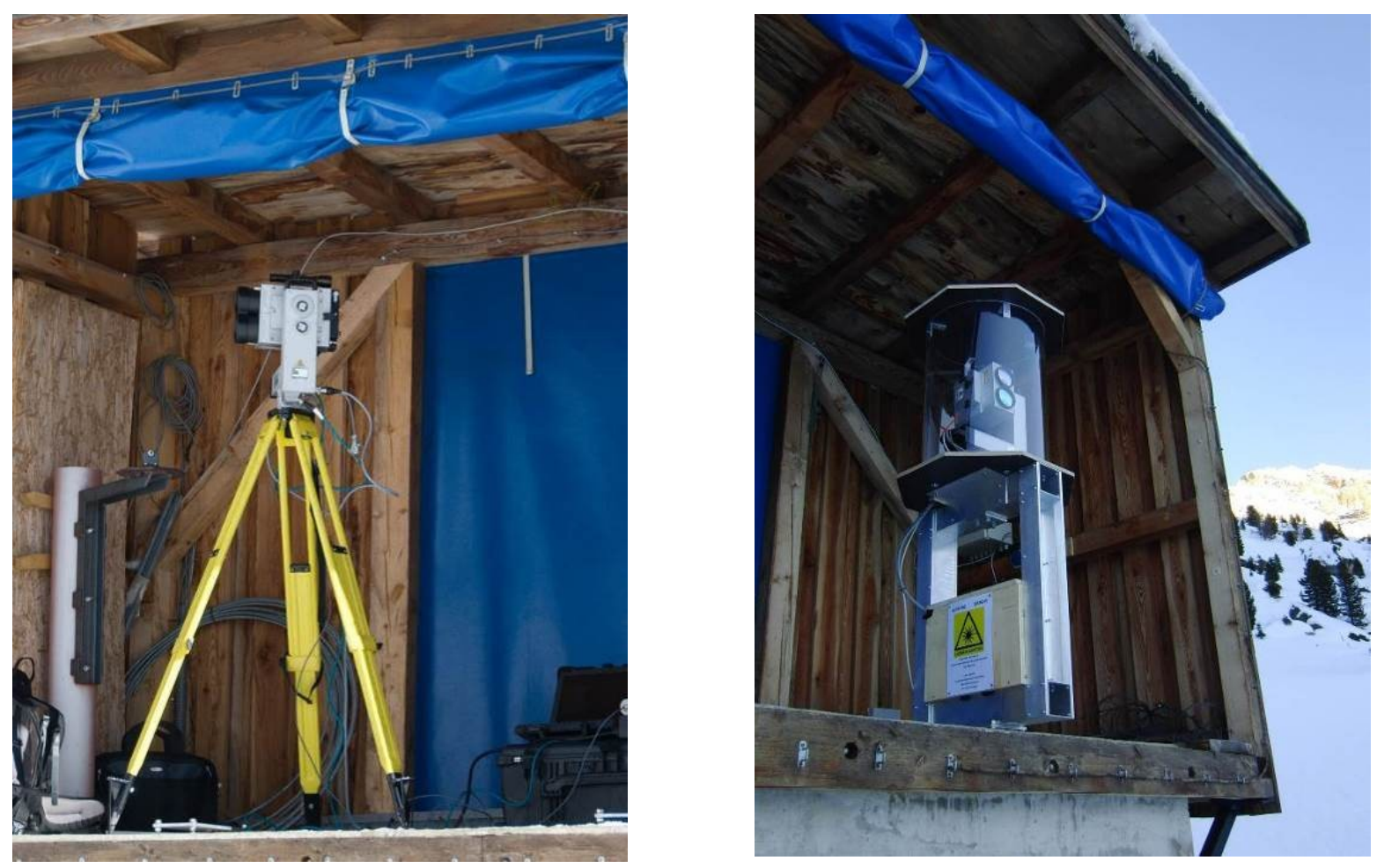

Figure 12: Riegl LPM-321 (left) and LPM 98-2k (right) in operation for snow depth monitoring at the Austrian study site on 11 Feb 2015 and 13 Feb 2015, respectively. 


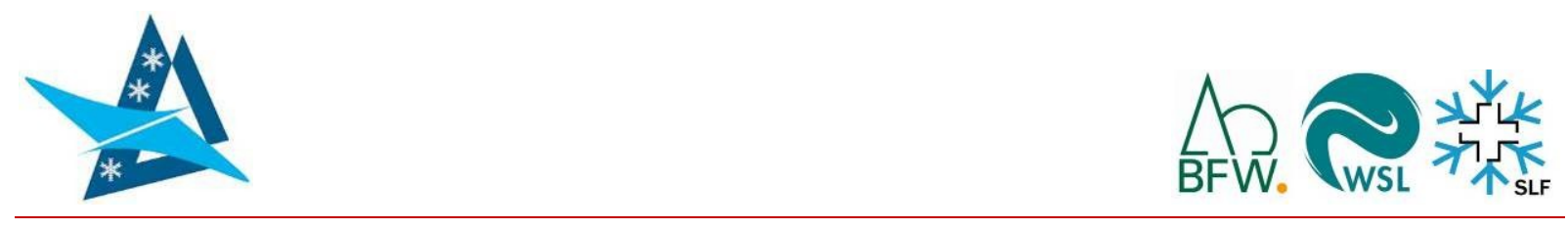

The TLS instruments were located at an elevated position over the valley, set to scan the valley bottom in a single scan window (Figure 13). However, unfavourable geometry of the measurement setup and the inherent scanning routine of the instruments caused some occlusions, especially in the western section of the study site, and inhomogeneous point distances (e.g. 0.05-0.1 m in $10 \mathrm{~m}$ and 0.3-0.4 $\mathrm{m}$ spacing in $300 \mathrm{~m}$ distance from the scanner). Of the total 34 TLS-scans, four were selected for validation of the RPAS-data, based on temporal proximity to RPAS-campaigns, quality and completeness of the scans. Details of these scans are summed up in Table 1. The number of measured TLS-points was reduced during post-processing ('AOI' column), to minimise this bias in the validation procedure (as described in Chapter 0 ). The columns 'point distances', provide descriptive statistics of the unfiltered point cloud, with mean values in the range of RPAS-OP ground sampling distance (GSD) (0.2 m).
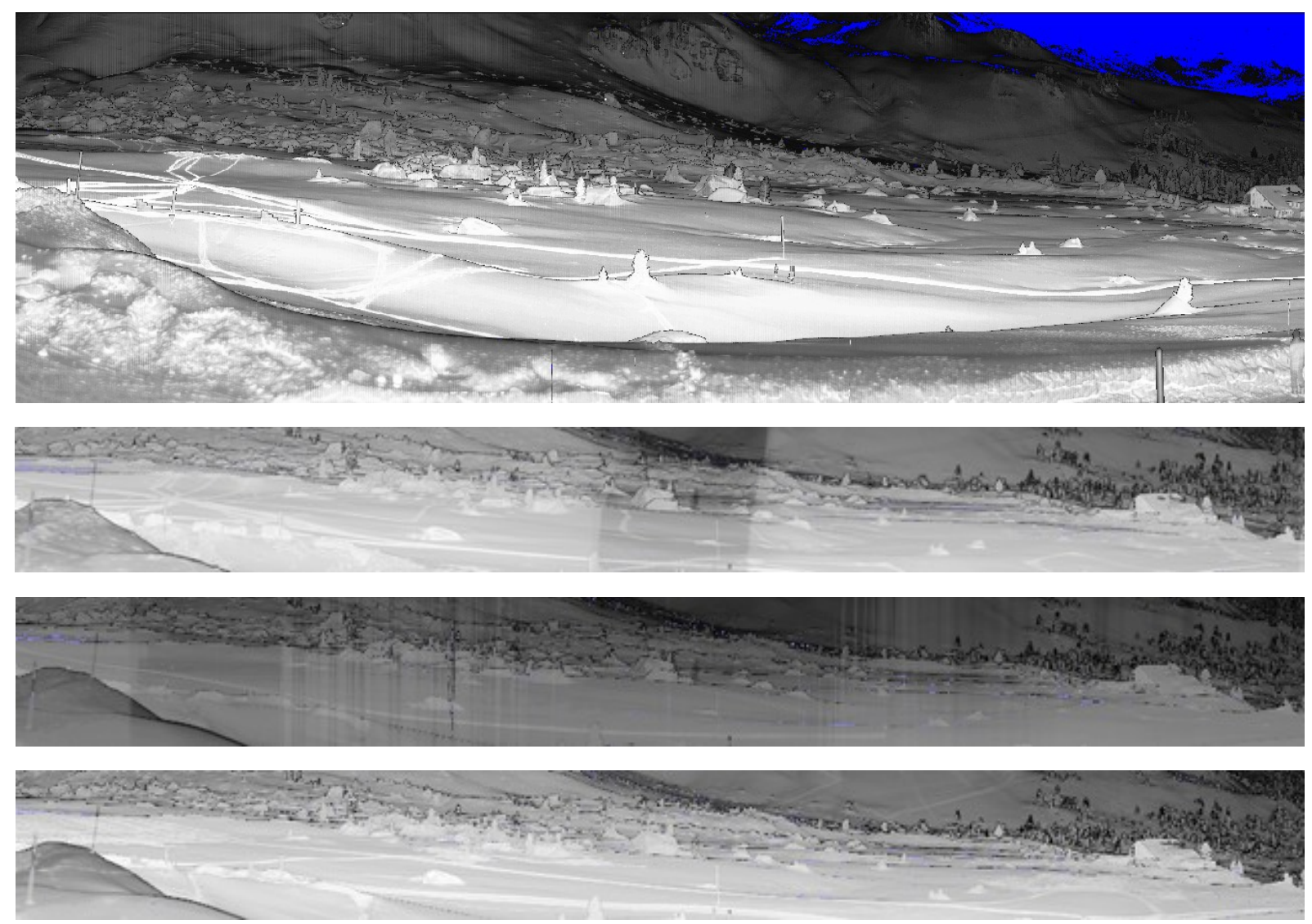

Figure 13: Greyscale intensity plots of the TLS-measurements used for validation - the darker the grey, the lower the amount of energy received at the TLS instrument (blue pixels = NoData); top to bottom - 11 February 2015, 14 February 2015, 3 March 2015 \& 11 March 2015.

Table 1: Details on the TLS-scans of the valley floor used for validation in RPAS4SNOW.

\begin{tabular}{|c|c|c|c|c|c|c|c|c|c|c|c|}
\cline { 2 - 12 } \multicolumn{1}{c|}{} & \multicolumn{3}{c|}{ Scanner Settings } & \multicolumn{3}{c|}{ Number of Points } & \multicolumn{4}{c|}{ Point Distances [m] } & \multicolumn{2}{c|}{ Standard } \\
\hline Date & Instrument & Resolution X & Resolution Y & Total & AOI & Filtered & Mean & Minimum & Maximum & Stand. Dev. & Deviation Residues \\
\hline 11.02 .2015 & LPM-321 & $0.063^{\circ}$ & $0.063^{\circ}$ & 828,576 & 271,511 & 171,983 & 0.13 & 0.001 & 5.46 & 0.10 & 0.07 \\
\hline 14.02 .2015 & LPM 98-2K & $0.054^{\circ}$ & $0.054^{\circ}$ & 446,276 & 268,155 & 183,064 & 0.16 & 0.001 & 8.77 & 0.12 & 0.11 \\
\hline 03.03 .2015 & LPM 98-2K & $0.107^{\circ}$ & $0.108^{\circ}$ & 114,790 & 63,077 & 56,766 & 0.29 & 0.001 & 9.68 & 0.21 & 0.07 \\
\hline 11.03 .2015 & LPM 98-2K & $0.107^{\circ}$ & $0.108^{\circ}$ & 114,789 & 69,371 & 57,298 & 0.26 & 0.001 & 20.64 & 0.22 & 0.11 \\
\hline
\end{tabular}




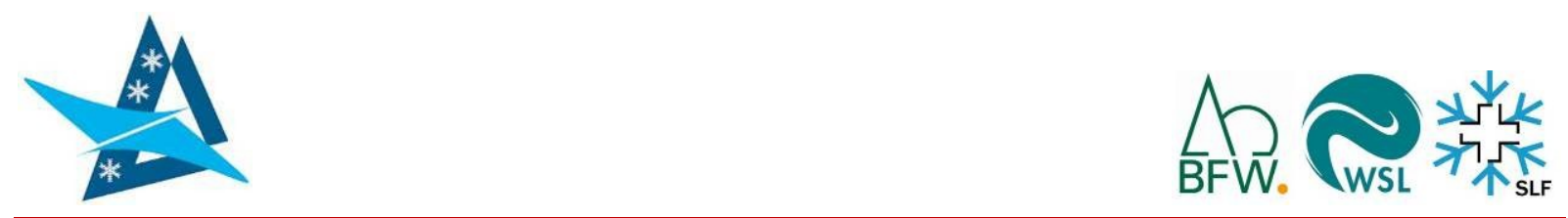

The routine to georeference the TLS-data consisted of consecutively scanning five targets before and after each scan (Figure 14, left). These targets, consisting of $0.3-1 \mathrm{~m}$ rectangular aluminium plates, coated with highly reflective material, were installed in the target area prior to the measurement campaigns (Figure 14, right). Their position was determined with a total station (Trimble M3).
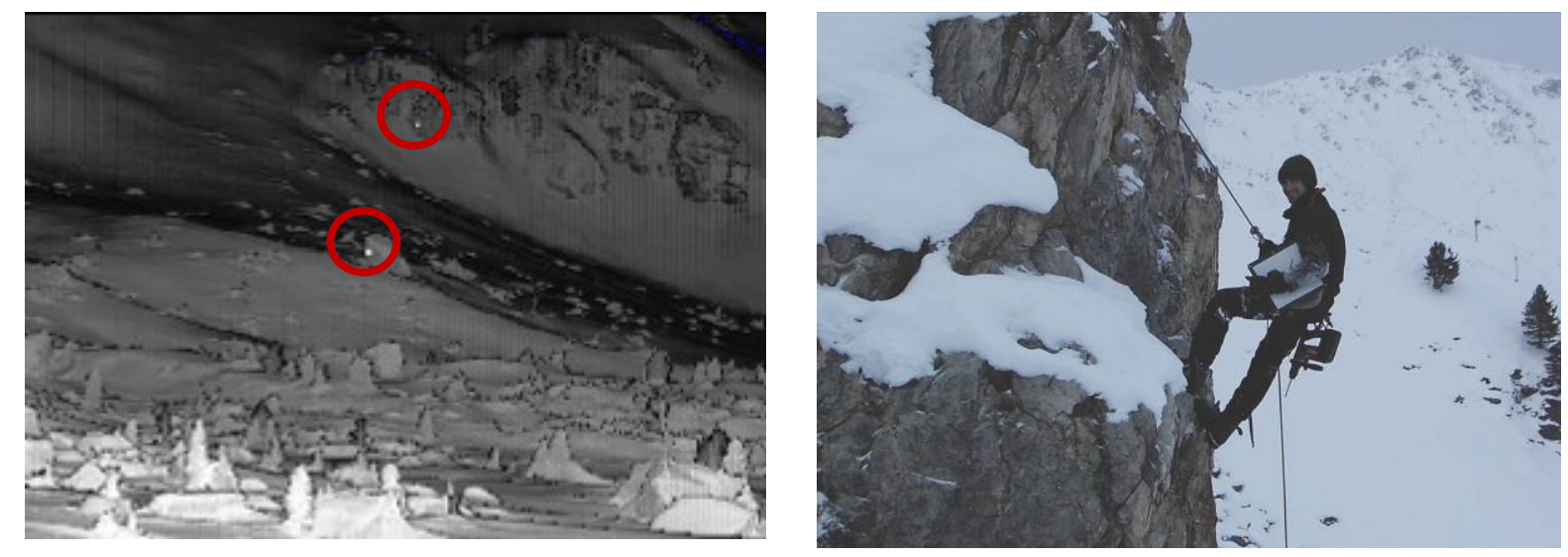

Figure 14: Reflective target showing up in TLS intensity plot as white spots (red circles) (left); installing a TLStarget at the Austria study site (right).

\subsection{Large Frame Aerial Sensors (LFAS)}

The airborne digital pushbroom scanner ADS80 (Leica Geosystems) is able to acquire high spatial resolution imagery with a dynamic range of 12 bits in five spectral bands. It has been used in previous campaigns by the WSL/SLF (e.g. Bühler et al., 2009; Ginzler et al., 2013) and allows a direct comparison of low-cost RPAS and manned high-cost aerial imagery data collection. The accuracy of this technique was assessed by Ginzler et al. (2013) and showed a high correlation coefficient $(R=$ 0.95 ) with in-situ measurements performed on the same day as the airborne campaign. For details the reader is kindly referred to Boesch et al. (2015).

\subsection{Manual probing / in-situ measurements}

In-situ measurements of the snow depth were performed in the Swiss and Austrian study sites (Figure 4). The measurements were conducted by manually sounding the snow cover with an avalanche probe at defined intervals along several transects (Figure 15). At each stop, five measurements were performed, by probing all four corners and the centre of a square $(2 \mathrm{~m} \times 2 \mathrm{~m})$. The snow depth was recorded to the nearest centimetre. Additionally, a GNSS was used to record the coordinates of the central snow depth sounding location (Garmin GPSMap 64s). Examples for the distribution of manual measurement locations within two study sites are provided in Figure 16. 

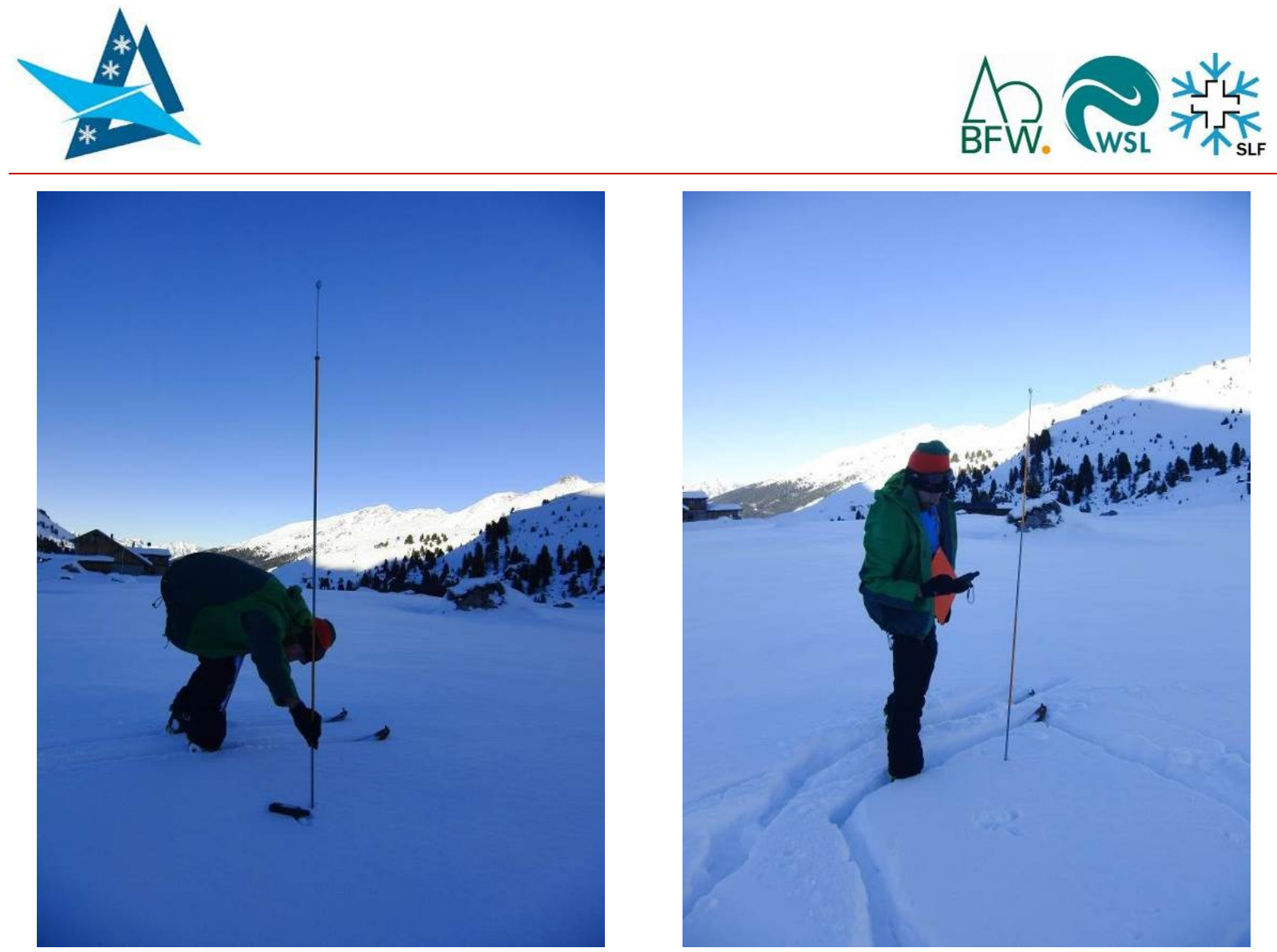

Figure 15: In-situ snow depth measurements at the Austrian study site on 11 Feb 2015.
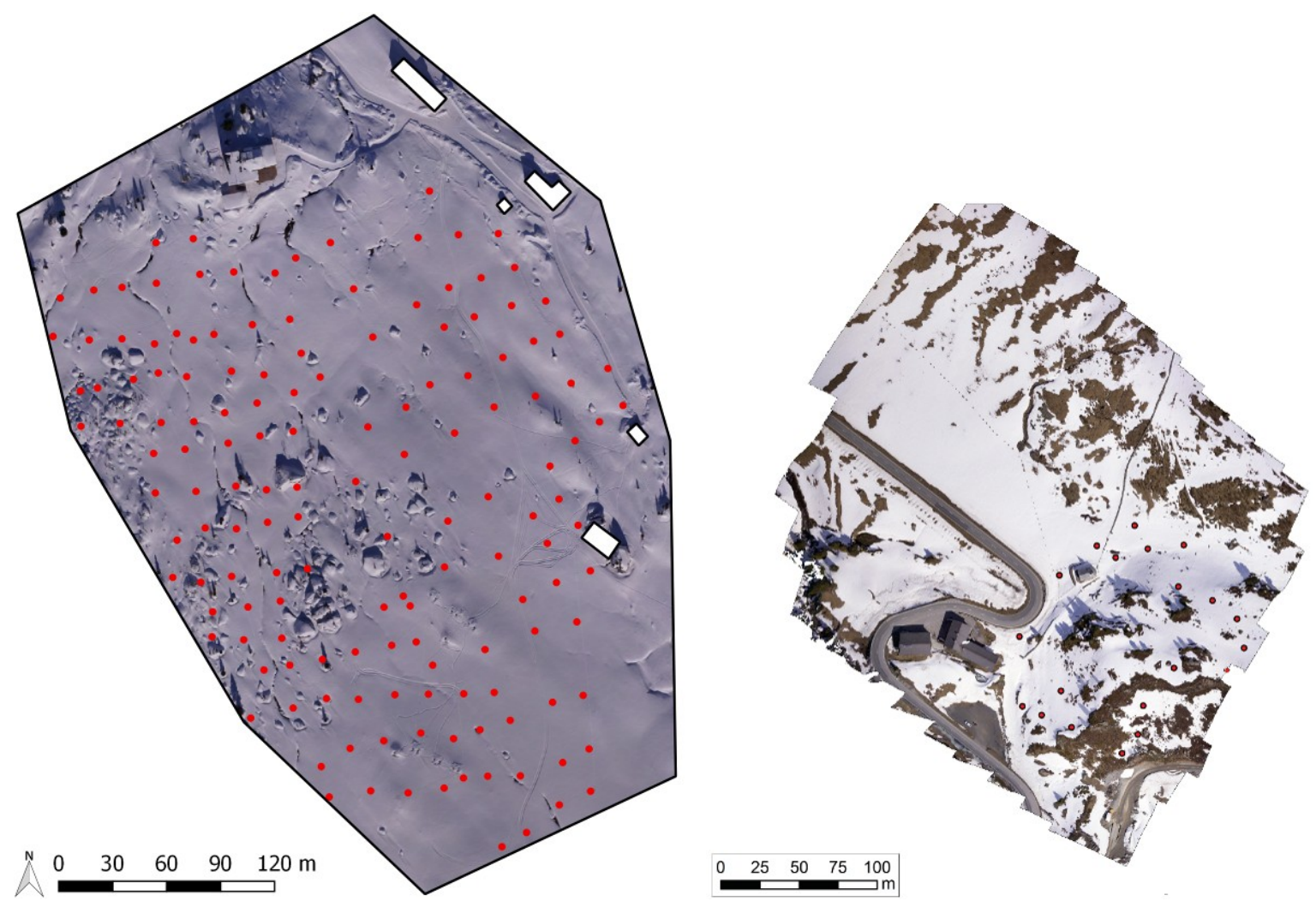

Figure 16: Position of manual snow depth validation measurements (red dots) at study sites Lizum on 11 March 2015 (left) and Tschuggen on 24 April 2015 (right); in the background the respective UAS-OP. 


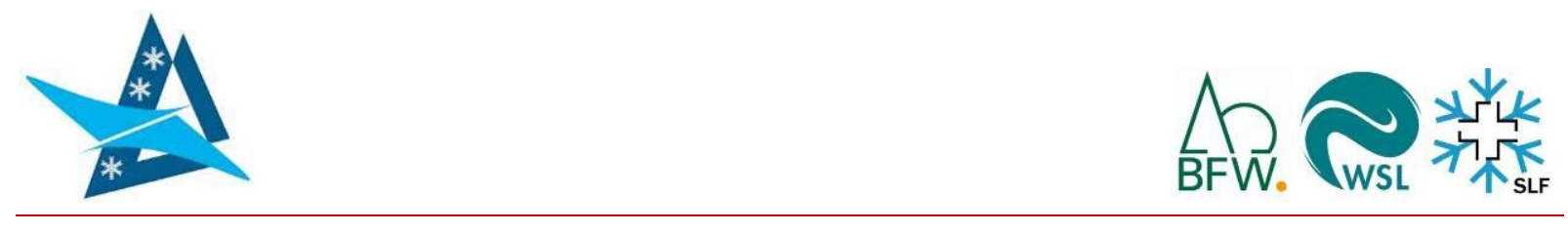

The AWS close to the RPAS target area provides hourly measurements of HS (ultrasonic sensor), temperature (air and snow surface), wind (average and peak speed / direction), solar radiation, as well as air pressure and moisture (Table 2). This data was mainly used to estimate how representative the AWS-location is for HS measurement at the study site. In further leading studies the AWS could also provide input for a sensitivity analysis to check whether the accuracy of the RPAS is linked to any of the meteorological parameters.

Table 2: Example of meteorological data recorded by the Lizum AWS (11 February 2015).

Station 1 - Wattener Lizum - Fernerkundung - 2041m

Mittwoch, 11.02.2015

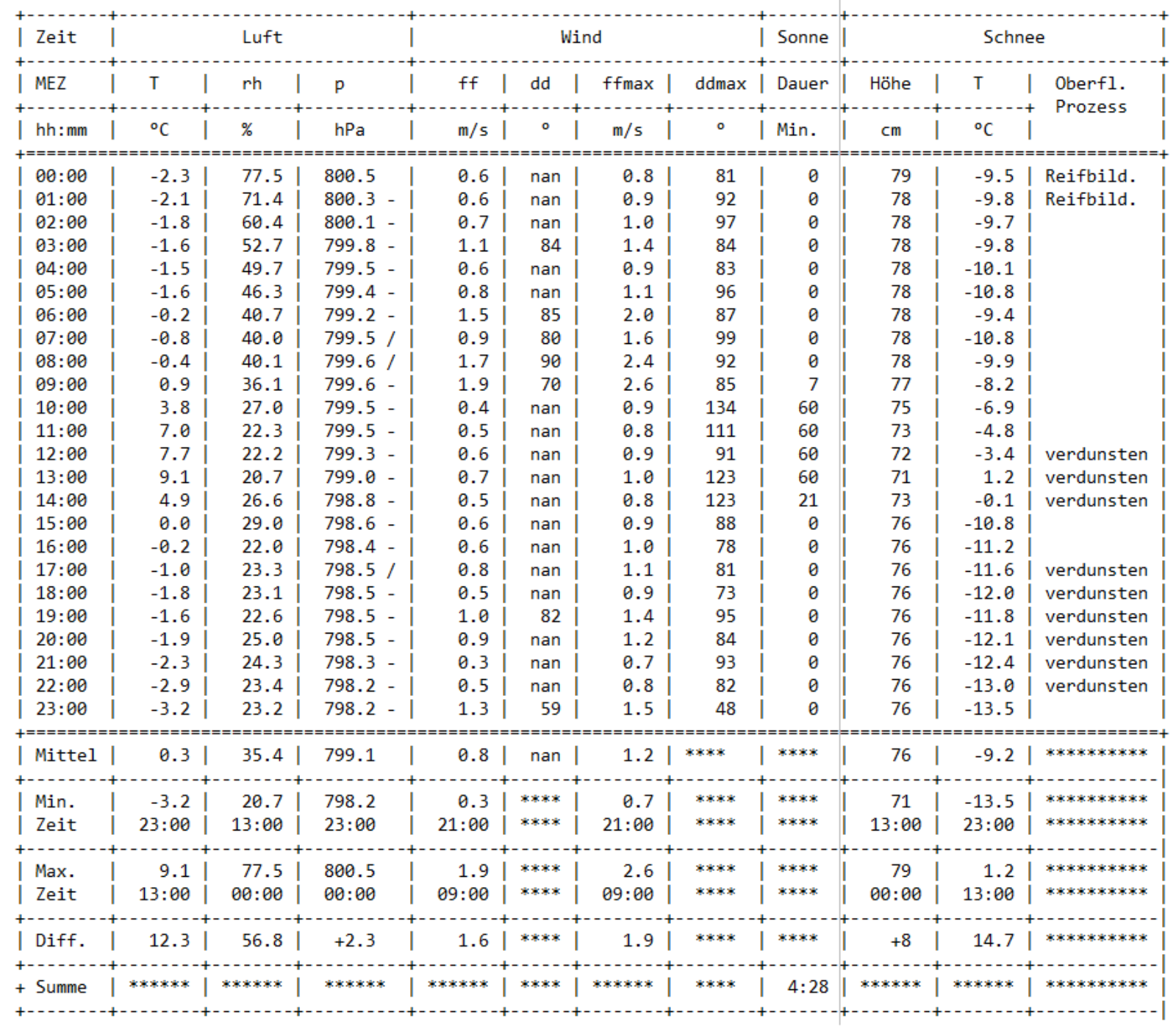




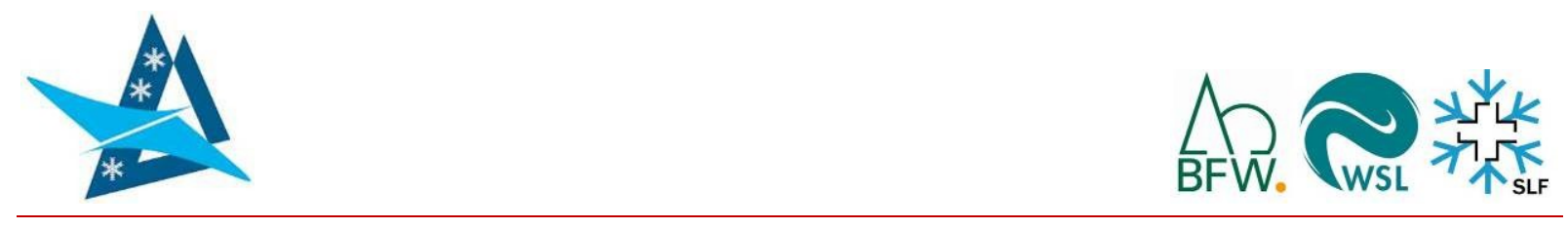

\section{$4 \quad$ Data Processing and Analyses}

\subsection{Photogrammetry}

All UAS-images were processed with Agisoft's PhotoScan Pro (PSP) (version 1.2.3) (Agisoft LLC, 2016), a commercially available photogrammetric software suite, that is widely spread in the UAScommunity (Tonkin et al., 2014). PSP is credited to be among the most reliable (Sona et al., 2014), accurate (Gini et al., 2013), effective (Mancini et al., 2013) and up-to-date (Colomina \& Molina, 2014) software packages available for this task. It is based on a structure-from-motion algorithm (Verhoeven, 2011; Koenderink \& van Doorn, 1991) and provides a complete, photogrammetric workflow, with particular emphasis on multi-view stereopsis (Harwin et al., 2015). This workflow consists of the following steps: i) tie point matching; ii) bundle adjustment (here constrained by assigning high weights to the GCP coordinates - known as indirect georeferencing or conventional aerotriangulation (Vander Jagt et al., 2015)); iii) linear seven-parameter conversion; removal of nonlinear deformations; iv) dense point cloud (DPC) generation with multiview stereo reconstruction; v) export of georeferenced OPs and DSMs. DSMs were recorded both in snow-free and snow covered conditions. The calculate the snow depth for each pixel, the snow-free DSM was subtracted from the snow-covered DSM. We referenced all data to the respective standard national coordinate systems (EPSG-Code 31254, Gebrauchshöhen Adria).

\section{Scripting}

\section{Description and motivation of scripting in PSP}

A script language is written for a special run-time environment and can be executed automatically or by a human operator. In the most cases, it is an interpreter language rather than a compiled code. Primitives are usually the elementary tasks or Application Programming Interface (API) calls, and the language allows them to be combined into more complex programs.

Scripting ensures that exactly the same procedures are applied to different data sets. Interaction by a user on the other hand may introduce errors or uncertainties, while executing repeated routines. Dozens of such calls are required for photogrammetric data processing, and several of these procedures run for hours. Scripting avoids time loss caused by waiting for data entry by the user. Minimising run-time for data processing and ensuring consistent data processing are thus the main advantages for scripting in this context. Most of the RPAS data acquisitions in Austria were executed with a fixed-wing RPAS. The photos were taken in a constant interval (about 0.8 seconds). During a flight over 20 to 30 minutes, on average 1,600 images were recorded. Thus, the automated routine allowed efficient processing of the approximately 42,000 images within a reasonable timespan.

\section{Basics of scripting in PSP}

PSP allows scripting by using the Python environment. The user can start only a routine inside PSP. This limits the development of more sophisticated algorithms or requires investing additional time to create work-arounds. 


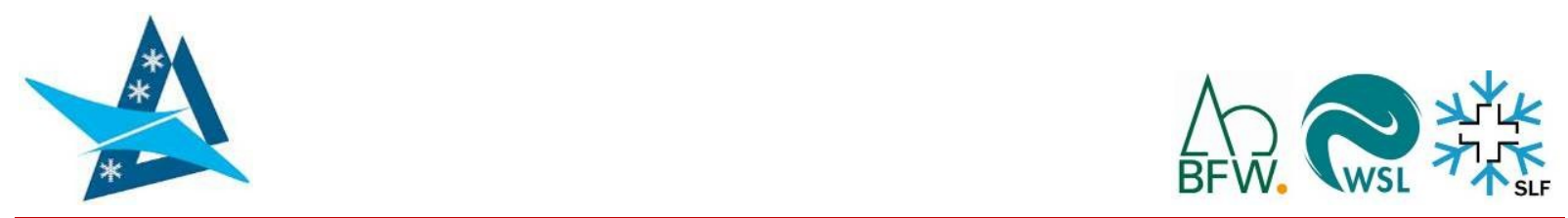

The following PSP functionalities can be accessed from Python scripts (Agisoft LLC, 2016):

- Open/save/create PSP projects

- Add/remove chunks, cameras, markers

- Add/modify camera calibrations, ground control data, assign geographic projections and coordinates

- Perform processing steps (align photos, build dense cloud, build mesh, texture, decimate model, etc.)

- Export processing results (models, point clouds, textures, OPs, DSMs)

- Access data of generated models, point clouds, images

The below example from PSP illustrates the main processing steps on an already existing PSP project (Figure 17). The script first loads the PSP library; a document is then created and the project loaded into the document; thereafter the chunk of the document is used for several procedures. These procedures represent the main steps of the workflow in the PSP software. At the end of the script, the results are saved back into the file.

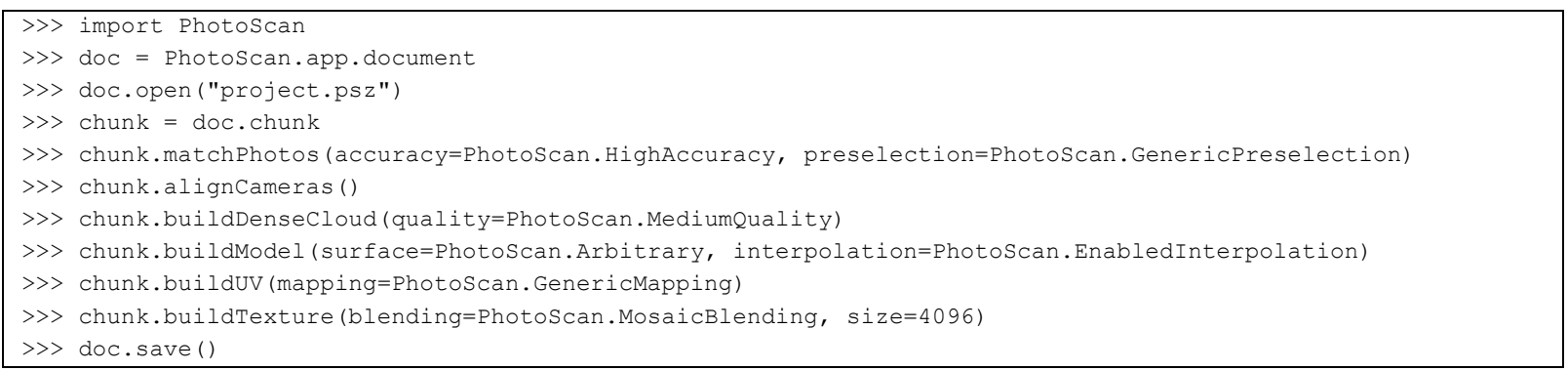

Figure 17: Example for a simple script in PSP (Agisoft LLC, 2016).

\section{Tasks for our applications}

Pre-processing of the RPAS-images includes erasing irrelevant imagery (captured during start / landing phase) or poor quality images (e.g. blurry, overexposed). While the user is easily able to manually delete irrelevant images, the identification of poor quality images of snow surfaces without any structure is more challenging. In RPAS4SNOW we therefore tried to find an independent index or feature, in order to classify the image quality, but without success. However, we found that the image quality index (QI) - available within PSP - is an acceptable identifier for our purpose.

Therefore, a pre-processing script was developed, which calculates the QI for each photo and displays the frequency distribution of the photo series (Figure 18). Firstly, the overall quality of the acquisition can be estimated; secondly, the histogram helps to determine a threshold for the QI, which allows differentiating between acceptable and unacceptable images. 


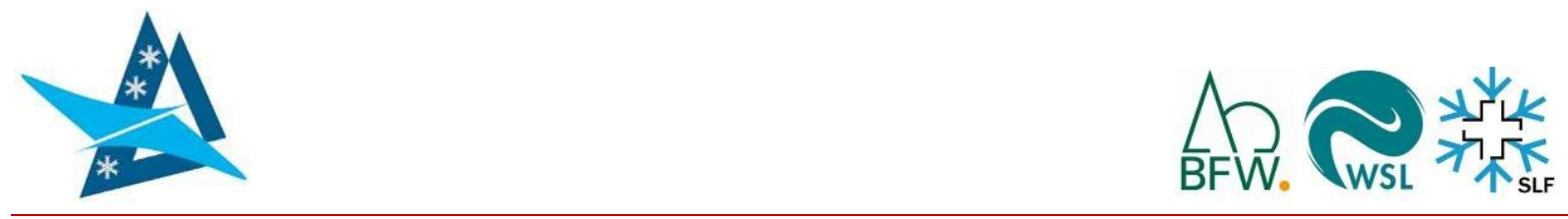

\begin{tabular}{|c|c|c|c|}
\hline \multirow{2}{*}{ ID } & \multicolumn{2}{|c|}{ Range } & \multirow{2}{*}{ Frequency } \\
\cline { 2 - 4 } & from & to & \\
\hline 1 & 0 & 0.55 & 0 \\
\hline 2 & 0.55 & 0.58 & 2 \\
\hline 3 & 0.58 & 0.61 & 6 \\
\hline 4 & 0.61 & 0.64 & 40 \\
\hline 5 & 0.64 & 0.67 & 47 \\
\hline 6 & 0.67 & 0.7 & 75 \\
\hline 7 & 0.7 & 0.73 & 136 \\
\hline 8 & 0.73 & 0.76 & 212 \\
\hline 9 & 0.76 & 0.79 & 336 \\
\hline 10 & 0.79 & 0.82 & 157 \\
\hline 11 & 0.82 & 0.85 & 27 \\
\hline 12 & 0.85 & 0.88 & 2 \\
\hline 13 & 0.88 & 0.91 & 0 \\
\hline
\end{tabular}

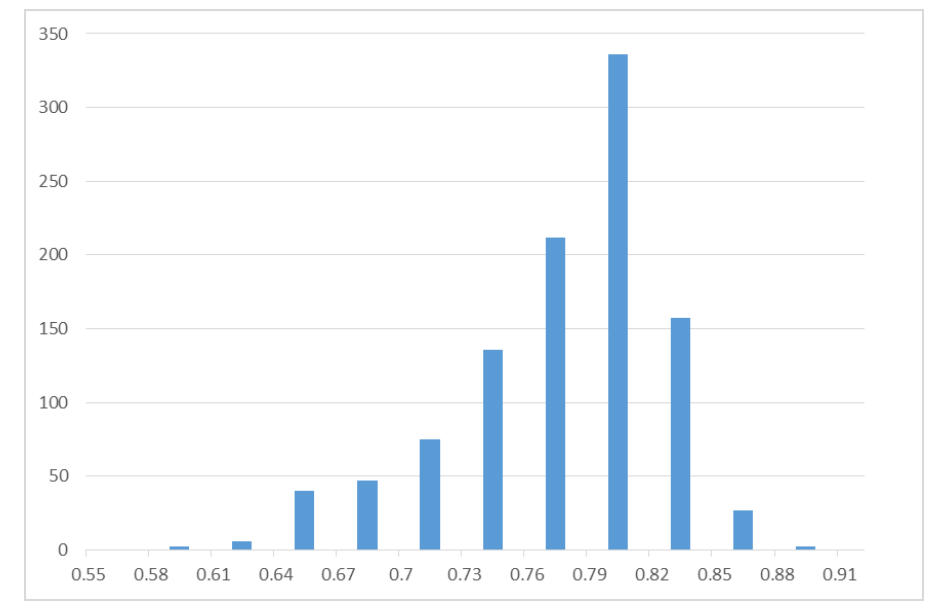

Figure 18: Example of a histogram for the QI of images collected on 13 Feb 2015 (flight 1).

In the first step of the photogrammetric workflow, a script loads photos from a single flight and creates a chunk. Photos with a QI below a threshold defined by the user (based on the above histogram results) are deleted. PSP identifies unique structures in the chunk. Using this information, the photos are aligned and matched. The sparse point cloud is generated, which contains the location of these structures. An optimisation is executed, which reduces the number of points in the sparse point cloud. Step 1 is completed by saving the project the PSP-project.

Now, user interaction is required. The position of the GCPs must be set in the photos and the corresponding coordinates acquired by GNSS entered into PSP. After placing a certain GCP, PSP displays only those photos, where that GCP is also located, according to the triangulation results from the previous step. The location of each GCP in the respective images must be checked before continuing.

The second step a script calculates the DPC and mesh; the surface texture is built and tiled; finally, DSM and OP are calculated and exported. The second step is completed by again saving the PSPproject.

A further issue during the photogrammetric workflow is how to deal with outliers in the sparse and DPCs. Outliers may be generated by PSP, in case of misaligned or blurry source images. To exclude extreme outliers in the sparse point cloud, a bounding box may be defined, limiting the points available to subsequent procedures. However, the points inside this box (i.e. points closer to the correctly matched points) may be difficult to identify. The problem arises in the first step, where the geometry is not yet scaled. Therefore, the approach to remove points with atypical distances to neighbouring points (especially in vertical direction) is not possible by defining a distance threshold. In addition, the run-time for the calculation of the minimal distances between all points is very long. Our solution in RPAS4SNOW was to manually remove major outliers, by viewing the sparse point cloud from various perspectives. Outliers in the DPC were only filtered automatically in PSP by choosing the setting 'moderate' for 'depth filtering' during the DPC generation. 


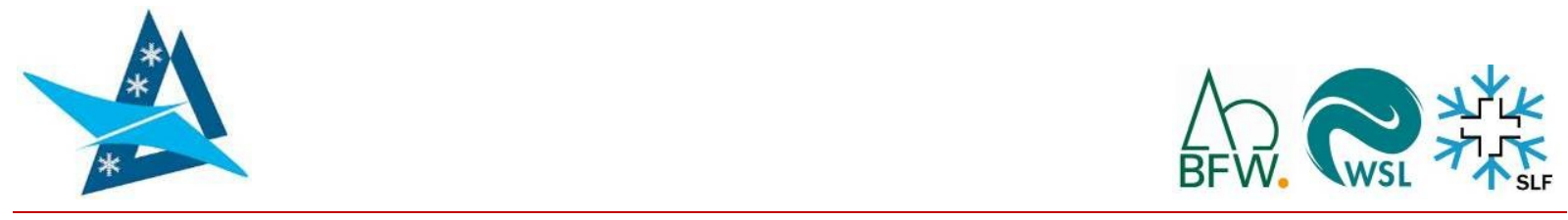

\section{Comparison of photogrammetric software packages}

To evaluate PSP's matching performance and result accuracy, we compared it to the following alternative commercial photogrammetric software packages:

\begin{tabular}{|c|c|c|c|}
\hline Company & Link & Product & Version \\
\hline Trimble & www.trimble.com & Inpho Match-T & 7.0 \\
\hline nFrames & nframes.com & SURE & 1.2 \\
\hline
\end{tabular}

For this assessment, data from two flights performed on 13 February 2015 (flight 1 \& 3; VIS and NIR imagery, respectively) were used. For photogrammetric orientation, seven GCPs were used (as described in Chapter 3.2). PSP was employed for external orientation and bundle adjustment for both flights. The orientation errors for both flights are as follows:

\begin{tabular}{|c|c|c|c|c|}
\hline & $\mathbf{X Y}[\mathrm{cm}]$ & $\mathbf{Z}[\mathrm{cm}]$ & Total $[\mathrm{cm}]$ & Projections \\
\hline VIS & 8.6 & 4 & 9.5 & 49 \\
\hline NIR & 3.9 & 1.3 & 4.2 & 50 \\
\hline
\end{tabular}

PSP can export the orientation results as Inpho-project, which is required as input for the Match-T and SURE processing workflows. Using an identical orientation is required to evaluate the matching performance of different software packages.

Algorithms for the retrieval of 3D-information can be separated into two general categories, which are actually influenced by development history. The first and older category covers the retrieval of image orientations using manually or automatically determined distinct features in the images, followed by a bundle adjustment. The newer category, mainly based on computer vision paradigms, represents surface reconstruction methods, where dense image matching algorithms exploit the previously derived orientation of the images to reconstruct complete surfaces. PSP and SURE have implemented the newer processing approach, in contrast to Match-T, which has its roots in the traditional photogrammetry processing chain. Because all packages are commercial, comparable details or detailed explanations about the implemented algorithms are not known or only to a very limited extent. Therefore, details of the dense matching process cannot be investigated and the workflow is defined as black box operation with different application-specific parameters. The following overview illustrates the completely different parameter spaces for each package:

\section{nFrames SURE Professional 1.2.0.779}

The parameter set of SURE is very comprehensive, overall 271 parameters can be defined within the following control files during processing:

controlBootstrap.txt

controlDsm.txt

controlDsmMesh.txt

controlFusion.txt

controllnit.txt

controllnvalidate.txt

controlRect.txt

controlSgm.txt

controlTriang.txt

controlTrueOrtho.txt 


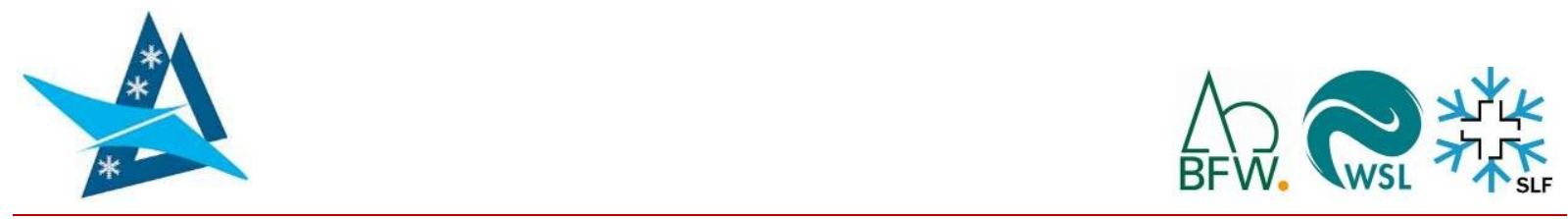

\section{Agisoft PhotoScan Professional 1.2.3}

PSP was used with different quality parameters for building the DPC.

Quality: Low, Medium, High

Filter: Aggressive, Moderate

SurfaceType: HeightField

Interpolation: Disabled

FaceCount: High

Trimble Inpho Match-T DSM 7.0.0.49397

Optimization type: UAS

Generate point cloud output: on

Create tile manager files: off

Finite element filtering (AUTOMATIC): off

3D filtering (AUTOMATIC): off

2.5D filtering (AUTOMATIC): on

$X Y$ spacing for 2.5D filtering: 3 [pixels]

Use morphological data: off

Number of DEM levels: 7

Refraction correction: on

Earth curvature correction: on

Epipolar line distance: 3 [pixels]

Parallax bound: 14.000000 [pixel]

Threshold for correlation coefficient: 0.800000

Window size for correlation coefficient: $5 \times 5$ [pixels]

Resampling: on

Adaptive matching: on

FBM refinement for interest points: on

LSM refinement for interest points: on

Maximum number of iterations: 4 / 6

Smoothing/robustness (3D points): $1.000 / 0.300$

Smoothing/robustness (X curvature): $1.000 / 0.400$

Smoothing/robustness ( $Y$ curvature): $1.000 / 0.400$

Smoothing/robustness (torsion): $1.000 / 0.400$

Theoretical height accuracy (3D point): 0.215946 [m]

Terrain type: Undulating

DEM generation type: Surface

The following comparison was conducted with the final DPCs [million points]. PSP was evaluated with the DPC quality parameters "low" and "high".

\begin{tabular}{|c|c|c|c|c|}
\hline & MatchT & PSP low & PSP high & SURE \\
\hline VIS & 73.4 & 18.1 & 73 & 6129.4 \\
\hline NIR & 68.9 & 17.6 & 70.6 & 4417.6 \\
\hline
\end{tabular}




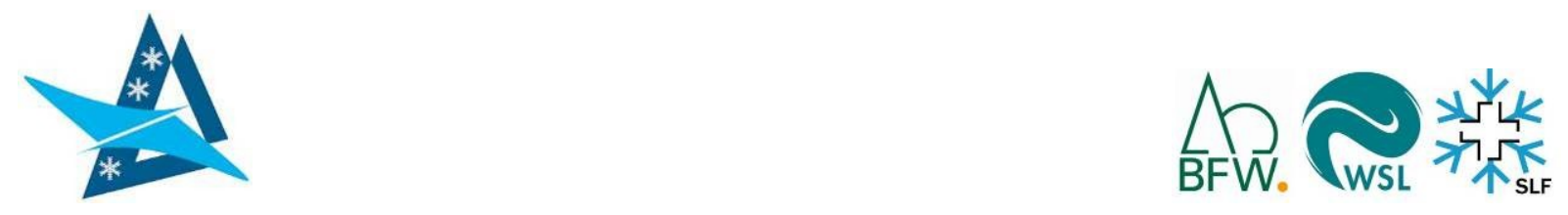

\section{Evaluation}

The height evaluation of DSMs is normally conducted with reference measurements on the ground, typically with a vertical accuracy of $0.1 \mathrm{~m}$ or better, which can be achieved with currently available differential GNSS equipment and related post-processing. Due to technical malfunction of the GNSS device, the acquired manual reference values could not be used and the seven GCPs (Figure 19) had already been used in the external orientation of the photogrammetric projects. Therefore, another comparison approach had to be applied, which was not a true replacement, but allowed estimating the relative performance of the different software packages.
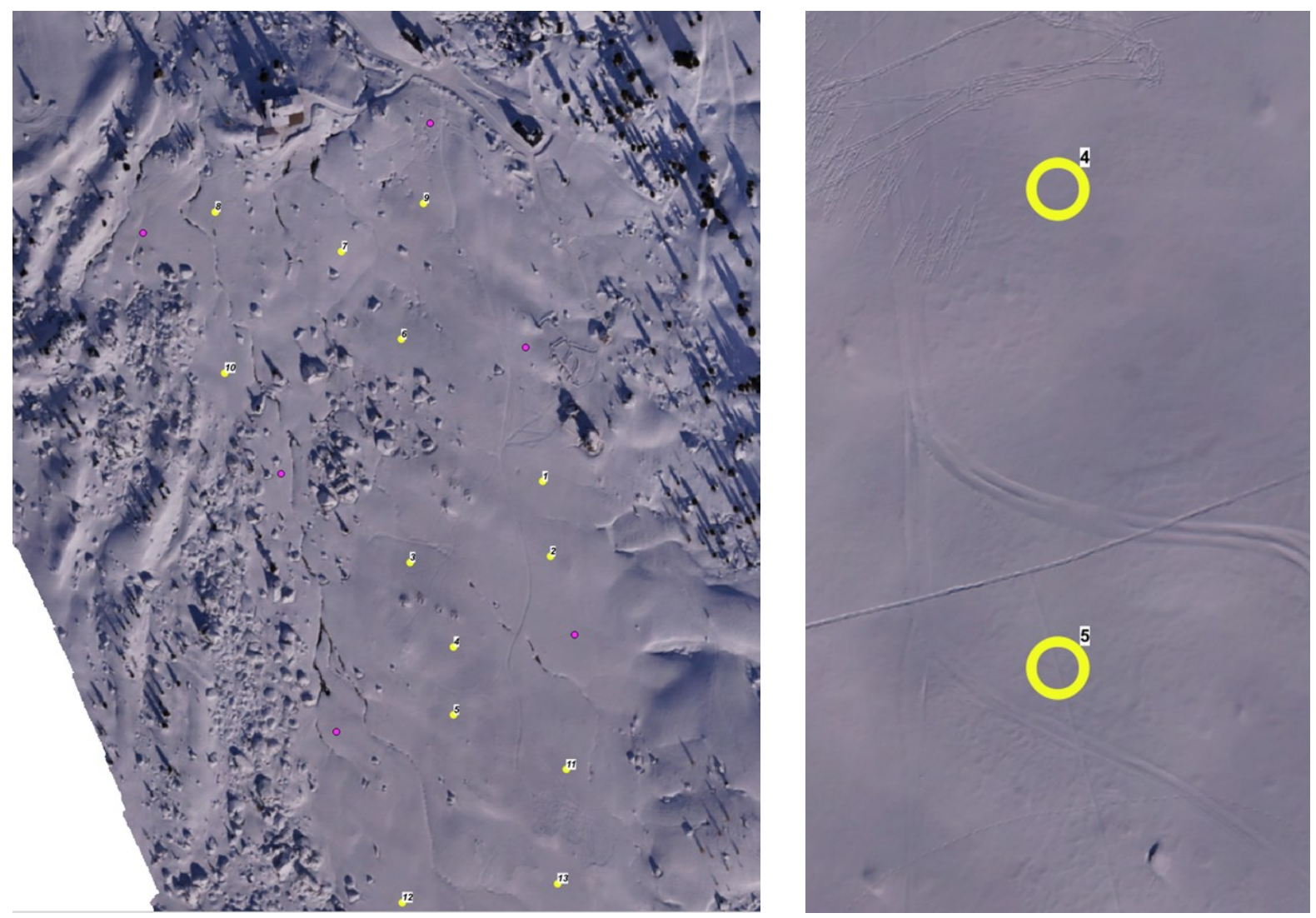

Figure 19: Study site Lizum, with GCP-locations (magenta circles) and evaluation-spots (yellow circles); overview (left) and detail (right).

A smooth and preferably horizontal area with a circle of radius $1 \mathrm{~m}$ was visually selected. All DSM points within this circle were used to estimate the representative height value of the circle centre. The median height value of the circle area was robust enough, so bias caused by ripples or tracks were filtered out. 14 evaluation spots were selected within the relatively smooth regions of the valley floor at the Lizum study site.

The enlarged evaluation spot (Figure 20) reveals, that the DPC distribution (green dots) of PSP shows an expected irregular distribution (left), in contrast to Match-T (right), where the point cloud seems to be sampled from a raster data structure. 

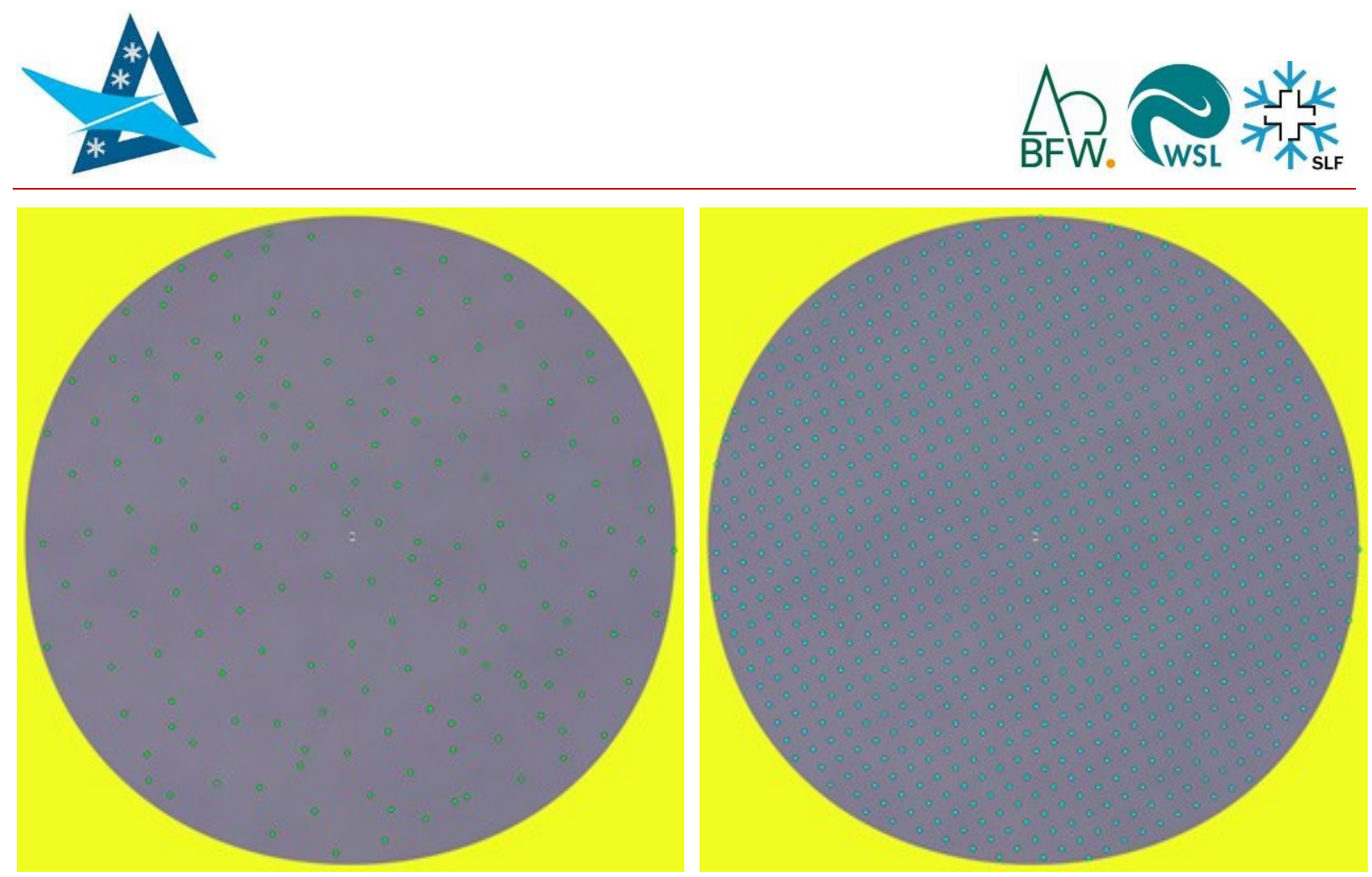

Figure 20: Point density within evaluation spot no. 5 (PSP, left; Match-T, right).

\section{Dense cloud interpolation}

In contrast to other point cloud filtering options, one of the parameters in PSP controls an interpolation mechanism during dense cloud calculation. To investigate the influence of this early interpolation, a further comparison between interpolated and non-interpolated VIS point clouds was conducted. The evaluation of the 14 spot heights revealed no significant difference and the direct comparison of the point clouds shows, that the interpolation has very little effect on the point cloud size itself (Table 3).

Table 3: Dense cloud sizes for PSP with VIS data.

\begin{tabular}{|c|c|c|c|c|c|}
\hline Quality & Filter & Interpolation ON & Interpolation OFF & \multicolumn{2}{|c|}{ Difference } \\
\hline Low & aggressive & 18147014 & 18146816 & 198 & $<<1 \%$ \\
\hline Low & moderate & 18219295 & 18146816 & 2479 & $<<1 \%$ \\
\hline Medium & aggressive & 70036290 & 70022235 & 14055 & $<<1 \%$ \\
\hline Medium & moderate & 70635519 & 70635349 & 170 & $<<1 \%$ \\
\hline High & moderate & 283332113 & 283327599 & 4514 & $<<1 \%$ \\
\hline
\end{tabular}

For more details on this section, the reader is kindly referred to Boesch et al. (2016). 


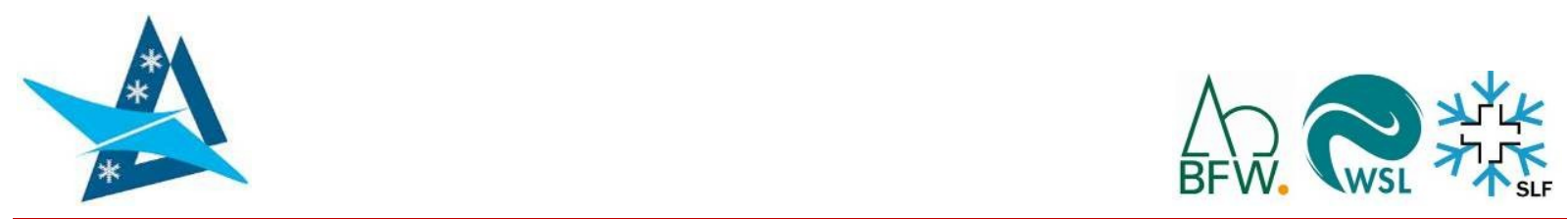

\subsection{Validation Data}

\section{TLS}

Point clouds from both TLS-instruments were georeferenced within the Riegl software RiPROFILE (version 1.5.7, Riegl 2016) to the respective standard national coordinate systems (EPSG-Code 31254, Gebrauchshöhen Adria). After reading in the location of the targets in the global coordinate system, the software tried to link these locations to the values of the target locations in the scanner own coordinate system. The best solution of this procedure was found by minimising the standard deviation of the residues (as reported in Table 1). The georeferenced point clouds were exported as TXT-files and loaded into the geographic Information System GIS) Quantum GIS (QGIS) for validation. To avoid overrepresentation of TLS points recorded close to the scanner, resulting from distantdependant point density, mean z-values were calculated within a $0.2 \mathrm{~m}$ raster (corresponding to RPAS-DSM resolution) and the raster centre location plotted for validation. The direct comparison of TLS and RPAS data was performed between the DSMs, not the calculated HS.

\section{LFAS}

(the reader is kindly referred to Boesch et al., 2016 for details)

\section{In-situ measurements}

To validate the RPAS-HS accurately, the centre-location of the in-situ data was corrected by plotting them on the resulting OP and manually adjusting their position accordingly. In order to minimise the effect of the micro-topography below the snowpack on the results, the mean values from all five measurements were calculated. For the validation procedure, the mean RPAS-DSM values of all pixels within a $1 \mathrm{~m}$ radius were averaged. 


\section{$5 \quad$ Results}

\subsection{Snow Depth Mapping}

\subsubsection{Lizum}

At the Austrian study site, OPs with $0.05 \mathrm{~m}$ and DSMs with $0.2 \mathrm{~m}$ GSD were calculated from approximately 16,000 images. Below, a selection of the most interesting results is presented (a complete compilation is provided in the Annex - Figure 40 through Figure 56). Figure 21 gives an overview of the main processing outputs in a subsection of the target area. HS-values range from $>1.5 \mathrm{~m}$ in the $\mathrm{N}$ and $\mathrm{W}$ areas to $0 \mathrm{~m}$ along the cleared roads. Some negative values are visible, where temporary objects were moved (close to hut in the NW) or where vegetation is present (SW).
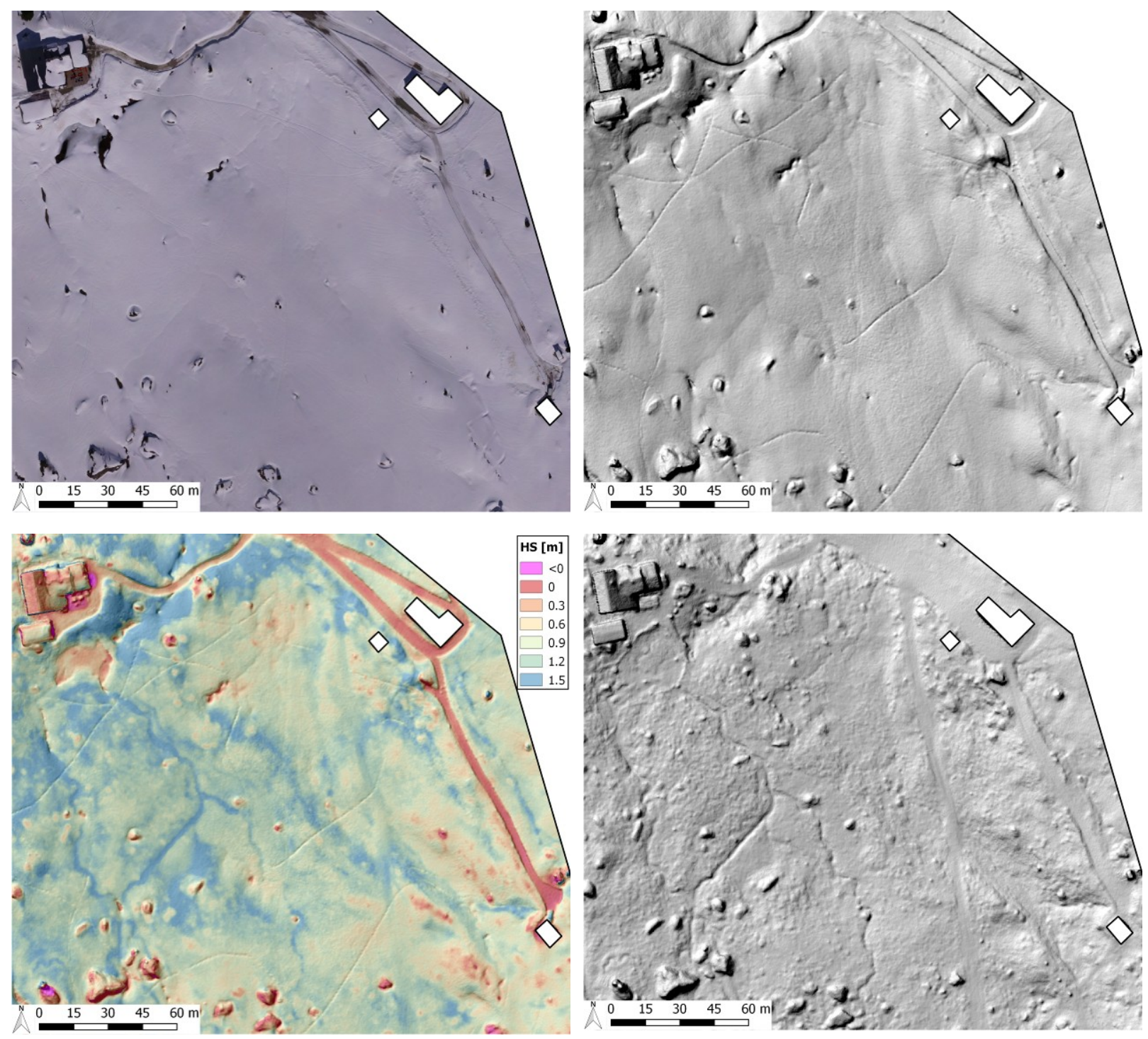

Figure 21: Main outputs from RPAS-data processing, exemplified with results from 10 April 2015, VIS-flight 1 - OP (top left); shaded DSM (top right); HS map (bottom left), calculated with snow-free DSM (hillshade, bottom right). 


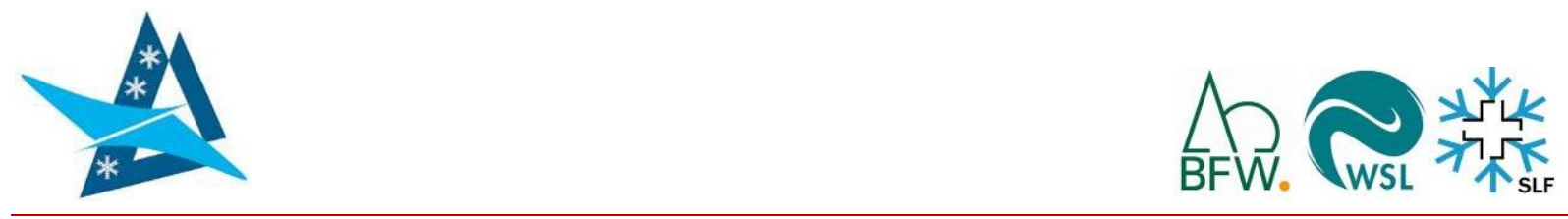

\section{Snow depth differences between campaigns and AWS / RPAS}

A further output from the RPAS-campaigns were relative HS maps, which show the difference in HS from one campaign date to the next, as exemplified in Figure 22 (blue - positive, green - negative changes). For example, linear HS changes indicate where roads, rivers and ski tracks, still visible on the 13 February, were filled up with snow during the course of the winter.
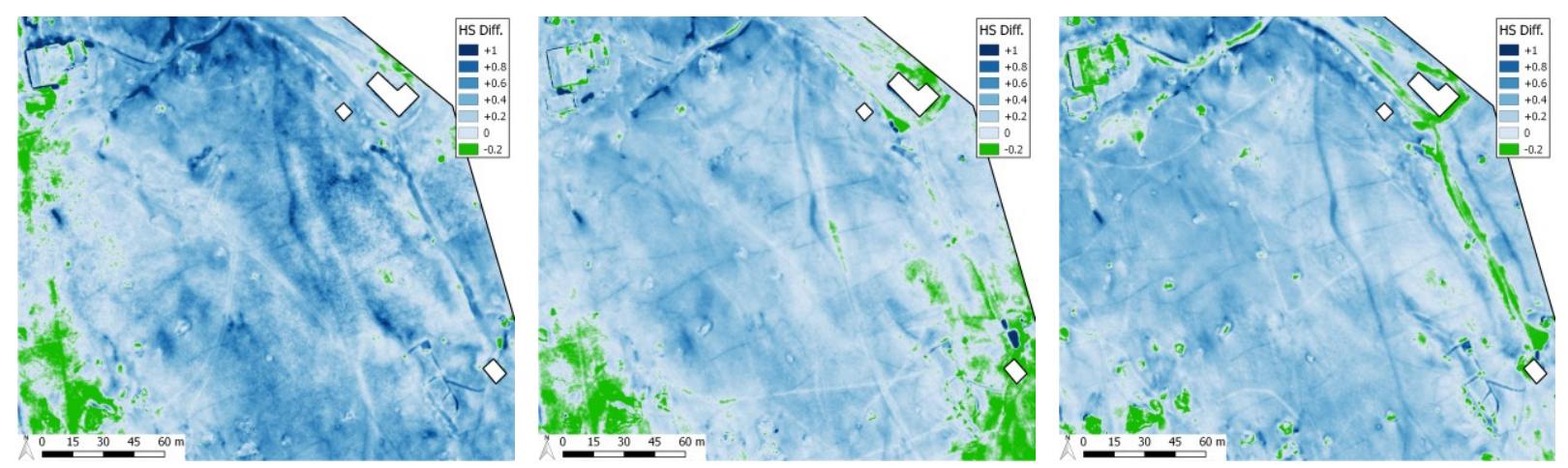

Figure 22: Relative HS changes between 13 February 2015 (flight 3) and i) 3 March 2015 (flight 2) (left); ii) 13 March 2015 (flight 1) (centre); iii) 10 April 2015 (flight 3) (right).

To evaluate the representativeness of the AWS location, a comparison of AWS and RPAS HS values, averaged over the entire AOI, was performed (Table 4). While the first two dates (13 February \& 3 March) show relatively good agreement between AWS \& RPAS $(0.1 \mathrm{~m})$, the deviation rises to an average $0.3 \mathrm{~m}$ on the last two campaign dates.

Table 4: Absolute HS values measured by AWS and RPAS.

\begin{tabular}{|c|c|c|c|}
\hline Date & HS AWS [m] & HS RPAS [m] & Difference [m] \\
\hline 13 February & 0.72 & 0.61 & $\mathbf{0 . 1 1}$ \\
\hline 3 March & 0.98 & 0.89 & $\mathbf{0 . 0 9}$ \\
\hline 13 March & 0.92 & 0.64 & $\mathbf{0 . 2 8}$ \\
\hline 10 April & 1.12 & 0.8 & $\mathbf{0 . 3 2}$ \\
\hline
\end{tabular}

To explore the relation between AWS and RPAS HS measurement further, the HS changes between the dates detailed in Figure 22 above were calculated and compared. Again, the agreement between AWS and RPAS is good for 3 March $(+0.01 \mathrm{~m})$, it is poorer for the last two dates $(-0.17 \mathrm{~m}$ ) ('gain/loss'). However, when only summing up the positive HS changes between these dates ('gain only'), the overall deviations can be reduced markedly $(+0.1-+0.7 \mathrm{~m})$.

Table 5: Comparison of HS changes, relative to 13 February 2015, as measured by AWS and RPAS (average over whole AOI) on three campaign dates.

\begin{tabular}{|c|c|c|c|c|}
\hline \multirow{2}{*}{ Date } & \multirow{2}{*}{ HS AWS [m] } & \multicolumn{2}{|c|}{ HS RPAS [m] } & \multirow{2}{*}{ Difference [m] } \\
\cline { 3 - 5 } & & gain/loss & gain only & \\
\hline 3 March & +0.26 & +0.28 & +0.34 & $\mathbf{+ 0 . 0 1 / + 0 . 0 7}$ \\
\hline 13 March & +0.2 & +0.03 & +0.22 & $\mathbf{- 0 . 1 7 / + 0 . 0 2}$ \\
\hline 10 April & +0.4 & +0.2 & +0.27 & $\mathbf{- 0 . 1 7 / + 0 . 1}$ \\
\hline
\end{tabular}




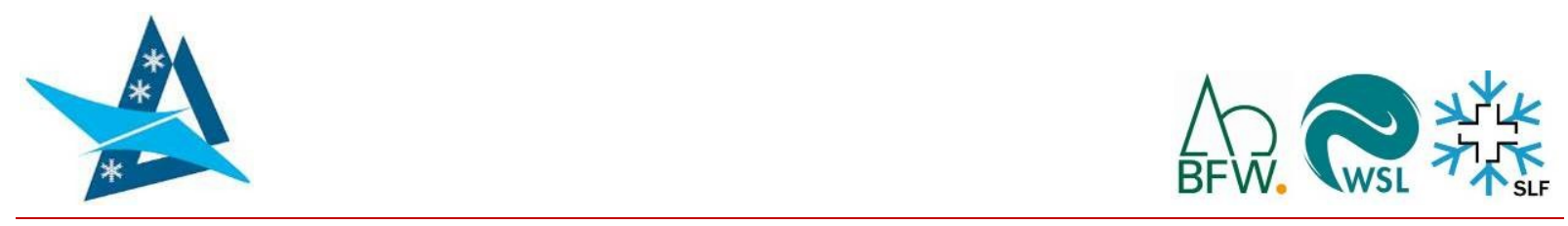

\section{NIR data}

As reported above, both VIS and NIR data was collected at the Austrian study site. Figure 23 gives an impression of the results of two RPAS-flights, where the sensor was fitted with a NIR830 filter, performed on 10 April 2015 (flights 2 and 4, top and bottom, respectively). On both flights HS values reach $1.5 \mathrm{~m}$ in the $\mathrm{N}$ and centre of the $\mathrm{AOI}$, while slightly positive values $(0.3 \mathrm{~m})$ can be observed on the cleared roads in both HS maps.
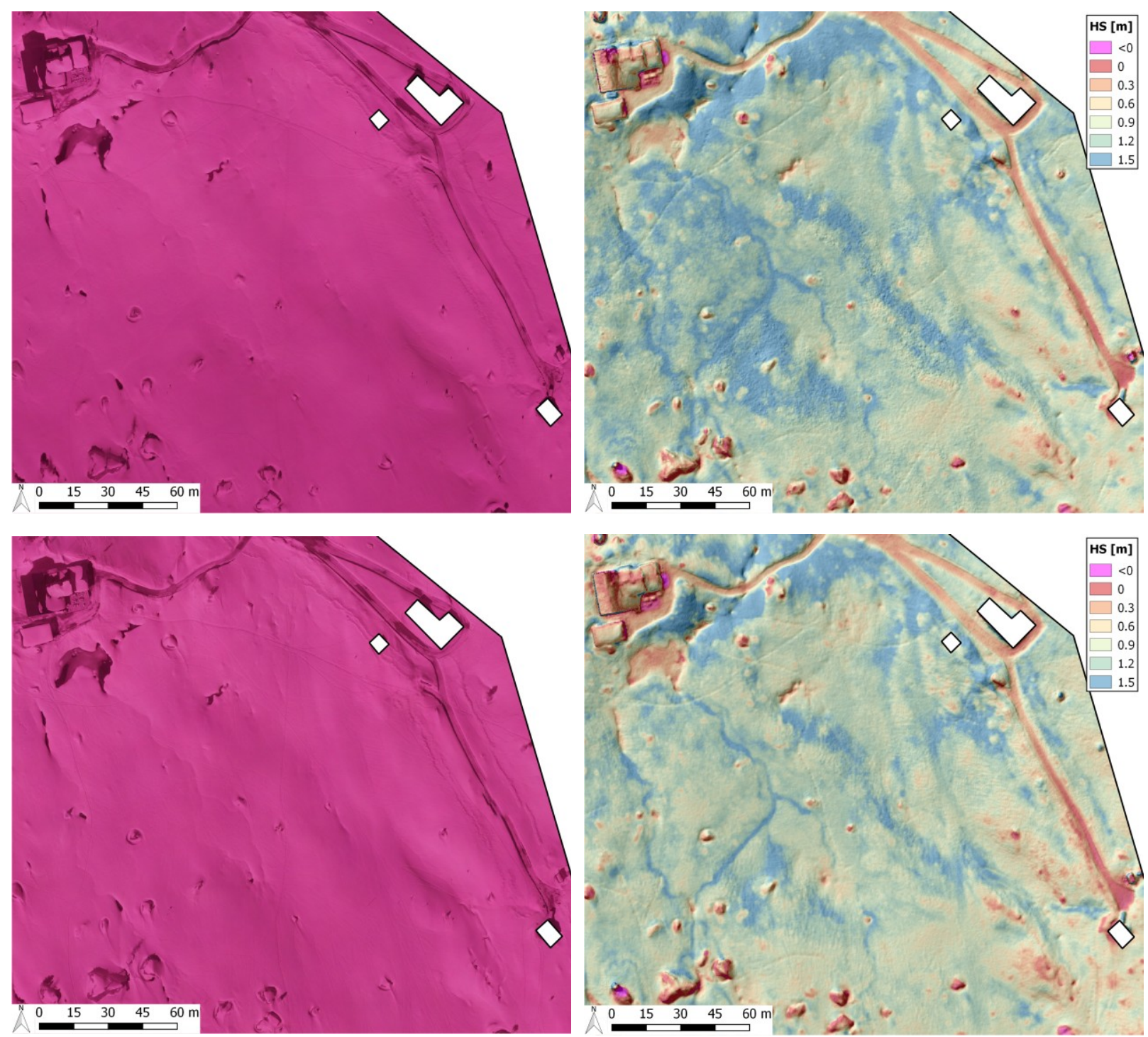

Figure 23: Results from NIR830 data collection (OP, left; HS map, right).

\subsubsection{Tschuggen}

(the reader is kindly referred to Bühler, et al. 2016 for details)

\subsubsection{Brämabühl}

(the reader is kindly referred to Bühler, et al. 2016 for details) 


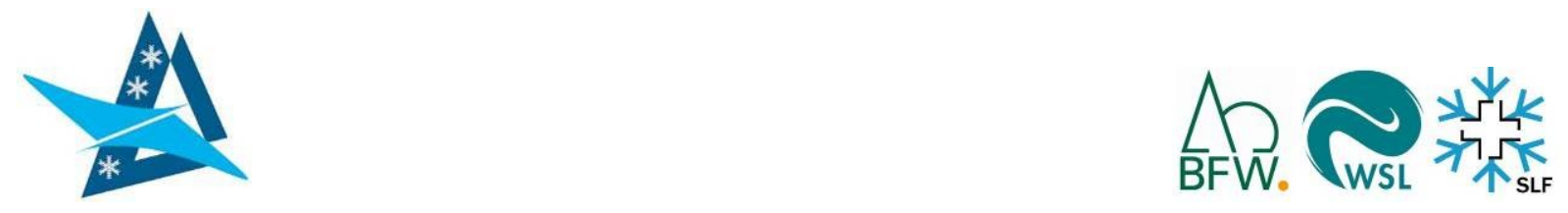

\subsection{Avalanche Mapping (Wildi)}

The results from mapping the avalanche at Wildi showed that around $20,000 \mathrm{~m}^{3}$ of mainly dry snow released (average release depth $0.8 \mathrm{~m}$ ) and flowed approximately $1,000 \mathrm{~m}$ horizonal and $700 \mathrm{~m}$ vertical distance into the Dischma valley. Figure 24 gives an impression of the OP (left) and HS map (right) in the release area; take off points, reference points and derived release zones of the avalanche are indicated in the OP.

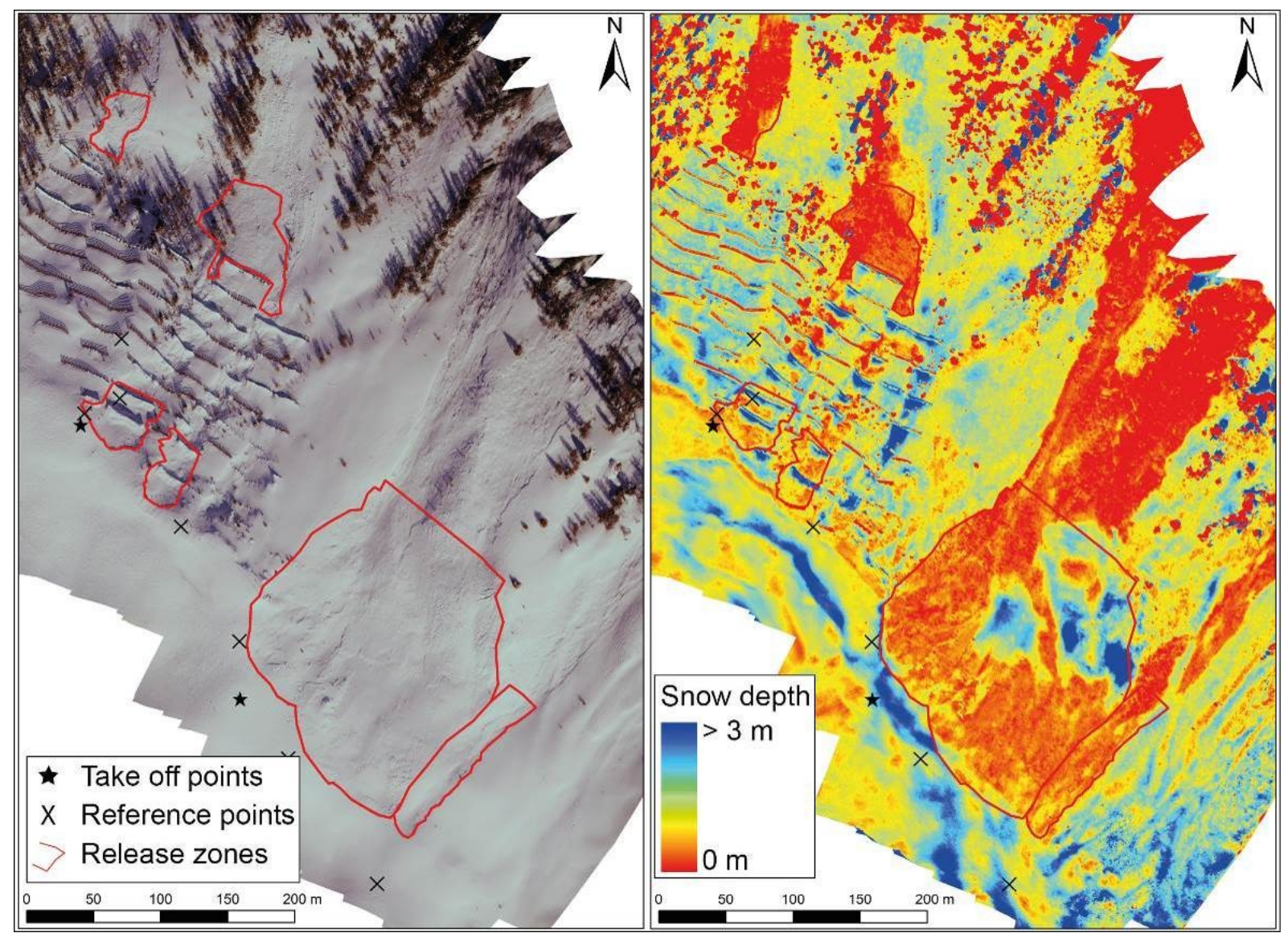

Figure 24: OP of the release zone (left) and calculated snow depth (HS) values (right).

Along the track, the avalanche eroded moist snow, depositing approximately $40,000 \mathrm{~m}^{3}$ of very dense, wet snow in the runout zone (Figure 25). 

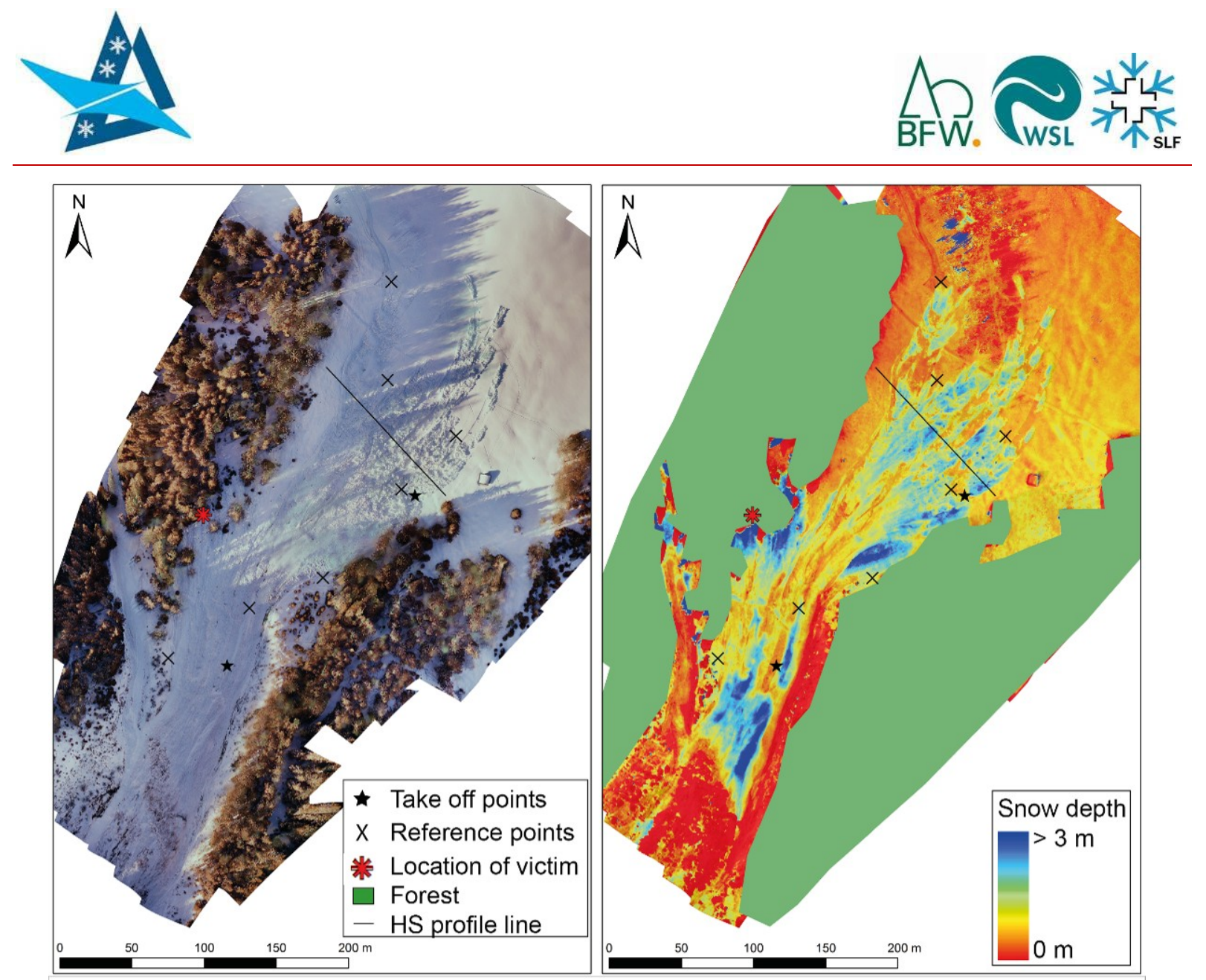

Snow depth profile

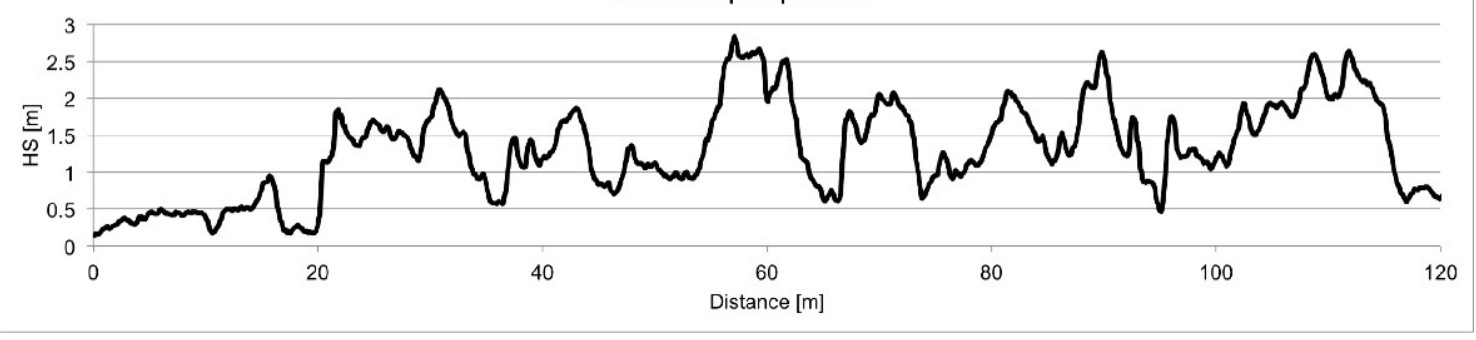

Figure 25: OP of the deposition zone (left) and calculated snow depth (HS) values (right). The HS profile illustrates the scattering of the deposition into different flow arms with very variable deposition depth.

\subsection{Validation}

\subsubsection{Lizum}

TLS

For TLS-validation, the height values of the RPAS-DSMs were directly compared to the TLS-point measurements (not the derived HS values). The scanning routine of the TLS provided a very dense sampling of the RPAS data with up to 183,000 points measured over approximately $70 \%$ of the $A O I$. Figure 26 provides four examples of validation results. A majority of the TLS-points acquired to validate the two flights conducted in March (Figure 27, top row) show good agreement with the RPAS-DSMs $( \pm 0.2 \mathrm{~m}$ ). Of those two, slightly poorer results were achieved on 13 March (flight 1 ), as deviations of $0.2-1 \mathrm{~m}$ were detected in the $\mathrm{S}$ sector of the $\mathrm{AOI}$. 


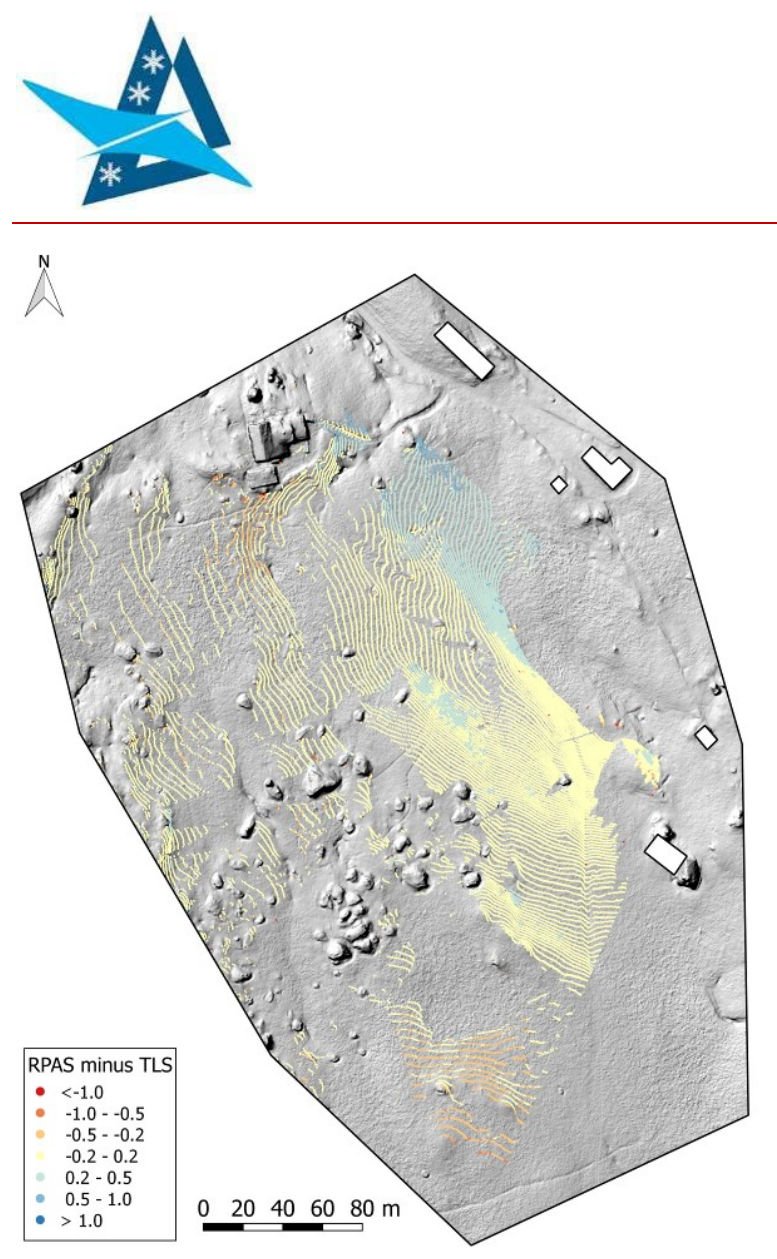

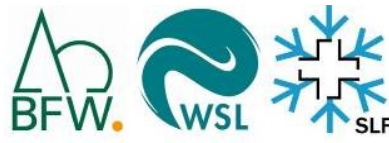
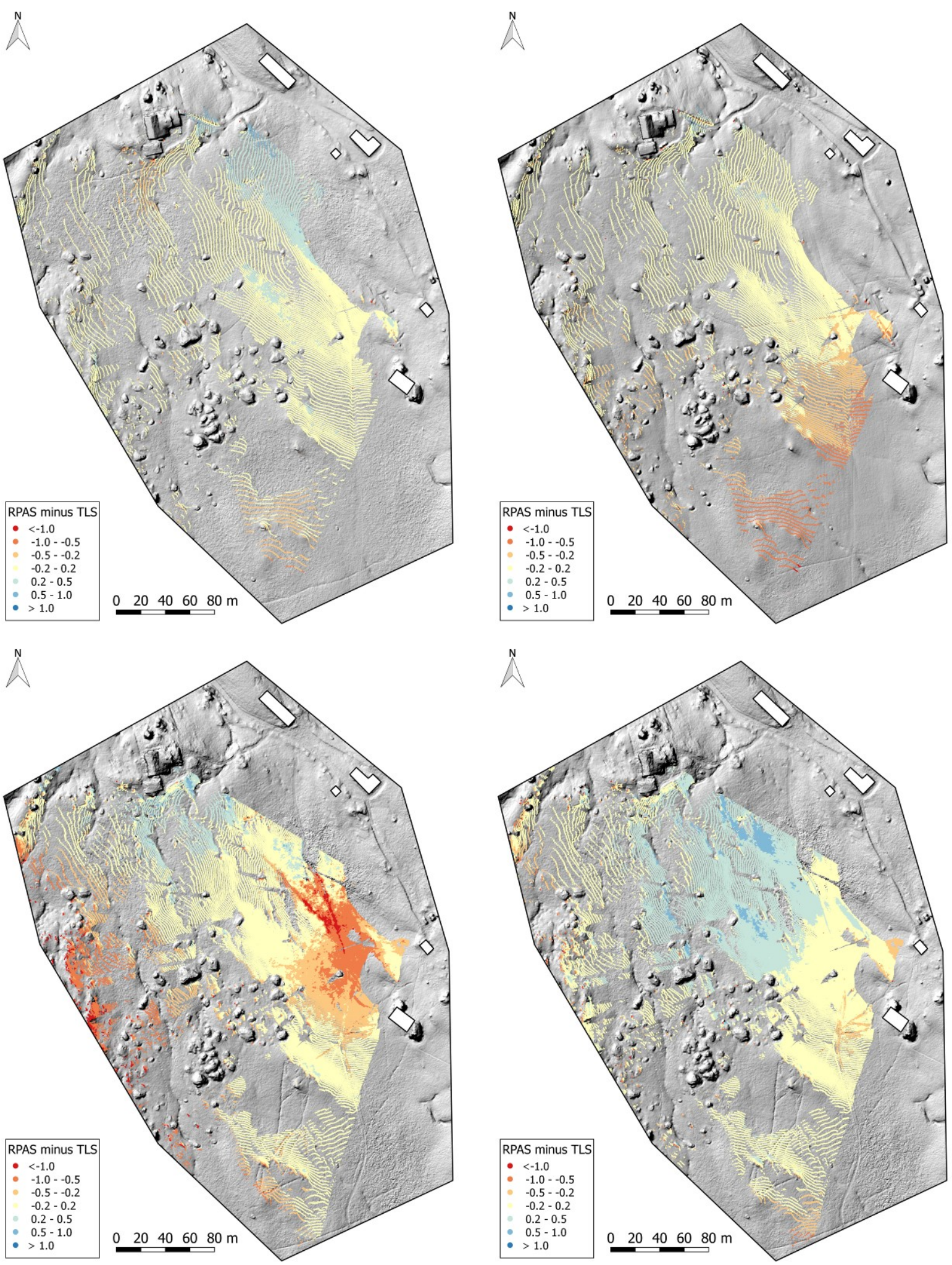

Figure 26: Four examples of TLS-validation results - each point represents a TLS-measurement, colour-coded by degree of positive (reds) and negative (blues) deviation of the RPAS from the TLS DSM [m]; 3 March 2015, flight 2 (top left); 13 March 2015, flight 1 (top right); 11 February 2015, flight 1 (bottom left); 11 February 2015, flight 2 (bottom right). 
The bottom row of Figure 27 shows two examples from poor RPAS-DSM results collected on 11 February 2015, especially for flight 1 , where deviations of $>1 \mathrm{~m}$ were identified in the $E$ and $W$ of the AOI. Flight 2 shows better agreement with the TLS results, but features substantial positive bias of the RPAS-DSM in the $\mathrm{N}$ section of the AOI $(<1 \mathrm{~m})$. The rest of the TLS-validation results are included in the Annex (Figure 57 and Figure 58). A summary of the TLS-validation is provided in Figure 27. Highest accuracy (i.e. with the lowest spread and a median close to the TLS data ('0' on y-axis)) was achieved for results of flights 3 \& 4 (13 February 2015) and both flights performed on 3 March 2015 (median within $0.1 \mathrm{~m}$ and spread of no more than $0.3 \mathrm{~m}$ from TLS data). The poorest accuracy is reached by RPAS-DSMs recorded on 11 February (flight 1 ) and 13 February (flight 5), where the data is spread up to $1.5 \mathrm{~m}$ around the TLS-validation value (at one standard deviation). Additionally, the root mean square error (RMSE) was calculated and is reported in Table 6. Overall, the RMSE reflects the same results as the boxplots, with accuracies ranging from $0.18 \mathrm{~m}$ (flights $3 \& 4$, 13 February 2015) to $>0.7$ m (13 February, flight 5 \& 13 March, flight 3).

Table 6: RMSE of TLS-validation of RPAS-DSMs.

\begin{tabular}{|c|c|c|c|c|c|c|c|c|c|c|c|c|}
\hline Date & \multicolumn{3}{|c|}{ 11 February 2015 } & \multicolumn{4}{|c|}{13 February 2015 } & \multicolumn{3}{|c|}{3 March 2015 } & \multicolumn{3}{|c|}{13 March 2015 } \\
\hline FlightNo. & F1 & F2 & F3 & F1 & F3 & F4 & F5 & F1 & F2 & F1 & F2 & F3 \\
\hline RMSE & 0.42 & 0.28 & 0.22 & 0.23 & 0.18 & 0.18 & 0.77 & 0.22 & 0.22 & 0.27 & 0.35 & 0.70 \\
\hline
\end{tabular}

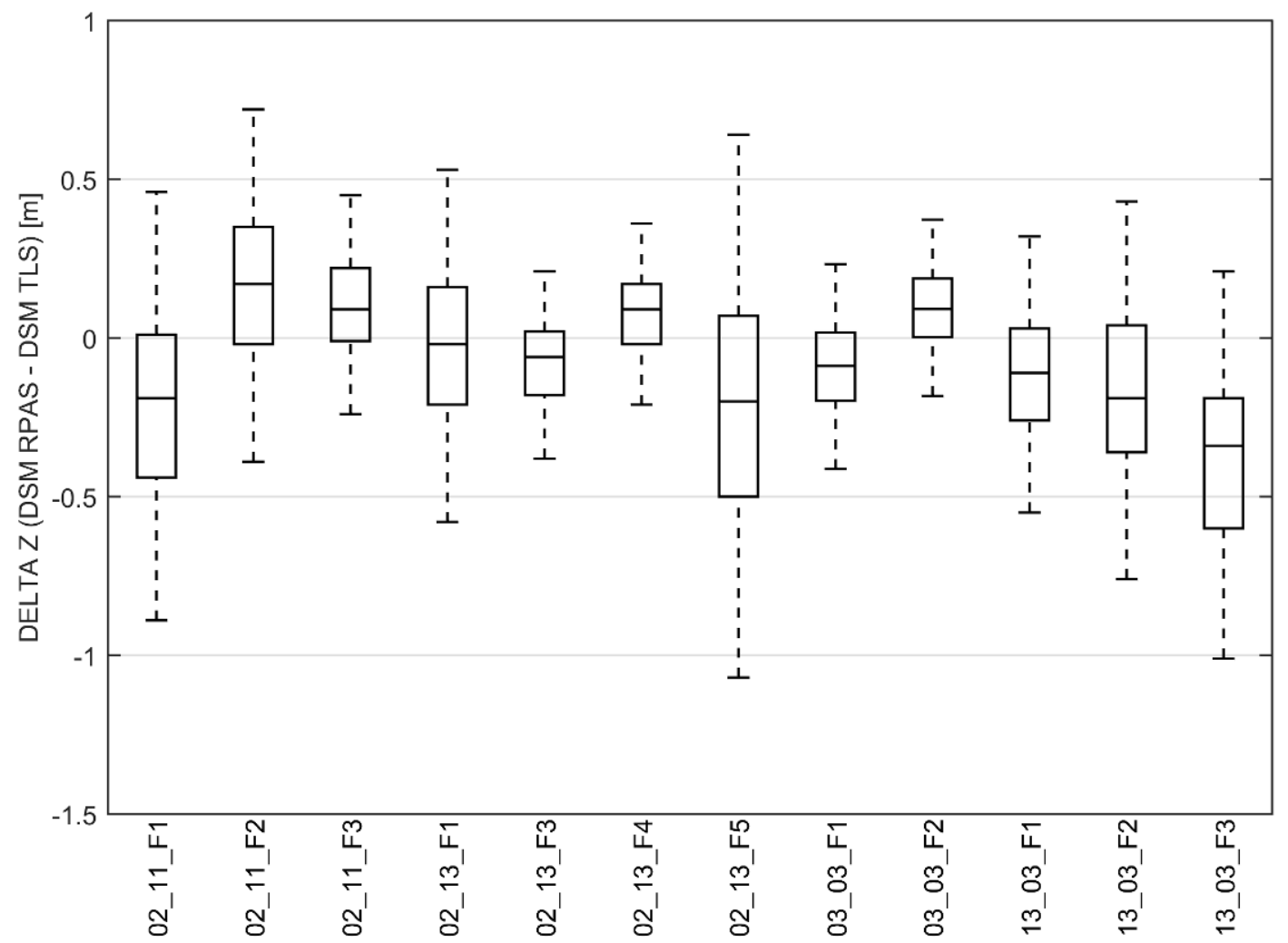

Figure 27: Results of the TLS-validation; on the y-axis the deviation of RPAS-DSM from TLS-DSM [m] is marked; flight ID (MM_DD_flightnumber) is plotted on $\mathrm{x}$-axis - each boxplot corresponds to one UAS-flight; whiskers in boxplot correspond to one standard deviation, outliers not included; the boxplots are based on 50,000 randomly selected samples from the TLS-point clouds. 
In-situ

The HS-values were also directly validated by performing in-situ measurements as described above. An overview of results of the February in-situ campaign are presented in Figure 28 . The in-situ results generally show a negative bias, with all medians and most upper quartiles lying below the measured in-situ values (' 0 ' on the $y$-axis). Furthermore, compared to the TLS-validation, the spread of the insitu data is considerably smaller. However, the in-situ data reflects the same trends observed in the TLS-validation above: The highest accuracy (median $<0.2 \mathrm{~m}$ and spread $<0.5 \mathrm{~m}$ from reference data) is again achieved by flights 3 and 4 (13 February 2015), while the poorest agreement is reached on 11 February (flight 1) and 13 February (flight 5) (median $0.3 \mathrm{~m}$ and spread up to $1 \mathrm{~m}$ from reference data). Additional results from the March 2015 campaign are included in the Annex (Figure 59).

Here too, the RMSE was calculated (Table 7). Most results feature a uniformly low RMSE $(<0.3 \mathrm{~m})$, with only three datasets (11 February, flight 1; 13 February, flight 5; 13 March, flight 3) reaching decidedly higher values $(0.52,0.48 \& 0.97 \mathrm{~m}$, respectively).

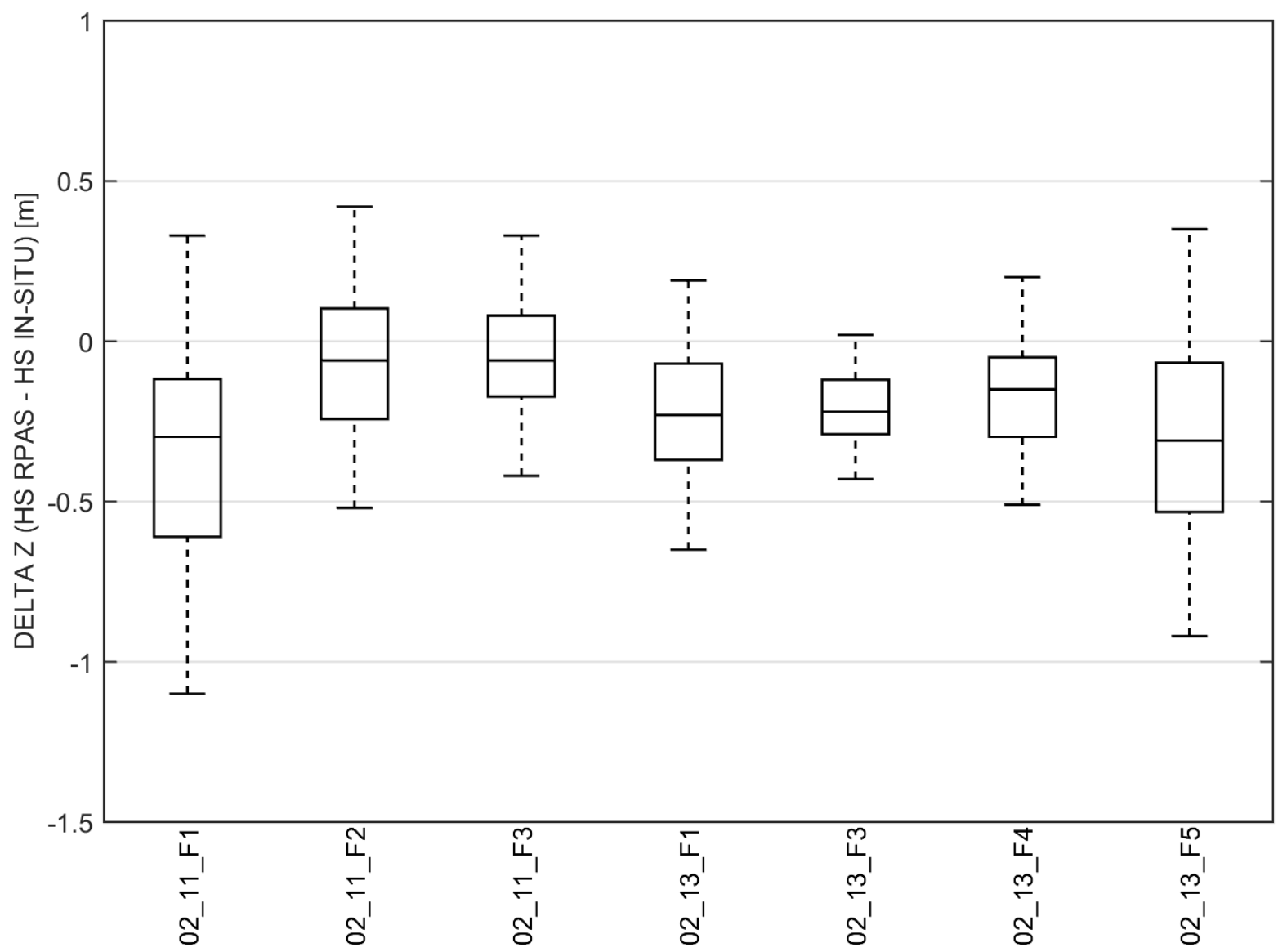

Figure 28: Results from the in-situ validation of RPAS-HS maps in February 2015; on the y-axis the deviation of RPAS-HS values from in-situ-HS values [m] is marked; flight ID (MM_DD_flightnumber) is plotted on x-axis - each boxplot corresponds to one UAS-flight; whiskers in boxplot correspond to one standard deviation, outliers not included. 
Table 7: RMSE of RPAS-HS maps' in-situ-validation ( $n=150$ on 11 and 13 February; $n=37$ on 13 March).

\begin{tabular}{|c|c|c|c|c|c|c|c|c|c|c|}
\hline Date & \multicolumn{3}{|c|}{ 11 February 2015} & \multicolumn{4}{|c|}{ 13 February 2015 } & \multicolumn{3}{|c|}{ 13 March 2015 } \\
\hline FlightNo. & F1 & F2 & F3 & F1 & F3 & F4 & F5 & F1 & F2 & F3 \\
\hline RMSE & 0.52 & 0.30 & 0.25 & 0.32 & 0.28 & 0.29 & 0.48 & 0.23 & 0.27 & 0.97 \\
\hline
\end{tabular}

\section{Precision}

The above-mentioned validation procedure evaluated the accuracy of the RPAS data, i.e. its deviation from the 'true' value - represented here by TLS and in-situ data. The precision of the RPAS results (i.e. repeatability / reproducibility) was estimated by comparing DSM values on selected areas for several flights. These areas are surfaces, which were not expected to change in the course of the measurement campaigns, i.e. remain snow-free. Unfortunately, the AOI includes very few such areas (one roof and one terrace), as the roads were (partially) cleared only during one campaign and all others surfaces are snow-covered. For these surfaces the mean deviation between snow-covered and snow-free DSM was calculated and the RMSE reported.

The results indicate that the RPAS-measurements have a precision of $0.21 \mathrm{~m}$, averaged over all 16 RPAS-campaigns and both validation areas (terrace: $0.24 \mathrm{~m}$; roof: $0.17 \mathrm{~m}$ ).

\subsubsection{Tschuggen}

(the reader is kindly referred to Bühler, et al. 2016 for details)

\subsubsection{Brämabühl}

(the reader is kindly referred to Bühler, et al. 2016 for details)

\subsection{Software Comparison}

The varying point density for PSP is caused by the processing with different parameters. SURE calculates a very high point density in the default configuration, which leads to an unnecessarily high point density. The artificially narrow point density of Match-T is mainly caused by the regular point pattern, but also due to partial matching errors.

The value of Z-range (Figure 29) is equal to the interquartile range (IQR) of all Z-values from the evaluated spot heights. The Z-range of $0.03 \mathrm{~m}$ for most PSP spots (VIS and NIR) confirms, that PSP height measurements are very consistent for all spots and also independent of the spectral range.

The Z-range of Match-T evaluation spots reveals $0.23 \mathrm{~m}$ for the VIS dataset, a slightly better value of $0.15 \mathrm{~m}$ can be observed for the NIR dataset. The unexpectedly high variation of $0.25 \mathrm{~m}$ for SURE can be explained (to a certain extent) with the very high point cloud density $\left(>20,000 \mathrm{pts} / \mathrm{m}^{2}\right.$, Figure 30$)$. Only a few outlier values in the unfiltered point cloud are responsible for triggering the height variation. 

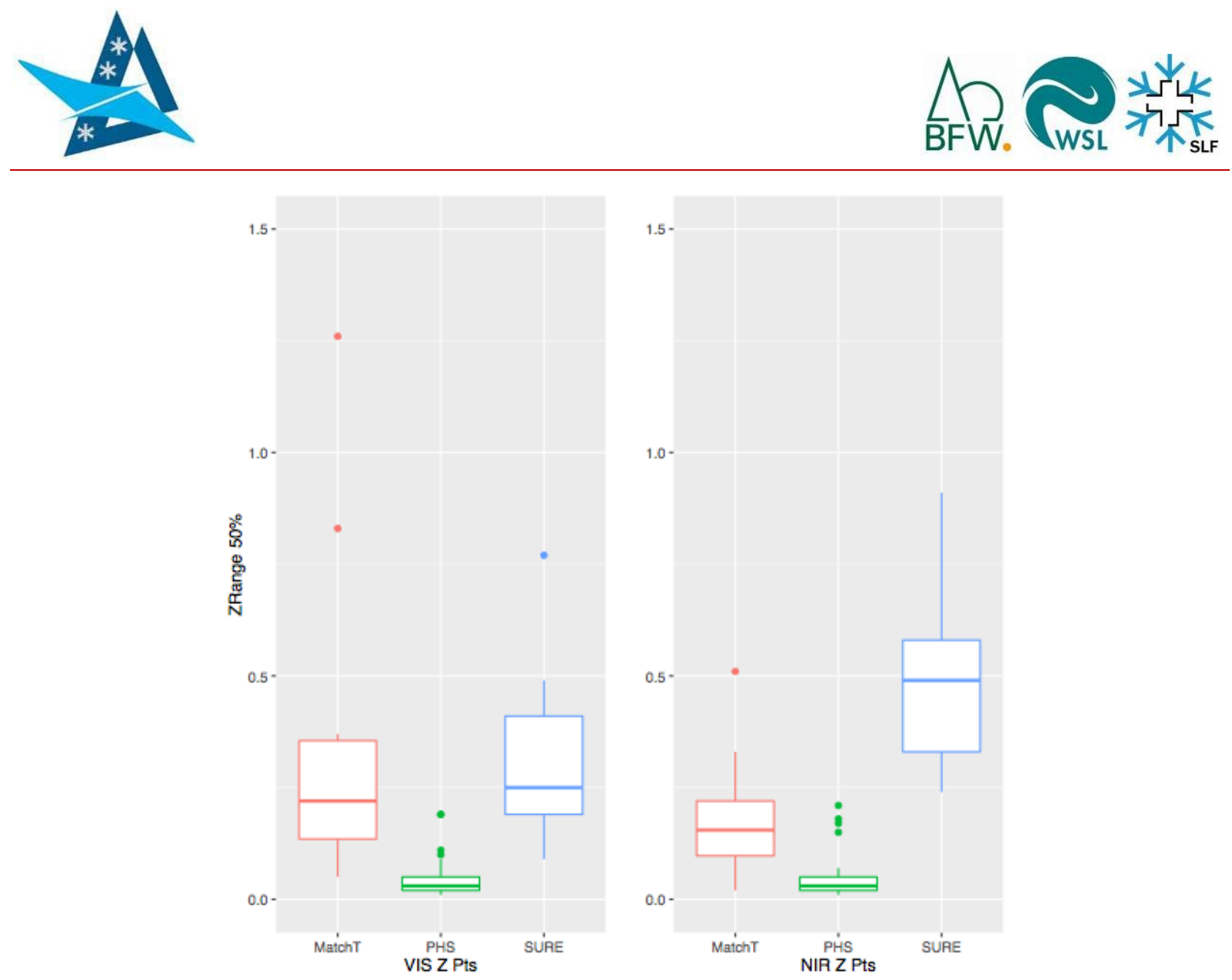

Figure 29: Variation of all evaluated spot heights.
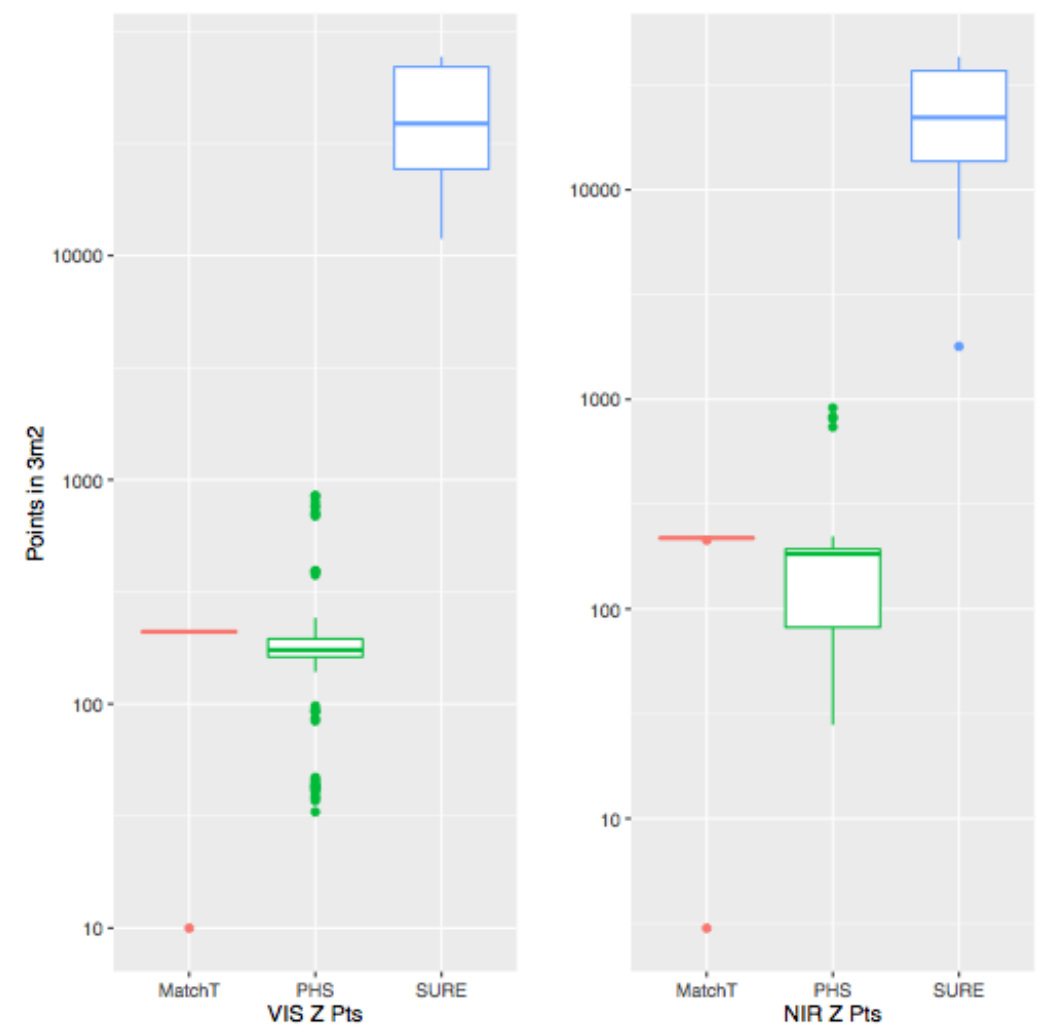

Figure 30: Point density within the evaluation spots 1-14. 

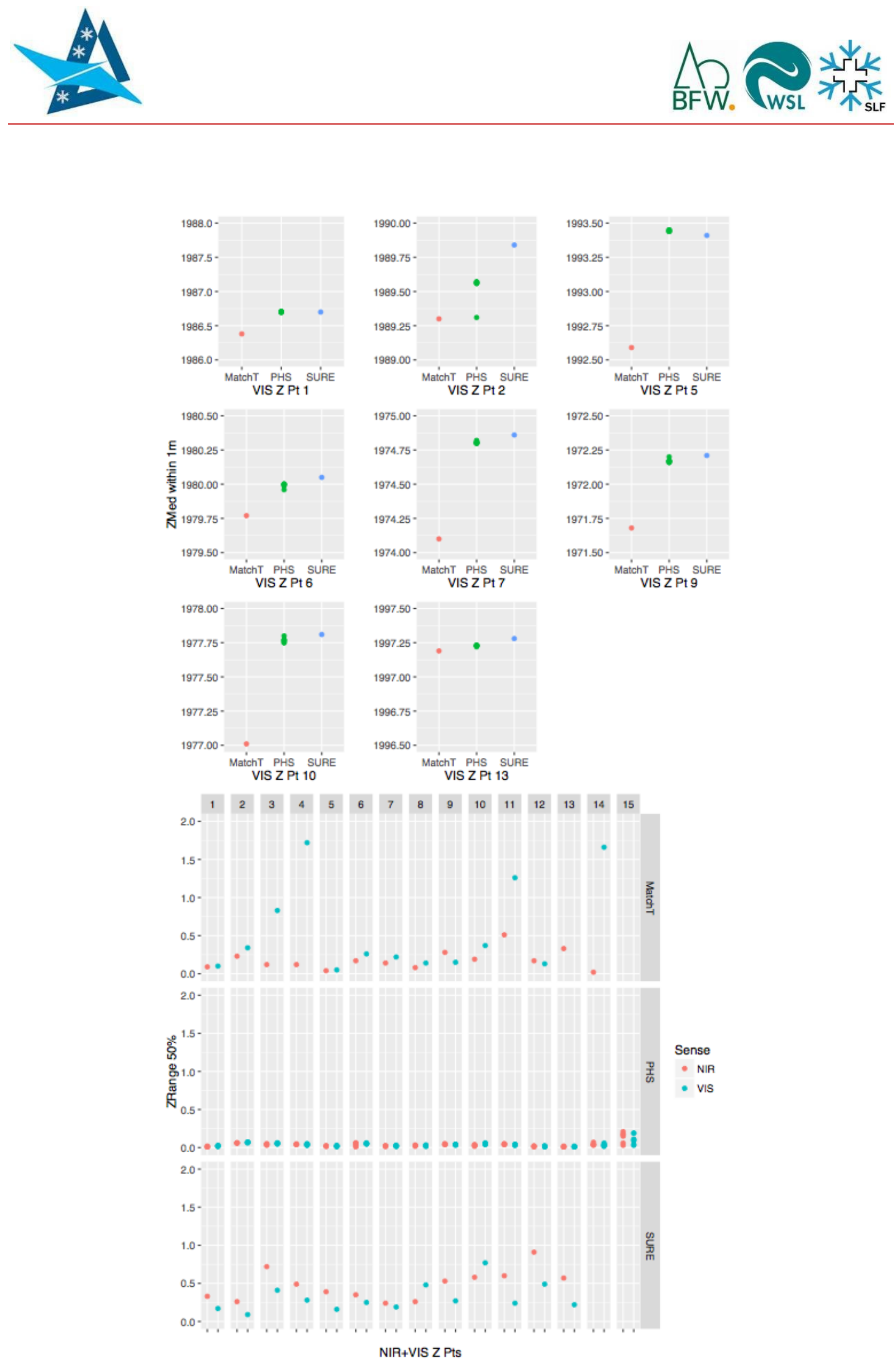

Figure 31: Variation of single evaluated spot heights. 


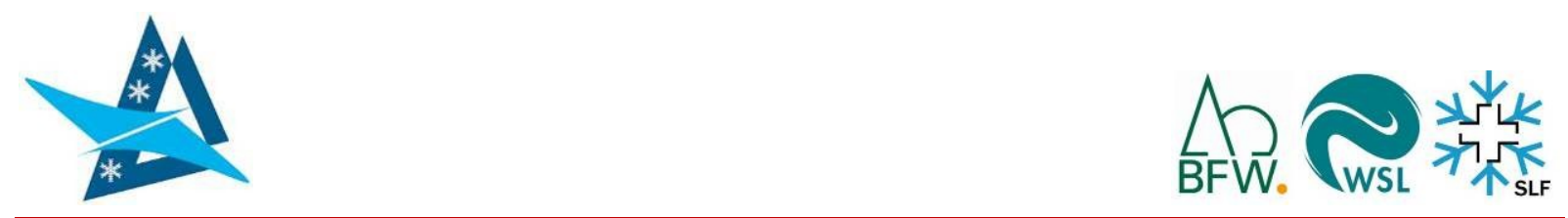

The median values (Figure 31) for each spot show, that only PSP measures the height in the spot area with small variance and independent of the spectral range. Match-T shows a distinct variation and underestimates the height significantly compared with PSP and SURE (e.g. points. 7, 9 \& 10). Because all three software packages do not share software implementations, the resulting height values are calculated independently and the coincident height measurements of most PSP and SURE evaluation points are therefore highly probable. The visual inspection of two sample areas for all three software packages (Figure 32) confirms the results of the spot evaluations. PSP and SURE show details more correctly, e.g. snow traces, roof area or shape of rocks in the lower sample. The matching algorithm of Match-T produces many artefacts, especially linear structures seem to get exaggerated. The noisy appearance of the SURE DSM is mainly caused by the very high point density, where the PSP DSM has been slightly smoothed by filtering.
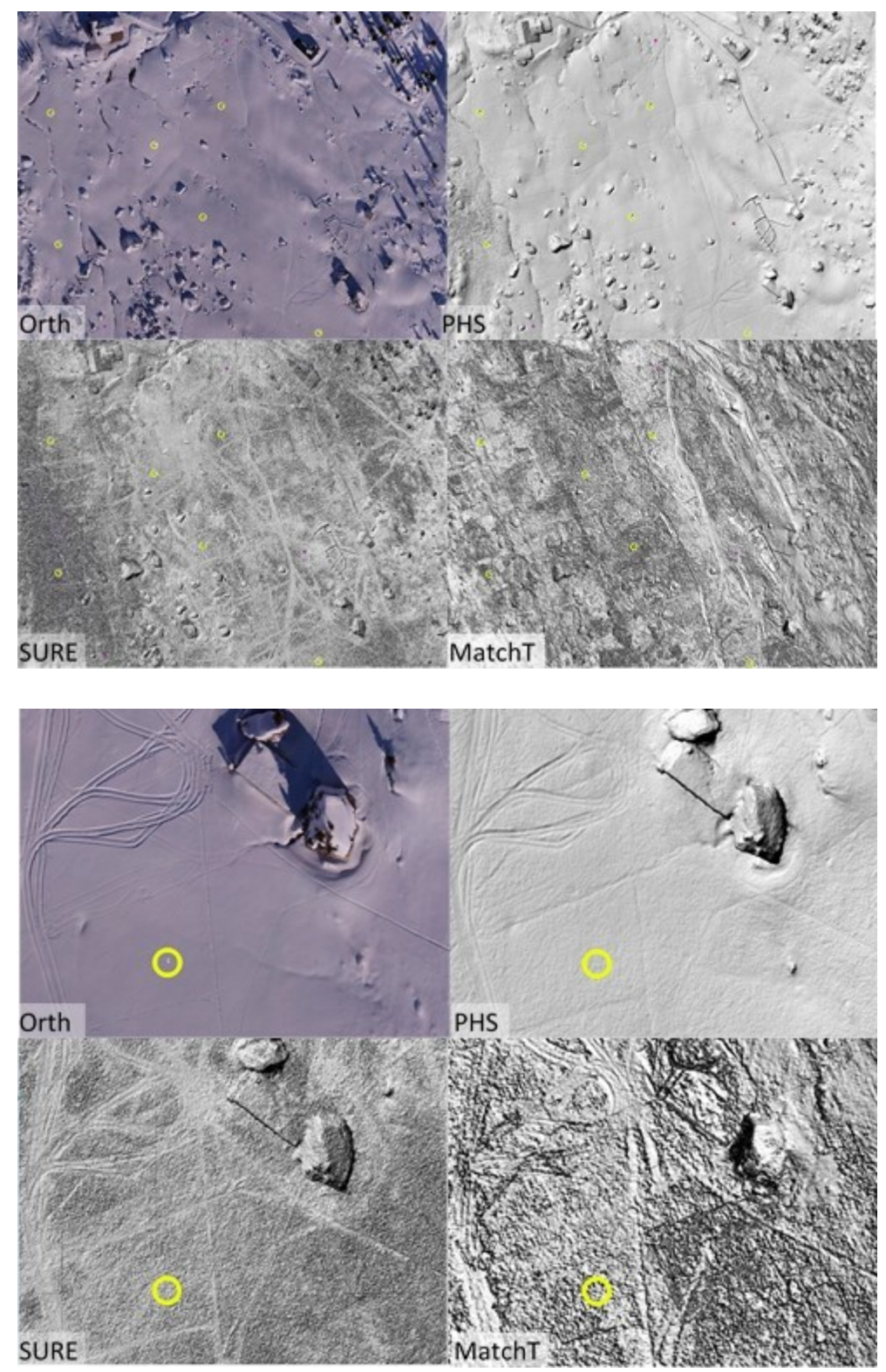

Figure 32: Visual inspection of shaded DSM. 


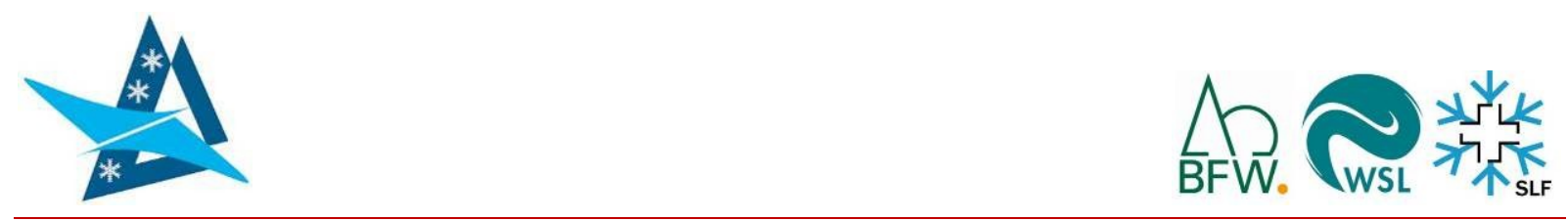

\section{Discussion}

\section{Applying RPAS in high-alpine terrain}

High-alpine terrain in winter is a very harsh environment for RPAS campaigns: Low temperatures (down to $-30^{\circ} \mathrm{C}$ ), high wind speeds / gusts (often more than $10 \mathrm{~m} \mathrm{~s}^{-1}$ ), high altitude (>2,000 $\mathrm{m}$ a.s.l.), high solar radiation, rapidly changing illumination and weather conditions, as well as the threat of avalanches are typical for these regions. Successful RPAS application therefore greatly depends on the ability of the platform and sensor, as well as the personnel to handle such conditions. All three types of RPAS (fixed-wing, helicopter and multicopter) were tested in high-alpine terrain in the frame of RPAS4SNOW; a comparison of their operational capabilities according to our experiences is provided in Figure 33.

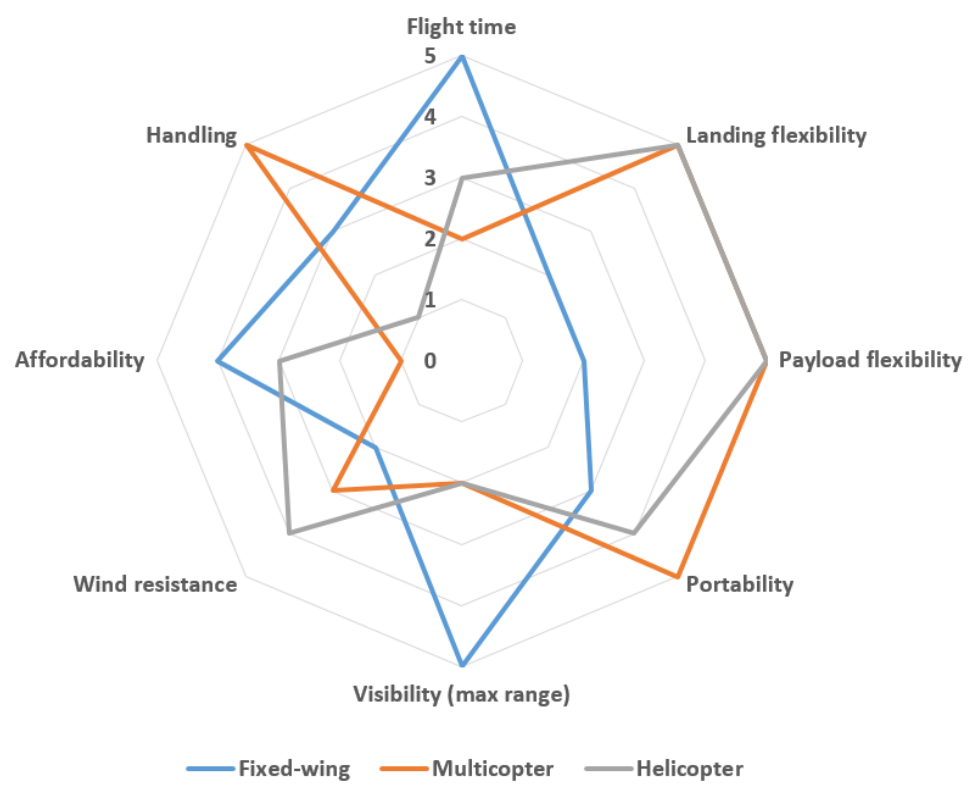

Figure 33: Comparison of different RPAS-platforms with regard to their suitability for application in wintry high-alpine terrain in RPAS4SNOW; each category was rated from 1 (very poor) to 5 (very good).

While the fixed-wing platform used in RPAS4SNOW is able to map comparably large areas ( $<50$ hectare), due to its long flight time ( $<45$ minutes) and good visibility (maximum range of $1,500 \mathrm{~m}$ ), it is less flexible with regard to the required landing space (flat, open area), payload capacity (limited by fuselage volume) and portability (fragile wing / tail unit). The multicopter was substantially limited by short flight time (6-10 minutes with one battery charge) and poor visibility (orientation generally difficult to recognise due to uniform structure). Additionally, the multicopter used in RPAS4SNOW had a relatively high cost of purchase, compared to the other RPAS used in the project. However, it could be started and landed on the spot, giving it a strong advantage in rugged, steep terrain, showed good wind resistance (even under foehn conditions, where wind speeds reached $20 \mathrm{~m} \mathrm{~s}^{-1}$ ) and easy portability (transport in a standard daypack while travelling on skies). Multicopter payload limits for volume and weight are less restrictive, than for fixed-wing RPAS and provided compatibility with the gimbal unit, a wide range of sensors may be used on this platform 


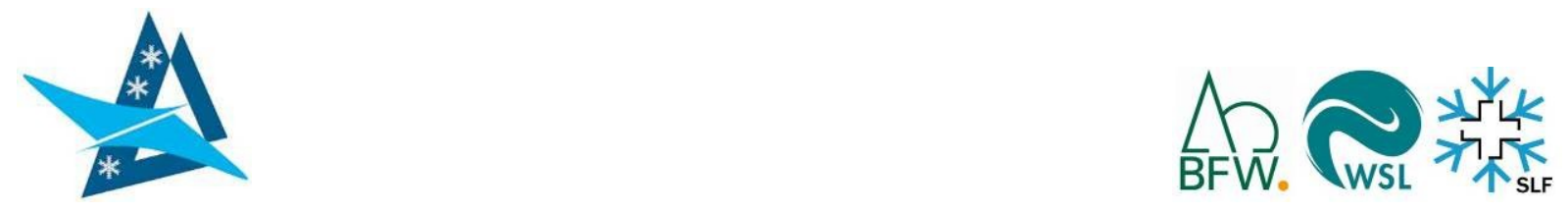

(Colomina \& Molina, 2014). The performance of the helicopter is similar to the multicopter, in fact it outperforms the latter with regard to wind resistance, flight time and payload capacity. The main drawback of the helicopter however, is its very complex handling (substantial piloting skills required for calibration and navigation) and its sophisticated and thus error-prone, fragile mechanical layout. It is therefore less easily portable and needs to be recalibrated where necessary, strongly limiting operational use.

While some of the above-mentioned criteria are rather specific to the models used in RPAS4SNOW (e.g. affordability, portability), the comparison does generally reflect some intrinsic characteristics of the different platforms (e.g. payload capacity, visibility). No weighting of the criteria was considered in this comparison; on the one hand the limited copter range might be a substantially limiting factor, when mapping avalanche terrain, as the pilot has to be in close proximity to the AOI (legal regulations in most countries require RPAS-flights to be conducted within visual line of sight); the easy handling (i.e. required piloting skills) of the multicopter on the hand is probably one of the main reasons for its wide-spread use and might therefore outweigh the short flight time.

\section{Photogrammetric snow depth mapping with RPAS}

Until very recently, photogrammetric HS mapping was deemed unfeasible (e.g. Bühler et al., 2016b). With the advent of large-frame digital sensors and digital photogrammetric processing technology, substantial progress was made in this field during the last years (Bühler, et al.; 2015, Nolan et al.; 2015; Lee et al., 2008). While digital sensors feature a much higher dynamic range than analogue film and are thus less hampered by difficulties arising from changing exposures, the issue remains, that snow surfaces are generally characterised by very low contrast. Although the identification of meaningful matching points does not depend on the manual skill of the photogrammetrist anymore, smooth snow surfaces and different illumination conditions still pose challenges for photogrammetric software (Nolan et al., 2015), as demonstrated in the following example.

As the Austrian study site is located in a valley, framed by high peaks, the late afternoon sun would drop behind the ridge in the west, casting a shadow over the valley floor. Four RPAS-flights were conducted on 13 February 2015: two while the target area was either partially (flight 4) or fully (flight 5) shadowed (Figure 34 and Figure 35, bottom row); two while the AOI was direct sunlight (Figure 34 and Figure 35, top row). Within each illumination scenario, VIS- (Figure 34) and NIR-flights (Figure 35, NIR830 filter, top; NIR700 filter, bottom) were performed. This makes for interesting results, as a direct comparison of the performance of the software with data acquired in different wavelengths and different illumination conditions is possible. The VIS shadow data shows a generally very noisy surface with large areas of implausible negative HS values in the centre and $E$, as well as very shallow HS results in the SE, especially in comparison to the VIS data recorded in direct sunlight. The NIR results on the other hand seem to suffer less from the lack of contrast, featuring only small noisy areas in the $E$, close to the light-shadow boarder. These results support the conclusion of Bühler et al. (2015b) that NIR-bands provide a valuable addition when mapping HS, especially under suboptimal lighting conditions and very homogeneous snow cover. These results were confirmed by further studies, detailed in Bühler et al. (2016b). 


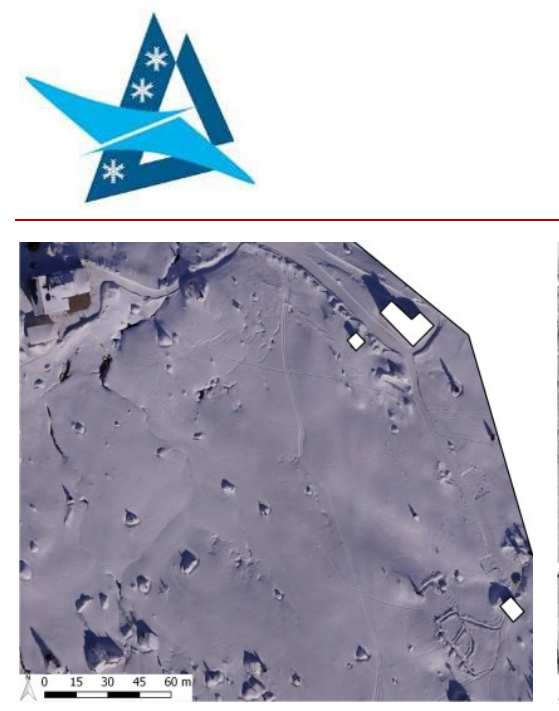

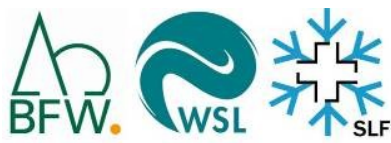
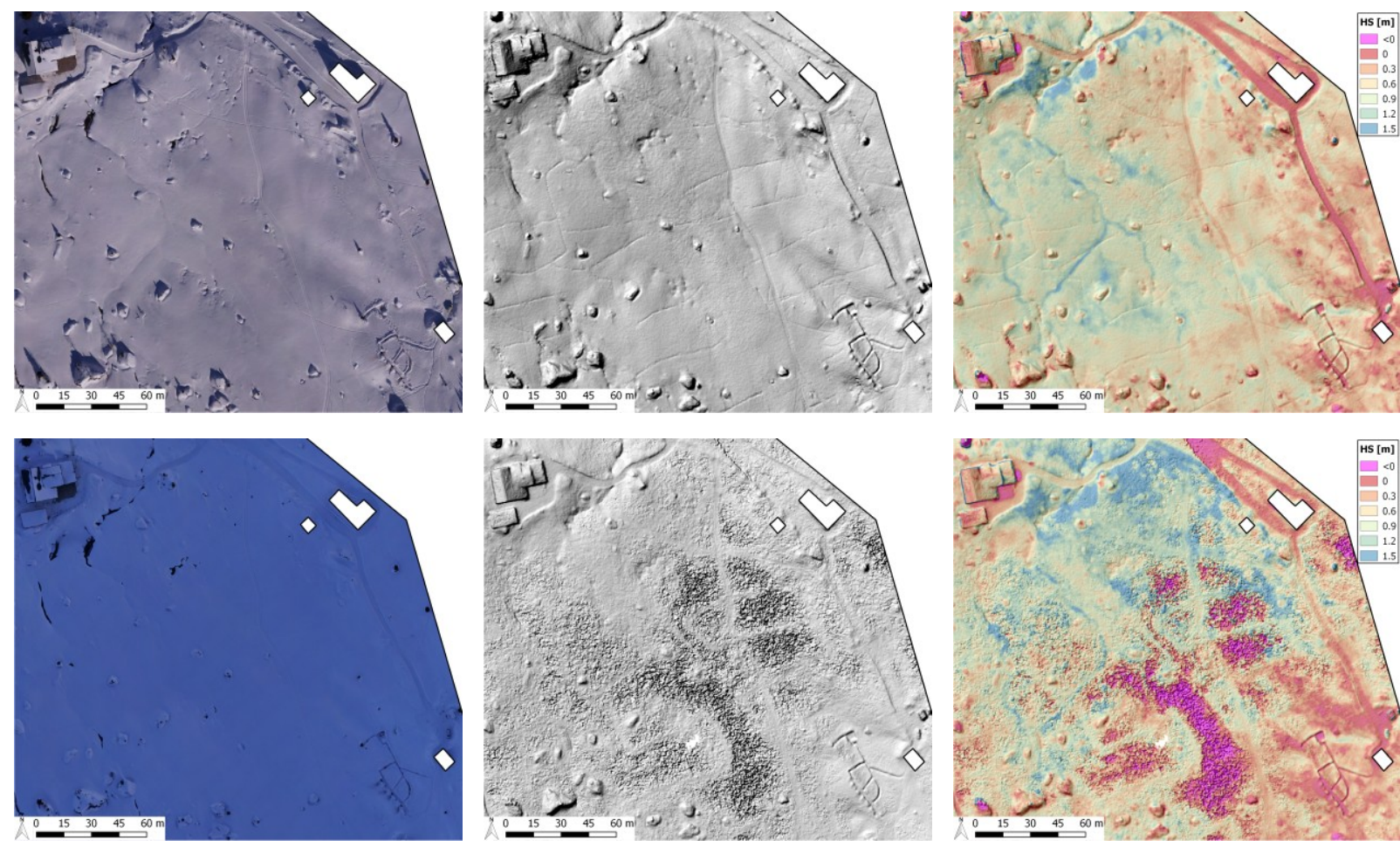

Figure 34: VIS data recorded with RPAS, while AOI was in direct sunlight (top row) and shadowed (bottom row) on 13 February 2015 (flight 1 \& 5, respectively); OP (left), shaded DSM (centre) and HS maps (right).
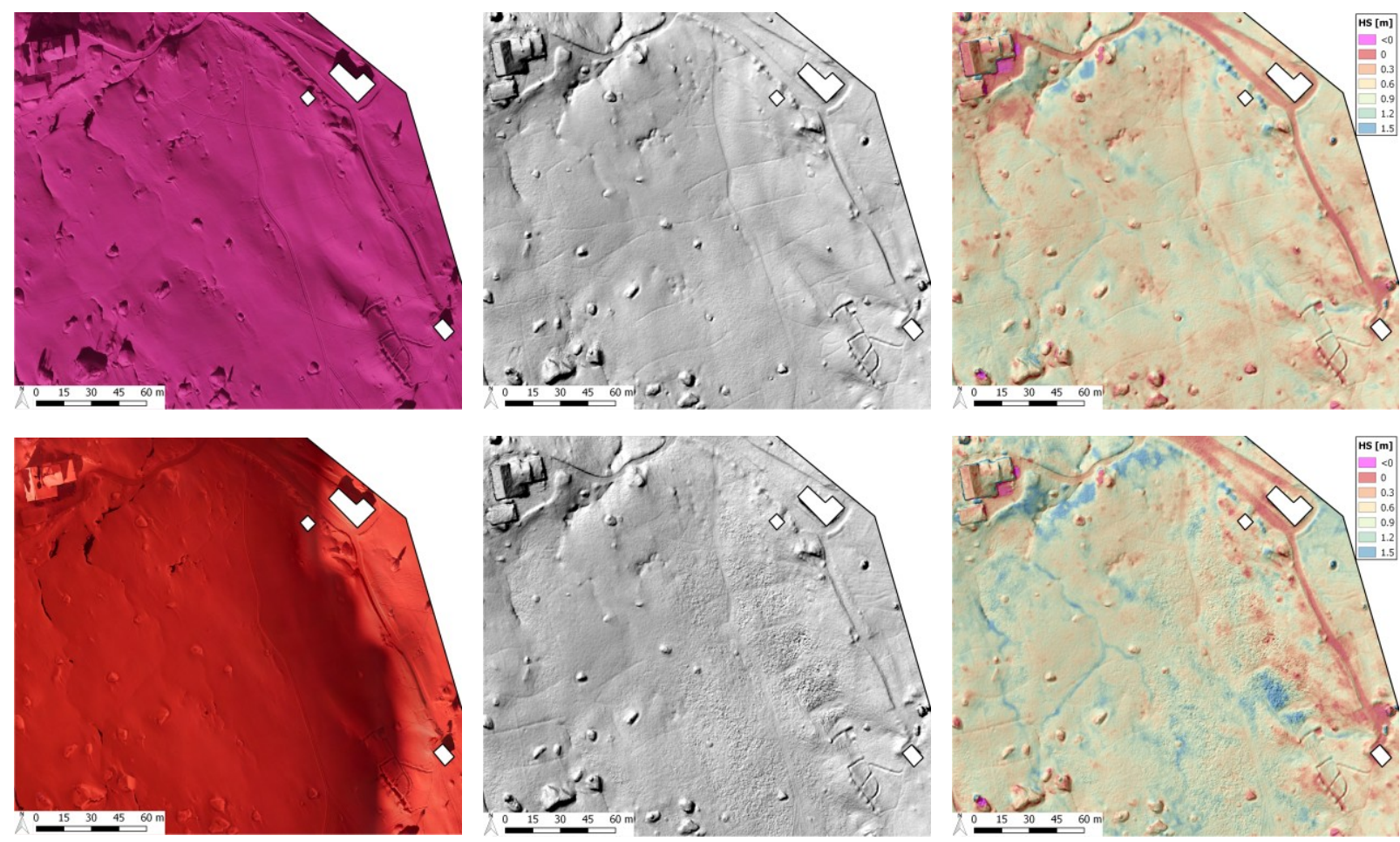

Figure 35: NIR data recorded with RPAS, while AOI was in direct sunlight (top row, NIR830) and mostly shadowed (bottom row, NIR700) on 13 February 2015 (flight 3 \& 4, respectively); OP (left), shaded DSM (centre) and HS maps (right). 


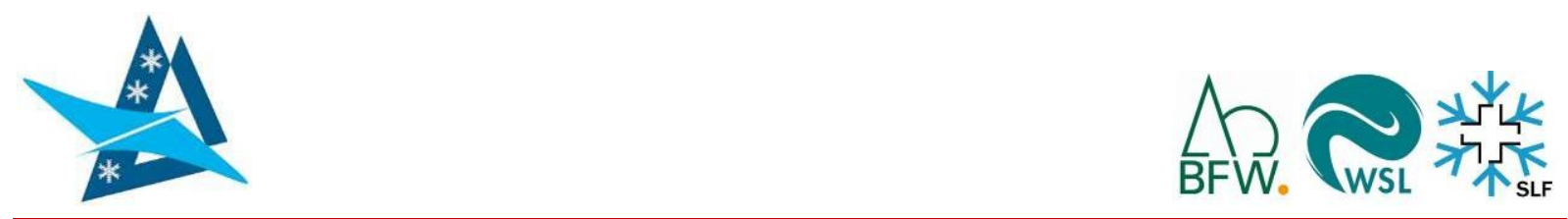

\section{Issues arising from blurry images}

The choice of the correct camera settings prior to an RPAS-campaign generally requires a trade-off between shutter speed, ISO and aperture, as highlighted by O'Connor et al. (2016) (Figure 36).

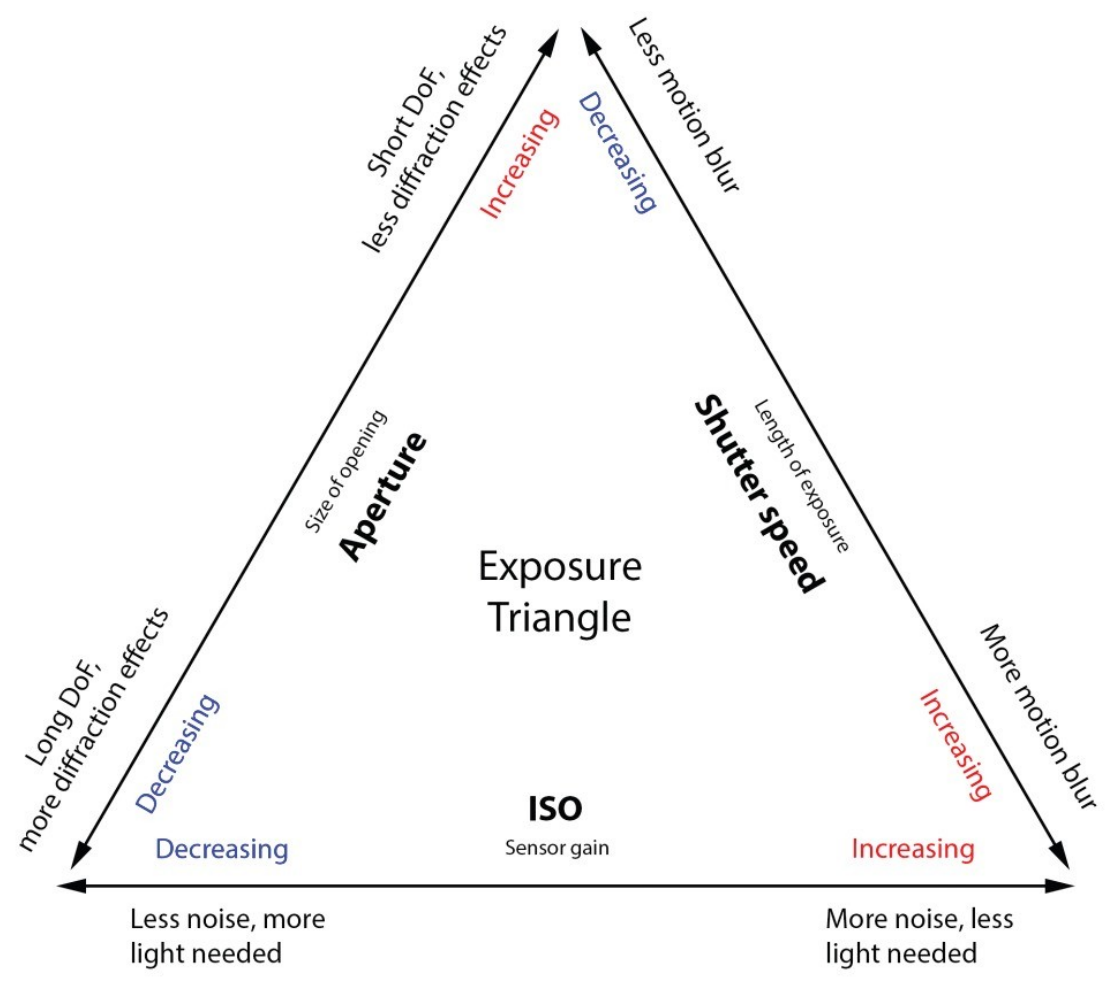

Figure 36: Exposure Triangle, showing the dependency of shutter speed, aperture and ISO (after O'Connor et al., 2016).

One of the main reasons for corrupt RPAS-imagery is motion blur, which may result from too slow shutter speeds in relation to the movement of the RPAS platform. This applies in particular to motion in direction of the platform's roll-axis, resulting from cross-winds and increases with the length of the camera lens. As the sensor on-board our fixed-wing RPAS was not stabilised by a gimbal and the platform was, compared to the copters, more affected by wind, up to $15 \%$ of the imagery was corrupted by motion blur. An example of the impact of blurry imagery on the quality of the HS maps is provided in Figure 37. As described in Chapter 4.1, the Agisoft QI was identified as a meaningful indicator for overall RPAS-imagery quality. While illumination, camera settings and image properties of both flights presented in Figure 37 are comparable (Table 3), the images collected on 13 February 2015, (flight 3, top) had a reasonably high QI (0.72), while the data from 11 February 2015 (flight 1, bottom) were generally very blurry (no QI could be calculated). Although data acquisition was only two days apart, distinct difference can be seen in the respective HS maps: While flight 3 shows plausible HS values (snow free areas close to $0 \mathrm{~m} \mathrm{HS}$ ), flight 1 is generally characterised by high noise (high roughness of snow surface) and implausible negative HS values in the centre and NE sector of the figure. This is due to the fact that blurry images provide less potential matching points for the photogrammetric software to use for triangulation and point cloud densification. Therefore, the QIcheck was routinely implemented in the RPAS4SNOW processing routine. 

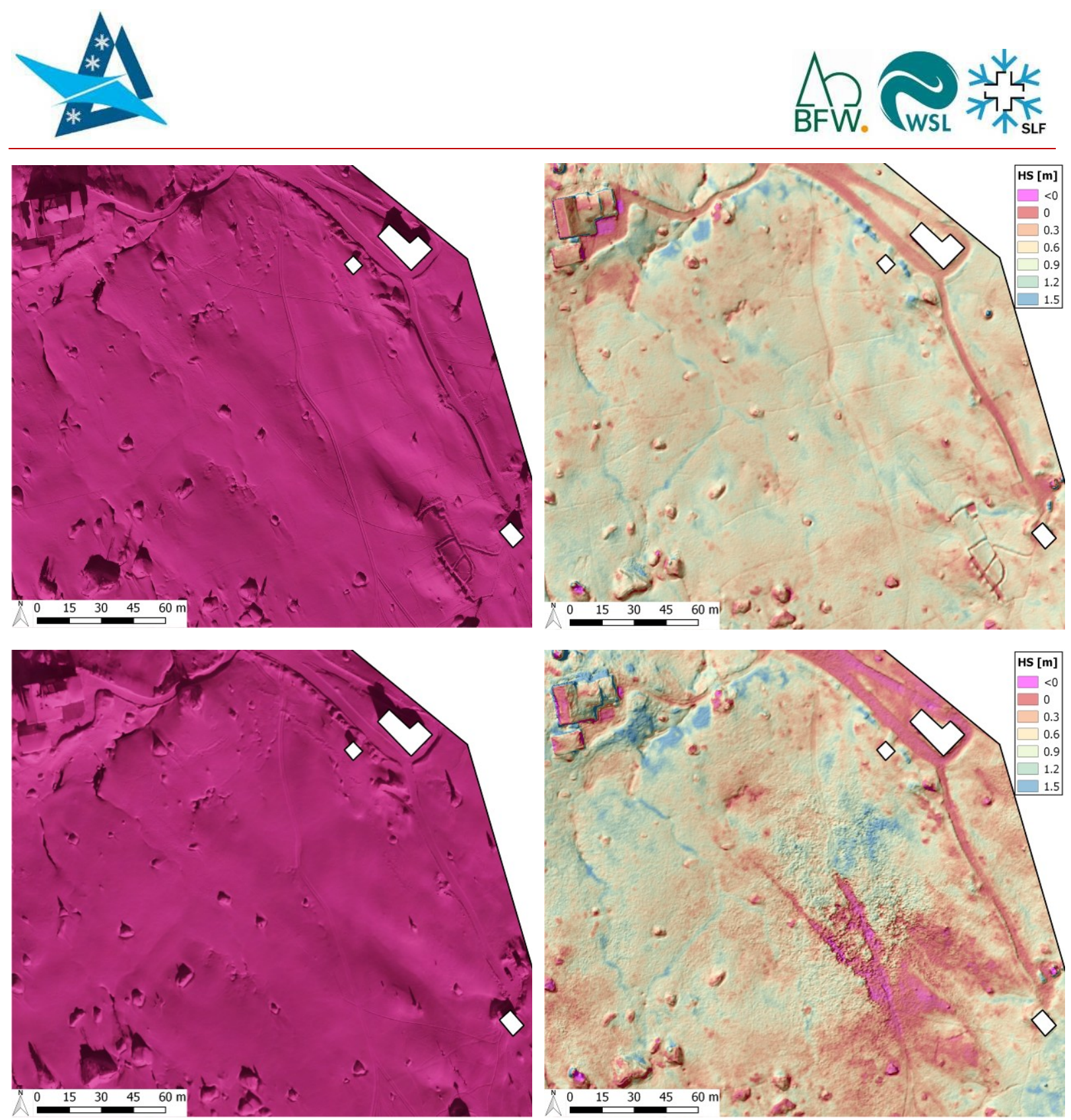

Figure 37: OP \& HS of two NIR830 flights (top: 13 February 2015, flight 3; bottom: 11 February 2015, flight 1).

\section{Influence of vegetation on snow depth mapping}

Figure 38 shows a section in the $\mathrm{W}$ of the Austrian study site, with some dark-green patches of medium-rise vegetation (pinus mugo) (top left - overview; top right - detail), which can reach several meters in height. The winter-OP (bottom left) from an RPAS-campaign conducted on 10 April 2016 shows, that they are mostly covered with snow. The corresponding HS map (bottom right) however, reports very shallow or negative HS values, while the areas surrounding the pinus mugo reach $>1.5 \mathrm{~m}$ HS. Similar implausible values are mapped for trees (mostly pinus cembra) at the study site. These irregularities are caused by the vegetation being compressed by the snow cover during the course of the winter. When comparing the snow-covered to the snow-free DSM, the net value might still be negative (i.e. the snow cover is lower than the vegetation in summer), depending on the HS. However, as the Lizum area is used as alpine pasture and lies close to the treeline, only very small areas of medium or high-rise vegetation are present and thus affected by these discrepancies. 

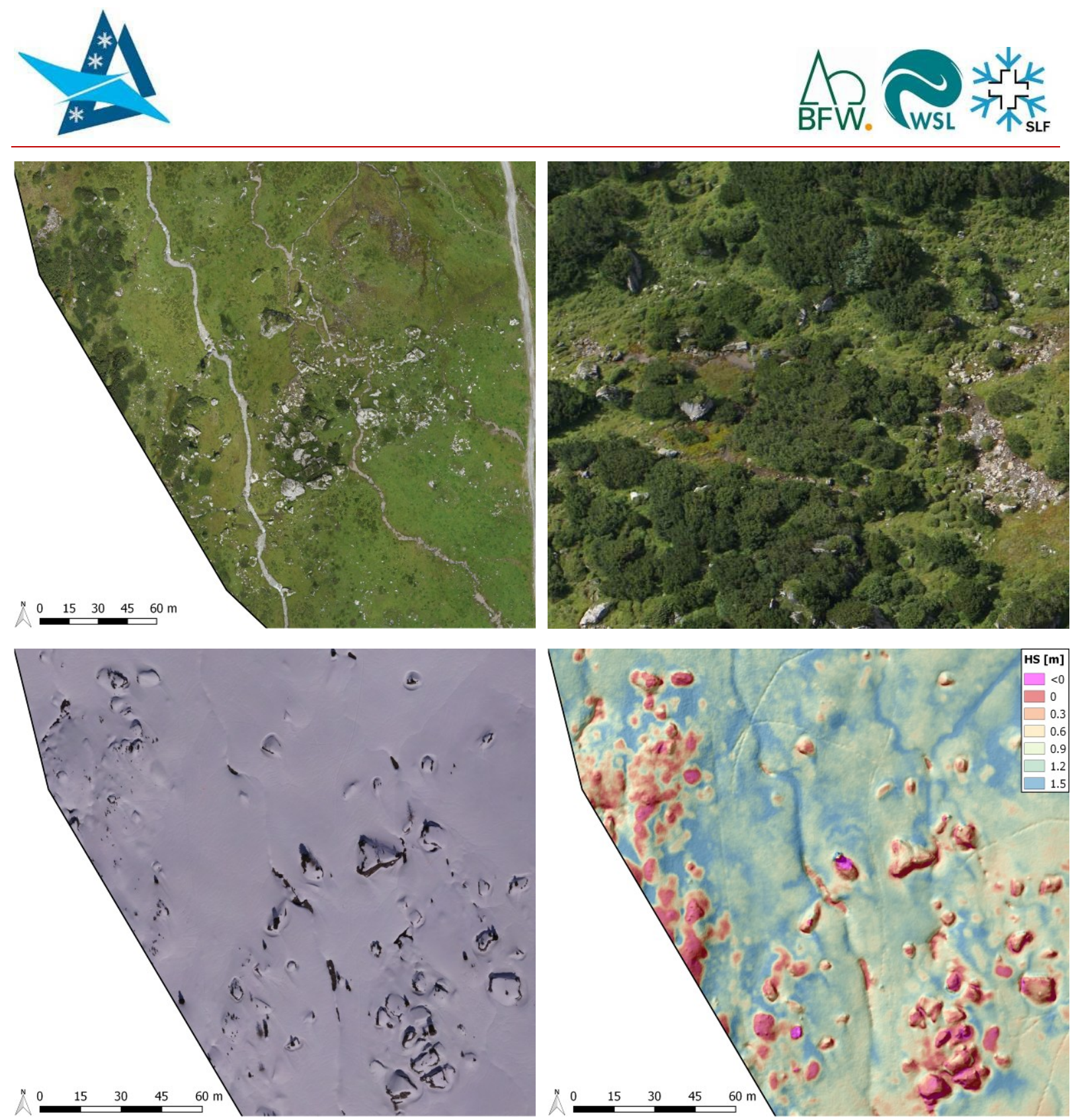

Figure 38: Area with medium-rise vegetation in summer (OP - top left; aerial photograph - top right) and winter (OP - bottom left; HS map - bottom right).

\section{Validation issues}

In RPAS4SNOW we employed various state-of-the-art methods to collect reference data, in order to evaluate the accuracy of the RPAS-based HS maps. The error-margin of these methods is well-known, as they have been evaluated and reported in detail in previous publications (Chapter 1). However, some issues were experienced in RPAS4SNOW with regard to the validation methods, which should be kept in mind, when interpreting the accuracy and precision evaluation of RPAS-data presented here:

1. Manual measurements: As described in Chapter 5.3.1, the results from the in-situ HS measurements show a negative bias (on average $0.18 \mathrm{~m}$ ). This can most likely be attributed to the fact, that the photogrammetrically calculated snow-free DSM reports the surface height of vegetation (e.g. surface of grass cover), rather than the height of the ground below 


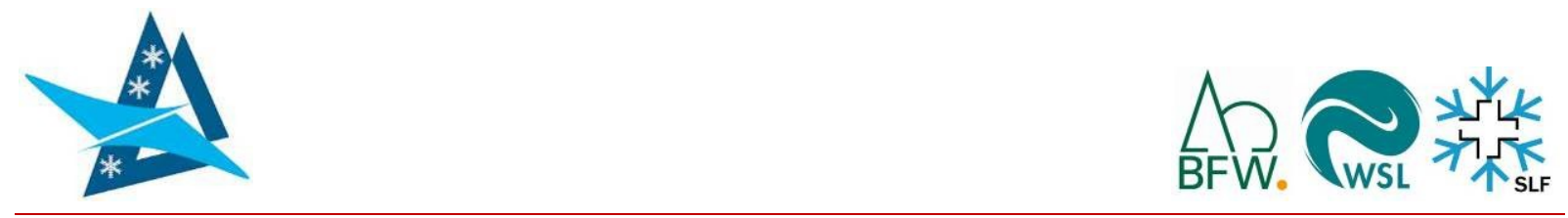

(as would be the case for example with LiDAR-data). When sounding the depth of the snow cover, the probe will penetrate the vegetation cover and most likely also part of the top soil, resulting in a general overestimation of HS values. Furthermore, the representativeness of the in-situ data has to be seen in relation to the number of recorded measurements $(n=37-$ 150 ), especially in comparison to TLS-data ( $n \leq 183,000$ ). The in-situ data were generally collected after the RPAS-flights had been finalised. However, on 13 February, the tracks from the previous campaign were still visible, neither precipitation nor snow drift had occurred during this time $(0.04 \mathrm{~m}$, as observed by the AWS). The disturbance of the snow cover by the skies of the field crew, where the manual measurements were taken, created detectable matching points for the photogrammetry software on an otherwise homogeneous snow cover. Figure 39 shows the OP of a section in the SE of the AOI on 13 February (flight 1) on the left, and a HS map from later that day (flight 5) on the right. In this comparison, the positive influence of the ski tracks on the calculated HS values can be observed. The in-situ data will therefore probably generally overestimate the accuracy of the RPAS-HS maps, compared to the remote sensing techniques used for validation.
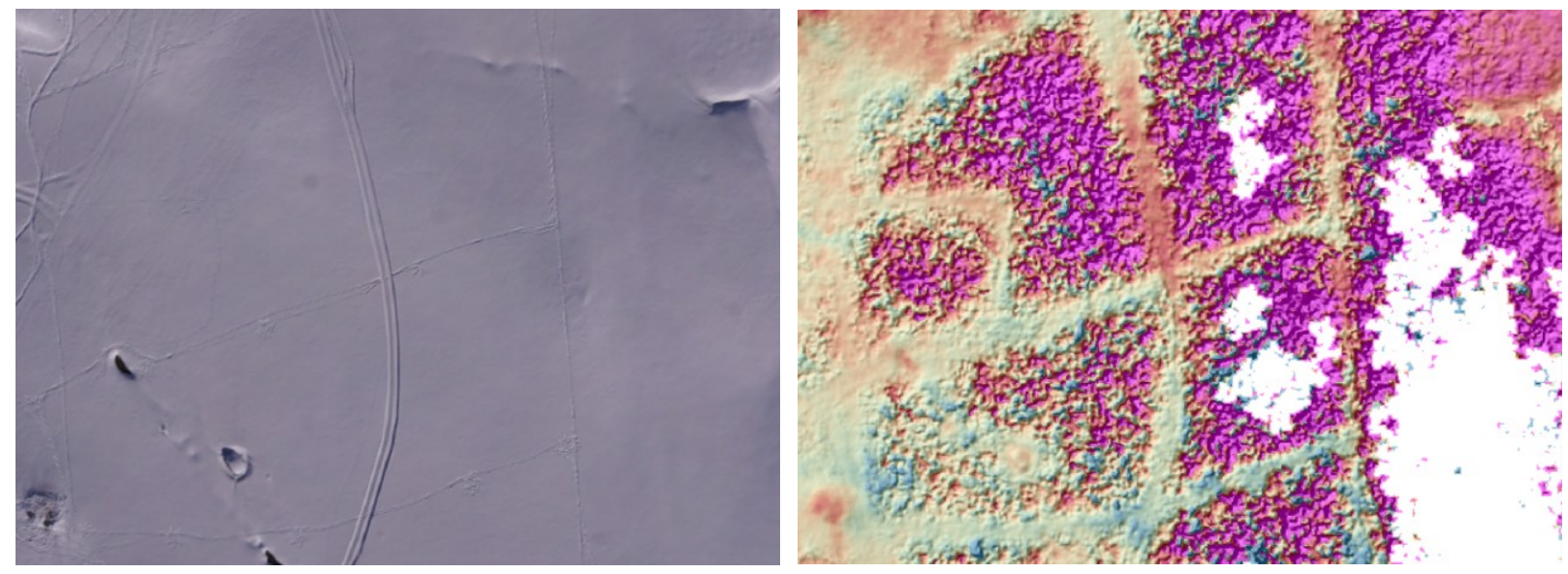

Figure 39: Example for the relationship between ski tracks (OP, left) and quality of HS maps (right; violet = negative, implausible HS values).

2. TLS-measurements: The overall accuracy of the TLS-measurements is well known and the large number of point measurements $(n \leq 183,000)$ and large coverage of the AOI $(70 \%)$ gives a very good impression of the accuracy. However, the measurement principle of the TLS results in a generally decreasing point density with distance from the instrument, resulting in an overrepresentation of validation point in the foreground of the TLS, i.e. in the $E$ of the AOI. Additionally, the unfavourable geometry of the measurement setup (high number of acute angles, especially in the $\mathrm{W}$ of the AOI) has a negative influence on the validity of the results.

3. LFAS-measurements: (the reader is kindly referred to Boesch et al., 2016)

4. Evaluation of precision: The precision of the RPAS-data at the Austrian study site has a very limited informative values, as it is based on the comparison of very small areas. 


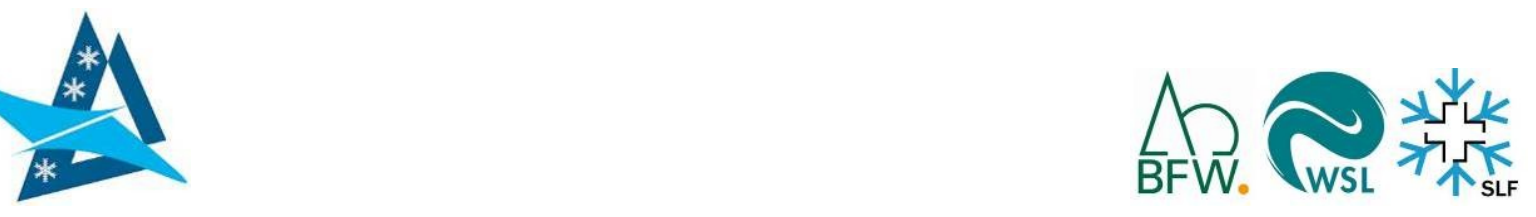

\section{Software comparison}

PSP and SURE calculate correct DSM for two differently acquired datasets over fresh snow coverage. The height variation of Match-T is not sufficient in relation to the available high GSD of $0.036 \mathrm{~m}$. It has to be shown, if the parameter selection for Match-T was completely inappropriate. The processing time for SURE (144 h) was roughly 10x compared with PSP and Match-T. SURE unfortunately selects the highest precision and product options, therefore at least a significant performance improvement can be expected by deselecting processing options. 


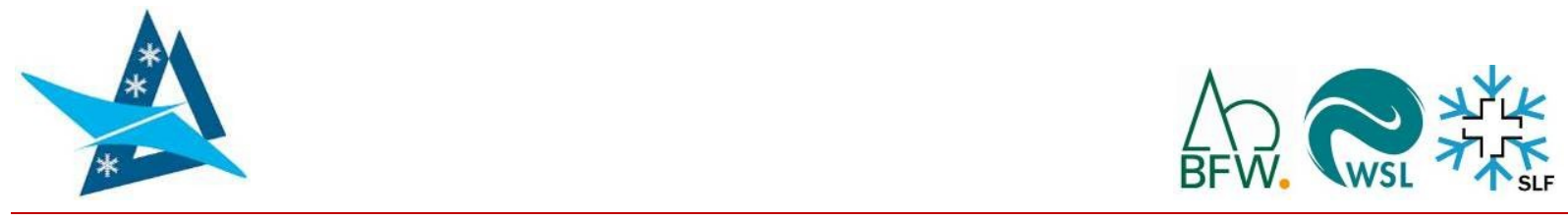

\section{Conclusions and Outlook}

In this report we described the feasibility of applying remotely piloted aerial systems to map snow depth at very high spatial resolutions under the harsh environment of wintry (high-) alpine terrain. In the presented pilot study RPAS4SNOW, we used three different types of small RPAS platforms (fixedwing, multicopter \& helicopter) to acquire aerial photographs over snow-covered mountainous terrain. These RPAS had a typical weight of $2-5 \mathrm{~kg}$, flight times of $12-40$ minutes, a wing span of $<1.6 \mathrm{~m}$, and were optimised for easy field deployment / recovery and transport. They were fitted with different commercial off-the-shelf sensors, which allowed recording data in the visible and nearinfrared part of the electromagnetic spectrum. The appropriate choice of platform / sensor depends on the application (i.e. requirements for data - spectral / spatial resolution), size and accessibility or target area, technical specifications of the platform, and piloting skills. Using different structurefrom-motion photogrammetry software and indirect georeferencing, we successfully calculated OPs, DSMs and by comparison with snow-free DSM, snow depth maps from the RPAS-imagery.

The accuracy of the RPAS results was validated with in-situ snow depth measurements, TLS and LFAS data and is in the range of $0.07-0.3 \mathrm{~m}$, depending on the type of RPAS platform and sensor used. The precision (i.e. repeatability) of the RPAS data was assessed by comparing results from multiple flights over the same area and lies at $0.045-0.21 \mathrm{~m}$. These values are in the same range as results reported in recent studies, where snow depth was mapped from manned aircraft (Nolan et al., 2015) or RPAS (Harder et al., 2016; de Michele et al., 2016 and Vander Jagt et al., 2015). It was shown in this study, that the use of low-cost NIR-sensors (modified commercial off-the-shelf cameras) for RPAS-based snow depth mapping, improves the accuracy of the results considerably, thus confirming findings from previous studies with manned aircraft data (e.g. Bühler et al., 2015b). More elaborate and costly multispectral cameras are now available, which are small and light enough for application in RPAS (e.g. MicaSense RedEdge, TetraCam Micro MCA, Camer Link Condor 5). In contrast to the cameras used in RPAS4SNOW these multispectral cameras consist of several sensors, combined into a multi-camera array, allowing calibrated data collection at narrow, designated wavelength windows. All operate with different kind of band-pass filters. The subsequent processing allows combinations of different channels to calculate indices with specific characteristics (e.g. NVDI). At the end of RPAS4SNOW, the consortium conducted first tests with a MicaSense RedEdge, however to results were generated during project lifetime. The presence of vegetation underneath the snow cover substantially influences the accuracy of the RPAS-based snow depth maps and should be taken into consideration during campaign planning and data analyses.

While RPAS-based snow depth mapping is limited to relatively small areas (less than 50 hectares per sortie with a fixed-wing platform), it may provide reliable snow depth information on-demand at an unprecedented level of detail (centimetres to millimetres), which are easily and cost-efficiently repeatable. A considerable drawback of the indirect georeferencing technique used here, was the requirement to distribute GCPs in the target area and determine their position with GNSS. Besides being a very time-consuming and potentially dangerous task, it reduces the benefits of a close-range sensing technique considerably. New light-weight electronic components are in development and their interaction with the corresponding software tools is being continuously improved. RTK-GNSS 


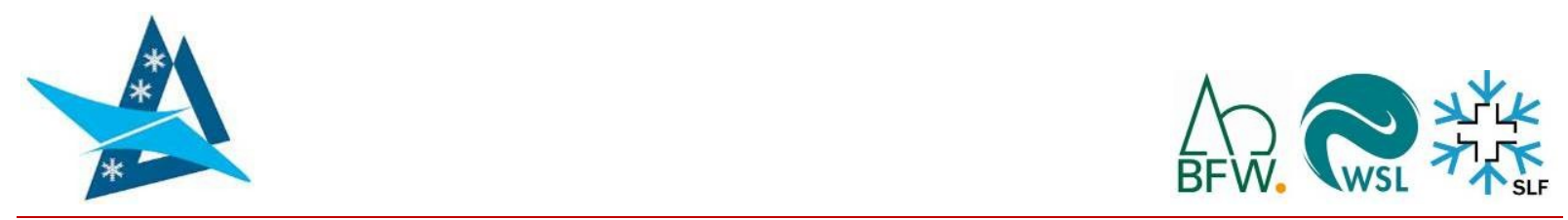

(real time kinematic global navigation satellite system) are now available on the market for a low budget. RTK-GNSS aims to use the phase shift from the carrier wave of the satellite signal between a fixed receiver and a receiver in motion. This should allow on the fly processing and improve the accuracy of the determined position remarkably. RTK-GNSS were not used in RPAS4SNOW, but we already started with first tests. The assignment of GCPs is established in PSP by a user interaction. PSP already supports the detection of individual symbols as GCPs in order to skip this step. This helps to realise a photogrammetric work flow without user interaction. Unfortunately, the size of these symbols must be around one square meter caused by the height of the RPAS above ground and the camera specifications. Boards with such large GCP symbols are uncomfortable to be used in the field. Therefore, they were not applied in RPAS4SNOW. 


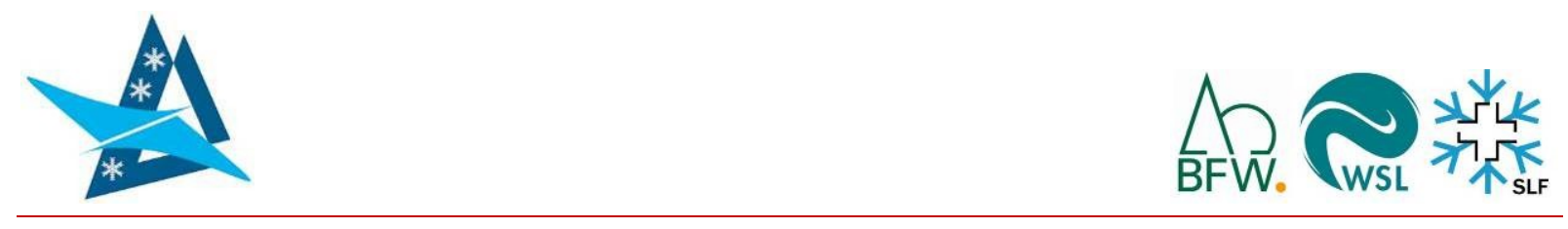

\section{References}

Aber, J. S., Marzloff, I. \& Ries, J. B. (2010): Small-Format Aerial Photography. Principles, Techniques and Geoscience Applications. Elsevier, Amsterdam.

Adams, M., Huber, A. \& Gigele, T. (2015): Applying Terrestrial Laserscanning to Continuous Snow Cover Monitoring in an Alpine Environment - A Feasibility Study

Adams, M.S. (2008): Critical evaluation of terrestrial laser scanning in a snow-covered Alpine environment. Master thesis, Institute of Geography; University of Innsbruck, Austria.

Adams, M.S., Fromm, R. \& Lechner, V. (2016): High-resolution debris flow volume mapping with unmanned aerial systems (UAS) and photogrammetric techniques. ISPRS Archives (accepted).

Adams, M.S., Gleirscher, E., Gigele, T. \& Fromm, R. (2013): Automated Terrestrial Laser Scanner measurements of small-scale snow avalanches. International Snow Science Workshop (ISSW), 711. October 2013, Grenoble / Chamonix Mont Blanc, p. 101.

Agisoft LLC, 2016. PhotoScan Python Reference, Release 1.2.3, 63 pages.

Akyürek, Z. \& Sorman, A.Ü. (2002): Monitoring snow-covered areas using NOAA-AVHRR data in the eastern part of Turkey. Hydrological Sciences, 47, pp. 243-252.

Austro Control (2013): Lufttüchtigkeits- und Betriebstüchtigkeitshinweis Nr. 67, Lufttüchtigkeits- und Betriebstüchtigkeitsanforderungen für unbemannte Luftfahrzeuge bis $150 \mathrm{~kg}$. Available online via http://www.austrocontrol.at/luftfahrtbehoerde/lizenzen_bewilligungen/flugbewilligungen/unbe mannte_Ifz.

Bair, E.H. (2013): Forecasting artificially-triggered avalanches in storm snow at a large ski area. Cold Regions Science and Technology, 85, pp. 261-269.

Bartelt, P.; Buehler, Y.; Buser, O.; Christen, M. \& Meier, L. (2012): Modeling mass-dependent flow regime transitions to predict the stopping and depositional behavior of snow avalanches. Journal of Geophysical Research-Earth Surface, 2012, p. 117.

Basnet, K., Muste, M., Constantinescu, G., Ho, H. \& Xu, H. (2016): Close range photogrammetry for dynamically tracking drifted snow deposition. Cold Regions Science and Technology, 121, 141-153.

Bavay, M., Lehning, M., Jonas, T. \& Löwe, H. (2009): Simulations of future snow cover and discharge in Alpine headwater catchments, Hydrological Processes, 23, 95-108.

Beniston, M. (1997): Variations of Snow Depth and Duration in the Swiss Alps over the last 50 Years: Links to Changes in Large-Scale Climatic Forcings. Climatic Change 36, pp. 281-300.

Bilodeau, F., Gauthier, G. \& Berteaux, D. (2013): The effect of snow cover on lemming population cycles in the Canadian High Arctic, Oecologia, 172, 1007-1016. 


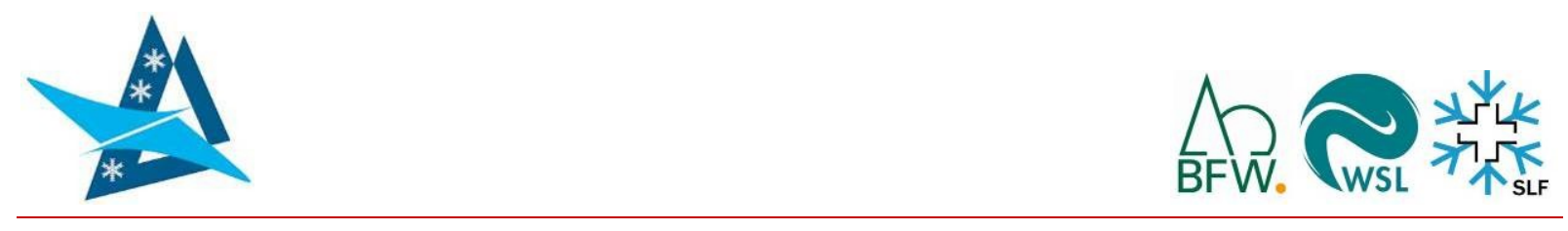

Bláha, M., Eisenbeiss, H, Grimm, D. \& Limpach, P. (2011): Direct georeferencing of UAVS. International Archives of the Photogrammetry, Remote Sensing and Spatial Information Sciences, Vol. XXXVIII-1/C22 UAV-g 2011, Conference on Unmanned Aerial Vehicle in Geomatics, Zurich, Switzerland.

Böhm, B. et al (2010): ANDROMEDA. Anwendung Drohnen-basierter Luftbilder - Mosaikierung, Entzerrung und Datenauswertung; Abschlussbericht des Verbundforschungsprojekts. Hrsg.: Friedrich-Schiller-Universität Jena, Institut für Geographie, Lehrstuhl für Geoinformatik, Geohydrologie und Modellierung, Jena, Germany.

Bollmann, E., Sailer, R., Briese, C., Stötter, J. \& Fritzmann, P. (2011): Potential of airborne laser scanning for geomorphologic feature and process detection and quantifications in high alpine mountains. Zeitschrift für Geomorphologie Supplementary Issues, 55(2), 83-104.

Briese, C., Fortner, R., Sager, P. \& Pfeifer, N. (2013): Vom Modellflughobby zu unbemannten Flugsystemen für die Geodatenerfassung. Österreichische Zeitschrift für Vermessung und Geoinformation (VGI), 101 (2013), 2+3, pp. 64-74.

Bühler, Y., Adams, M.S., Boesch, R. \& Stoffel, A. (2016b): Mapping snow depth in alpine terrain with unmanned aerial systems (UAS): potential and limitations. The Cryosphere, 10, 1075-1088.

Bühler, Y., Hüni, A., Christen, M., Meister, R. \& Kellenberger, T. (2009): Automated detection and mapping of avalanche deposits using airborne optical remote sensing data. Cold Regions Science and Technology, 57, pp. 99- 106.

Bühler, Y., Marty, M. \& Ginzler, C. (2012): High Resolution DEM Generation in High-Alpine Terrain Using Airborne Remote Sensing Techniques. Transactions in GIS, 2012, 16, 5, pp. 635-647.

Bühler, Y., Marty, M., Egli, L., Veitinger, J., Jonas, T., Thee, P. \& Ginzler, C. (2015a): Snow depth mapping in high-alpine catchments using digital photogrammetry, The Cryosphere, 9, 229-243.

Bühler, Y., Meier, L., and Ginzler, C. (2015b): Potential of operational, high spatial resolution near infrared remote sensing instruments for snow surface type mapping, Geoscience and Remote Sensing Letters, IEEE, 12, 821 - 825.

Bühler, Y., Stoffel, A., Adams, M., Boesch, R. \& Ginzler, C. (2016a): UAS photogrammetry on homogenous snow cover. Proceedings Dreiländertagung 7.-9. Juni 2016, Bern.

Buser, O., Föhn, P., Good, W., Gubler, H. \& Salm, B. (1985): Different methods for the assessment of avalanche danger. Cold Regions Science and Technology, 10, 3, pp. 199-218.

Cappabianca, F., Barbolini, M. \& Natale, L. (2008): Snow avalanche risk assessment and mapping: A new method based on a combination of statistical analysis, avalanche dynamics simulation and empirically-based vulnerability relations integrated in a GIS platform. Cold Regions Science and Technology, 54, 3, pp. 193-205. 


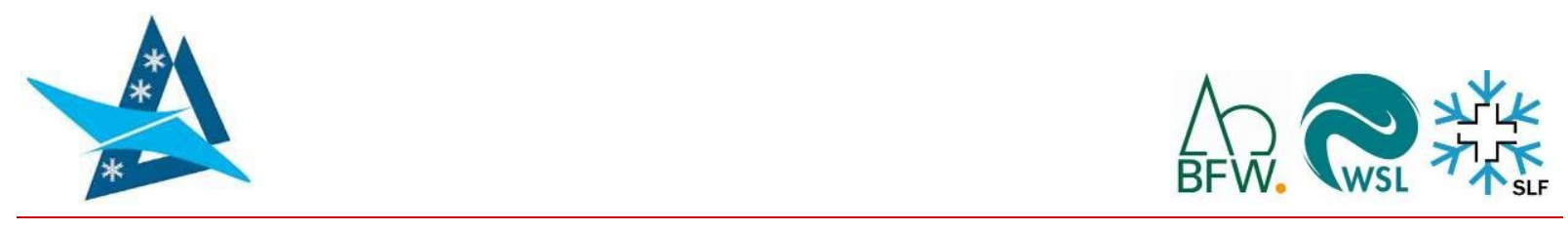

Chrustek, P., Wezyk, P., Kolecka, N., Biskupic, M., Bühler, Y. \& Christen, M. (2013): Using High Resolution LiDAR Data for Snow Avalanche Hazard Mapping. In: Kozak, J.; Ostapowicz, K.; Bytnerowicz, A.; Wyzga, B. (eds.) The Carpathians: Integrating Nature and Society Towards Sustainability. Environmental Science and Engineering. Berlin, Heidelberg, Springer, pp. 597-613.

Cline, D. W. (1993): Measuring alpine snow depths by digital photogrammetry: Part 1. conjugate point identification, Proceedings of the Eastern Snow Conference, Quebec City.

Cline, D. W. (1994): Digital Photogrammetric Determination Of Alpine Snowpack Distribution For Hydrologic Modeling, Colorado State University, CO, USA.

Cline, D.W., Bales, R.C. \& Dozier, J. (1998): Estimating the spatial distribution of snow in mountain basins using remote sensing and energy balance modeling. Water Resources Research, 34, 5, pp. 1275-1285.

Colomina, I. \& Molina, P. (2014): Unmanned aerial systems for photogrammetry and remote sensing: A review. ISPRS Journal of Photogrammetry and Remote Sensing, 92, pp. 79-97.

D’Oleire-Oltmanns, S., Marzolff, I., Peter, K. \& Ries, J. (2012): Unmanned Aerial Vehicle (UAV) for monitoring soil erosion in Morocco. Remote Sensing 4, pp. 3390-3416.

Dall'Asta, E., Delaloye, R., Diotri, F., Forlani, G., Fornari, M., Morra di Cella, U., Pogliotti, P., Roncella, R., Santise, M. (2015): Use of UAS in a high mountain landscape: The case of Gran Sommetta rock glacier (AO). ISPRS International Archives of the Photogrammetry, XL-3/W3, pp. 391-397.

Danzi, M., Di Crescenzo, G., Ramondini, M., Santo, A. (2013): Use of unmanned aerial vehicles (UAVs) for photogrammetric surveys in rockfall instability studies. Rend. Online Soc. Geol. It., 24, pp. 8285.

De Michele, C., Avanzi, F., Passoni, D. Barzaghi, R., Pinto, L., Dosso, P., Ghezzi, A., Gianatti, R. \& Della Vedova, G. (2016): Using a fixed-wing UAS to map snow depth distribution: an evaluation at peak accumulation. The Cyrosphere, 10, 511-522.

Deems, J. S. \& Painter, T. H. (2006): Lidar measurement of snow depth: Accuracy and error sources, Proceedings International Snow Science Workshop ISSW 2006, Telluride, CO, Proceedings International Snow Science Workshop ISSW, 384-391.

Deems, J. S., Gadomski, P. J., Vellone, D., Evanczyk, R., LeWinter, A. L., Birkeland, K. W. \& Finnegan, D. C. (2015): Mapping starting zone snow depth with a ground-based lidar to assist avalanche control and forecasting, Cold Regions Science and Technology, doi: 10.1016/j.coldregions.2015.09.002.

Deems, J. S., Painter, T. H. \& Finnegan, D. C. (2013): Lidar measurement of snow depth: A review, Journal of Glaciology, 59, 467-479.

Dietz, A.J., Kuenzer, C., Gassner, U \& Dech, S. (2012): Remote sensing of snow -a review of available methods. International Journal of Remote Sensing, 33:13, pp. 4094-4134. 


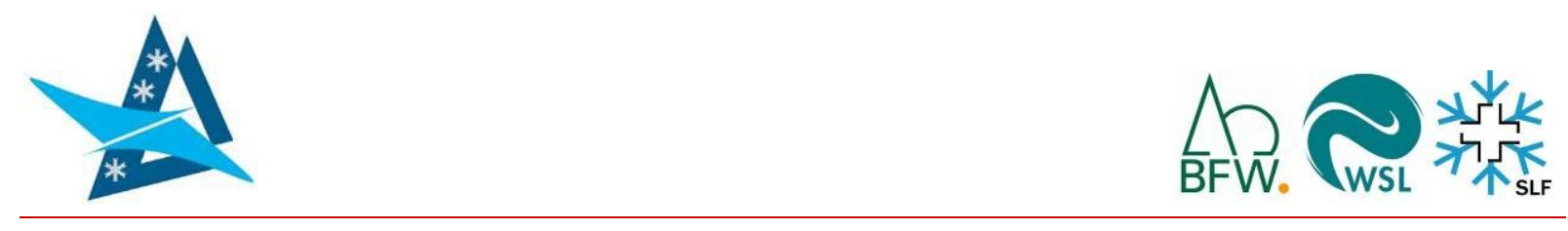

Drusch, M., Del Bello, U., Carlier, S., Colin, O., Fernandez, V., Gascon, F., Hoersch, B., Isola, C., Laberinti, P., Martimort, P., Meygret, A., Spoto, F., Sy, O., Marchese, F. \& P. Bargellini (2012): GMES Sentinel-2 mission. Remote sensing of Environment.

Eckardt, A., Arnold, G., Lorenz, E., Jahn, H., Oertel, D. \& Borner, A. (2004): Advanced sensors for surveying and mapping. Electro-Optical and Infrared Systems: Technology and Applications, 2004, 5612, pp. 172-179 39.

Eckerstorfer, M., Bühler, Y., Frauenfelder, R., \& Malnes, E. (2016): Remote sensing of snow avalanches: Recent advances, potential, and limitations, Cold Regions Science and Technology, $121,126-140$.

Eckert, N., Keylock, C.J., Bertrand, C., Parent, E., Faug, T., Favier, P. \& Naaim, M. (2012): Quantitative risk and optimal design approaches in the snow avalanche field: Review and extensions. Cold Regions Science and Technology, 79-80, pp. 1-19.

Eisenbeiss, H. \& Sauerbier, M. (2011): Investigation of UAV systems and flight modes for photogrammetric applications. Photogrammetric Record 26, pp. 400-421.

Elder, K., Dozier, J. \& Michaelsen, J. (1991): Snow Accumulation and Distribution in an Alpine Watershed. Water Resources Research, 27, 7, pp. 1541-1552.

Elder, K., Michaelsen, J. \& Dozier, J. (1995): Small basin modelling of snow water equivalence using binary regression tree methods. Biochemistry of seasonally snow-covered catchments. Proceedings of a Boulder Symposium. IAHS publications no 228.

Enßle, F., Fritz, A., and Koch, B. (2015): Comparing Icesat/Glas Based Elevation Heights with Photogrammetric Terrain Heights from UAV-Imagery on the East Tibetan Plateau, ISPRS - International Archives of the Photogrammetry, Remote Sensing and Spatial Information Sciences, XL3/W3, 385-390.

Falk, M. (2010): A dynamic panel data analysis of snow depth and winter tourism. Tourism Management, Volume 31, Issue 6, December 2010, pp. 912-924.

Falk, M. (2013): A survival analysis of ski lift companies. Tourism Management, 36, pp. 377-390.

Fernández, T., Pérez, J. L., Cardenal, F. J., López, A., Gómez, J. M., Colomo, C., Delgado, J. \& Sánchez, M. (2015): Use of a light UAV and photogrammetric techniques to study the evolution of a landslide in Jaén (southern Spain), ISPRS Archives, XL-3/W3, 241-248.

Fierz, C., Armstrong, R. L., Durand, Y., Etchevers, P., Greene, E., McClung, D. M., Nishimura, K., Satyawali, P. K., \& Sokratov, S. A. (2009): The International classification for seasonal snow on the ground, IACS, UNESCO, Paris, France.

Foppa, N., Stoffel, A. \& Meister, R. (2007): Synergy of in situ and space borne observation for snow depth mapping in the Swiss Alps. International Journal of Applied Earth Observation and Geoinformation, 9, pp. 294-310. 


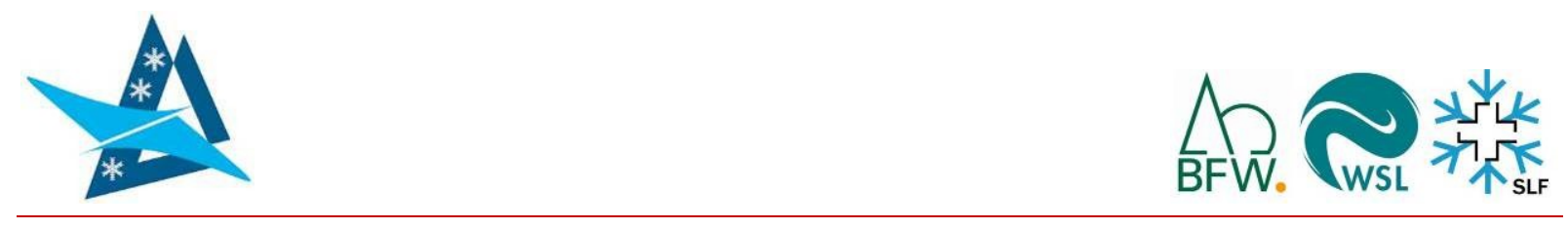

Gigele, T., Fromm, R. \& Adams, M. (2013): Field report on the implementation of a remotely controlled Automated Terrestrial Laser Scanner. International Snow Science Workshop (ISSW), 711. October 2013, Grenoble / Chamonix Mont Blanc.

Gini, R., Pagliari, D., Passoni, D., Pinto, L., Sona, G. \& Dosso, P. (2013): UAV photogrammetry: block triangulation comparisons. ISPRS - Int. Arch. Photogramm. Remote Sens. Spatial Inform. Sci., pp. 157-162.

Ginzler, C., Marty, M. \& Bühler, Y. (2013): Grossflächige hochaufgelöste Schneehöhenkarten aus digitalen Stereoluftbildern. DGPF Tagungsband 22, pp. 71-78.

Grünewald, T., Schirmer, M., Mott, R. \& Lehning, M. (2010): Spatial and temporal variability of snow depth and ablation rates in a small mountain catchment, The Cryosphere, 4, pp. 215-225

Haala, N., Cramer, M., Weimer, F \& Trittler, M. (2011): Performance test on UAV-based photogrammetric data collection. International Archives of the Photogrammetry, Remote Sensing and Spatial Information Sciences, Vol. XXXVIII-1/C22 UAV-g 2011, Conference on Unmanned Aerial Vehicle in Geomatics, Zurich, Switzerland.

Harder, P., Schirmer, M., Pomeroy, J., and Helgason, W.: Accuracy of snow depth estimation in mountain and prairie environments by an unmanned aerial vehicle, The Cryosphere Discuss. 20169.

Hardin, P.J. \& Jensen, R.R. (2011): Small-scale unmanned aerial vehicles in environmental remote sensing: challenges and opportunities. GIScience \& Remote Sensing 48, pp. 99-111.

Harwin, S., Lucieer, A., Osborn, J. (2015): The impact of the calibration method on the accuracy of point clouds derived using unmanned aerial vehicle multi-view stereopsis. Remote Sensing, 7 (9), pp. 11933-11953.

Hay, L.E., Leavesley, G.H., and Clark, M.P., 2006. Use of remotely-sensed snow covered area in watershed model calibration for the Sprague River, Oregon. Joint 8th Federal Interagency Sedimentation Conference and 3rd Federal Interagency Hydrologic Modeling Conference, April 26, 2006, Reno, Nevada.

Heilig, A., Schober, M., Schneebeli, M. \& Fellin, W. (2008): Next level for snow pack monitoring in real-time using Ground-Penetrating Radar (GPR) technology. ISSW 2008, International Snow Science Workshop, Whistler, Canada, September 2008.

Hobi, M.L. \& Ginzler, C. (2012): Accuracy assessment of digital surface models based on worldview-2 and ADS80 stereo remote sensing data. Sensors 12: pp. 6347-6368.

Hodgson, M. \& Bresnahan, P. (2004): Accuracy of airborne LiDAR-derived elevation: Empirical assessment and error budget. Photogrammetric Engineering and Remote Sensing, 2004, 70, pp. 331-339

Hugenholtz, C.H., Moorman, B.J., Riddell, K. \& K. Whitehead (2012): Small unmanned aircraft systems for remote sensing and earth science research. EOS, vol. 93, pp. 236-237. 


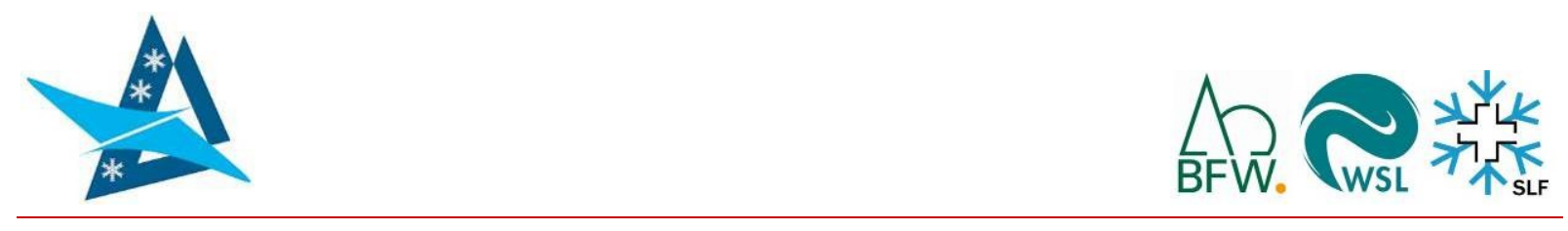

Hugenholtz, C.H., Whitehead, K. Brown, O. Barchyn, T.E., Moorman, B.J., LeClair, A. Riddell, K. \& T. Hamilton (2013): Geomorphological mapping with a small unmanned aircraft system (sUAS): Feature detection and accuracy assessment of a photogrammetrically-derived digital terrain model. Geomorphology, vol. 194, pp. 16-24.

ICAO (2014): Official website of the International Civil Aviation Organization (http://www.icao.int).

Jain, S.K., Goswami, A. \& Saraf, A.K. (2008): Accuracy assessment of MODIS, NOAA and IRS data in snow cover mapping under Himalayan conditions. International Journal of Remote Sensing, 29, pp. 5863-5878.

Jelalian, A.V. (1992): Laser Radar Systems. Artech House Radar Library, pp. 308.

Jonas, T., Marty, C. \& Magnusson, J. (2009): Estimating the snow water equivalent from snow depth measurements in the Swiss Alps Original Research Article. Journal of Hydrology, 378, 1-2, pp. 161167.

Kääb, A., Huggel, C., Fischer, L., Guex, S., Paul, F., Roer, I., Salzmann, N., Schlaefli, S., Schmutz, K., Schneider, D., Strozzi, T. \& Weidmann, Y. (2005): Remote sensing of glacier- and permafrostrelated hazards in high mountains: an overview. Natural Hazards and Earth System Science. 5, pp. 527-554.

Kern, M. (2010): Future missions for Cryosphere. 1st ESA DUE GlobSnow User Workshop, Innsbruck, Austria 12 - 13 January 2010.

Koenderink, J.J. \& van Doorn, A.J. (1991): Affine structure from motion. Journal of the Optical Society of America A 8 (2), pp. 377-385.

LaChapelle, E. (1980): The fundamental processes of conventional avalanche forecasting. Journal of Glaciology, 26, 94, pp. 75-84.

Lato, M., Frauenfelder, R. \& Bühler, Y. (2012): Automated avalanche deposit detection of fresh snow avalanches: Segmentation and classification of optical remote sensing imagery. Natural Hazards and Earth System Sciences. 12, pp. 1-14.

Lebourgeois, V., Bégué, A., Labbé, S., Mallavan, B., Prévost, L. \& Roux, B. (2008): Can commercial cameras be used as multispectral sensor? A crop monitoring test. Sensors Journal, pp. 7300-7322.

Lee, C. Y., Jones, S. D., Bellman, C. J. \& Buxton, L. (2008): DEM creation of a snow covered surface using digital aerial photography, The International Archives of the Photogrammetry, Remote Sensing and Spatial Information Sciences, 37.

Lucieer, A., Turner, D., King, D.H. \& Robinson, S.A. (2014): Using an Unmanned Aerial Vehicle (UAV) to capture micro-topography of Antarctic moss beds. International Journal of Applied Earth Observation and Geoinformation 27 (2014) pp. 53-62. 


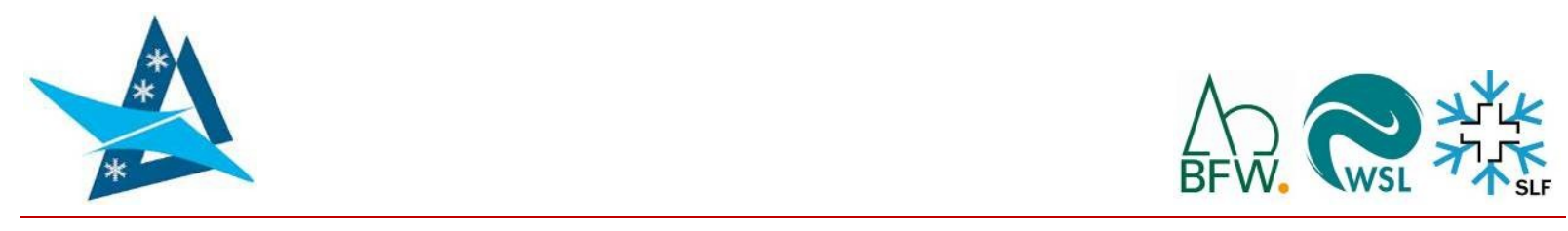

Luzi, G., Noferini, L., Mecatti, D., Macaluso, G., Pieraccini, M., Atzeni, C., Schaffhauser, A., Fromm, R. \& Nagler, T. (2009): Using a Ground-Based SAR Interferometer and a Terrestrial Laser Scanner to Monitor a Snow-Covered Slope: Results From an Experimental Data Collection in Tyrol (Austria). IEEE Transactions on Geoscience and Remote Sensing, 47, 2, pp. 382-393.

Malnes, E., Buanes, A., Nagler, T., Bippus, G., Gustafsson, D., Schiller, C., Metsämäki, S., Pulliainen, J., Luojus, K., Larsen, H. E., Solberg, R. Diamandi, A. \& Wiesmann, A. (2015): User requirements for the snow and land ice services - CryoLand. The Cryosphere, 9, pp. 1191-1202.

Malnes, E., Eckerstorfer, M., Jonsson, A. \& Solb $\varnothing$, S. (2013): Remote sensing of avalanches in northern Norway using Synthetic Aperture Radar. International Snow Science Workshop (ISSW), 7-11. October 2013, Grenoble / Chamonix Mont Blanc.

Mancini, F., Dubbini, M., Gattelli, M., Stecchi, F. Fabbri, S. \& Gabbianelli, G. (2013): Unmanned Aerial Vehicles (UAV) for High-Resolution Reconstruction of Topography: The Structure from Motion Approach on Coastal Environments. Remote Sens., 5, pp. 6880-6898.

Marti, R., Gascoin, S., Berthier, E., de Pinel, M., Houet, T. \& Laffly, D. (2016): Mapping snow depth in open alpine terrain from stereo satellite imagery. The Cryosphere Discussions, 11.

Marty, C. (2008): Regime shift of snow days in Switzerland. Geophysical Research Letters, 35.

Melvold, K. \& Skaugen, T. (2013): Multiscale spatial variability of lidar-derived and modeled snow depth on Hardangervidda, Norway, Annals of Glaciology, 54, 273-281.

Mitterer, C., Heilig, A., Schweizer, J. \& Eisen, O. (2011): Upward-looking ground-penetrating radar for measuring wet-snow properties. Cold Regions Science and Technology, 69 (2-3), pp. 129-138.

Molina, J.-L., Rodríguez-Gonzálvez, P., Molina, C., González-Aguilera, D. \& Espejo, F. (2013): Geomatic methods at the service of water resources modelling. Journal of Hydrology 509 (2014), 150-162

Moreno Banos, I., Ruiz Garcia, A., Marturia I Alavedra, J., Oller I Figueras, P., Pina Iglesias, J., Garcia Selles, C., Martinez I Figueras, P. \& Talaya Lopez, J. (2009): Snowpack depth modelling and water availability from LIDAR measurements in eastern Pyrenees, Proceedings of the International Snow Science Workshop ISSW 2009 Europe, 27 September-2 October 2009, Davos, Switzerland, pp. 202206, 2009.

Moser, A., Geigl, B., Steffan, H., Bauer, A., Paar, G., Fromm, R., Schaffhauser, H., Köck, K., Schönhuber, M. \& Randeu, W. L. (2001): SAMPLE - Snow Avalanche Monitoring Prognosis by Laser Equipment - Entwicklung eines Meßsystems zur Bestimmung der zeitlichen und örtlichen Schneehöhe in Lawinenhängen als verbesserte Grundlage für die Lawinenprognose und ihre Anwendung am Präbichl. Final report.

Niethammer, U., James, M.R., Rothmund, S., Travelletti, J. \& Joswig, M. (2012): UAV-based remote sensing of the Super-Sauze landslide: evaluation and results. Engineering Geology 128, pp. 2-11.

Nolan, M., Larsen, C. \& Sturm, M. (2015): Mapping snow depth from manned aircraft on landscape scales at centimeter resolution using structure-from-motion photogrammetry. The Cryosphere, 9 , pp. 1445-1463. 


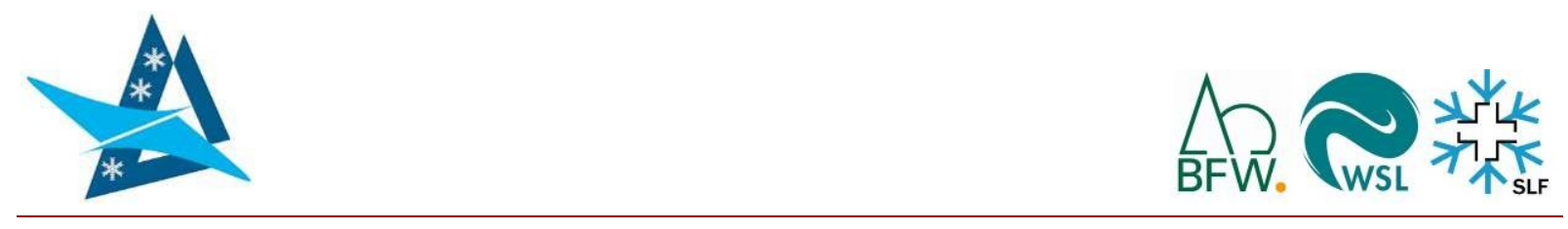

Nolin, A.W. (2010): Recent advances in remote sensing of seasonal snow. Journal of Glaciology, 56, 200, pp. 1141-1150.

O'Connor, J., Smith, M. \& James, M.R. (2016): Camera settings for optimal image quality. Geophysical Research Abstracts, 18 (EGU2016-18165), EGU General Assembly 2016 17-22 Apr. 2016, Vienna.

Peng, S., Piao, S., Ciais, P. \& Fang, J. (2010): Change in winter snow depth and its impacts on vegetation in China. Global Change Biology, 16, pp. 3004-3013.

Pfeifer, N. \& Briese, C. (2007): Geometrical Aspects of Airborne and Terrestrial Laser Scanning. Keynote Lecture: ISPRS Workshop Laser Scanning 2007, Espoo, Finland (invited); 2007-09-12 2007-09-14; in: "IAPRS", XXXVI Part 3 / W52 (2007), ISSN: 1682-1777.

Previatia, M., Godiob, A. \& Ferrarisa, S. (2011): Validation of spatial variability of snowpack thickness and density obtained with GPR and TDR methods. Journal of Applied Geophysics, 75, 2, pp. 284293.

Prokop, A. (2008): Assessing the applicability of terrestrial laser scanning for spatial snow depth measurements. Cold Regions Science and Technology, 54, 3, pp. 155-163.

Prokop, A., Schoen, P., Singer, F., Pulfer, G., Thibert, E. \& Naaim, M. (2013): Determining avalanche modeling input parameters using terrestrial laser scanning technology. International Snow Science Workshop (ISSW), 7-11. October 2013, Grenoble / Chamonix Mont Blanc.

Prokop, A., Schön, P., Singer, F., Pulfer, G., Naaim, M., Thibert, E. \& Soruco, A. (2015): Merging terrestrial laser scanning technology with photogrammetric and total station data for the determination of avalanche modeling parameters, Cold Regions Science and Technology, 110, 223-230.

Rabatel, G., Goretta, N. \& Labbé, S. (2014): Getting simultaneous red and near-infrared band data from a single digital camera for plant monitoring applications: Theoretical and practical study. Biosystems Engineering, Special Issue: Image Analysis in Agriculture, 117, pp. 2-14.

Rees, W.G. (2006): Remote sensing of snow and ice. Boca Raton, FL, CRC Press.

Riegl (2008): Long-range laser profile measuring system LPM-321 - Technical documentation \& user's instructions.

Rixen, C., Teich, M., Lardelli, C., Gallati, D., Pohl, M., Pütz, M. \& Bebi, P. (2011): Winter tourism and climate change in the Alps: An assessment of resource consumption, snow reliability, and future snowmaking potential. Mountain Research and Development, 31, pp. 229-236.

Rosnell, T. \& Honkavaara, E., (2012): Point cloud generation from aerial image data acquired by a quadrocopter type micro unmanned aerial vehicle and a digital still camera. Sensors 12 , pp. 453480.

Ryan, J. C., Hubbard, A. L., Box, J. E., Todd, J., Christoffersen, P., Carr, J. R., Holt, T. O. \& Snooke, N. (2015): UAV photogrammetry and structure from motion to assess calving dynamics at Store Glacier, a large outlet draining the Greenland ice sheet, The Cryosphere, 9, 1-11. 


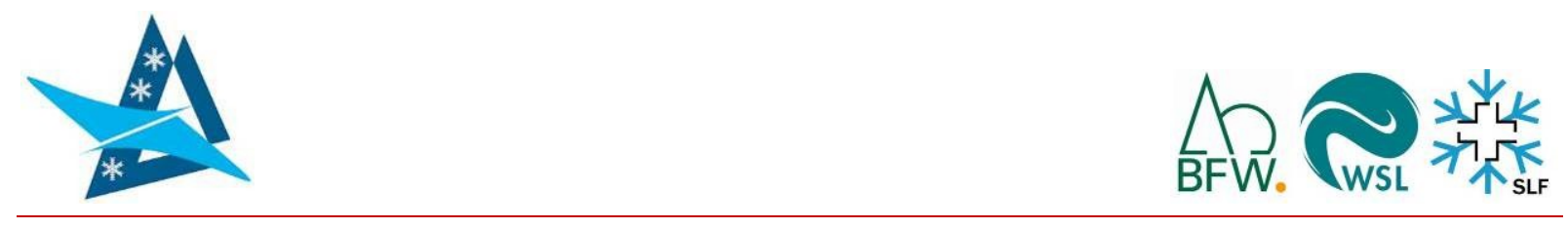

Sailer, R., Fromm, R., Jörg, P., Schaffhauser, A. \& Adams, M. (2008): Ground Based Remote Sensing of Snow Properties and Avalanche Simulation. Proceedings of Earth Conference 2008, Lesvos, Greece.

Schaffhauser, A., Adams, M., Fromm, R., Joerg, P., Luzi, G., Noferini, L. \& Sailer, R. (2008): Remote sensing based retrieval of snow cover properties. Cold Regions Science and Technology, 54, pp. 164-175.

Schöber, J., Schneider, K., Helfricht, K., Schattan, P., Achleitner, S., Schöberl, F. \& Kirnbauer, R. (2014): Snow cover characteristics in a glacierized catchment in the Tyrolean Alps - Improved spatially distributed modelling by usage of Lidar data. Journal of Hydrology, in press.

Schweizer, J. \& Kronholm, K. 2007. Snow cover spatial variability at multiple scales: Characteristics of a layer of buried surface hoar. Cold Regions Science and Technology, 47, pp. 207-223.

Schweizer, J.; Kronholm, K.; Jamieson, J. B. \& Birkeland, K. W. (2008): Review of spatial variability of snowpack properties and its importance for avalanche formation. Cold Regions Science and Technology, 51, 253-272

Singh, P., Spitzbart, G., Hübl, H. \& Weinmeister, W.M. (1997): Hydrological response of snowpack under rain-on-snow events: a field study. Journal of Hydrology, 202, 1-4, pp. 1-20.

Smith, F., Cooper, C. \& Chapman, E. (1967): Measuring Snow Depths by Aerial Photography, Proceedings of the Western Snow Conference, April 1967, Boise, Idaho, USA.

Sony (2014): Manufacturer website of the company Sony (www.sony.at); last visited on 26 March 2014.

Sortier B., Graf A. \& Kleemayr K. (2012): Einsatz von UAV in Forstwirtschaft und Naturgefahrenmanagement. Zeitschrift für Wildbach-, Lawinen-, Erosions- und Steinschlagschutz, 76(169).

Sotier, B., Graf, A. \& Kammerlander, J. (2013): Einsatz von UAV im alpinen Gelände: Erfahrungsbericht und Anwendungsbeispiel aus der Naturgefahrenpraxis. Österreichische Zeitschrift für Vermessung und Geoinformation (VGI), 101 (2013), 2+3; 110- 118.

Sui, J. \& Koehler, G. (2001): Rain-on-snow induced flood events in Southern Germany. Journal of Hydrology, 252, 1-4, pp. 205-220.

Sundström, N., Kruglyak, A. \& Friborg, J. (2012): Modeling and simulation of GPR wave propagation through wet snowpacks: Testing the sensitivity of a method for snow water equivalent estimation. Cold Regions Science and Technology, Volumes 74-75, May 2012, pp. 11-20.

Tampubolon, W. \& Reinhardt, W. (2015): Analysis of Radar and Optical Space Borne Data for Large Scale Topographical Mapping. In: STILLA, Uwe / HEIPKE, Christian (Hrsg.): PIA15, Photogrammetric Image Analysis + HRIGI15, High-Resolution Earth Imaging for Geospatial Information - Joint ISPRS Conference, 25-27 March 2015, Munich, Germany. International Archives of the Photogrammetry, Remote Sensing and Spatial Information Sciences, Vol. XL-3/W2. Technische Universität München, München, S. 235-242 


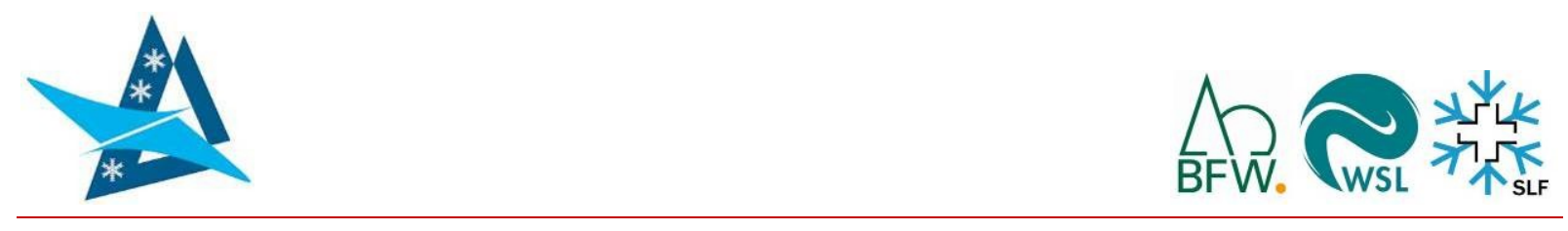

Techel, F., Zweifel, B. \& Marty, C., 2015: Schnee und Lawinen in den Schweizer Alpen. Hydrologisches Jahr 2014/15. ISSN 2296-3448 (Print) / 2296-3456 (online) (in press).

Thibert, E., Bellot, H., Ravanat, X., Ousset, F., Pulfer, G., Naaim, M., Hagenmuller, P., Naaim-Bouvet, F., Faug, T., Nishimura, K., Ito, Y., Baroudi, D., Prokop, A., Schön, P., Soruco, A., Vincent, C., Limam, A. \& Héno, R. (2015): The full-scale avalanche test-site at Lautaret Pass (French Alps), Cold Regions Science and Technology, 115, 30-41.

TIRIS (2016): Tiroler Rauminformationssystem | Land Tirol; https://www.tirol.gv.at/tiris (last accessed 08.06.2016).

Tonkin, T., Midgley, N.G., Graham, D.J. \& Ladadz, J. (2014): The potential of small unmanned aircraft systems and structure-from-motion for topographic surveys: A test of emerging integrated approaches at Cwm Idwal, North Wales. Geomorphology 226: 35-43.

Trawöger, L. (2014): Convinced, ambivalent or annoyed: Tyrolean ski tourism stakeholders and their perceptions of climate change. Tourism Management, Volume 40, February 2014, pp. 338-351.

Trimble, 2015. GPS Pathfinder Office Software Help.

Tucker, C. J. (1979): Red and photographic infrared linear combinations for monitoring vegetation, Remote Sens. Environ., 8, 127-150.

Turner, D., Lucieer, A. \& Watson, C. (2012): An automated technique for generating georectified mosaics from ultra-high resolution unmanned aerial vehicle (UAV) imagery, based on structure from motion (SfM) point clouds. Remote Sensing 4, pp. 1392-1410.

UVS-INFO (2016): 2016 RPAS Yearbook - RPAS: The Global Perspective; $14^{\text {th }}$ Annual Edition, Blyenburgh \& Co @); www.uvs-info.com, pp. 248.

Vallet, J., Panissod, F., Strecha, C. \& Tracol, M. (2012): Photogrammetric performance of an ultra-light weight swinglet 'UAV'. In: ISPRS- International Archives of the Photogrammetry, Remote Sensing and Spatial Information Sciences, XXXVIII-1/C22, UAV-g 2011 Conference on Unmanned Aerial Vehicle in Geomatics, Zurich, Switzerland, pp. 253-258.

Vander Jagt, B., Lucieer, A., Wallace, L., Turner, D. \& Durand, M. (2015): Snow Depth Retrieval with UAS Using Photogrammetric Techniques, Geosciences, 5, 264-285.

Varley, P. \& Medway, D. (2011): Ecosophy and Tourism: Rethinking a Mountain Resort. Tourism Management, 32, 4, pp. 902-911.

Verhoeven, G. (2011): Taking computer vision aloft - archaeological three-dimensional reconstructions from aerial photographs with PhotoScan. Archaeological Prospection 18, pp. 6773.

Vikhamar, D. \& Solberg, R. (2003): Snow-cover mapping in forests by constrained linear spectral unmixing of MODIS data. Remote Sensing of Environment, 88, pp. 309-323.

Watts, A.C., Ambrosia, V.G. \& Hinkley, E.A. (2012): Unmanned aircraft systems in remote sensing and scientific research: classification and considerations of use. Remote Sensing 4, pp. 1671-1692. 


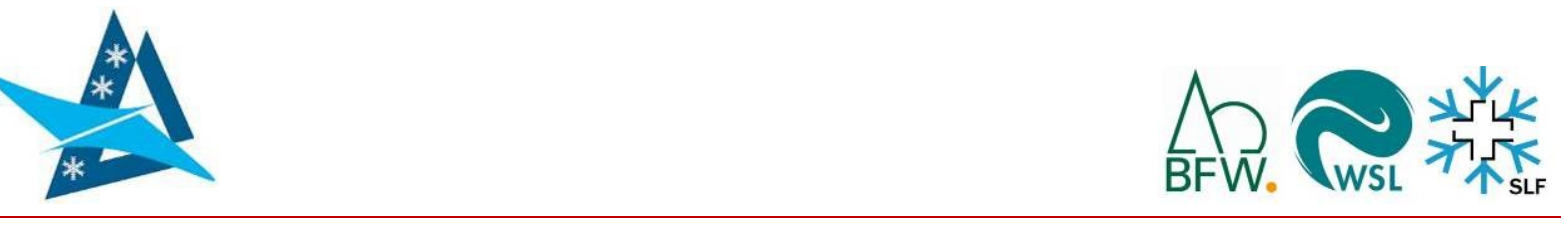

Whitehead, K., Moorman, B.J. \& Hugenholz, C.H. (2013): Low-cost, on demand aerial photogrammetry for glaciological measurement. The Cryosphere Discussions, 7, 3043-3057.

Wiatr, T., Reichertera, K., Papanikolaoub, I., Fernández-Steegerc, T. \& Masona, J. (2013): Slip vector analysis with high resolution t-LiDAR scanning. Tectonophysics, 608, pp. 947-957.

Wipf, S., Stoeckli, V. \& Bebi, P. (2009): Winter climate change in alpine tundra: Plant responses to changes in snow depth and snowmelt timing. Climatic Change, 94, pp. 105-12.

Xiao, X., Moore, B., Qin, X, Shen, Z. \& Boles, S. (2002): Large-scale observations of alpine snow and ice cover in Asia: Using multi-temporal VEGET ATION sensor data. International Journal of Remote Sensing, 23, 11, pp. 2213-2228. 


\section{D垱标

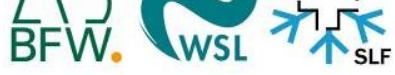

\section{Annex}

Table 8: Details on all RPAS-flights performed at the Austrian study site; RPAS - MM (fixed-wing); ML (helicopter); Camera: N5 (Sony NEX 5A/R); A7 (Sony Alpha 7R).

\begin{tabular}{|c|c|c|c|c|c|c|c|c|c|c|c|c|c|c|c|c|}
\hline \multirow{3}{*}{$\begin{array}{c}\text { Date } \\
18102014\end{array}$} & \multicolumn{3}{|c|}{\begin{tabular}{|l|} 
Flight Properties \\
\end{tabular}} & \multicolumn{7}{|c|}{ Sensor Properties } & \multicolumn{2}{|c|}{ Image Properties } & \multicolumn{4}{|c|}{ Processing } \\
\hline & No. & RPAS & Height & Camera & Focal LeVIS & Aperture & Exposure & Filter & Brightn. Comp. & ISO & No. Photos (filt.) & Format & QI & Overlap & \begin{tabular}{|l|} 
MarkerError \\
\end{tabular} & ReprojError \\
\hline & 1 & MM & 400 & N5 & $50 \mathrm{~mm}$ & $F / 5-13$ & $1 / 320$ & VIS & -1 & 400 & 1073 & JPEG & - & - & - & - \\
\hline & 2 & MM & 150 & N5 & $16 \mathrm{~mm}$ & F/5.6-14 & $1 / 320$ & VIS & -1 & 400 & 951 & JPEG & - & - & - & - \\
\hline \multirow{2}{*}{ 19.10.2014 } & 1 & MM & 400 & N5 & $50 \mathrm{~mm}$ & $\mathrm{n} / \mathrm{a}$ & $\mathrm{n} / \mathrm{a}$ & VIS & $n / a$ & $n / a$ & 0 & $n / a$ & - & - & - & - \\
\hline & 2 & MM & 150 & N5 & $16 \mathrm{~mm}$ & F/6.5-13 & $1 / 320$ & VIS & -1 & 400 & 1135 & JPEG & - & - & - & - \\
\hline \multirow[t]{2}{*}{31.10 .2014} & 1 & MM & 400 & N5 & $50 \mathrm{~mm}$ & $f / 10-16$ & $1 / 400$ & VIS & -1 & 400 & 1357 & JPEG & - & - & - & - \\
\hline & 2 & MM & 150 & N5 & $16 \mathrm{~mm}$ & $f / 4-14$ & $1 / 400$ & 700 & -1 & 400 & 1088 & RAW & - & - & - & - \\
\hline \multirow[t]{3}{*}{11.02 .2015} & 1 & MM & 400 & N5 & $50 \mathrm{~mm}$ & $f / 4.5-8$ & $1 / 320$ & 830 & 0 & 100 & 1060 & JPEG & 0.00 & 10 & 0.14 & $0.2 / 4.3$ \\
\hline & 2 & $\mathrm{MM}$ & 400 & N5 & $50 \mathrm{~mm}$ & $f / 10-18$ & $1 / 320$ & VIS & 0 & 100 & 536 & JPEG & 0.62 & 9 & 0.09 & $0.3 / 1.7$ \\
\hline & 3 & MM & 400 & N5 & $50 \mathrm{~mm}$ & $f / 8-18$ & $1 / 400$ & VIS & 0 & 100 & 894 & JPEG & 0.52 & 11 & 0.08 & $0.3 / 1.4$ \\
\hline \multirow[t]{5}{*}{ 13.02.2015 } & 1 & MM & 400 & N5 & $50 \mathrm{~mm}$ & f/7.1-14 & $1 / 500$ & VIS & 0 & 100 & 884 & JPEG & 0.57 & 16 & 0.08 & $0.3 / 1.4$ \\
\hline & 2 & MM & 400 & N5 & $50 \mathrm{~mm}$ & $n / a$ & $1 / 500$ & 830 & 0 & 100 & 0 & JPEG & - & - & - & - \\
\hline & 3 & MM & 400 & N5 & $50 \mathrm{~mm}$ & $f / 4-9$ & $1 / 320$ & 830 & 0 & 100 & 973 & JPEG & 0.72 & 6 & 0.22 & $0.9 / 3.7$ \\
\hline & 4 & MM & 400 & N5 & $50 \mathrm{~mm}$ & $f / 4-16$ & $1 / 400$ & 700 & 0 & 100 & 893 & JPEG & 0.66 & 10 & 0.1 & $0.3 / 4.2$ \\
\hline & 5 & MM & 400 & N5 & $50 \mathrm{~mm}$ & $f / 5-18$ & $1 / 320$ & VIS & 0 & 100 & 680 & JPEG & 0.65 & 4 & 0.03 & $0.3 / 1.4$ \\
\hline \multirow{3}{*}{03.03 .2015} & 1 & MM & 400 & N5 & $50 \mathrm{~mm}$ & $f / 8-18$ & $1 / 500$ & VIS & 0 & 100 & 652 & JPEG & 0.71 & 7 & 0.16 & $0.3 / 1.7$ \\
\hline & 2 & MM & 400 & N5 & $50 \mathrm{~mm}$ & $f / 4-7.1$ & $1 / 500$ & 830 & 0 & 100 & 965 & JPEG & 0.40 & 7 & 0.19 & $0.3 / 1.6$ \\
\hline & 3 & MM & 400 & N5 & $50 \mathrm{~mm}$ & $f / 5.6-14$ & $1 / 500$ & 700 & 0 & 100 & 0 & JPEG & 0.82 & 14 & 0.13 & $0.4 / 2.2$ \\
\hline \multirow{3}{*}{13.03 .2015} & 1 & MM & 400 & N5 & $50 \mathrm{~mm}$ & f/7.1-13 & $1 / 500$ & VIS & 0 & 100 & 920 & JPEG & 0.81 & 11 & 0.11 & $0.4 / 4.6$ \\
\hline & 2 & MM & 400 & N5 & $50 \mathrm{~mm}$ & $f / 4-11$ & $1 / 800$ & VIS & 0.7 & 100 & 500 & JPEG & 0.00 & 7 & 0.2 & $0.3 / 1.2$ \\
\hline & 3 & MM & 400 & N5 & $50 \mathrm{~mm}$ & $f / 2.5-14$ & $1 / 400$ & 830 & 0 & 400 & 544 & JPEG & 0.88 & 9 & 0.12 & $0.5 / 1.9$ \\
\hline \multirow[t]{4}{*}{\begin{tabular}{|l|l|}
10.04 .2015 \\
\end{tabular}} & 1 & MM & 400 & N5 & $50 \mathrm{~mm}$ & $f / 8-13$ & $1 / 1000$ & VIS & 0 & 100 & 1046 & JPEG & 0.71 & 7 & 0.9 & $0.3 / 1$ \\
\hline & 2 & MM & 400 & N5 & $50 \mathrm{~mm}$ & \begin{tabular}{|l|}
$f / 10-14$ \\
\end{tabular} & $1 / 500$ & 830 & 0 & 400 & 771 & JPEG & $\begin{array}{ll}0.84 \\
\end{array}$ & 9 & 0.15 & $0.3 / 5.7$ \\
\hline & 3 & MM & 150 & N5 & $16 \mathrm{~mm}$ & $f / 10-16$ & $1 / 800$ & VIS & 0 & 100 & 1449 & JPEG & 0.78 & 6 & 0.14 & $0.3 / 2.9$ \\
\hline & 4 & MM & 150 & N5 & $16 \mathrm{~mm}$ & $f / 8-13$ & $1 / 800$ & 830 & 0 & 400 & 1454 & JPEG & - & - & - & - \\
\hline \multirow{6}{*}{22.04 .2015} & 1 & MM & 400 & N5 & $50 \mathrm{~mm}$ & - & $1 / 1000$ & VIS & 0 & 100 & 0 & JPEG & - & - & - & - \\
\hline & 2 & MM & 400 & N5 & $50 \mathrm{~mm}$ & $f / 5.6-13$ & $1 / 640$ & 830 & 0 & 400 & - & JPEG & - & - & - & - \\
\hline & 3 & $\mathrm{ML}$ & 50 & A7 & $35 \mathrm{~mm}$ & - & $1 / 1250$ & VIS & -0.3 & 100 & - & JPEG & - & - & - & - \\
\hline & 4 & ML & 50 & A7 & $35 \mathrm{~mm}$ & - & $1 / 3200$ & VIS & 0 & 400 & - & JPEG & - & - & - & - \\
\hline & 5 & \begin{tabular}{|l|}
$M L$ \\
\end{tabular} & 50 & A7 & $35 \mathrm{~mm}$ & - & $1 / 640$ & 830 & 0 & 400 & - & JPEG & - & - & - & - \\
\hline & 6 & MM & 400 & N5 & $50 \mathrm{~mm}$ & $f / 5.6-20$ & $1 / 1000$ & 700 & 0 & 400 & - & JPEG & - & - & - & - \\
\hline \multirow[t]{4}{*}{21.08 .2015} & 1 & MM & 400 & N5 & $50 \mathrm{~mm}$ & $f / 3.5-10$ & $1 / 1000$ & VIS & -1 & 400 & 810 & JPEG & - & - & - & - \\
\hline & 2 & MM & 400 & N5 & $50 \mathrm{~mm}$ & $f / 4-10$ & $1 / 1000$ & VIS & -1 & 400 & 904 & JPEG & - & - & - & - \\
\hline & 3 & MM & 400 & N5 & $50 \mathrm{~mm}$ & $f / 7.1$ & $1 / 320-1 / 2000$ & VIS & -1 & 400 & 1371 & JPEG & 0.81 & 36 & 0.4 & $0.4 / 2.8$ \\
\hline & 4 & MM & 400 & N5 & $50 \mathrm{~mm}$ & $f / 5.6$ & $1 / 500-1 / 4000$ & VIS & -1 & 400 & - & JPEG & - & - & - & - \\
\hline
\end{tabular}




\section{Technical specifications of instruments}

\section{RPAS}

Table 9: Technical specifications of RPAS (top - Multiplex Mentor Elapor; middle - AscTec Falcon 8; bottom Mikado Logo 600SE).

\begin{tabular}{|c|c|}
\hline UAV type & Fixed-wing (custom-built) \\
\hline Dimensions & $1.63 \mathrm{~m}$ (wing span) \\
& $1.17 \mathrm{~m}$ (fuselage) \\
\hline Engine & 1 electrical, brushless motor \\
\hline Flight time & $30-40$ minutes \\
\hline Max. range & $<1500 \mathrm{~m}$ \\
\hline Empty weight & $2.25 \mathrm{~kg}$ \\
\hline Max. take off weight & $2,755 \mathrm{~kg}$ \\
\hline Max. payload weight & $0.505 \mathrm{~kg}$ \\
\hline Navigation & 3DR APM 2.6 (IMU, barometer) \\
\hline Wireless & 3DR uBlox GNSS with Compass Kit uBlox LEA-6H module \\
\hline communication & Graupner MX-20 HOTT 2,4 GHz (sender) \\
& Frequency 2400 ... 2484,5 MHz \\
\hline LiPo battery & Graupner GR-16 HOTT 2,4 GHz (receiver) \\
\hline
\end{tabular}

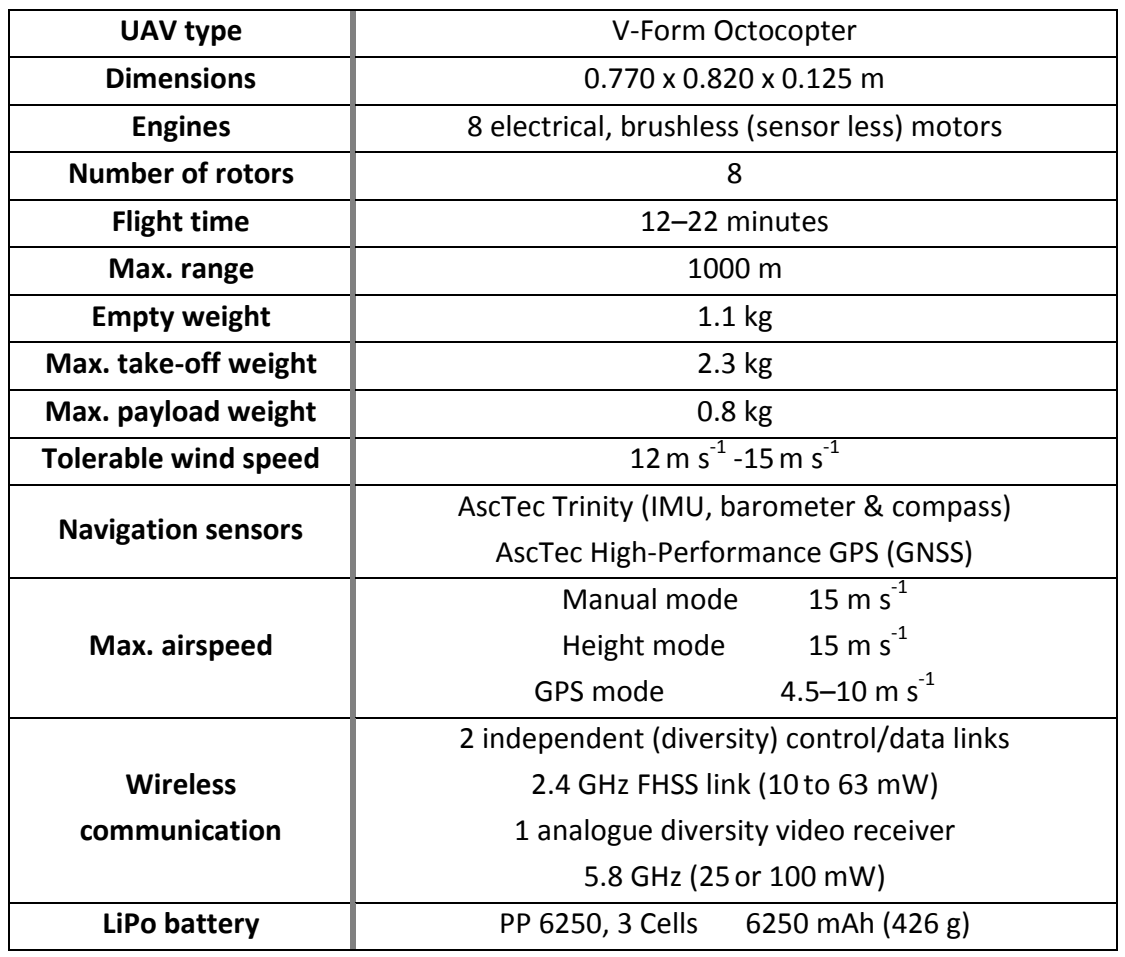




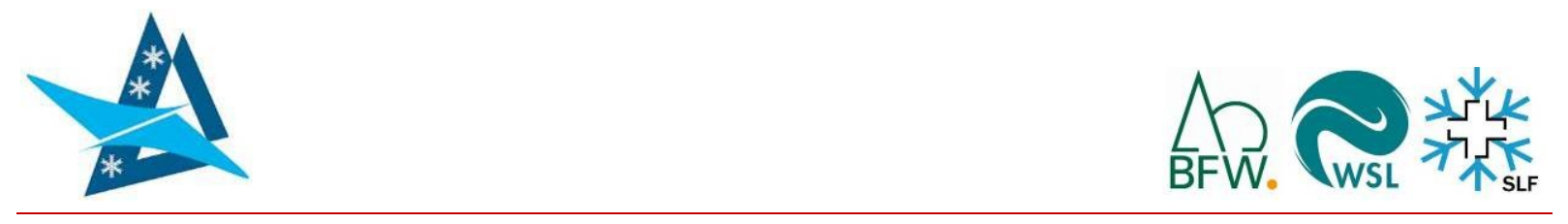

\begin{tabular}{|c|c|}
\hline UAV type & Helicopter (custom-built) \\
\hline Dimensions & $\begin{array}{c}1.57 \mathrm{~m} \text { (rotor diameter) } \\
1.35 \times 0.21 \times 0.47 \mathrm{~m}\end{array}$ \\
\hline Engine & 1 electrical, brushless motor \\
\hline Flight time & $15-25$ minutes \\
\hline Max. range & $<500 \mathrm{~m}$ \\
\hline Empty weight & $3,185 \mathrm{~kg}$ \\
\hline Max. take-off weight & $5 \mathrm{~kg}$ \\
\hline Max. payload weight & $1,815 \mathrm{~kg}$ \\
\hline Navigation & 3DR Pixhawk (IMU, barometer) \\
\hline Wireless & 3DR uBlox GNSS with Compass Kit uBlox LEA-6H module \\
\hline communication & Graupner MX-20 HOTT 2,4 GHz (sender) \\
& Frequency 2400 ... 2483,5 MHz \\
& Graupner GR-16 HOTT 2,4 GHz (receiver) \\
\hline LiPo batteries & LiPolice GreenLine Light Edition 5s \\
& 4900 mAh (591.5 g) \\
& SLS XTRON 6s 5000 mAh (747 g) \\
\hline
\end{tabular}

\section{Optical sensors}

Table 10: Technical specifications of RPAS sensors (source: Sony, 2016).

\begin{tabular}{|c|c|c|c|c|}
\hline Camera type & Sony NEX-5 & Sony NEX-5R & Sony NEX-7 & Sony $\alpha$ ILCE-7 \\
\hline Sensor type & CMOS APS-C & CMOS APS-C & CMOS APS-C & CMOS full frame \\
\hline Sensor size [mm] & $23.5 \times 15.6$ & $23.5 \times 15.6$ & $23.5 \times 15.6$ & $35.8 \times 23.9$ \\
\hline Sensor resolution [MP] & 16 & 16 & 24.3 & 36 \\
\hline ISO range & $100-25,600$ & $100-25,600$ & $100-16,000$ & $100-25,600$ \\
\hline Weight [g] & 380 & 380 & 560 & 594 \\
\hline Object lens [mm] & $\begin{array}{c}16 \& 50 \text { (prime } \\
\text { lenses) }\end{array}$ & $\begin{array}{c}16 \& 50 \text { (prime } \\
\text { lenses) }\end{array}$ & $\begin{array}{c}16 \text { \& } 50 \text { (prime } \\
\text { lenses) }\end{array}$ & $\begin{array}{c}35 \& 55 \text { (prime } \\
\text { lenses) }\end{array}$ \\
\hline Additional features & $\mathrm{n} / \mathrm{a}$ & adapted sensor and different changeable long- and band-pass \\
& & \multicolumn{2}{|r|}{ filters } \\
\hline
\end{tabular}

\section{GNSS}

To measure the GCP-positions, a Trimble GEOXT 2008 with external antenna (modell: hurricane) was used in the Austrian test site and a Trimble GEOXH at the Swiss study sites. The instruments are capable of receiving $1 \mathrm{~Hz}$ GNSS-data (GEOXT - GPS; GEOXH - GPS \& GLONASS) von 14 channels (12 channels L1/L2 code und carrier phases; 2 channels Satellite Based Augmentation System to increase reliability, accuracy and availability of positioning - European Geostationary Navigation Overlay Service in Europe). The GNSS-data was real-time corrected in the field with the Bundesamt für Eichund Vermessungswesen service APOS (Austrian Positioning Service) and swipos from the Federal Office of Topography swisstopo in Switzerland. In post-processing, differential correction was applied with Scripps Orbit and Permanent Array Centres (SOPAC) close to the study areas (Trimble, 2015). The expected accuracy of the GEOXT is $0.5 \mathrm{~m}$, for the GEOXH, $0.1 \mathrm{~m}$. 
TLS

Table 11: Technical specifications of LPM-321 (left) and LPM 98-2k (right).

\begin{tabular}{|c|c|}
\hline Laser wavelength $\lambda$ & $905 \mathrm{~nm}$ (near IR) \\
\hline Max. range $\rho \geq 0.8$ & $<6000 \mathrm{~m}$ (at $10 \mathrm{~Hz}$ ) \\
\hline Max. range $\rho \geq 0.1$ & $\geq 1500 \mathrm{~m}$ (at $10 \mathrm{~Hz}$ ) \\
\hline Accuracy & $\begin{array}{c}25 \mathrm{~mm} \text { (plus distance } \\
\text { depending error } \leq \pm 20 \mathrm{ppm} \text { ) }\end{array}$ \\
\hline Repeatability & $15 \mathrm{~mm}$ \\
\hline Measuring time & $0.25-1 \mathrm{sec}$. \\
\hline Beam divergence & typ. $0.8 \mathrm{mrad}$ \\
\hline Scanning range & $\begin{array}{c}\text { horizontally: } 360^{\circ} \\
\text { vertically: }-20^{\circ} / 130^{\circ}\end{array}$ \\
\hline Position accuracy & \pm 0.02 gon \\
\hline Angle readout accuracy & \pm 0.02 gon \\
\hline $\begin{array}{c}\text { System measurement } \\
\text { rate }\end{array}$ & 10 to 1000 points $/ \mathrm{sec}$. \\
\hline
\end{tabular}

\begin{tabular}{|l|l|}
\hline Laser wavelength $\lambda$ & $905 \mathrm{~nm}$ (near IR) \\
\hline Measuring range 1$)$ & \\
\hline \multicolumn{1}{|c|}{ good refl.coeff $(\rho \geq 0.8)$} & up to $2500 \mathrm{~m}$ \\
bad refl.coeff. $(\rho \geq 0.1)$ & $>800 \mathrm{~m}$ \\
Reflecting foil & $2500 \mathrm{~m}$ \\
\hline Accuracy & $+/-5 \mathrm{~cm}$ \\
\hline Measuring time & $0.25 \mathrm{up}$ to $1 \mathrm{~s}$ \\
\hline Beam divergence ${ }^{2)}$ & $1.2 \mathrm{mrad}\left(0.0688^{\circ}\right)$ \\
\hline Pulse duration approx. & $11 \mathrm{~ns}$ \\
\hline Scanning range & horizontal: $360^{\circ}$ \\
& vertical: $-20^{\circ} /+130^{\circ}$ \\
\hline Pulse frequency & $5 \mathrm{kHz}$ \\
\hline Weight & approx. $14 \mathrm{~kg}$ \\
\hline Power supply & $11-28 \mathrm{~V} \mathrm{DC}$ \\
\hline Temperature Range & \\
\hline $\begin{array}{l}\text { Operation } \\
\text { Storage }\end{array}$ & $0{ }^{\circ} \mathrm{C}$ to $+50^{\circ} \mathrm{C}$ \\
\hline
\end{tabular}




\section{4}

\section{RPAS-results (Lizum)}

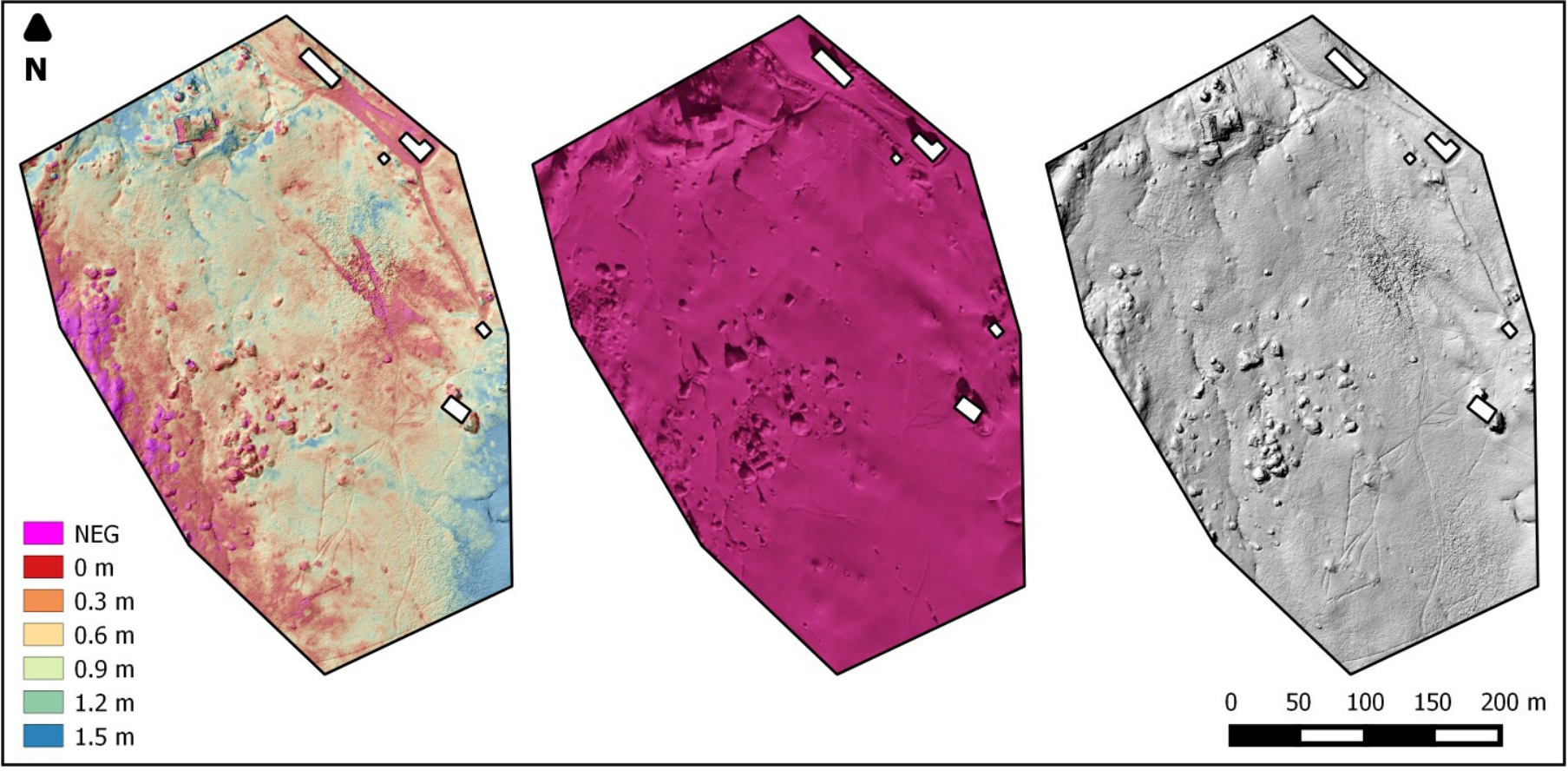

Figure 40: Results from 11 February 2015, flight 1, NIR830-filter; HS map, OP, shaded DSM (left to right)

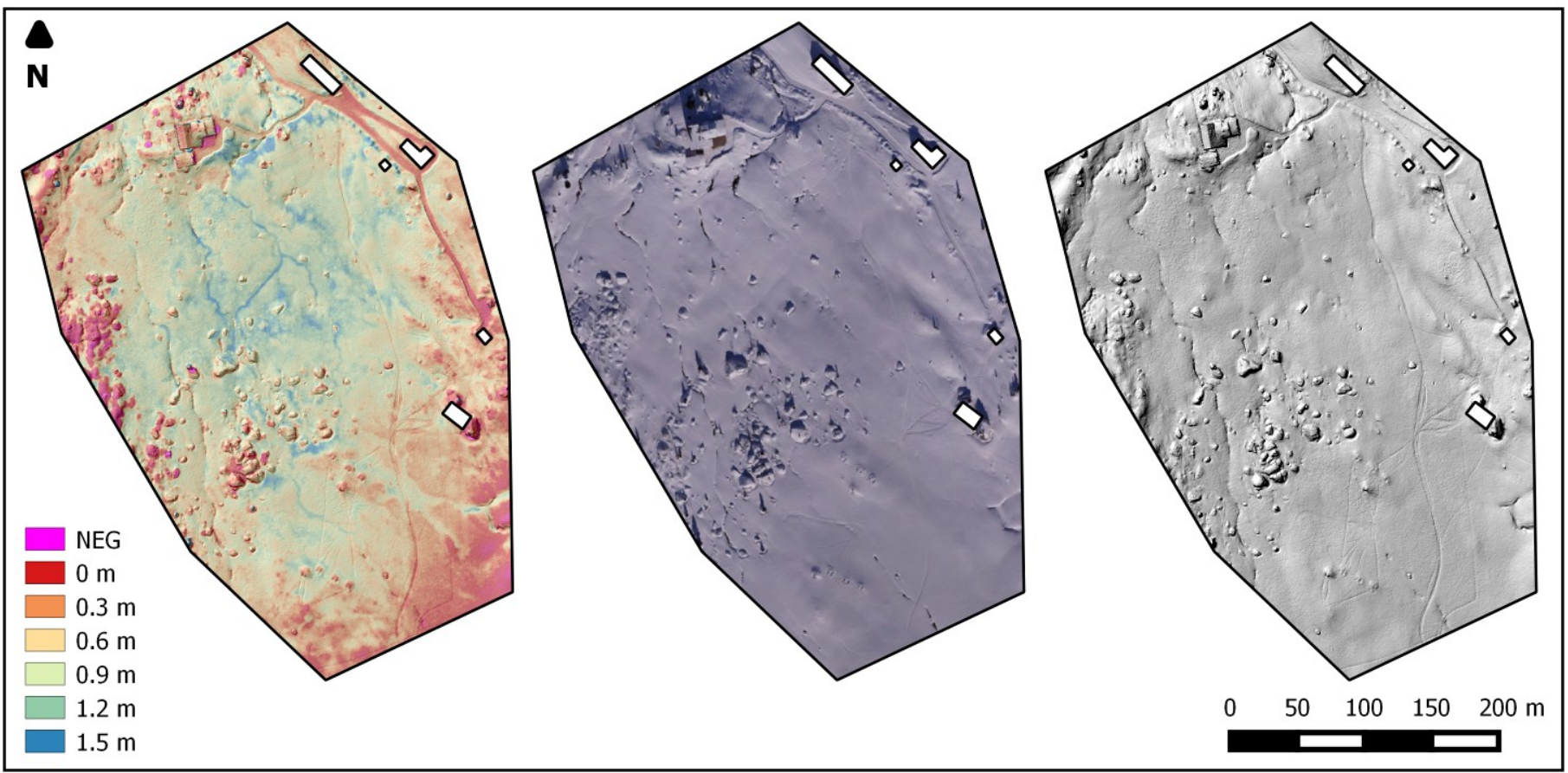

Figure 41: Results from 11 February 2015, flight 2, VIS; HS map, OP, shaded DSM (left to right) 


\section{4

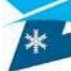

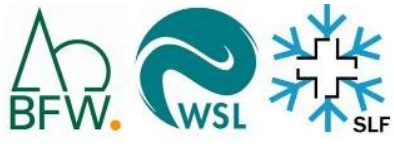

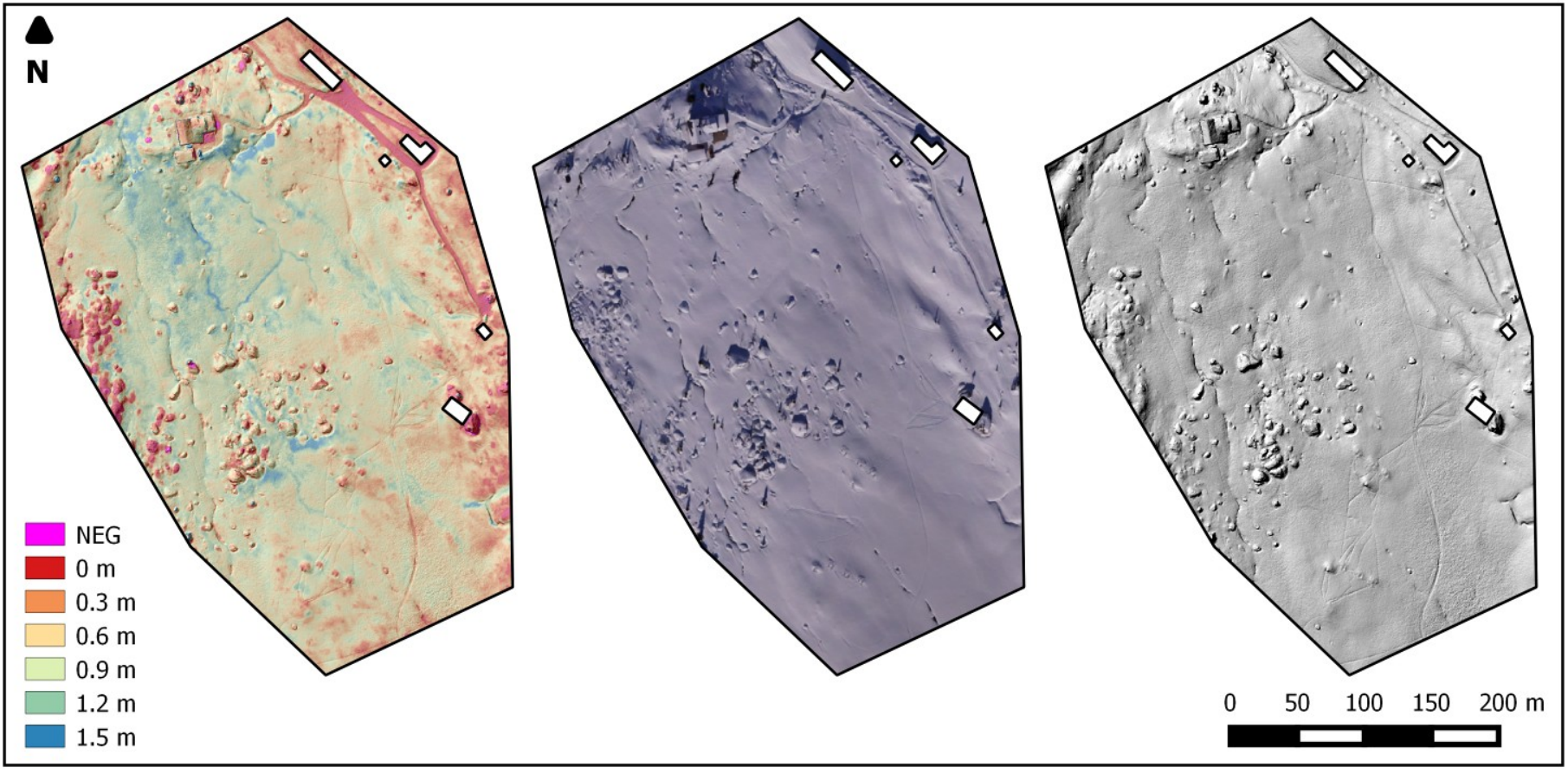

Figure 42: Results from 11 February 2015, flight 3, VIS; HS map, OP, shaded DSM (left to right)

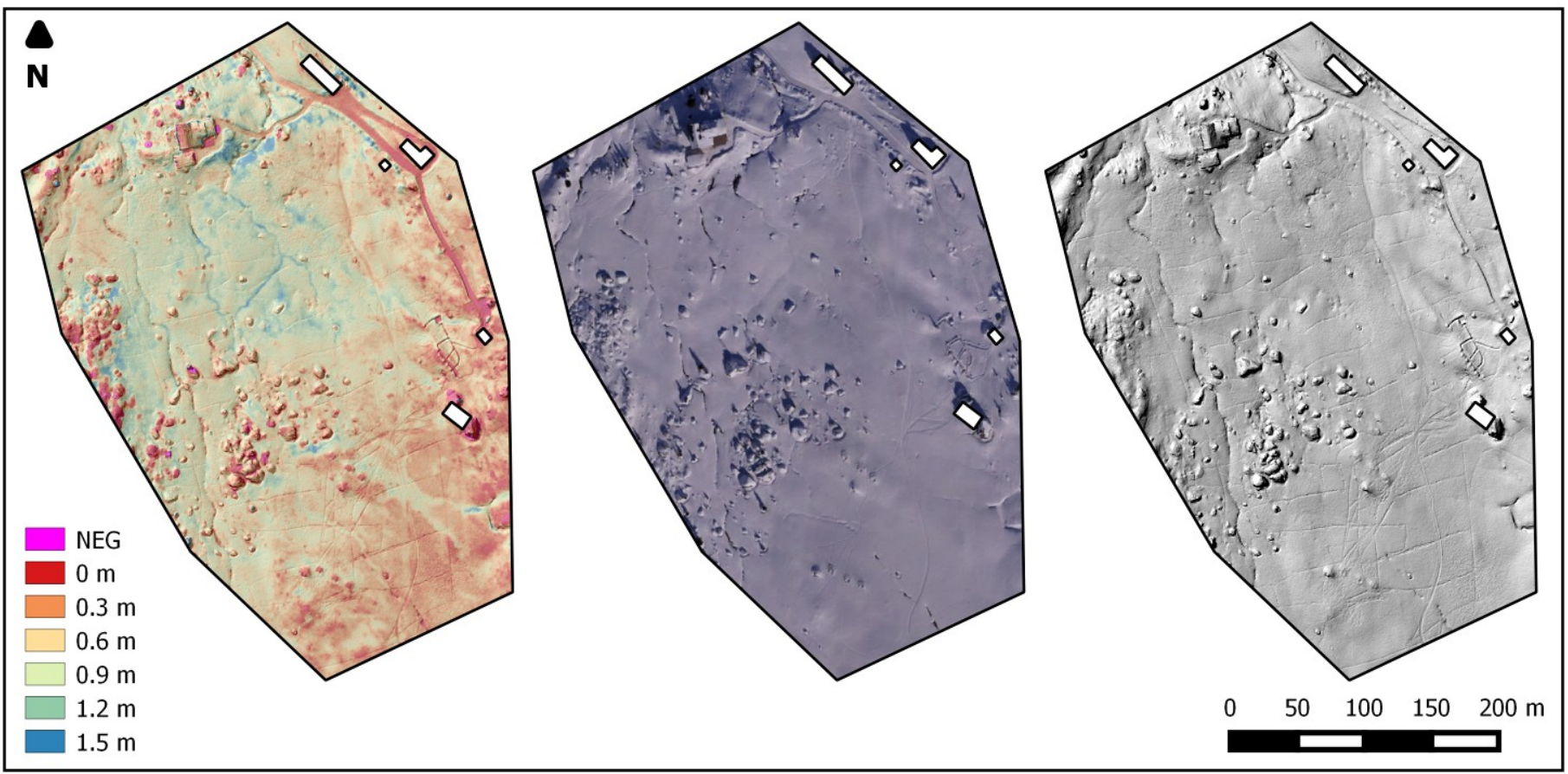

Figure 43: Results from 13 February 2015, flight 1, VIS; HS map, OP, shaded DSM (left to right) 


\section{A

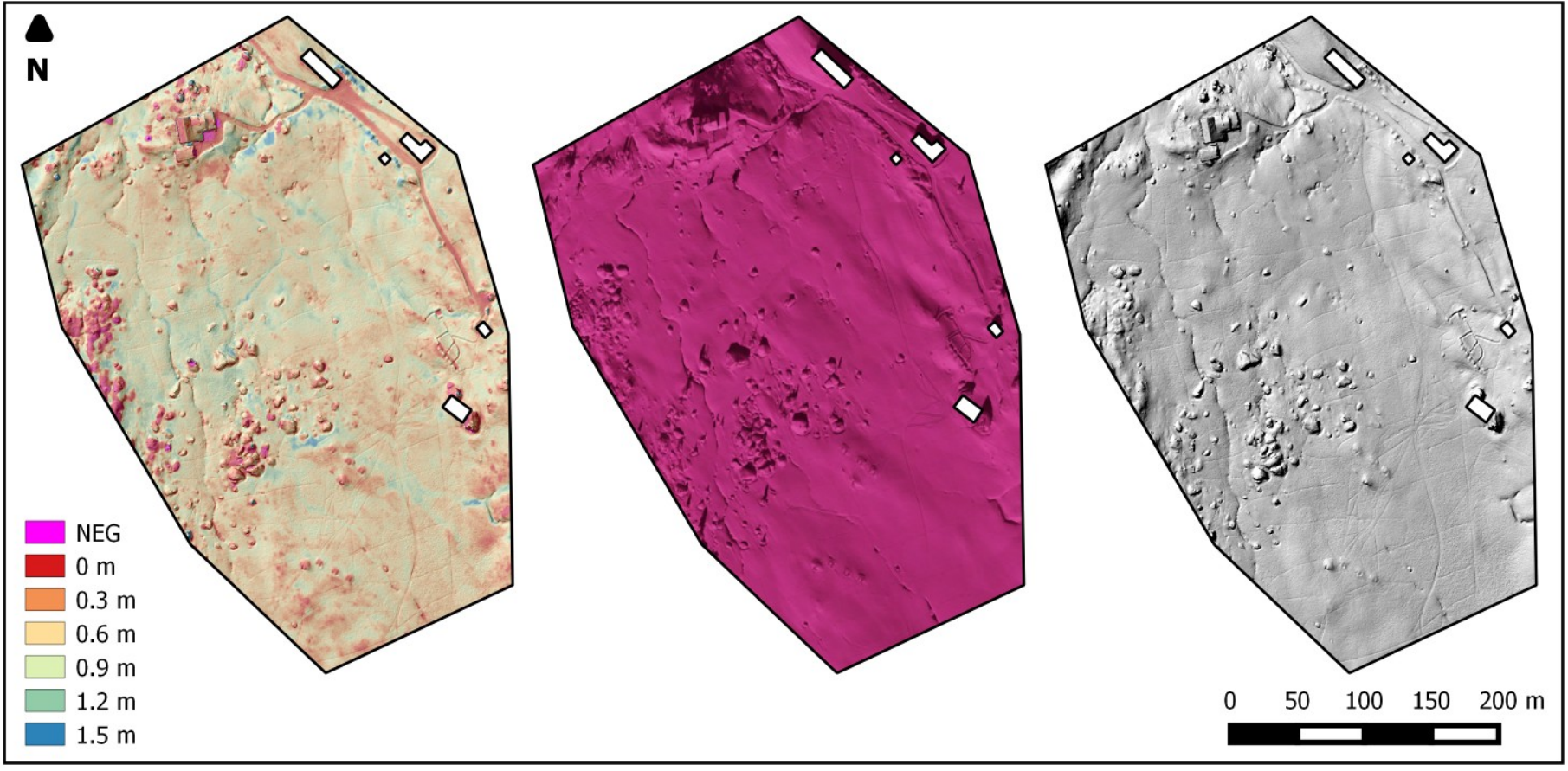

Figure 44: Results from 13 February 2015, flight 3, NIR830-filter; HS map, OP, shaded DSM (left to right)

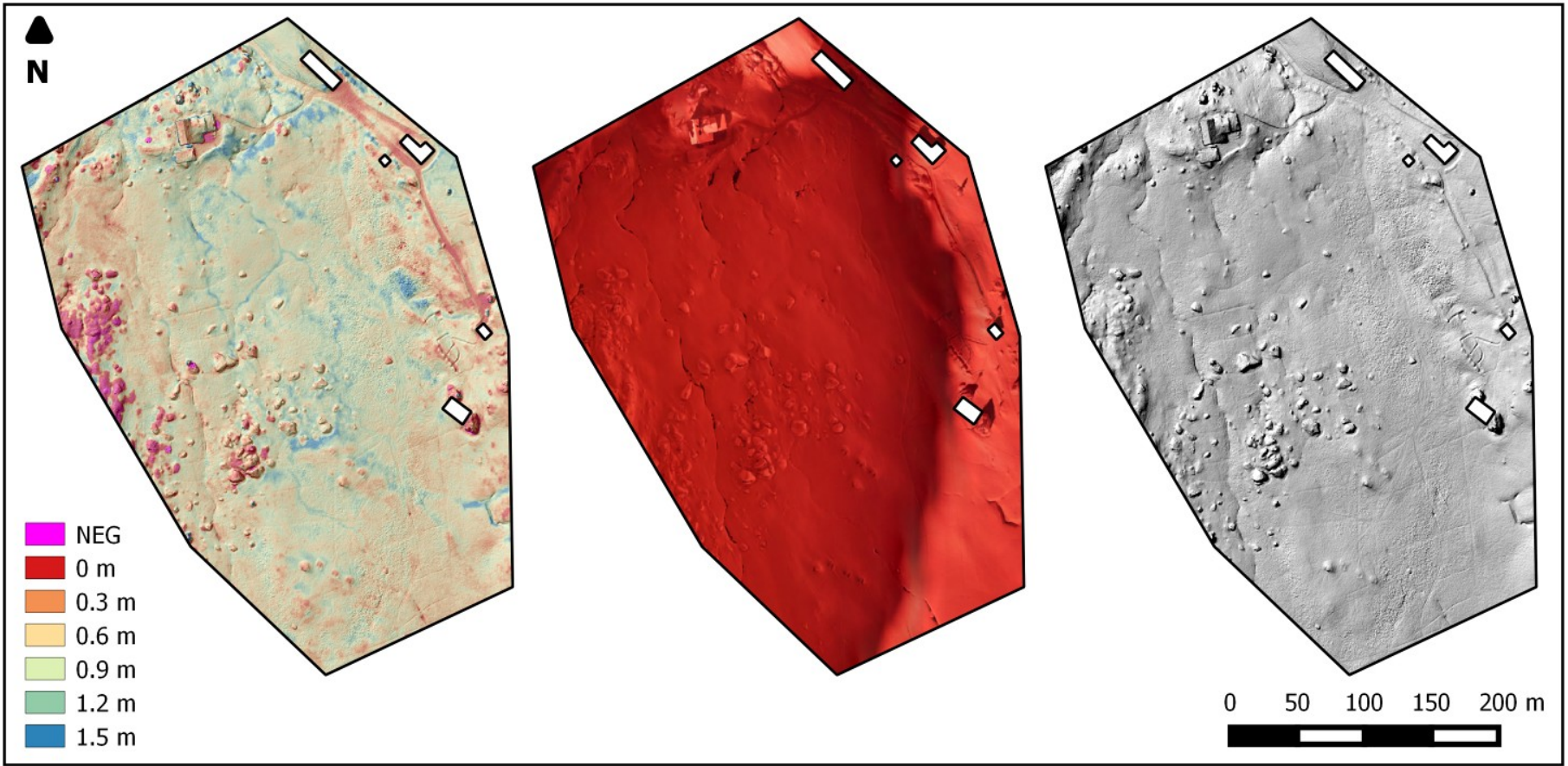

Figure 45: Results from 13 February 2015, flight 4, NIR700-filter; HS map, OP, shaded DSM (left to right) 


\section{4

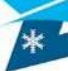

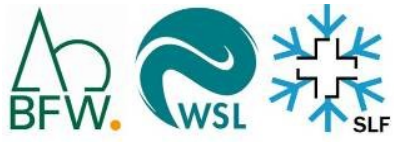

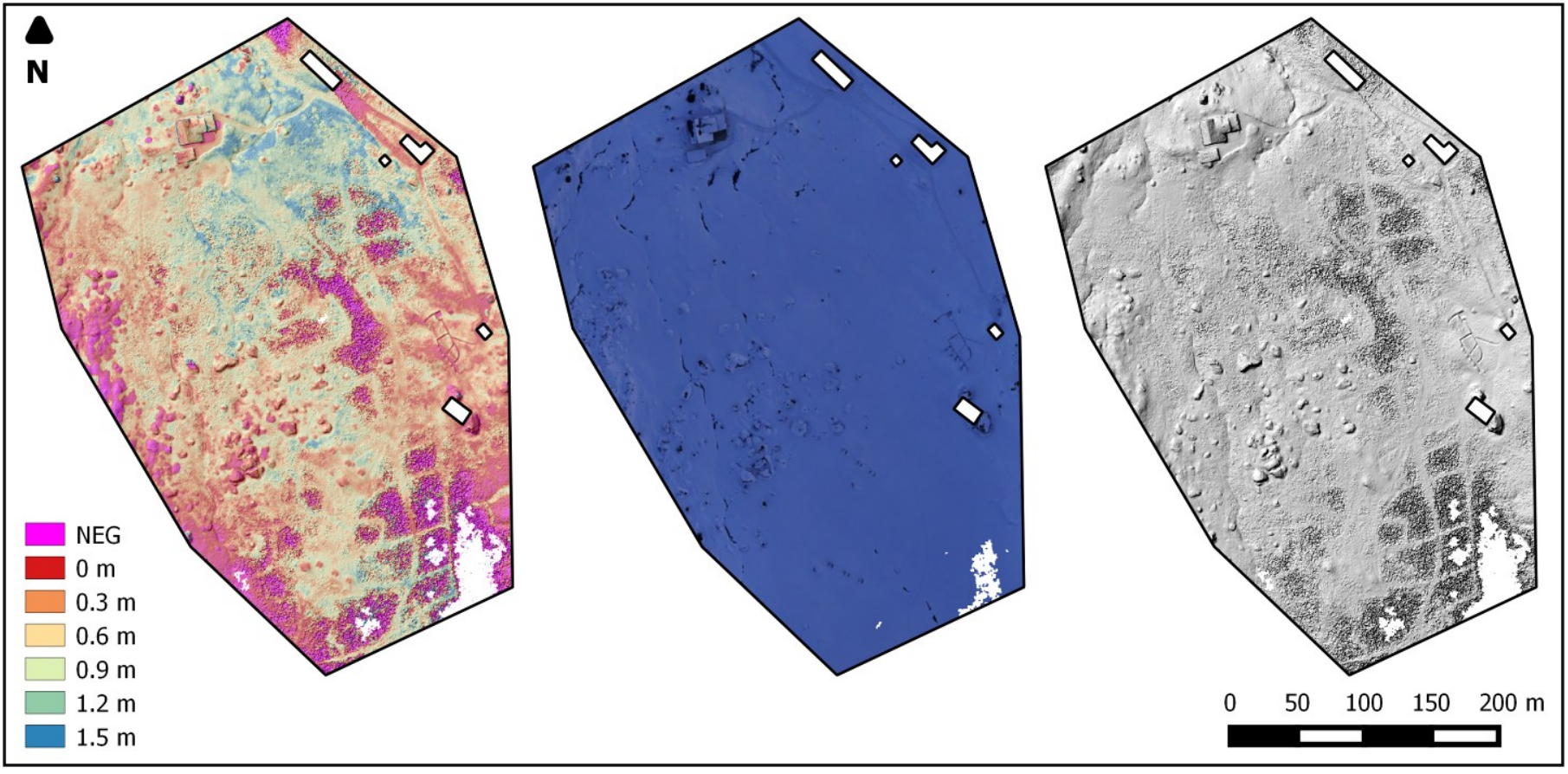

Figure 46: Results from 13 February 2015, flight 5, VIS; HS map, OP, shaded DSM (left to right)

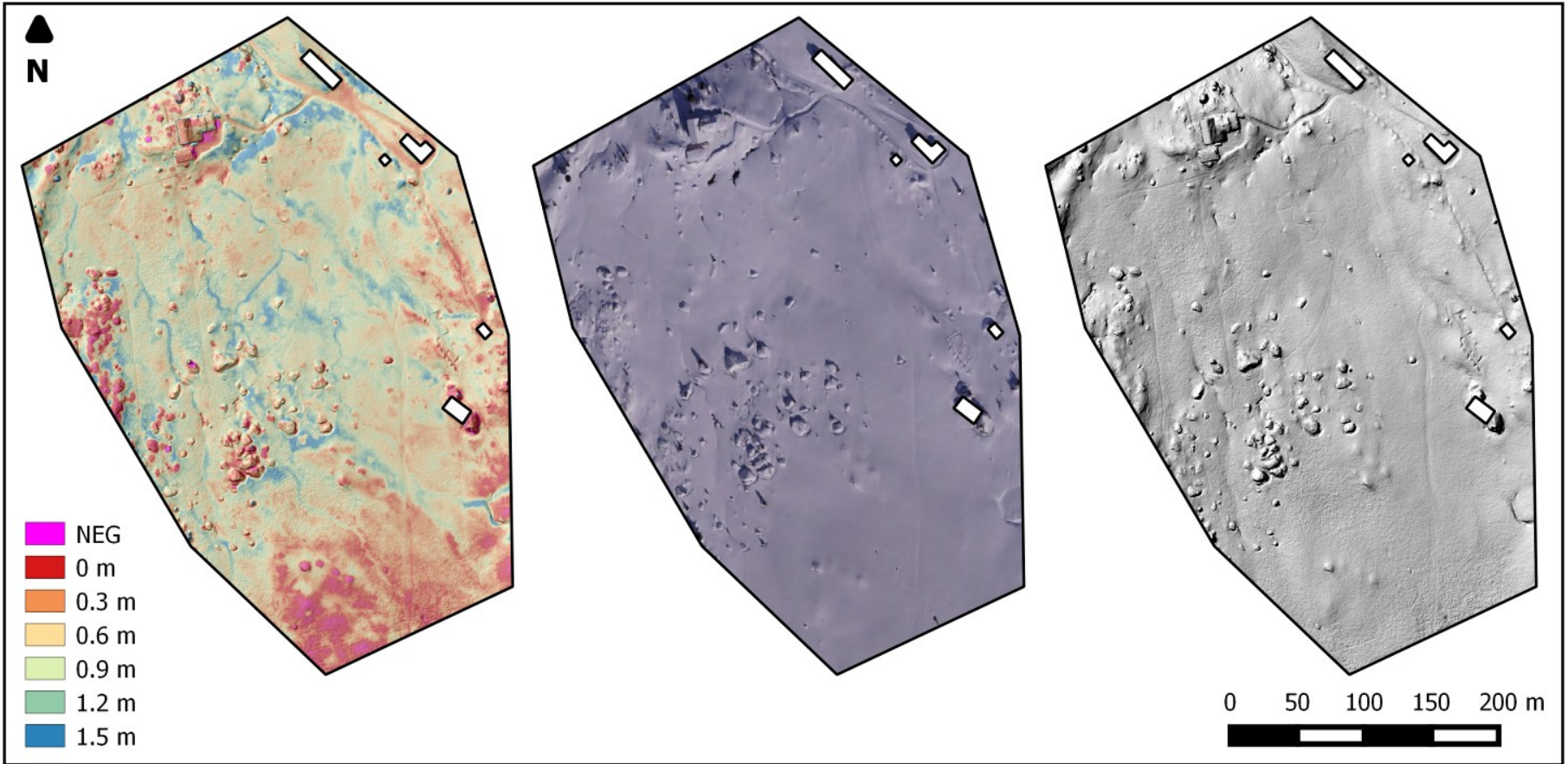

Figure 47: Results from 3 March 2015, flight 1, VIS; HS map, OP, shaded DSM (left to right) 


\section{4

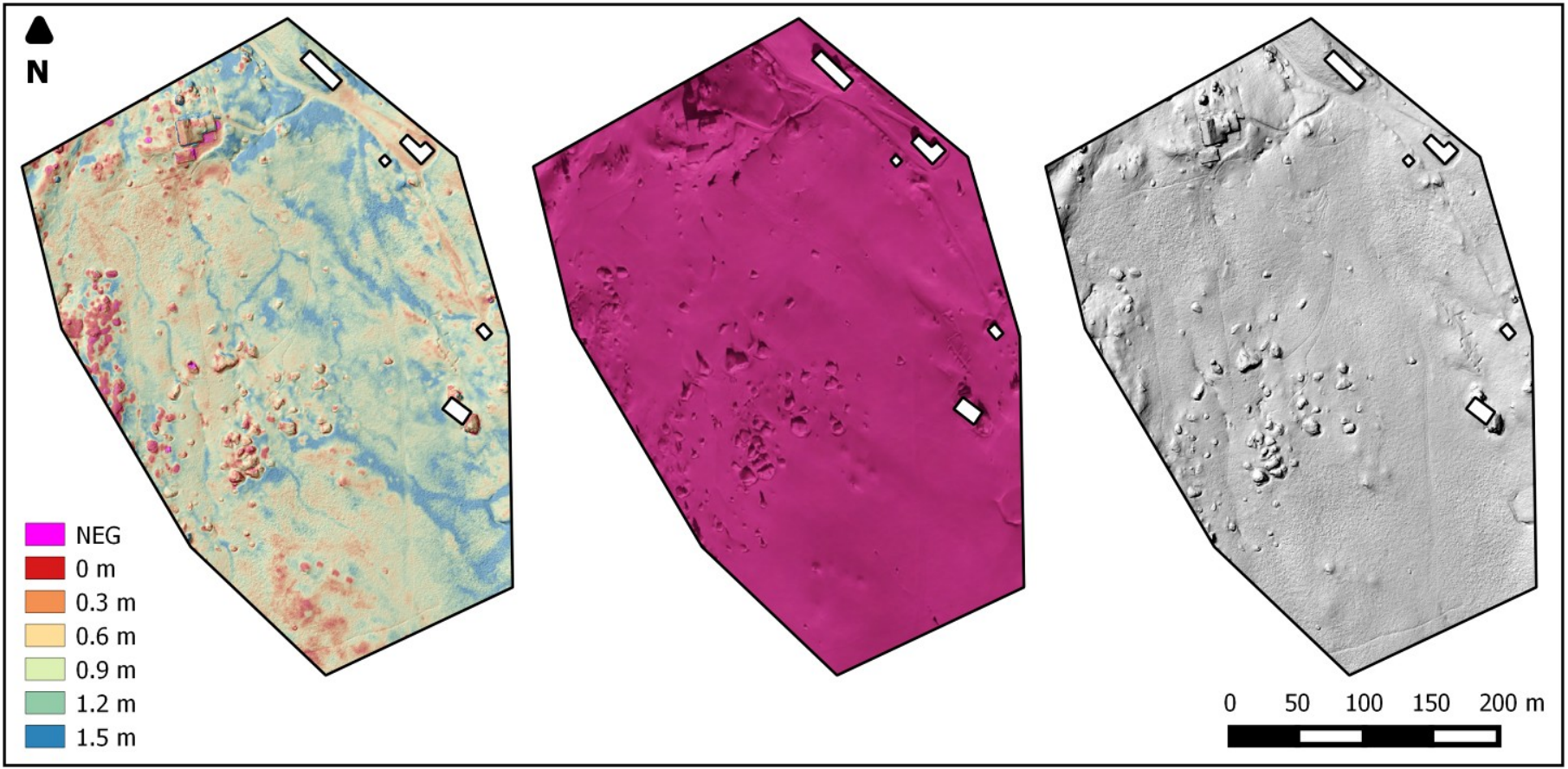

Figure 48: Results from 3 March 2015, flight 2, NIR830-filter; HS map, OP, shaded DSM (left to right)

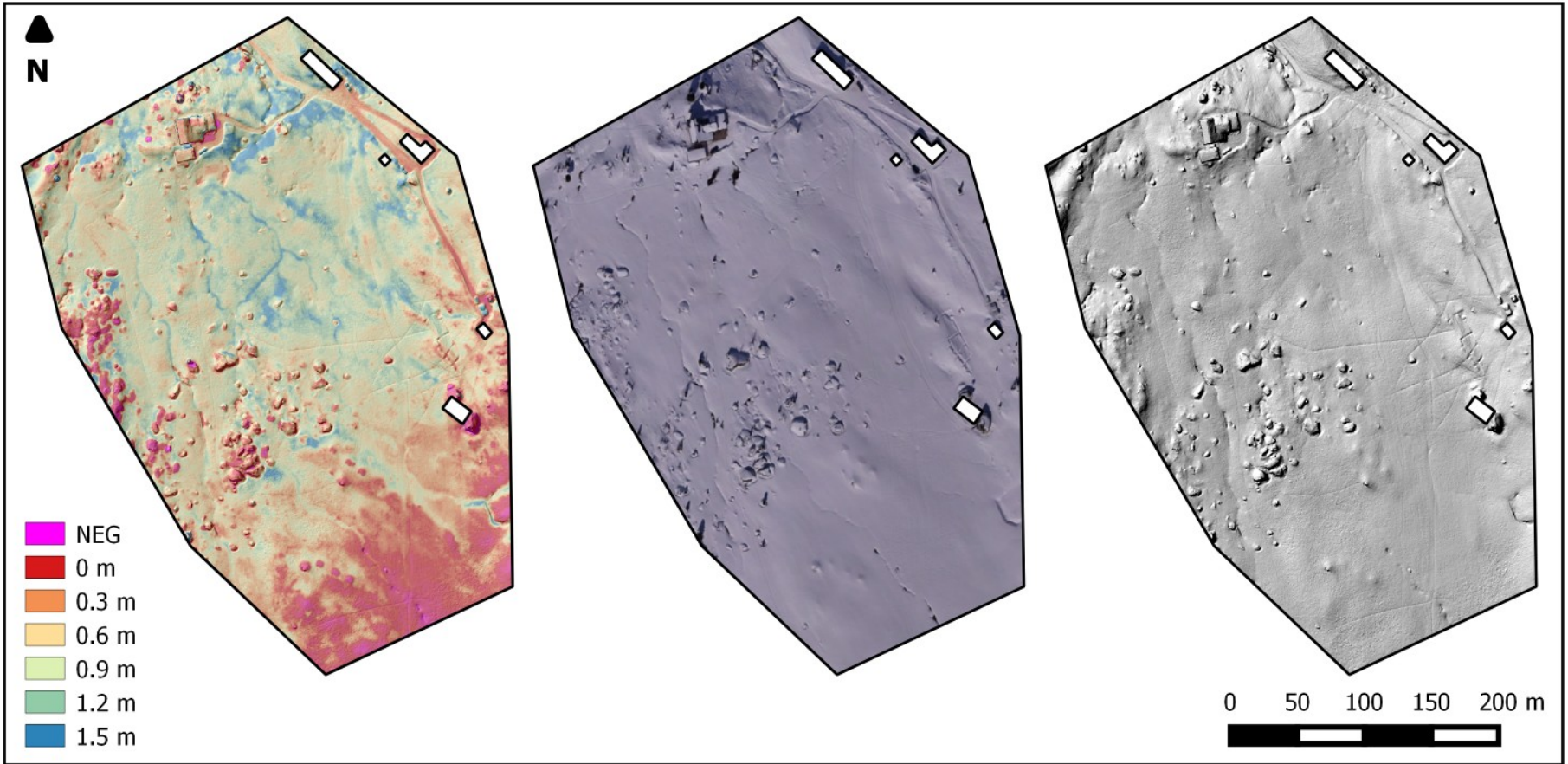

Figure 49: Results from 13 March 2015, flight 1, VIS; HS map, OP, shaded DSM (left to right) 


\section{4

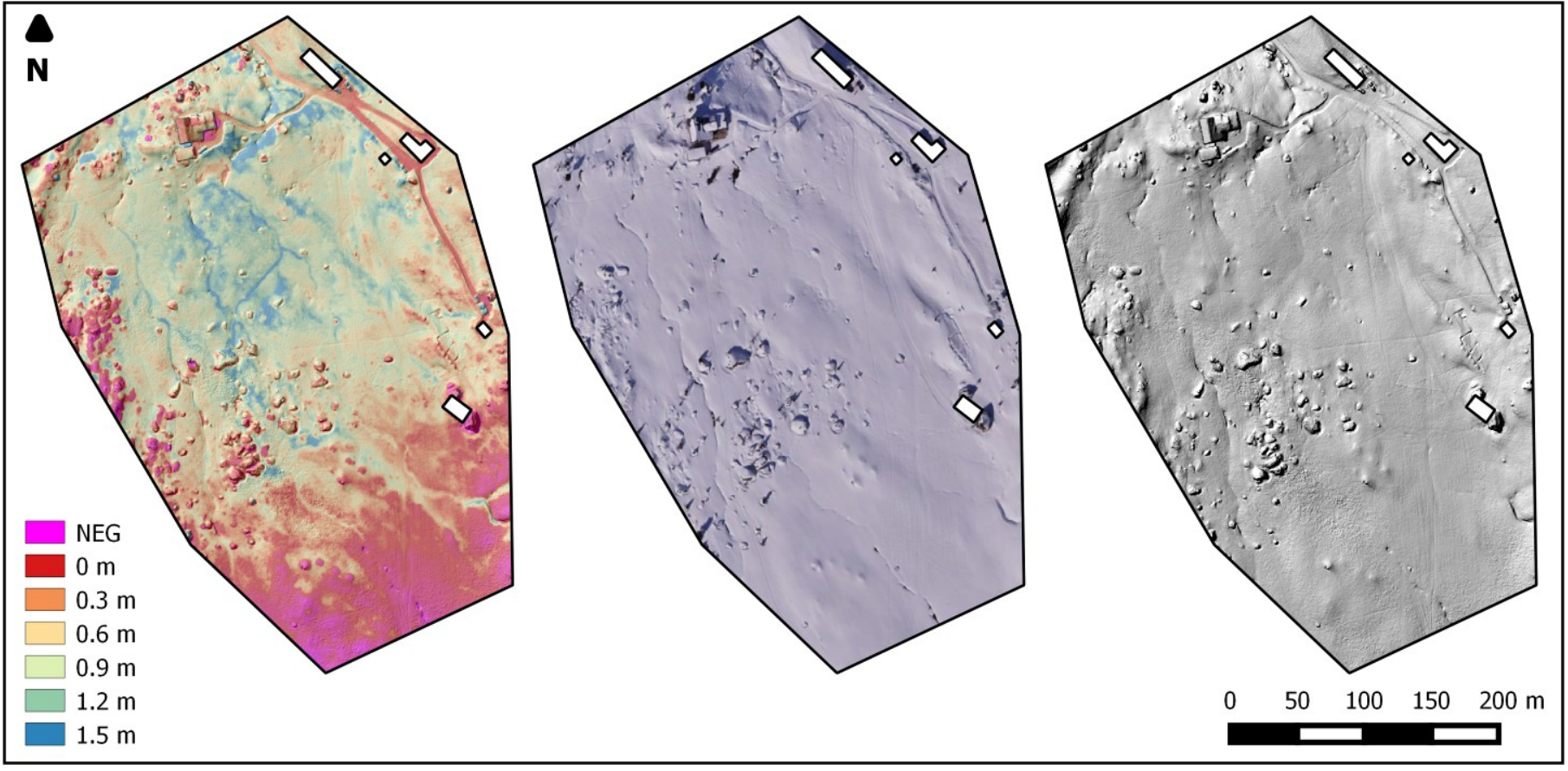

Figure 50: Results from 13 March 2015, flight 2, VIS; HS map, OP, shaded DSM (left to right)

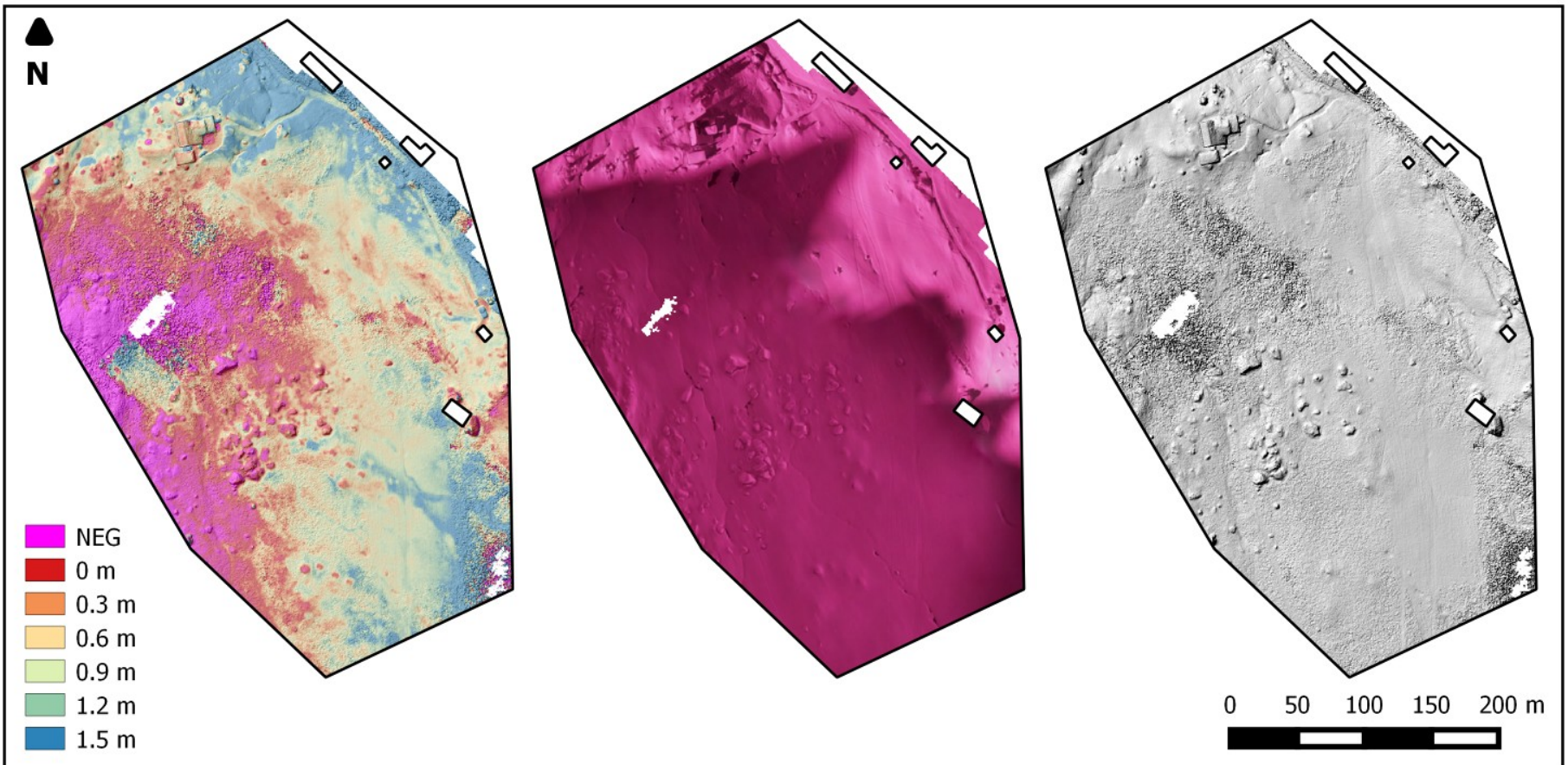

Figure 51: Results from 13 March 2015, flight 3, NIR830-filter; HS map, OP, shaded DSM (left to right) 


\section{4

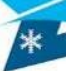

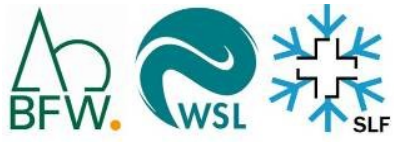

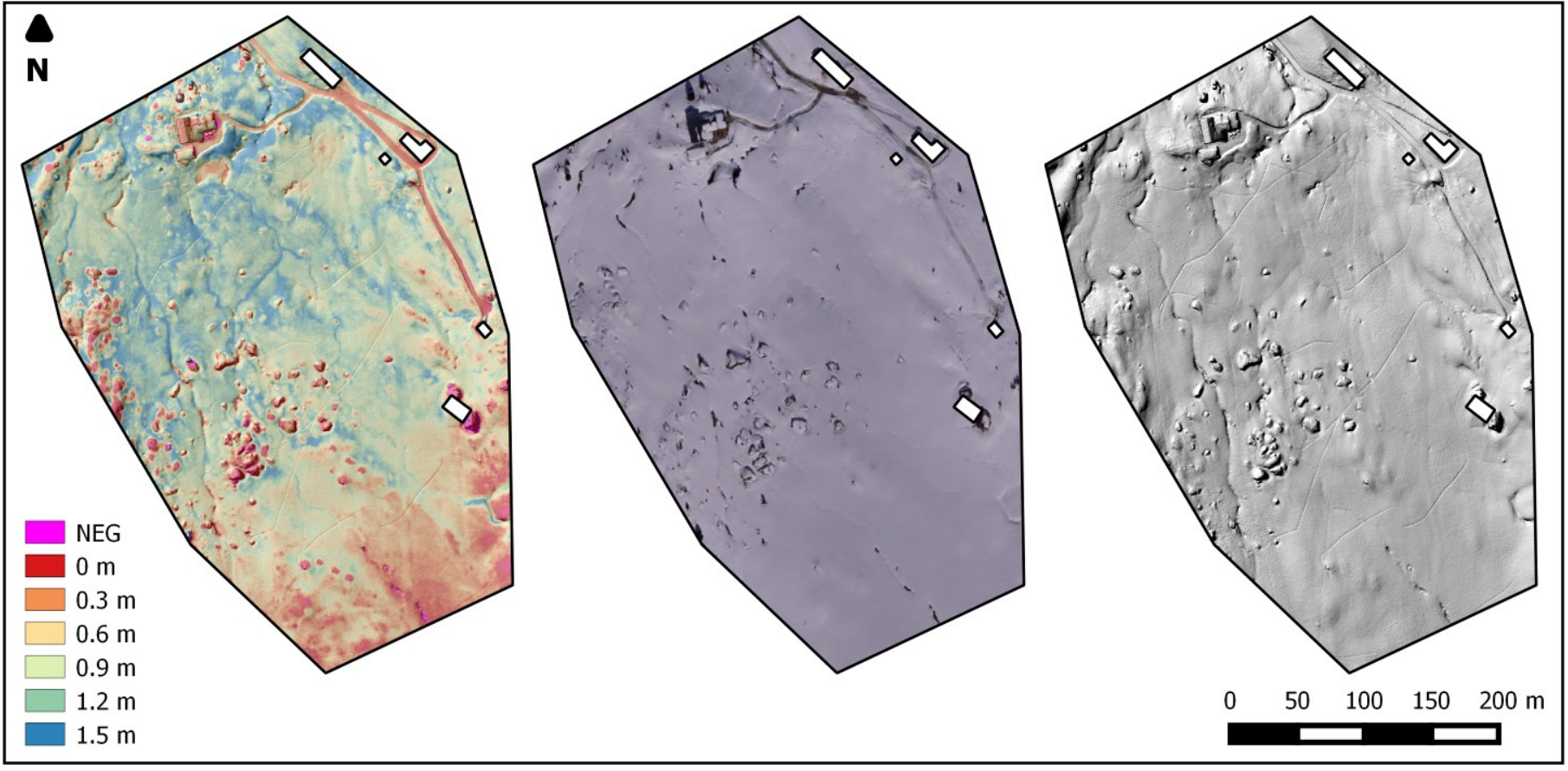

Figure 52: Results from 4 April 2015, flight 1, VIS; HS map, OP, shaded DSM (left to right)

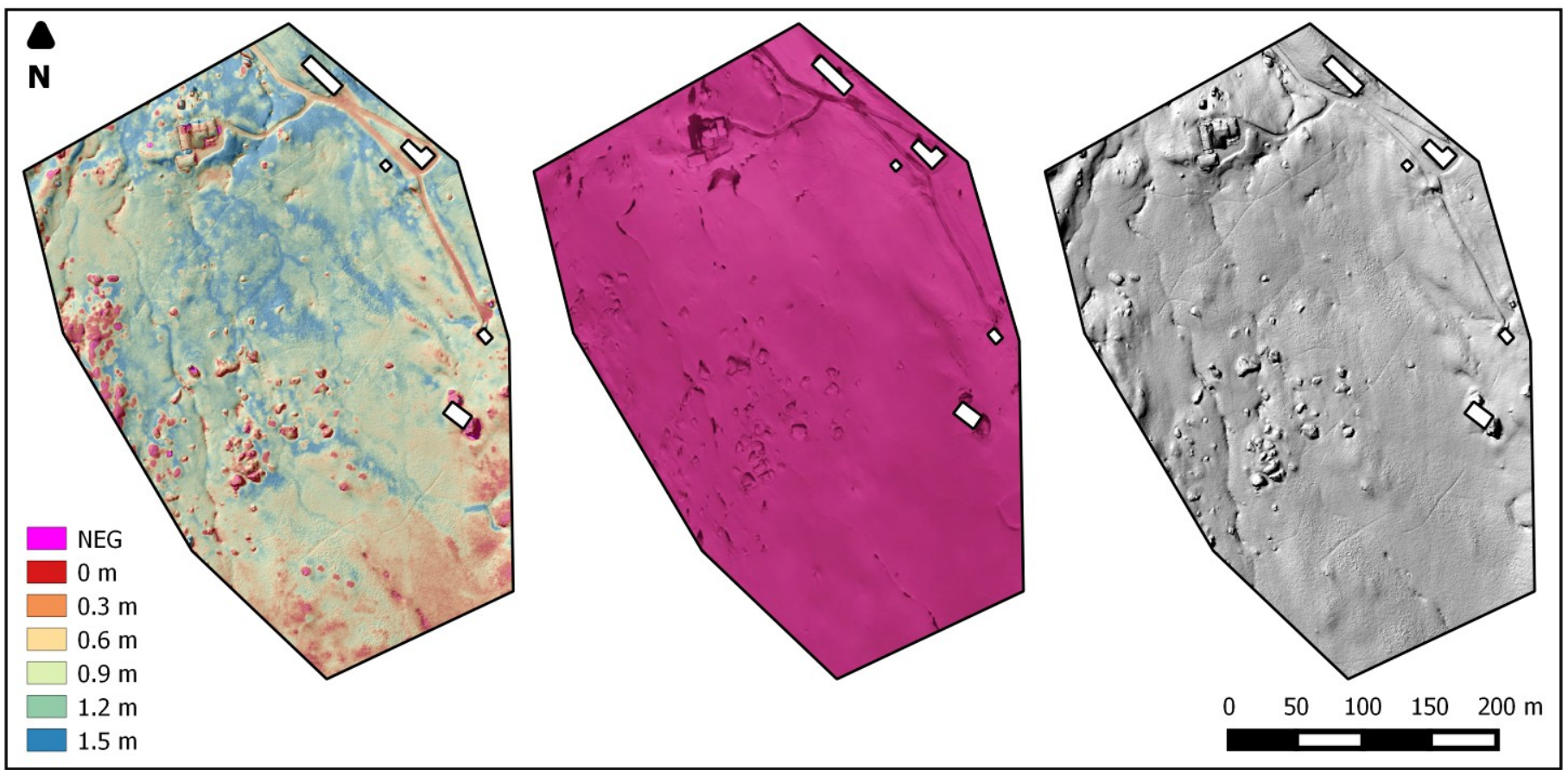

Figure 53: Results from 4 April 2015, flight 1, NIR830-filter; HS map, OP, shaded DSM (left to right) 


\section{4

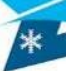

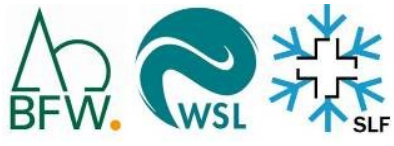

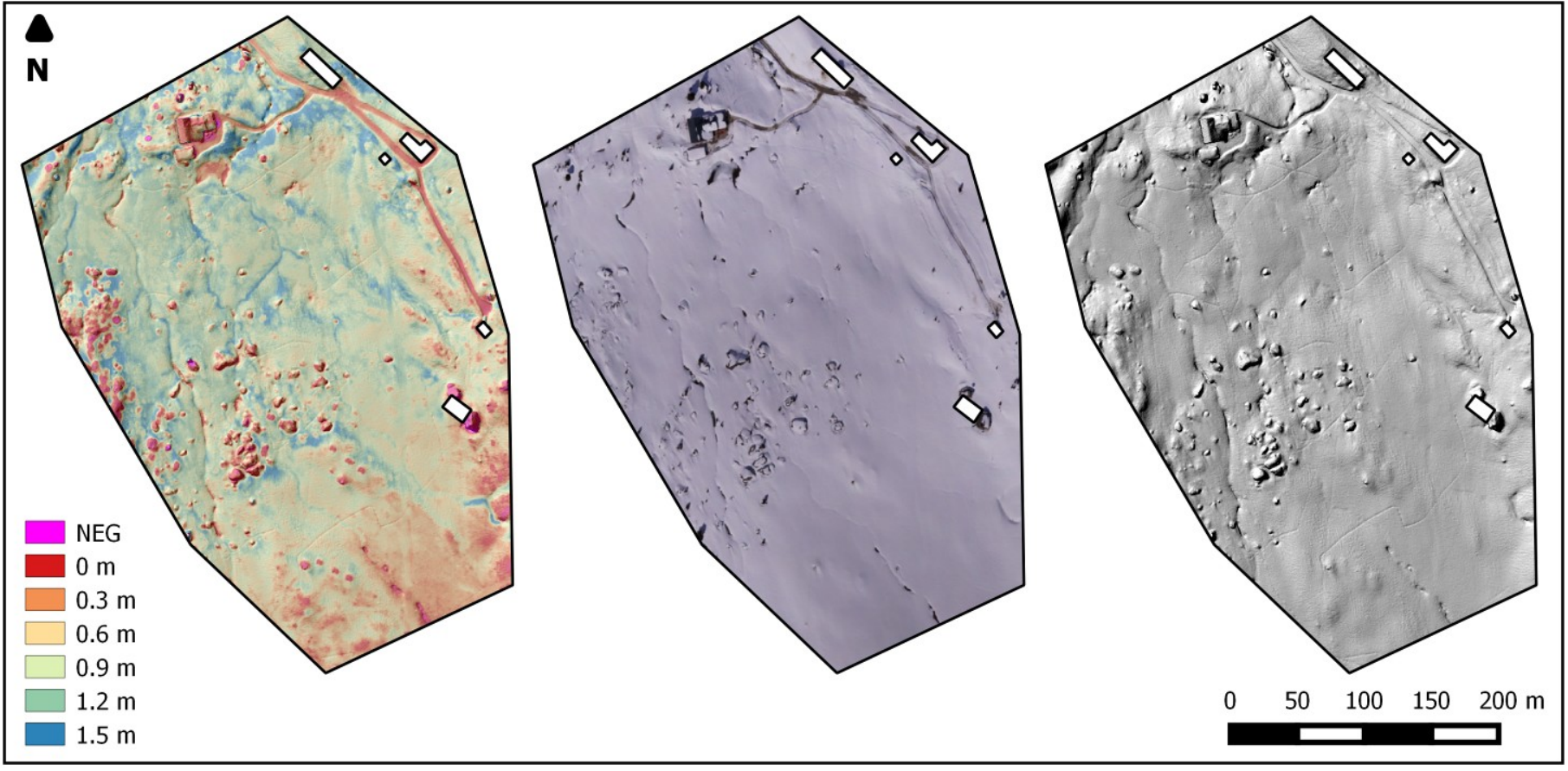

Figure 54: Results from 4 April 2015, flight 3, VIS; HS map, OP, shaded DSM (left to right)

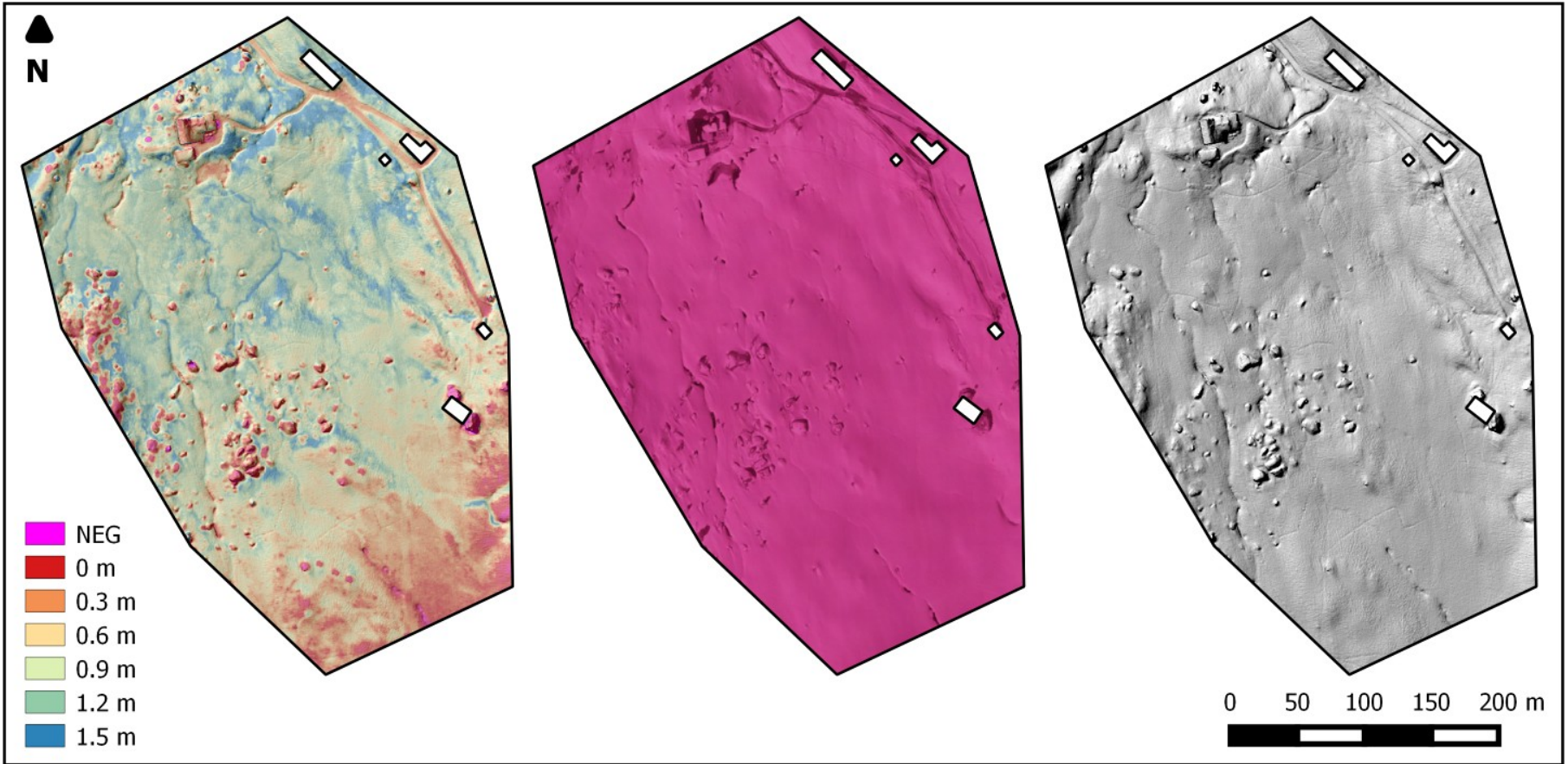

Figure 55: Results from 4 April 2015, flight 4, NIR830-filter; HS map, OP, shaded DSM (left to right) 


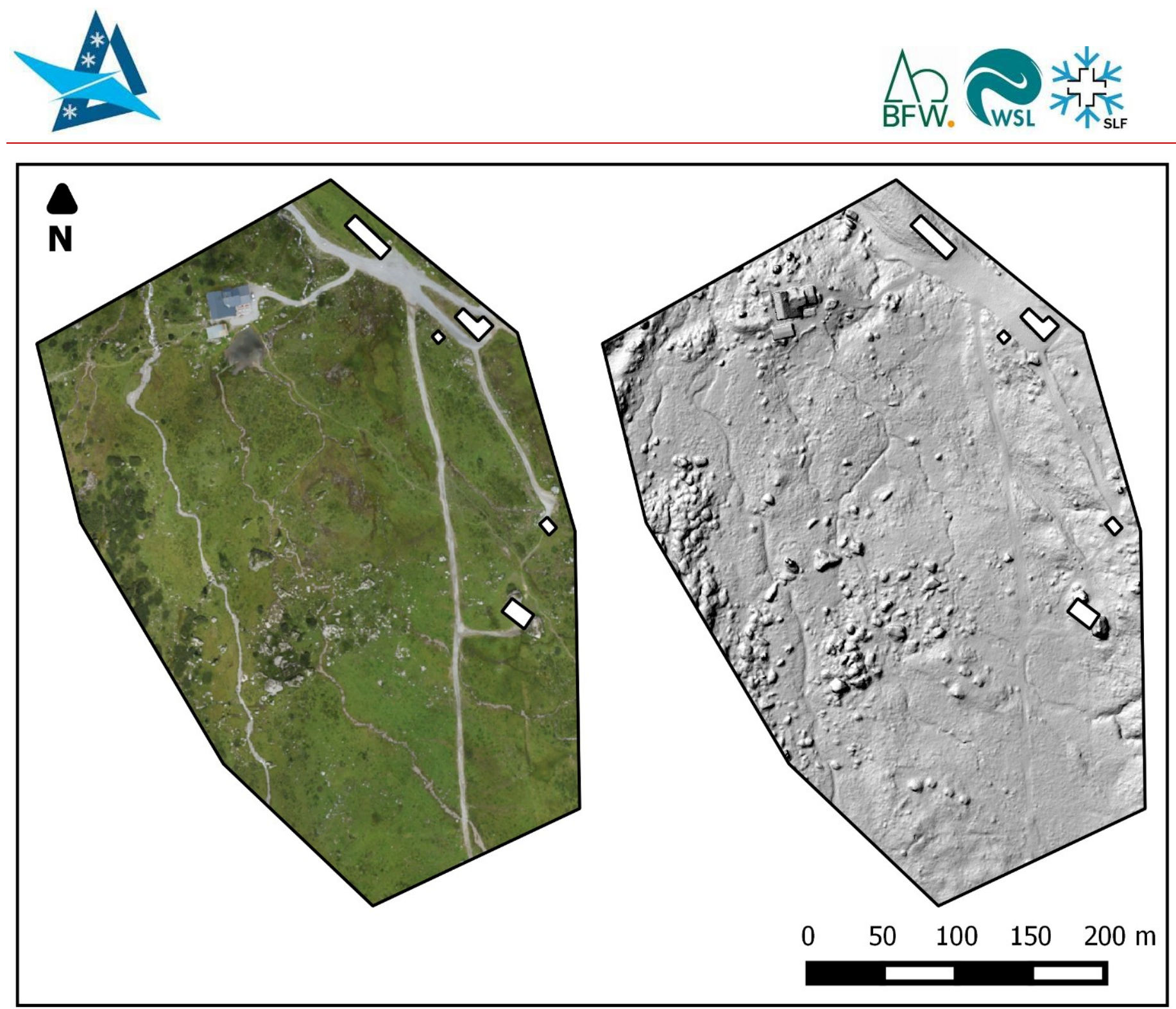

Figure 56: Results from 21 August 2015 (snow-free data acquisition), flight 3, VIS; OP, shaded DSM (left to right) 


\section{A

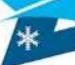

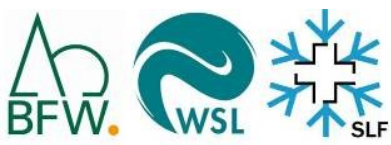

Additional results from TLS-validation
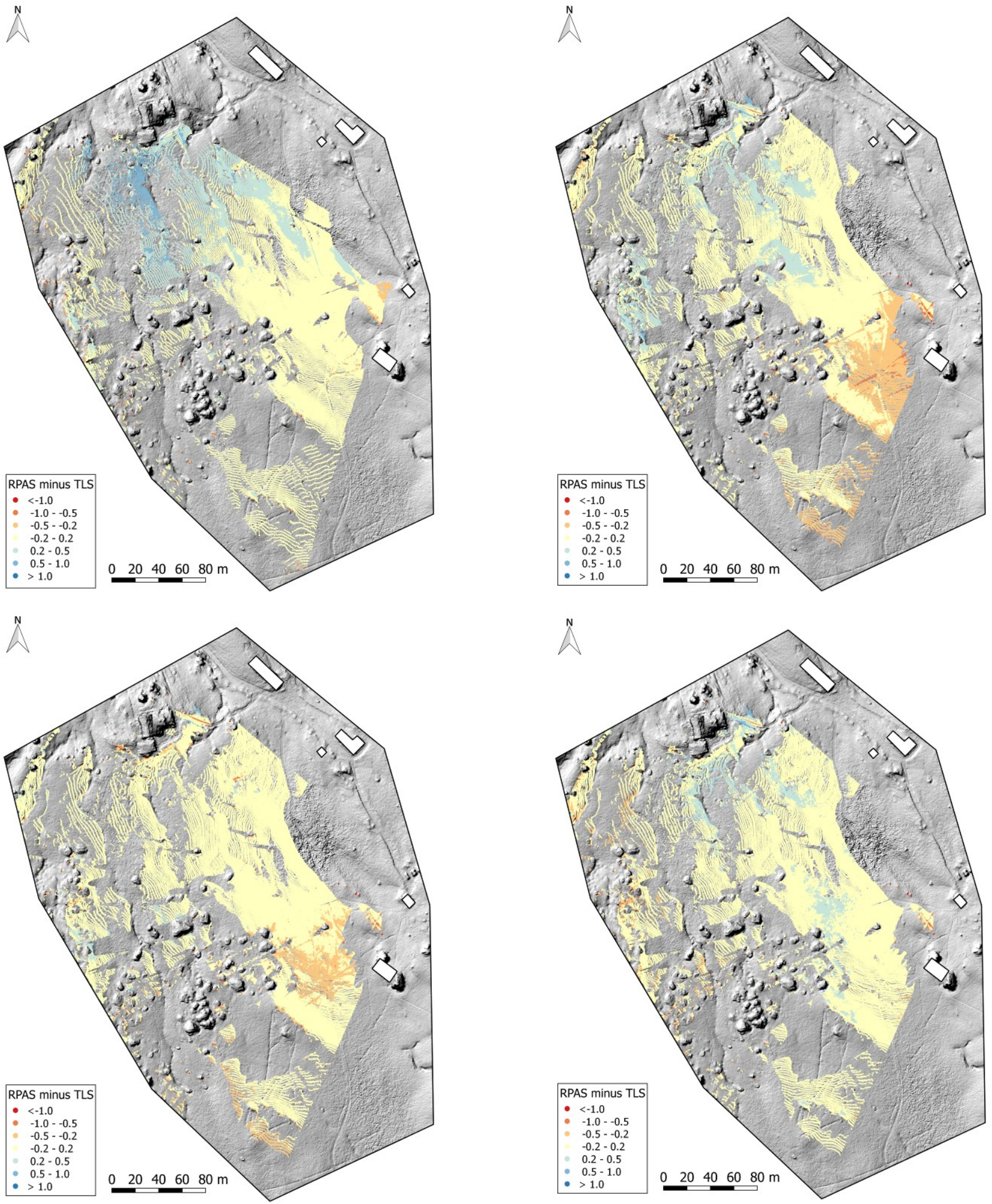

Figure 57: Each point represents a TLS-measurement, colour-coded by degree of positive (reds) and negative (blues) deviation of the RPAS from the TLS DSM [m]; 11 February 2015, flight 3 (top left); 13 February 2015, flight 1 (top right); 14 February 2015, flight 3 (bottom left); 14 February 2015, flight 4 (bottom right). 


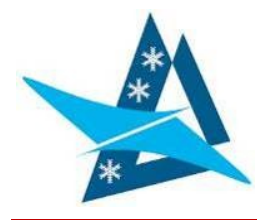

$\AA$

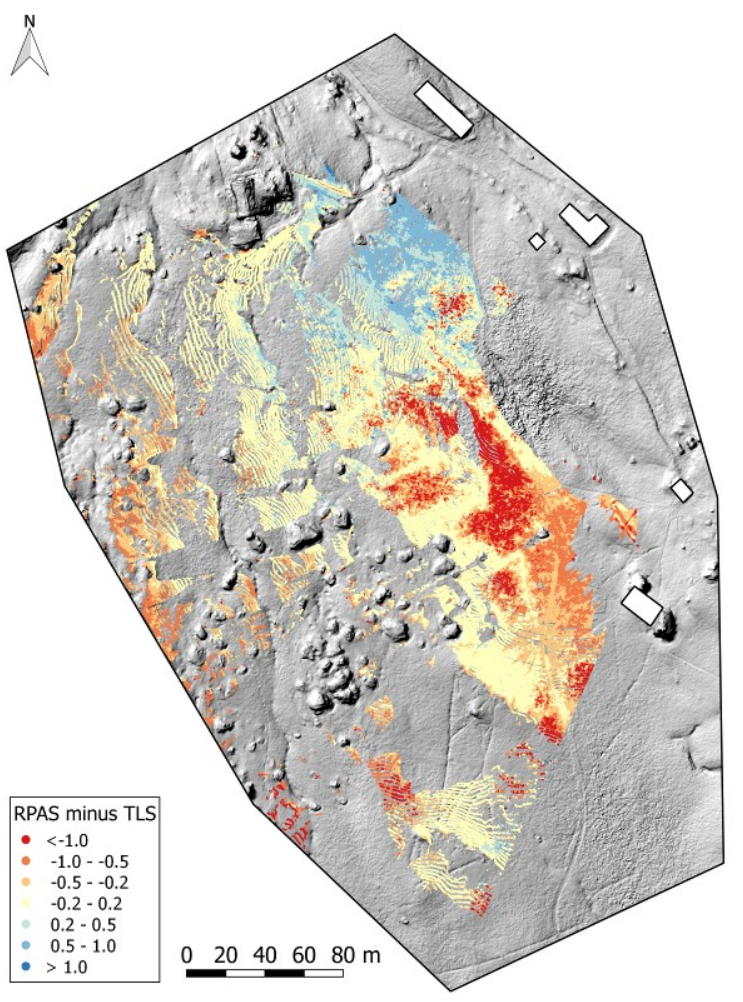

N

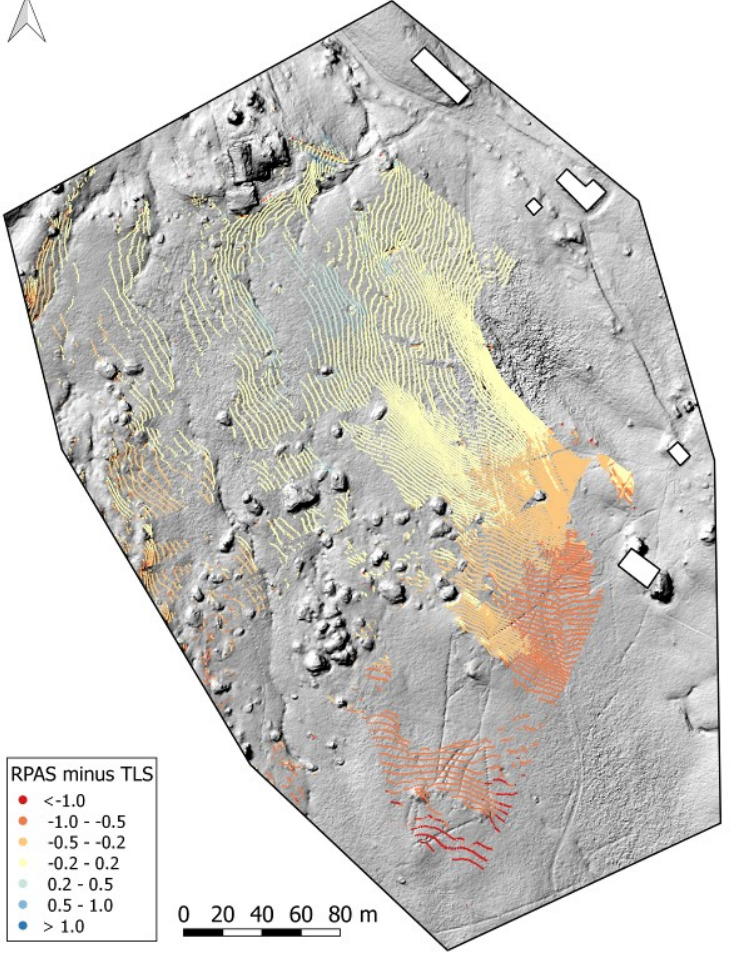

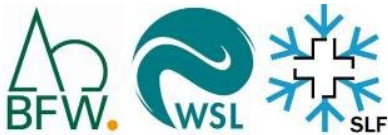
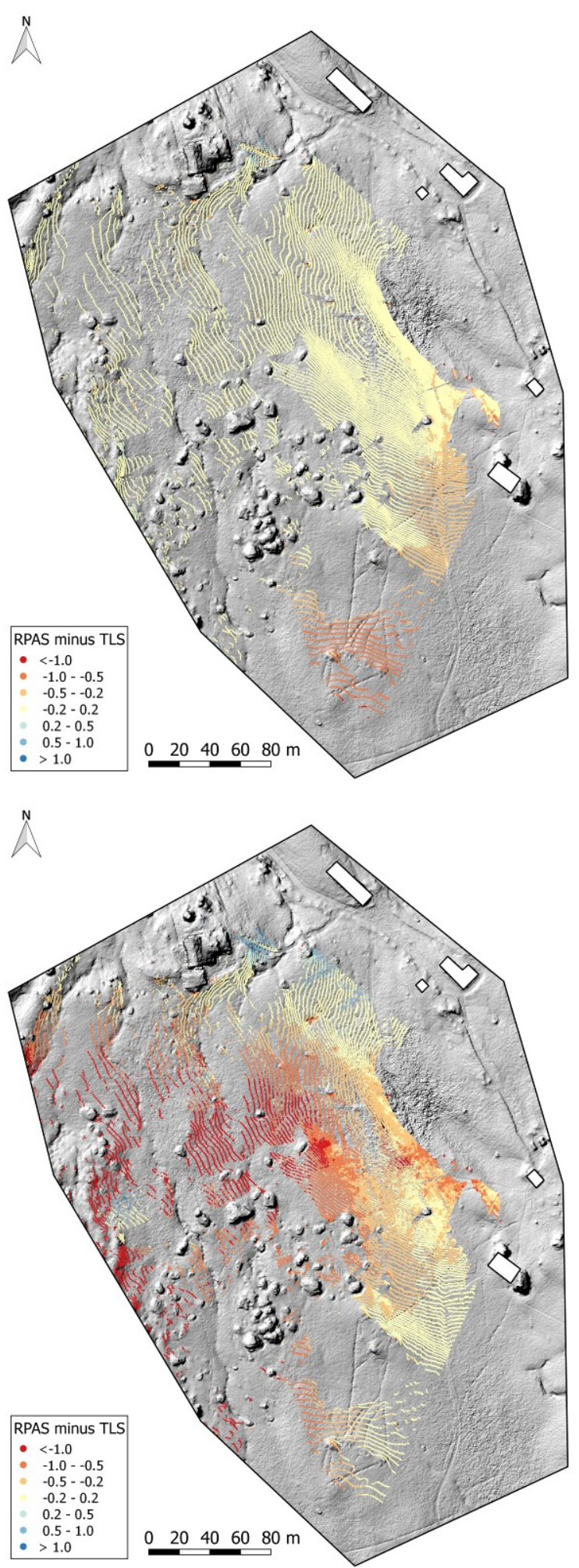

Figure 58: Each point represents a TLS-measurement, colour-coded by degree of positive (reds) and negative (blues) deviation of the RPAS from the TLS DSM [m]; 14 February 2015, flight 5 (top left); 3 March 2015, flight 1 (top right); 13 March 2015, flight 2 (bottom left); 13 March 2015, flight 3 (bottom right). 


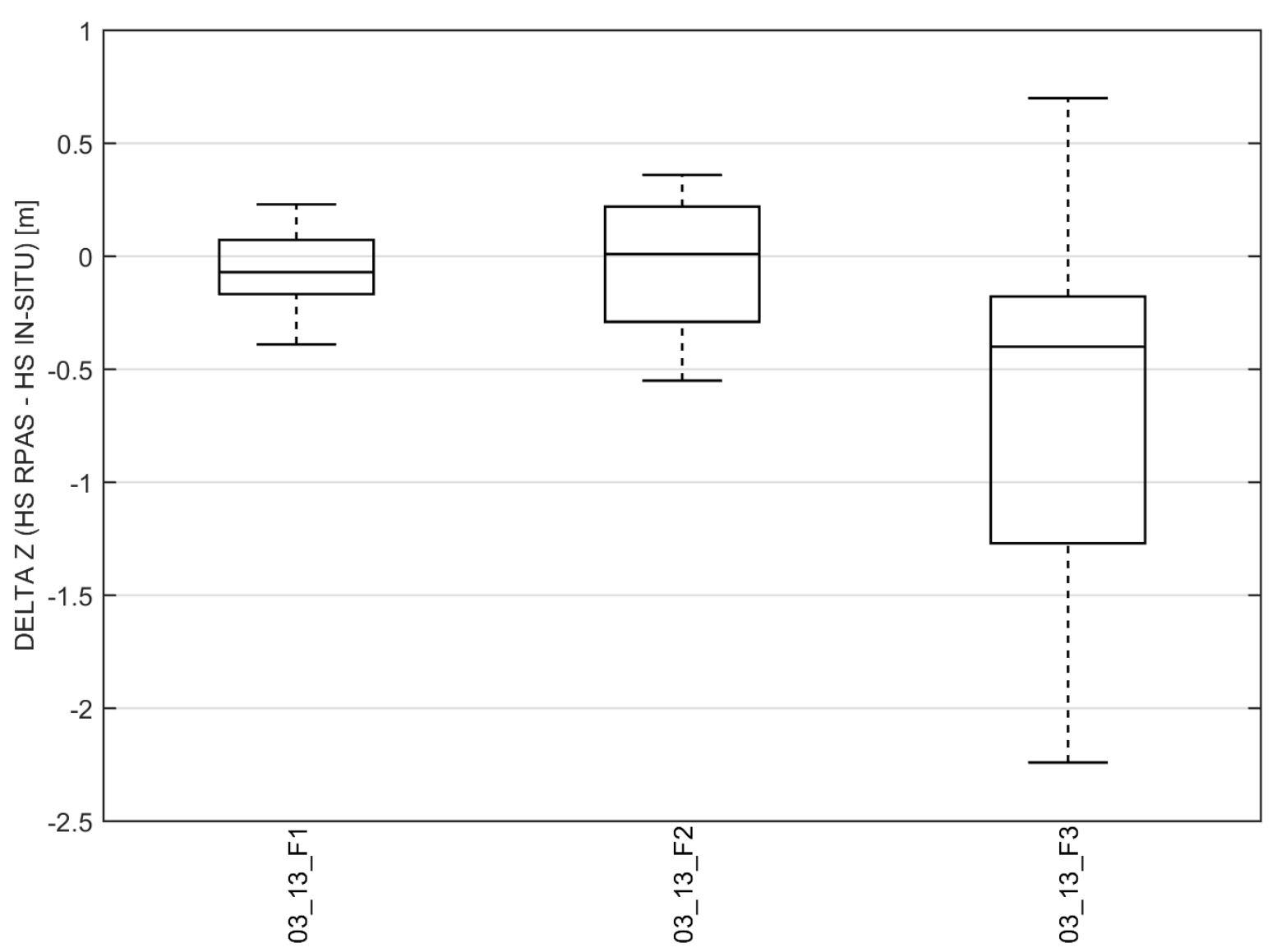

Figure 59: Results from the in-situ validation of RPAS-HS maps in March 2015; on the $y$-axis the deviation of RPAS-HS values from in-situ-HS values [m] is marked; flight ID (MM_DD_flightnumber) is plotted on $\mathrm{x}$-axis - each boxplot corresponds to one UAS-flight; whiskers in boxplot correspond to one standard deviation, outliers not included. 


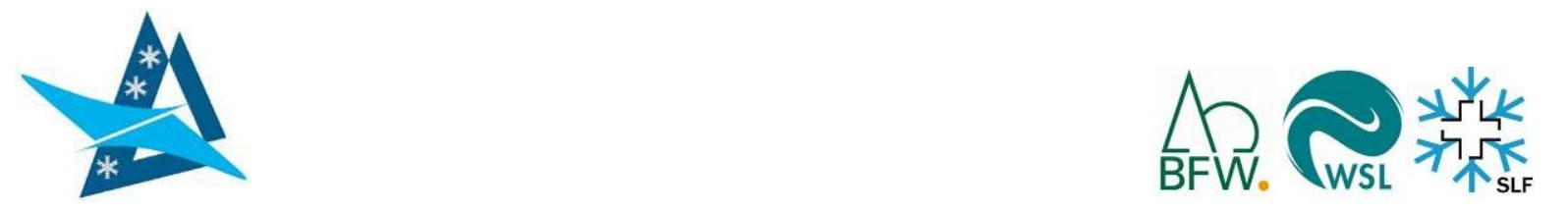

\section{Acknowledgements}

This work was funded by the Austrian Academy of Sciences under the research initiative Earth System Sciences (ESS), project RPAS4SNOW. The authors would like to express their sincere gratitude to the ÖAW and the Austrian Federal Ministry of Science, Research and Economy (BMWFW) for this support.

Furthermore, the authors would like to thank: Johann Zagajsek and his team (support at the Austrian test site), and Andreas Huber (field work). 